DEPARTAMENTO DE SISTEMAS Y RECURSOS NATURALES

ESCUELA TÉCNICA SUPERIOR DE INGENIEROS DE MONTES

\title{
EVOLUCIÓN DE LA VEGETACIÓN EN EL SECTOR BIOGEOGRÁFICO CASTELLANO CANTÁBRICO DURANTE EL CUATERNARIO FINAL, A TRAVÉS DEL REGISTRO TOBÁCEO
}

TESIS DOCTORAL

RAÚL IGLESIAS GONZÁLEZ

Ingeniero de Montes

DIRECTORES:

IGNACIO GARCÍA-AMORENA

Dr. Ingeniero de Montes
EDUARDO BARRÓN LÓPEZ

Dr. en Ciencias Biológicas 


\section{POLITÉCNICA}

Tribunal nombrado por el Mgfco. y Excmo. Sr. Rector de la Universidad Politécnica de Madrid, el día.........de................de 2015

Presidente D

Vocal D

Vocal D

Vocal D

Secretario D

Suplente D

Suplente D

Realizado el acto de defensa y lectura de la Tesis el día.........de de 2015 en ..................

EL PRESIDENTE

LOS VOCALES

EL SECRETARIO 


\section{AGRADECIMIENTOS}

El origen de la presente Tesis Doctoral fue el hallazgo accidental de una impresión de una piña de pino laricio en las tobas de Tubilla del Agua, una de las localidades de estudio de este trabajo. Intrigado por el descubrimiento, contacté con Ignacio García-Amorena, profesor de la escuela de Ingenieros de Montes de la U.P.M. para que valorase su interés científico. Nacho me animó a incluir el pequeño hallazgo en una publicación que estaba preparando, y me transmitió su entusiasmo por la paleobotánica, lo que en última instancia me llevó a matricularme en el programa de doctorado de Silvopascicultura.

Durante los primeros pasos de esta Tesis, ya con Nacho como mi director de Tesis, nos dimos cuenta que para llevar a buen puerto esta empresa necesitaríamos la ayuda de alguien con experiencia en la identificación de fósiles foliares. Fue entonces cuando se sumó al equipo Eduardo Barrón, mi segundo codirector, sin quien este trabajo difícilmente habría podido salir adelante. Agradezco a ambos, Ignacio García-Amorena y Eduardo Barrón todo el esfuerzo y ayuda que me han prestado para que pudiese recorrer este camino, así como sus consejos, revisiones y ánimos.

También quiero agradecer la ayuda prestada por otras personas que contribuyeron al desarrollo de esta Tesis Doctoral en alguna de sus fases. Los Dres. José Luis Pagés y Ángela Alonso Millán me guiaron en la definición del complejo tobáceo de Tubilla del Agua y en la toma de muestras para su datación. Sus comentarios sobre la formación de tobas me ayudaron a entender mejor este proceso, y el modelo evolutivo que bosquejaron sobre el complejo de Tubilla del Agua ha demostrado ser coherente con otras evidencias y dataciones que he ido recopilando posteriormente.

La recogida de fósiles y muestras de toba en los espacios naturales en los que los depósitos estudiados se localizan requirió la aprobación de la administración pública. En este sentido, debo agradecer a la Directora-Conservadora de los Parques Naturales de Montes 
Obarenes y Hoces del Ebro y Rudrón, Carmen Allué Camacho, el apoyo recibido. La ayuda de Carmen no se limitó a la concesión de los permisos necesarios para realizar las prospecciones, sino que también se mostró dispuesta a sufragar el coste de datación de una muestra con cargo al Servicio Territorial de Medioambiente de Burgos. La datación de sedimentos por el método de racemización de aminoácidos fue realizada desinteresadamente por el Dr. José Eugenio Ortiz Menéndez, investigador titular de la E.T.S. de Ingenieros de Minas y Energías de la Universidad Politécnica de Madrid, quien también me instruyó en la forma adecuada de tomar las muestras. El resto de las dataciones fueron sufragadas a cargo de los proyectos CGL2008-06005 BOS, CGL2009-0698 BOS y MIA.

Por último, he de agradecer a mi pareja, Jing, su paciencia y comprensión por todas las horas que he tenido que robar a nuestros proyectos comunes para la realización de esta Tesis Doctoral.

A todos vosotros, gracias. 


\section{ÍNDICE}

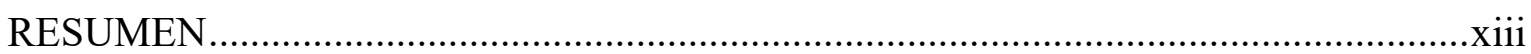

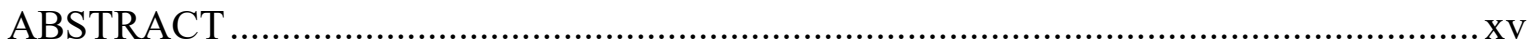

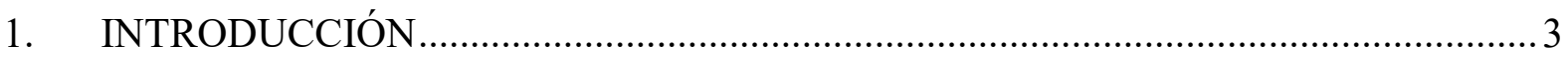

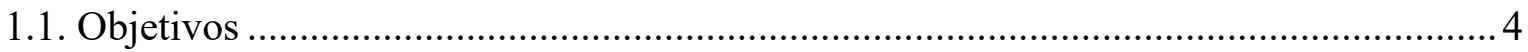

1.2. Contexto climático en el Cuaternario Final ................................................................ 4

1.3. Origen de la vegetación del sector Castellano Cantábrico ............................................ 6

1.4. Antecedentes de estudios paleobotánicos en el sector Castellano Cantábrico ................9

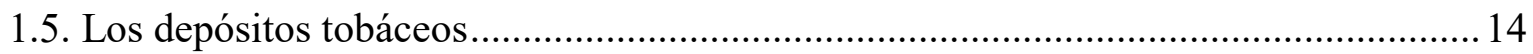

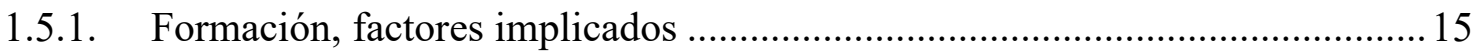

1.5.2. Principales morfotipos de acumulaciones tobáceas ...................................... 18

1.5.3. Aspectos tafonómicos de los depósitos tobáceos .........................................2 21

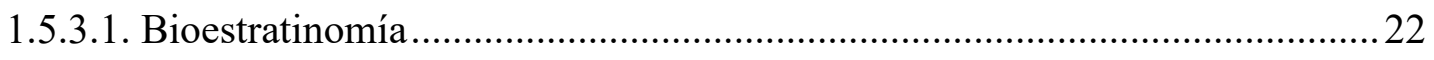

1.5.3.2. Composición de las tanatocenosis ..............................................................24

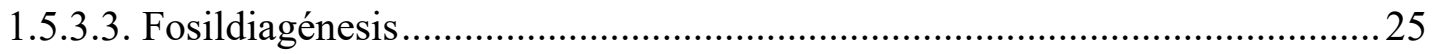

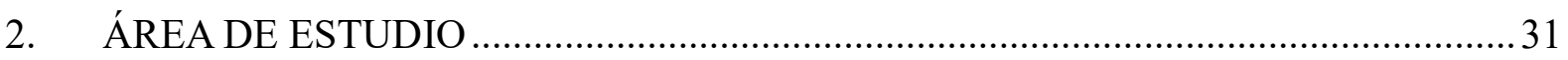

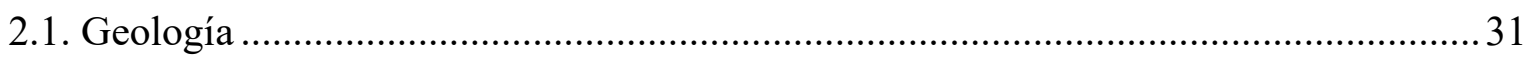

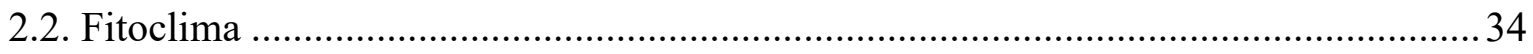

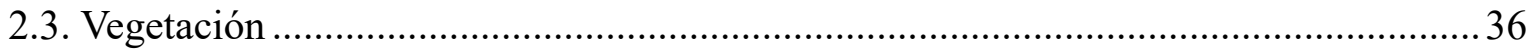

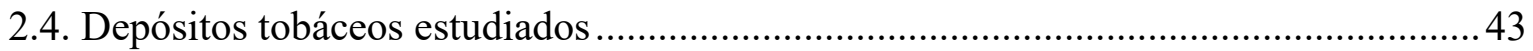

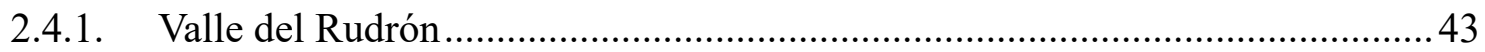

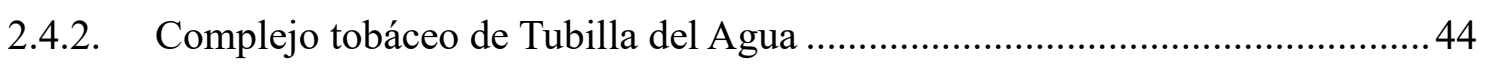

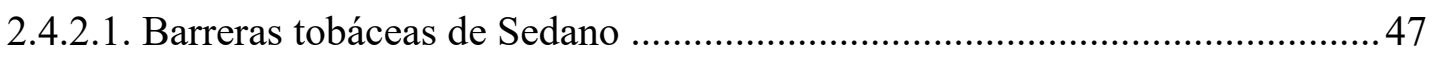

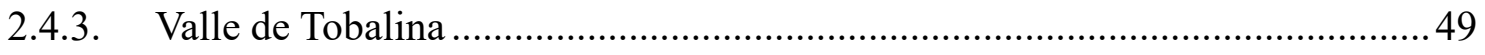

2.4.3.1. Complejo tobáceo del desfiladero del río Purón............................................50

2.4.3.2. Complejo tobáceo del desfiladero del río Molinar ........................................5 53

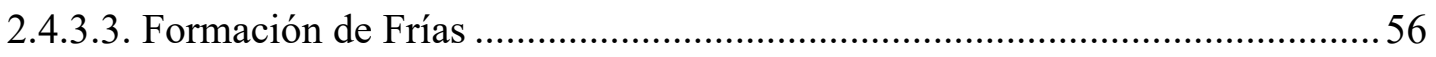

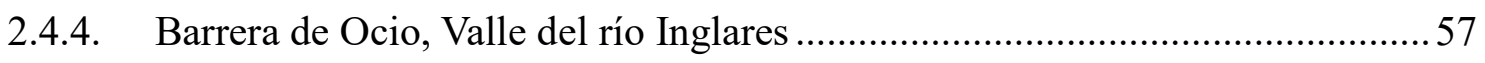

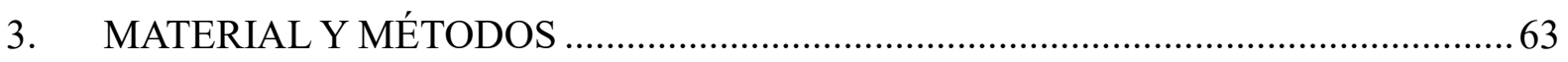

3.1. Selección de los yacimientos y determinación del área de estudio ..............................63

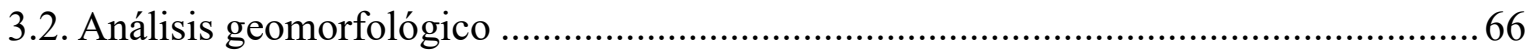




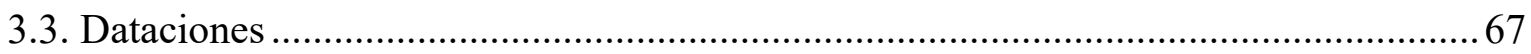

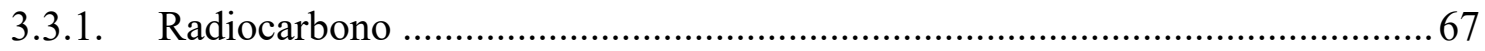

3.3.1.1. Fundamentos de la datación por radiocarbono ...........................................6 68

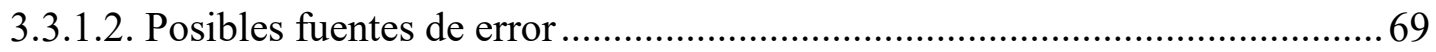

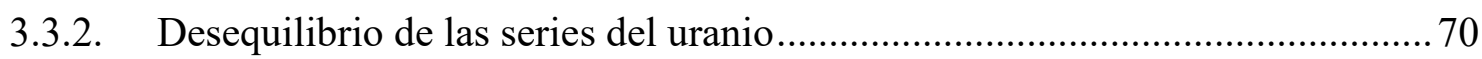

3.3.2.1. Fundamentos de la datación por uranio-torio ........................................... 70

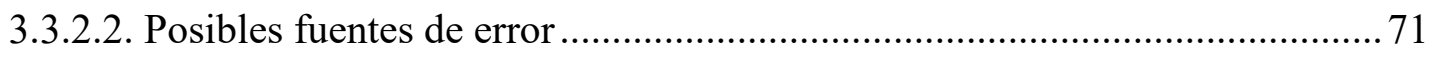

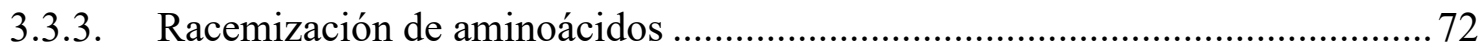

3.3.3.1. Fundamentos de la datación por racemización de aminoácidos ................... 73

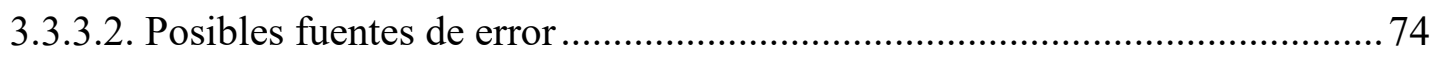

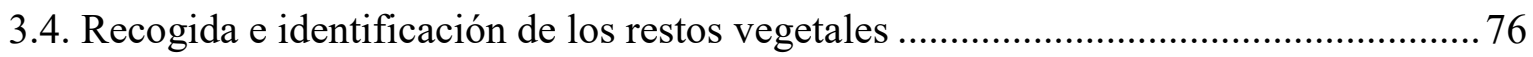

3.5. Distribución temporal de las unidades litológicas identificadas ................................. 78

3.6. Reconstrucción de las paleofitocenosis y de la evolución de la vegetación .................80

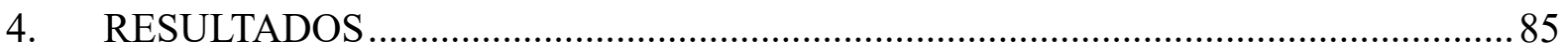

4.1. Selección de los depósitos a estudiar y determinación del área de estudio................... 85

4.2. Resultados del análisis geomorfológico de los yacimientos de Tubilla, Sedano y

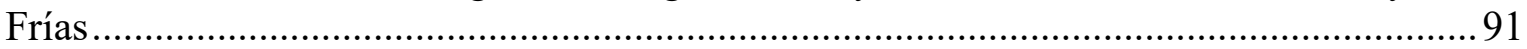

4.2.1. Complejo tobáceo de Tubilla del Agua ....................................................... 91

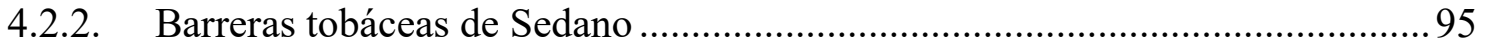

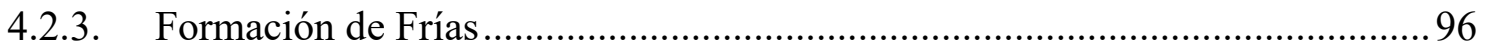

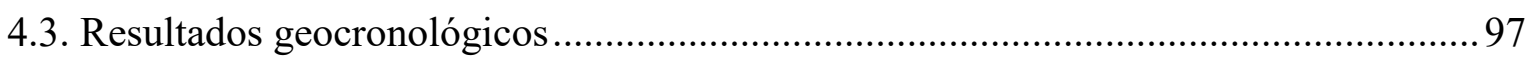

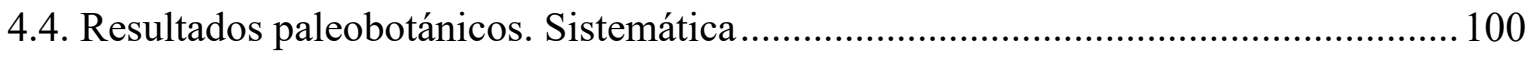

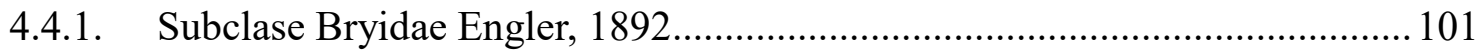

4.4.2. Subclase Polypodiidae Cronquist, Takhtajan \& W. Zimmermam, 1966 ........ 102

4.4.3. Subclase Pinidae Cronquist, Takhtajan \& W. Zimmermam, 1966 .................. 104

4.4.4. Subclase Magnoliidae Novák ex Takhtajan, 1967 ........................................ 110

4.5. Distribución temporal de los depósitos tobáceos y reconstrucción de las

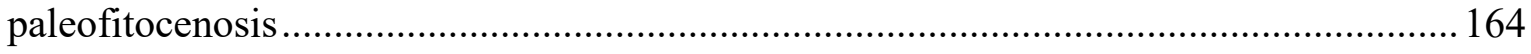

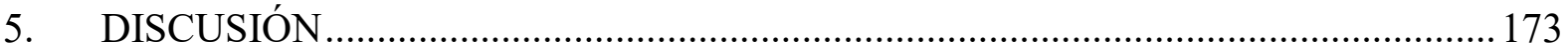

5.1. Análisis de la geocronología y evolución de los yacimientos de Tubilla del Agua,

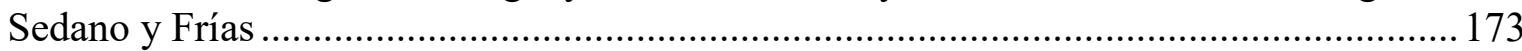

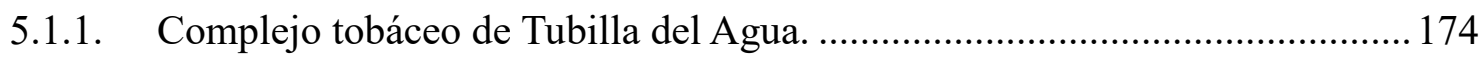

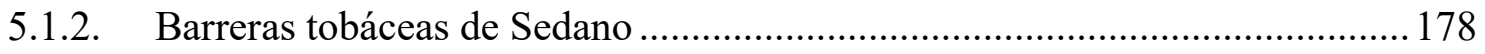

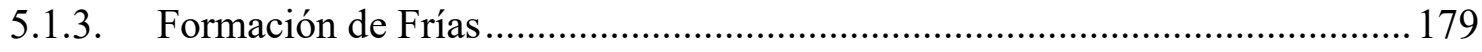


5.2. Consideraciones sobre la distribución temporal de los depósitos tobáceos estudiados

5.3. Análisis tafonómico del registro fósil

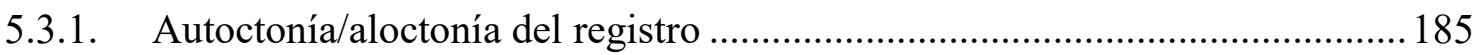

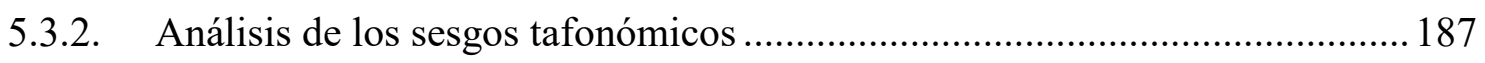

5.4. Aspectos complementarios sobre la reconstrucción de las paleofitocenosis .............. 191

5.4.1. Depósitos TUAG-PS, TUAG-T y Formación de Frías ................................. 192

5.4.1.1. Revisión del estudio paleobotánico de la formación de Frías (Álvarez Ramis \& Fernández Marrón, 1975)

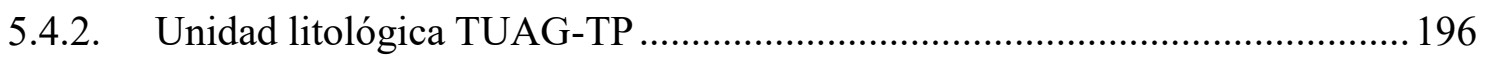

5.4.2.1. Comparación con la flora del yacimiento de El Prat — Beceite, Teruel— 197

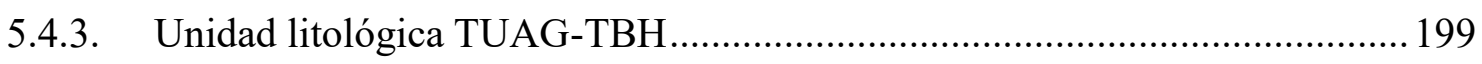

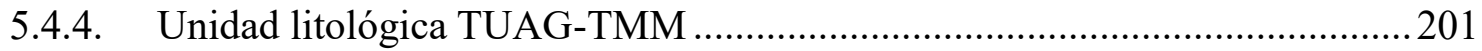

5.4.5. Depósitos TUAG-BH, TUAG-VBH, SD-BS, SD-BI, DRP, DRM y BO ......202

5.5. Evolución de la vegetación del sector Castellano Cantábrico en el Cuaternario

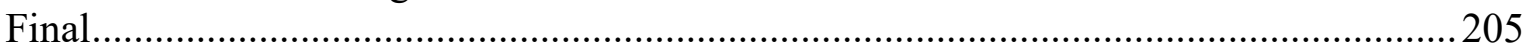

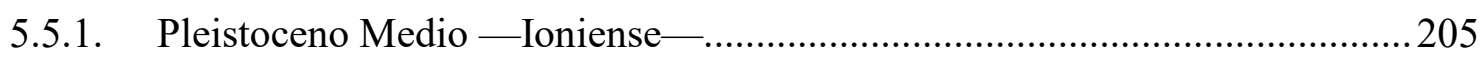

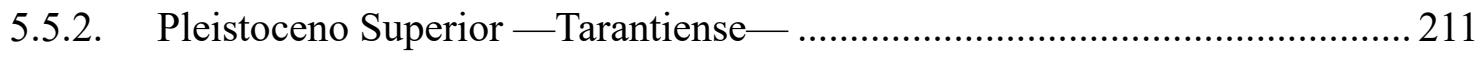

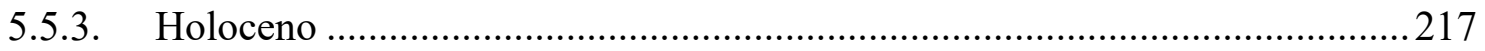

5.5.3.1. Presencia y extinción de Pinus en el sector Castellano Cantábrico durante Holoceno.....

5.6. El sector biogeográfico Castellano Cantábrico como refugio glacial ........................227

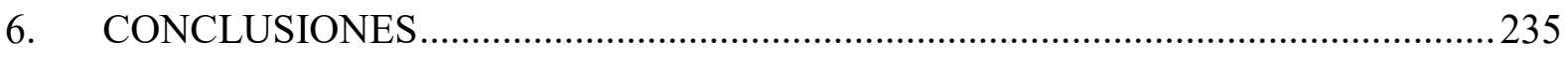

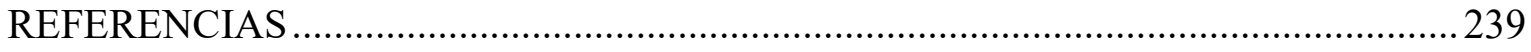

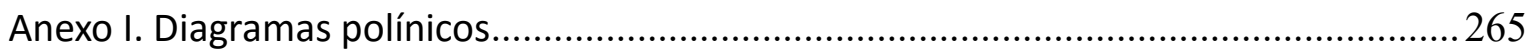

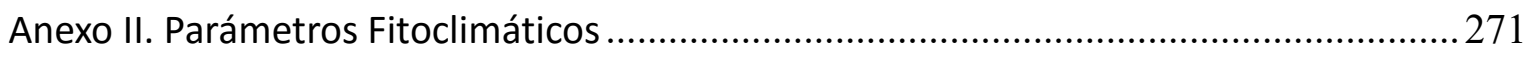

Anexo III. Leyenda del mapa de series de vegetación del sector Castellano Cantábrico. 275

Anexo IV. Siglado de los fósiles 


\section{ÍNDICE DE FIGURAS}

Fig. 1. Gráfica de la anomalía de la temperatura de los últimos 800 ka....................................5

Fig. 2. Mapa de los yacimientos paleobotánicos próximos al área de estudio.........................13

Fig. 3. Tipos generales de formaciones tobáceas de carácter autóctono.................................18

Fig. 4. Mapa geológico y de ubicación del sector Castellano Cantábrico..................................33

Fig. 5. Mapa de vegetación y de series de vegetación del sector Castellano Cantábrico........41

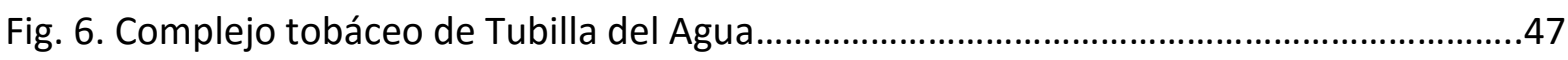

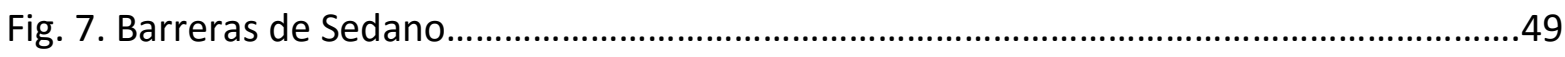

Fig. 8. Complejo tobáceo del desfiladero del río Purón...........................................................52

Fig. 9. Complejo tobáceo del desfiladero del río Molinar.........................................................55

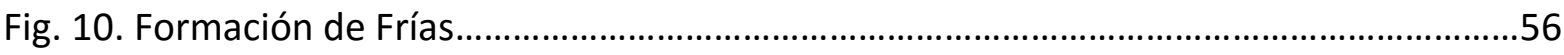

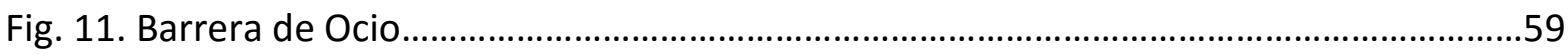

Fig. 12. Diagrama del proceso metodológico de la Tesis Doctoral.............................................64

Fig. 13. Mapa de los afloramientos tobáceos de Alto Ebro explorados.....................................89

Fig. 14. Unidades litológicas y perfil geológico del complejo de Tubilla del Agua....................94

Fig. 15. Unidades litológicas identificadas y perfil geológico de las barreras de Sedano.........96

Fig. 16. Diagrama sintético de los resultados del análisis geocronológico y paleobotánico.165

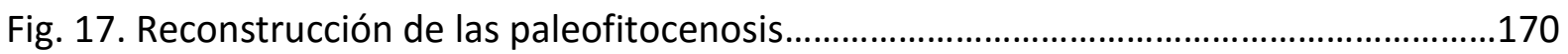

Fig. 18. Distribución temporal de los depósitos tobáceos estudiados...................................183

Fig. 19. Encostramientos de toba sobre acículas de Pinus sp.................................................185

Fig. 20. Cantidad de ejemplares recogidos de cada taxón agrupados por procedencia........189

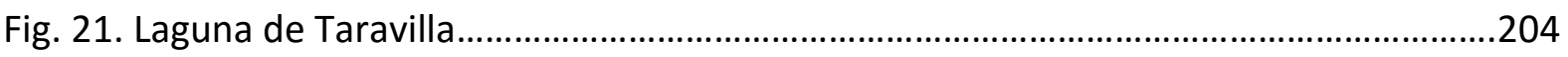

Fig. 22. Diagrama resumen de la evolución de la vegetación .................................................207

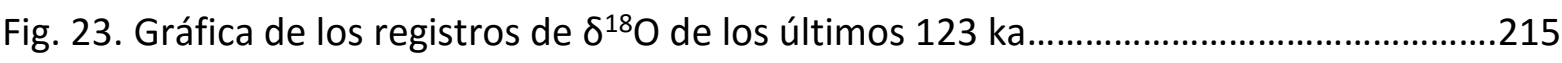

Fig. 24. Correlación entre las medidas de polen del sondeo KSO5 10 y otras variables.........222

Fig. 25. Mapa de las masas naturales de Pinus nigra y P. sylvestris en la Meseta Norte.......226 


\section{ÍNDICE DE LÁMINAS DE RESTOS FÓSILES}

Lám. 1. Fontinalis antipyretica Hedw., Asplenium scolopendrium L., Pinus nigra J.F. Arnold y Pinus sp. .105

Lám. 2. Restos subfósiles de Pinus nigra J.F. Arnold y Pinus sp. .110

Lám. 3. Fig. Poales incertae sedis 1, Poales incertae sedis 2, Juncus sp., Berberis vulgaris L. Buxus sempervirens L. y Salix eleagnos Scop.

Lám. 4. Salix sp. 1, Salix sp. 2 y Salix sp. 3. .124

Lám. 5. Amelanchier ovalis Medik., Sorbus aria (L.) Crantz y Rhamnus alpina L. .131

Lám. 6. Rhamnus frangula L., Betula sp. y Corylus avellana L. 139

Lám. 7. Fagus sylvatica L, Quercus faginea Lam. y Acer campestre L .144

Lám. 8. Acer cf. platanoides, Cornus sanguinea L. y cf. Tilia sp. .155

Lám. 9. Fraxinus sp. Hedera sp. L. y Dicotyphyllum sp. 1 . .158 


\section{ÍNDICE DE TABLAS}

Tabla 1. Dataciones publicadas del complejo tobáceo de Tubilla del Agua..............................45

Tabla 2. Dataciones publicadas de los depósitos tobáceos de Sedano.......................................48

Tabla 3. Dataciones publicadas de los depósitos tobáceos del desfiladero del río Purón.......51

Tabla 4. Dataciones publicadas de los depósitos tobáceos del desfiladero del río Molinar...54

Tabla 5. Dataciones publicadas de la barrera de Ocio................................................................58

Tabla 6. Datos de las muestras recogidas para su datación en esta Tesis Doctoral.................75

Tabla 7. Ubicación de los afloramientos tobáceos del Alto Ebro y resultados de la evaluación

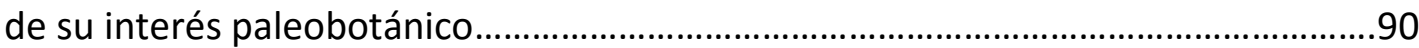

Tabla 8. Resultados de la datación mediante carbono-14 de las muestras del yacimiento de

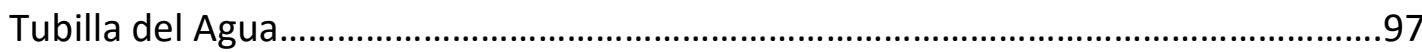

Tabla 9. Resultados de la datación mediante carbono-14 de las muestras del yacimiento de Sedano.

Tabla 10. Resultados de la datación mediante la técnica del uranio-torio de las muestras tomadas en el yacimiento de Tubilla del Agua.

Tabla 11. Resultados de la datación de mediante racemización de aminoácidos de las muestras tomadas del yacimiento de Frías.

Tabla 12. Número de ejemplares fósiles de toba recogidos en los yacimientos estudiados, contabilizados por taxón, afloramiento, localidad y comarca.

Tabla 13. Propuesta de revisión taxonómica de algunas de las impresiones foliares del yacimiento de Frías figuradas por Álvarez Ramis \& Fernández Marrón, (1975)...195

Tabla 14. Comparación con la flora encontrada por Martínez-Tudela, et al. (1986) y Gimeno \& Muñoz-Bertomeu (1999) en el yacimiento de Beceite -Teruel- 


\section{RESUMEN}

En esta memoria de Tesis Doctoral se aborda el estudio paleobotánico de seis yacimientos tobáceos situados en las localidades burgalesas de Tubilla del Agua, Sedano, Herrán, Tobera y Frías, y en la alavesa de Ocio. El registro fósil encontrado en estos afloramientos se analiza de forma conjunta con el objetivo de conocer la evolución de la vegetación en el sector biogeográfico Castellano Cantábrico. Este sector se considera el territorio para el cual los hallazgos paleobotánicos son representativos y extrapolables, en tanto que constituye una región homogénea desde el punto de vista florístico, que abarca todos los yacimientos prospectados.

El contexto temporal en el que se enmarca este estudio es el final del Cuaternario, desde el Pleistoceno Medio hasta la actualidad. Este intervalo se ha establecido a partir de la edad de los depósitos estudiados, la cual ha sido determinada — para los yacimientos de los que no se disponía de edades fiables- mediante la datación de muestras extraídas de las diferentes unidades litológicas identificadas. Para ello han sido empleadas las técnicas de carbono-14, desequilibrio de las series del uranio y racemización de aminoácidos. Los resultados geocronológicos obtenidos junto con el análisis geomorfológico de los yacimientos han permitido vincular la génesis de las 13 unidades litológicas identificadas con diferentes estadíos climáticos. Estos abarcan un amplio rango de condiciones ambientales, desde las más extremas del Último Máximo Glacial, hasta las más benignas de los Estadíos Isotópicos Marinos interglaciares 1 y 5 .

Como resultado de la prospección de los depósitos de toba fueron recuperados 1.820 fósiles, la mayoría impresiones foliares, pero también moldes de estróbilos femeninos, ramas y corteza, así como 42 carbones y restos subfósiles de Pinus sp. La identificación taxonómica de estos restos se ha realizado fundamentalmente a partir del análisis de caracteres 
diagnósticos morfológicos. Como resultado de ello, han sido descritos 28 taxones pertenecientes a las subclases Bryidae, Polypodiidae, Pinidae y Magnoliidae.

La flora de los yacimientos estudiados se puede clasificar en tres grupos en función de sus requerimientos ecológicos: (i) uno formado por dos especies de alta tolerancia a la continentalidad —Pinus nigra y Quercus faginea_, las cuales aparecen bien representadas en la mayoría de los depósitos; (ii) otro constituido fundamentalmente por un conjunto de árboles y arbustos que habitualmente tienen el papel de especies acompañantes en los bosques ibéricos submediterráneos y eurosiberianos; y (iii) un tercer grupo compuesto por taxones hidrófitos o edafohigrófilos asociados al ecosistema del fitohermo activo y la vegetación de ribera.

En el capítulo de Discusión se propone y analiza la hipótesis de que $P$. nigra y $Q$. faginea habrían sido las especies protagonistas de la vegetación zonal del sector Castellano Cantábrico durante el Cuaternario Final. Estas podrían haber persistido como tal incluso durante las épocas más frías, debido a su amplia valencia ecológica y a la capacidad de reproducirse vegetativamente en el caso del quejigo. Por el contrario, los taxones mesofíticos y eurosiberianos pudieron haber sufrido la expansión y retracción de sus poblaciones al ritmo de las oscilaciones climáticas. Sin embargo, la orografía diversa del sector Castellano Cantábrico proporciona emplazamientos en los que se combinan las diversas variables fisiográficas, de tal forma que pudieron haber existido microrrefugios en los que encontraron cobijo algunos taxones mesotérmicos y eurosiberianos durante los periodos glaciales.

Por último, la historia evolutiva reciente de la vegetación de este territorio ha estado marcada por la acción antrópica, la cual empezó a ser manifiesta a partir del Neolítico. Esta se tradujo en la degradación y reducción de la cubierta forestal, así como en la extinción del pino laricio del Sector Castellano Cantábrico en los dos últimos milenios. 


\section{ABSTRACT}

This PhD Dissertation focuses in the study of six tufa formations located nearby the villages of Tubilla del Agua, Sedano, Herrán, Tobera y Frías, all of them in the province of Burgos, and Ocio, which belongs to the province of Álava. We analyze the palaeobotanical archives of these sites with the purpose of unveiling and understanding the evolution of the vegetation of the Castilian Cantabrian biogeographical sector. This area is considered to be the territory that is represented in the palaeobotanical sample of the studied tufa archives. It is the homogeneous phitogeographical area with the lowest rank that include all the sites.

The time frame of this study is the last part of the Quaternary, since the Middle Pleistocene to the present time. This interval is defined by the age of the tufa deposits, which were dated — for the ones that there were not available datings — throughout the analysis of 20 tufa samples taken from the 13 identified lithostratigraphic units. The age of the samples has been determined by using the methods of radiocarbon, U-Th dating and amino acid racemization. Chronological results, along with the chronostratigraphic study of the sites has allowed us to relate the build-up of the 13 identified lithostratigraphic units with different climatic stages. These structures were deposited in a wide range of climatic conditions, from the most extreme ones of the Last Glacial Maximum, to the warmer ones of the Marine Isotopic Stages 1 and 5.

A total of 1,820 fossils were recovered from the tufa deposits, most of them were leaf impressions, but also pine cones, branches and bark moulds, along with charcoal and Pinus nigra macro remains. The taxonomical identification of these remains has been done mainly through the analysis of morphological traits. As a result of this process, 28 taxa belonging to the subclass of Bryidae, Polypodiidae, Pinidae and Magnoliidae were identified. 
The persistency of some taxa can be traced along different climatic stages in this fossil record. This fossil flora can be classified in three different groups: (i) the first one would be composed of two species with high continental climate tolerance _Pinus nigra y Quercus faginea-, which can be found in most of the deposits, (ii) the second group would be mostly formed by trees and shrubs that usually grow in the lberian forests as an accessory species and (iii) the third one is composed of hydrophytes or hydrophilic taxa associate to the streams, riparian zones or the active tufa ecosystem.

In the Discussion chapter we propose and analyse the hypothesis that P.nigra and Q. faginea were the main species of the zonal vegetation of the Castilian Cantabrian biogeographical sector during the last part of the Quaternary. This species could have persisted due to their wide ecological amplitude and also due to the capacity of asexual reproduction in the cases of the oak. On the other hand, mesophitic taxa could have suffered the retraction and expansion of their population following the climate oscillations. However, the diverse orography of the Castilian Cantabrian biogeographical sector provides a variety of combinations of physiographic variables, which could have been suitable refuges for some of the mesophitic taxa.

The recent evolutionary history of the vegetation in this territory has been affected by human activities, which started to be relevant since the Neolithic. This led to a reduction of the forests and eventually, to the extinction of $P$. nigra in the Castilian Cantabrian biogeographical sector in the last two thousands of years. 
El presente es la viviente suma total del pasado

Thomas Carlyle

xvii 
CAPÍTULO 1. INTRODUCCIÓN 


\section{INTRODUCCIÓN}

La vegetación de un determinado territorio es el resultado de la acción conjunta de procesos ecológicos y evolutivos que la han ido transformando a lo largo del tiempo (Willis \& McElwain, 2002). Los procesos evolutivos son aquellos que afectan a la diversidad genética, específica y de comunidades, como por ejemplo la deriva genética, la radiación adaptativa o la coevolución interespecífica (Stearns \& Hoekstra, 2000). Por su parte, los procesos ecológicos son los que resultan de la interacción entre la vegetación y el medioambiente. Estos procesos están mediados tanto por factores abióticos como bióticos (Chapman \& Reiss, 1992). De entre los factores abióticos —clima, suelo y fisiografía—, el clima es el más dinámico de todos ellos, y el más determinante en los procesos de evolución de la vegetación a escala temporal geológica. La relación entre el cambio climático y la modificación de la cubierta vegetal ha sido ampliamente contrastada en numerosos estudios paleobotánicos en periodos geológicos diferentes - p.e. Barrón (2003), Desprat et al. (2007), Barrón et al. (2010a), Diéguez, et al. (2010)—. Los factores ecológicos bióticos son aquellos que tienen su origen en la acción de otros seres vivos. Estos comprenden interacciones complejas a nivel de ecosistema, como la competencia, el mutualismo, el comensalismo, el antagonismo, etc. (Chapman \& Reiss, 1992). A estos factores anteriores se debe añadir la influencia antrópica, la cual ha sido determinante en la modificación de la cubierta vegetal en los últimos milenios (Blanco, et al., 1997; Carrión, et al., 2000a; Rubiales, et al., 2008). El conocimiento de la evolución pretérita de la vegetación ayuda a comprender los procesos que median en su cambio, lo cual, a su vez, ayuda a predecir el efecto que sobre la vegetación tendrán diversos agentes y su evolución futura. 


\subsection{Objetivos}

El objetivo principal de esta Tesis Doctoral es contribuir al conocimiento de la evolución de la vegetación durante el Cuaternario Final en el sector biogeográfico Castellano Cantábrico a través del estudio del registro paleobotánico contenido en los yacimientos tobáceos de este territorio. Para lograr este fin se han de cumplir los siguientes objetivos subordinados:

- Prospectar desde un punto de vista geomorfológico y paleobotánico los afloramientos tobáceos de la zona de estudio.

- Estudiar la geocronología y estructura de los yacimientos seleccionados.

- Estudiar el registro fósil de los yacimientos.

- Interpretar los resultados obtenidos en el contexto del conocimiento existente a escala del sector Castellano Cantábrico e ibérica.

\subsection{Contexto climático en el Cuaternario Final}

Como ha sido comentado en el apartado anterior, el clima es uno de los factores más determinantes en la evolución de la vegetación. El del Cuaternario se ha caracterizado desde su inicio, hace 2,6 millones de años (Gibbard \& Head, 2009), por la alternancia periódica de fases glaciares e interglaciares (Fig. 1) (Summerhayes, 2015). La causa principal de estas oscilaciones es la variación de la inclinación y precesión del eje de la tierra, así como de la excentricidad de su órbita alrededor del sol (Zachos, et al., 2001). En la segunda mitad del Cuaternario, en el periodo comprendido entre 1.2 y $0.5 \mathrm{Ma}$, tuvo lugar la denominada Revolución del Pleistoceno Medio, por la cual los ciclos de oblicuidad orbital de 41 Ka pasaron paulatinamente a ser de 100 ka (Head \& Gibbard, 2005). A partir de entonces, los periodos 
interglaciares pasaron a ocupar una proporción menor de los ciclos glacial-interglaciar que anteriormente, siendo a su vez más cálidos que los periodos interglaciares de los ciclos de 100 ka de amplitud (EPICA, 2004; Head \& Gibbard, 2005).

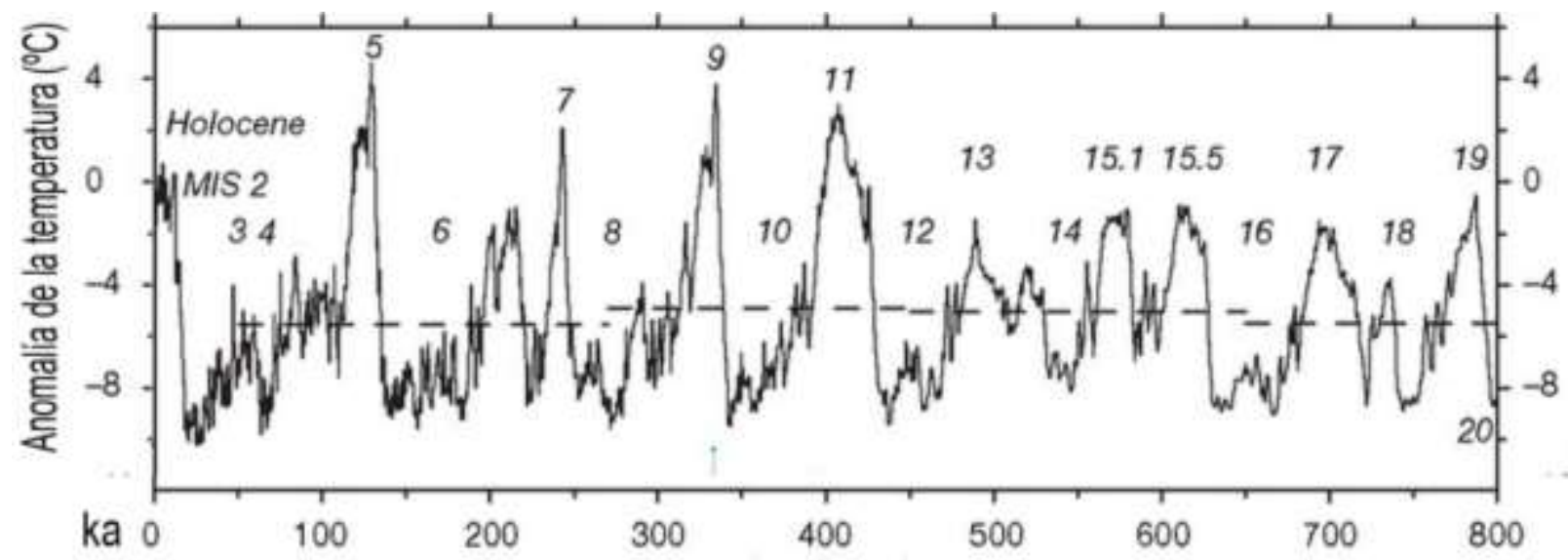

Figura 1. Anomalía de la temperatura de los últimos $800 \mathrm{ka}$ con respecto a la temperatura del último milenio. Elaborada a partir de los registros de deuterio del sondeo EPICA Dome C. Los números sobre la curva denotan los Estadios Isotópicos Marinos. Modificada de Luthi, et al. (2008).

El Último Interglacial, también conocido como Eemiense o interglacial Riss-Würn fue el último periodo en el que la temperatura media global fue tanto o más cálida que la actual (Kukla, et al., 2002). Este estadío climático —MIS 5e-comenzó en torno a hace unos 130 ka y concluyó abruptamente hace 110 ka con un rápido enfriamiento global (Fig. 1) (Martinson, et al., 1987). Desde el final del Eemiense hasta el inicio del Holoceno, hace 11.700 años (Adams, et al., 1999; Walker, et al., 2009), la tendencia general del clima fue hacia unas condiciones paulatinamente más frías y secas (Martinson, et al., 1987). Sin embargo, esta progresión no fue lineal, sino en forma de rápidas oscilaciones climáticas en las que se alternaron interestadiales más cálidos con otros más fríos, conocidos como ciclos DansgaardOechsger (Fig. 23) (Broecker \& Denton, 1989). Las condiciones más extremas de frío y aridez se dieron durante el último evento de Heinrich, entre 17 y $15 \mathrm{ka}$, justo después de que los casquetes polar ártico y antártico alcanzasen su máxima extensión, lo que se conoce como el Último Máximo Glacial (Heinrich, 1988; Adams, et al., 1999). 
Al periodo de calentamiento postglacial comprendido entre el Último Máximo Glacial y el comienzo del Holoceno se le conoce como Tardiglaciar. La mejoría de las condiciones climáticas durante el Tardiglaciar se vio sin embargo interrumpida por el pulso frío del Dryas Reciente, entre 12,9 y 11,5 ka (Rahmstorf, 2003; Walker, et al., 2009). El clima durante el Holoceno ha sido considerablemente más estable que el del Último Periodo Glacial (Dansgaard, et al., 1993). A pesar de ello, también se ha constatado cierta variabilidad climática durante este periodo. Por ejemplo, los registros extratropicales indican que las condiciones más cálidas y húmedas del Holoceno se alcanzaron hace aproximadamente 9.000 años, durante el Óptimo Climático Holoceno. Este periodo fue seguido de un evento brusco de enfriamiento hace 8.200 años -Evento 8,2 ka- (Daley, et al., 2011), constatándose a partir de entonces una tendencia hacia condiciones más frías (Marchal, et al., 2002; Rodrigues, et al., 2009).

\subsection{Origen de la vegetación del sector Castellano Cantábrico}

Uno de los rasgos más característicos del sector Castellano Cantábrico es su marcado carácter transicional, ya que en él entran contacto las elevaciones montañosas de la Cordillera Cantábrica con las cuencas sedimentarias del Duero y Ebro, el clima atlántico y con el mediterráneo continental, y las comunidades vegetales propias de estos dominios climáticos. Como consecuencia de ello, la vegetación actual de este territorio está constituida por elementos florísticos propios de los ámbitos biogeográficos eurosiberiano y mediterráneo (Loidi Arregui \& Fernández Prieto, 1986; Alejandre, et al., 2006), los cuales tienen una historia evolutiva diferente.

La mayoría de los taxones eurosiberianos tienen su origen en la vegetación que se desarrollaba en las zonas polares y circumpolares de clima templado-cálido entre el Paleógeno Superior y el Eoceno Medio. A esta vegetación se le conoce como Geoflora Arctoterciaria (Mai, 1989; Mai, 1991) y estaba compuesta por grupos de gimnospermas - 
especialmente coníferas-y angiospermas caducifolias. Los géneros más representativos de esta paleoflora fueron Osmunda L., Ginkgo L., Taxodium Rich., Sciadopitys Siebold \& Zucc., Abies Mill., Larix Mill., Picea A. Dietr., Pinus L., Tsuga (Endl.) Carrière, Thuja L., Alnus Mill., Betula L., Platanus L., Juglans L., Castanea Mill., Cercidiphyllum Siebold \& Zucc., Fagus L., Magnolia L., Liriodendron L., Populus L., Pterocarya Kunth, Quercus, Ulmus L., Zelkova Spach, Carpinus L., Corylus L., Acer L., Aesculus L, Vitis L., etc. (Barrón, 2003; Barrón, et al., 2010)

Al sur de esta banda de vegetación, en las latitudes bajas y medias de los continentes boreales, se desarrollaban floras subtropicales dominadas por angiospermas. Al grupo de taxones característico de este cinturón de vegetación se le conoce como Geoflora Paleotropical (Mai, 1989; Mai, 1991). En la Península Ibérica estaba formada por especies lauroides y perennifolias de géneros como Cinnamomum Schaeff., Litsea Lam., Neolitsea (Benth.) Merr., Persea Mill., Laurus L., Quercus L., Castanopsis (D. Don) Spach, Lithocarpus Blume, Chamaerops L., Livistona R. Br., Sabal Adans, Trachycarpus H. Wendl., etc. (Barrón, 2003; Barrón, et al., 2010)

El enfriamiento y aridificación del clima global, así como el aumento de las diferencias estacionales que tuvo lugar a partir del Eoceno medio (Eldrett, et al., 2009), provocaron que la Geoflora Paleotropical viese reducida su área de distribución hasta su práctica desaparición de las latitudes medias. Esto estuvo acompañado por la expansión hacia latitudes más meridionales de taxones arctoterciarios (Wolfe, 1985). Con la instauración del clima Mediterráneo en el Plioceno Superior (Abrantes, et al., 2012), la mayoría de estos elementos paleotropicales termófilos se extinguieron en la Península Ibérica (Jiménez-Moreno, et al., 2010).

Sin embargo, algunos taxones de la Geoflora Paleotropical más resistentes, que quizás anteriormente ya ocupaban estaciones más xéricas, sobrevivieron adaptándose a las 
nuevas condiciones (Palamarev, 1987). Este grupo de plantas de origen subtropical son el germen de una parte de las especies mediterráneas actuales, las cuales se diferencian de la flora mediterránea con otros orígenes por sus hojas esclerófilas, frutos carnosos, flores pequeñas y semillas grandes (Herrera, 1992). Forman parte de este grupo algunas especies de la flora mediterráneas del sector Castellano Cantabrico, como por ejemplo Pistacia terebinthus L., Rhamnus alaternus L. o Arbutus unedo L. (Herrera, 1992; Alejandre, et al., 2006). Aquellas especies que no poseen estas características se considera que, o bien evolucionaron cuando ya existían unas condiciones climáticas mediterráneas, o migraron hasta la cuenca mediterránea desde zonas con un clima similar (Herrera, 1992). Este último es el origen de algunos de los taxones más tolerantes a la continentalidad presentes en el sector Castellano Cantábrico, como por ejemplo Ephedra L., Chenopodiaceae, Artemisia L. y Stipa L., los cuales proceden la región florística irano-turinica (López, 2007).

Las oscilaciones climáticas cuaternarias a las que se ha aludido en el apartado anterior causaron importantes cambios en la distribución y composición de la vegetación heredada del Plioceno superior (Carrión, et al., 2000a; Morla, 2003). Durante las fases glaciales la flora mediterránea sufría la contracción de las áreas de distribución, refugiándose en los valles intramontanos y zonas litorales del sur del continente (Carrión, et al., 2000a). En el centro peninsular se instauraba un paisaje de estepa o bosque abierto dominado por pinos, en el que las quercíneas podían estar representadas en mayor o menor medida (Morla, 2003; González-Sampériz, et al., 2010). El mantenimiento de la fitodiversidad durante las glaciaciones en la Península Ibérica se vio favorecida por su diversidad orográfica y geológica, lo que propició el establecimiento de los refugios donde se cobijaron los taxones más termófilos, principalmente en zonas costeras, pero también en localidades del interior peninsular (González-Sampériz, et al., 2010).

A pesar de la existencia de estos refugios, las repetidas pulsaciones glaciares fueron dificultando la capacidad de recuperación de algunas especies, llevándolas a la extinción. Por 
ejemplo, en los niveles sedimentarios inferiores de Gran Dolina —Burgos—, en la cercana Sierra de Atapuerca, aparece polen de Cedrus Trew, Taxodium, Carya Nutt. y Pinus tipo haploxylon, pero al final de la unidad estratigráfica TD 8 - hace aproximadamente unos 500600 ka (Falguères, et al., 1999; Berger, et al., 2008)—, coincidiendo con un abrupto incremento de la proporción de los elementos atlánticos, desaparece de las secuencias polínicas (Rodríguez, et al., 2011). Otros taxones extinguidos de la flora ibérica en el Pleistoceno son Cupressus L., Zelkova Spach, Cathaya Chun \& Kuang, Liquidambar L., Tsuga, Ostrya Hill y Mimosaceae. Más tardíamente, durante la glaciación que dio paso al Holoceno, desaparecieron de la Península Ibérica Picea, Cedrus, Platanus y Aesculus (Postigo-Mijarra, et al., 2009; Postigo-Mijarra, et al., 2010).

\subsection{Antecedentes de estudios paleobotánicos en el sector Castellano Cantábrico}

Las investigaciones paleobotánicas llevadas a cabo en el sector Castellano Cantábrico no son muy numerosas, pero si tenemos en cuenta los realizados en las cercanías de este territorio, en su conjunto abarcan buena parte del Cuaternario Final. Álvarez Ramis \& Fernández Marrón (1975) estudiaron desde el punto de vista paleobotánico, la formación tobácea de Frías - Burgos- (Fig. 2), uno de los yacimientos objeto de estudio de esta Tesis Doctoral. Los autores citados identifican 10 taxones a partir del análisis de impresiones foliares encontradas: Carpinus grandis Ung., Myrica hakedefolia (Ung.) Sap., Salix sp., Populus sp., Zelkova ungeri aff. Z. crenata Spach., cf. Liquidambar europea Al. Br., Prunus sp., Cercis aff. Siliquastrum L., Byttneriophyllum tiliaefolium (Al. Br.) Knobl. et Kvacek y Berchemia multinervis Heer. El estudio de la paleobiogeografía de estos taxones llevó a Álvarez Ramis \& Fernández Marrón (1975) a proponer que la formación de este depósito tuvo lugar durante el Mioceno Superior. Sin embargo, la cronología propuesta difiere de la obtenida en esta Tesis Doctoral a partir de la datación de muestras tomadas de la misma formación, por lo que existen dudas sobre la correcta identificación de algunos ejemplares. En el 
apartado 5.4.4.1. del capítulo 5 se discute en detalle los resultados publicados por los autores citados.

Otros estudios paleobotánicos relevantes para alcanzar los objetivos de esta Tesis Doctoral son los realizados en los yacimientos de la Sierra de Atapuerca. Aunque fuera del área de estudio, sus registros son importantes por su cercanía (Fig. 2). Este territorio posee una litología caliza, al igual que la zona de estudio de esta Tesis (Pineda Velasco, et al., 1997), con la cual presenta también similitudes florísticas que han llevado a algunos autores a incluirlo dentro del sector biogeográfico Castellano Cantábrico en el pasado (Berastegi, et al., 1997). Los yacimientos de Atapuerca constituyen seis cavidades kársticas rellenas de sedimentos cuaternarios de diferente cronología. Las de La Galería, Trinchera, Gran Dolina, Cueva Mayor y Sima del Elefante se encuentran rellenas de sedimentos pleistocenos (Berger, 1978), mientras que El Mirador es de cronología holocena (Allué \& Euba, 2008). De los yacimientos pleistocenos, han sido estudiadas en detalle las secuencias polínicas de la Sima del Elefante, Gran Dolina y Galería, las cuales abarcan en conjunto el periodo comprendido entre 1.2 Ma y 200 ka (Falguères, et al., 1999; Berger, et al., 2008; Rodríguez, et al., 2011). Estas series registran la señal de las oscilaciones climáticas cuaternarias como la variación en la proporción del componente atlántico, mediterráneo y el de medios abiertos y secos ver Anexo I, Diagrama polínico 1-. Los taxones dominantes en la vegetación representada en estos yacimientos son los Quercus caducifolios, los perennifolios y Pinus (Rodríguez, et al., 2011).

También es relevante, por el rango temporal que comprende su secuencia polínica y por su proximidad al sector Castellano Cantábrico, la turbera de Quintanar de la Sierra Burgos- (Fig. 2) (Ruiz-Zapata, et al., 2002). Esta está situada en la Sierra de la Demanda, a $1.470 \mathrm{msnm}$. Su registro polínico abarca desde el Último Máximo Glacial hasta tiempos históricos, y en él se reflejan las oscilaciones climáticas del Tardiglaciar como la variación pronunciada en el porcentaje de Pinus, junto al que aparece Juniperus como especie arbórea 
acompañante. La expansión de los pinos tras el Tardiglaciar se registra hace unos $11 \mathrm{ka}$, aunque se vio interrumpida por el empeoramiento climático del Dryas Reciente. A partir de entonces, el polen de Pinus no deja de estar presente a lo largo de todo el Holoceno. Los cambios de vegetación más reseñables durante este periodo fueron la regresión de Juniperus junto con la progresión de Corylus y Betula hace 8.000 años y la irrupción de Fagus en entorno a los 3.000 años (Anexo I, Diagrama polínico 2).

Dentro de la cuenta sedimentaria del Duero, resulta relevante por la amplitud de su secuencia polínica, la turbera de Espinosa de Cerrato -Palencia- (Fig. 2). Este yacimiento constituye uno de los mejores registros de la evolución de la vegetación holocena en la Meseta Norte. El registro antracológico abarca desde comienzos del Holoceno -11.045 cal BP— hasta tiempos históricos —1.265 cal BP— (Franco-Múgica, et al., 2001). Su secuencia muestra la dominancia de Pinus hasta su declive hace aproximadamente 1.500 años (Anexo I, Diagrama polínico 3).

Otro yacimiento muy próximo al área de estudio es el abrigo de Peña Parda, Laguardia, Álava - situado en la vertiente meridional de la Sierra de Cantabria (Fig. 2). En este depósito sedimentario, datado en torno a hace 4.000 años, se ha encontrado polen de Buxus L., Juniperus, Corylus y Pinus de los tipos pinaster y sylvestris entre otros taxones, en niveles arqueológicos datados en el Bronce Antiguo (Ruiz-Zapata, et al., 2002; Pérez Díaz, et al., 2007).

En la localidad de Santa Gadea del Alfoz —Burgos_, próxima al embalse del Ebro y al sector Castellano Cantábrico, aunque perteneciente al ámbito biogeográfico eurosiberiano, se encuentra una turbera estudiada por Iriarte-Chiapusso, et al. (2003) (Fig. 2). La secuencia polínica de este depósito no ha sido datada de forma precisa, aunque de acuerdo con el autor, la base inferior de la secuencia podría datar de hace 8.500-9.000. Al comienzo de la serie, predomina el polen arbóreo, principalmente de Betula, junto al que aparecen Pinus tipo 
sylvestris, Quercus tipo robur, Fagus y Corylus avellana L. entre otros taxones. Posteriormente tiene lugar una regresión de las especies arbóreas al mismo tiempo que aumenta el de especies propias de medios abiertos y fríos; esta etapa se asocia al enfriamiento que tuvo lugar en torno a 8.200 años (Daley, et al., 2011). Tras esta fase se observa una recuperación del polen arbóreo, especialmente de Pinus, el cual alcanza su máxima representación de toda la secuencia. Posteriormente se observa una paulatina reducción tanto de este taxón en particular como de la cubierta arbolada en general. Muy cerca de la turbera de Santa Gadea se encuentra la de La Nava (Fig. 2), en la cual Menéndez Amor (1968) llevó a cabo tres sondeos. En sus secuencias, que no han sido datadas, Pinus constituye en elemento arbóreo dominante.

Además del mencionado estudio de la formación tobácea de Frías realizado por Álvarez Ramis \& Fernández Marrón (1975), dentro del sector Castellano Cantábrico se han llevado a cabo otras investigaciones paleobotánicas que han contribuido al conocimiento de la evolución de la vegetación en este territorio. En concreto, se han estudiado las secuencias polínicas de tres turberas: La Piedra, San Mamés de Abar y Huidobro. Además de estas turberas, todas ellas en la provincia de Burgos, se han estudiado también los restos subfósiles hallados en el depósito higroturboso de La Lomilla -Palencia- (Fig. 2). En cuanto a los estudios polínicos mencionados, el más detallado de ellos es el llevado a cabo en la turbera de La Piedra (Muñoz Sobrino, et al., 1996). Los registros de este yacimiento abarcan desde el Tardiglaciar hasta el Holoceno Final, aunque existe un hiato entre mediados del período Atlántico y el inicio del Subatlántico —entre hace 7.500 y 2.500 años (Salas, 1992)— (Muñoz Sobrino, et al., 1996). La parte inferior de la serie está dominada por polen de Pinus tipo sylvestris y Betula. La parte superior de la turbera, después del hiato, presenta niveles inferiores de polen de Pinus y aparecen además otros taxones que se interpretan como un indicio de actividades antrópicas, como por ejemplo Cyperaceae, Erica L., Poaceae, etc. (Anexo I, Diagrama polínico 4). Durante la prospección, en los niveles inferiores de la turbera se encontraron restos subfósiles de Pinus, Juniperus y Betula. 


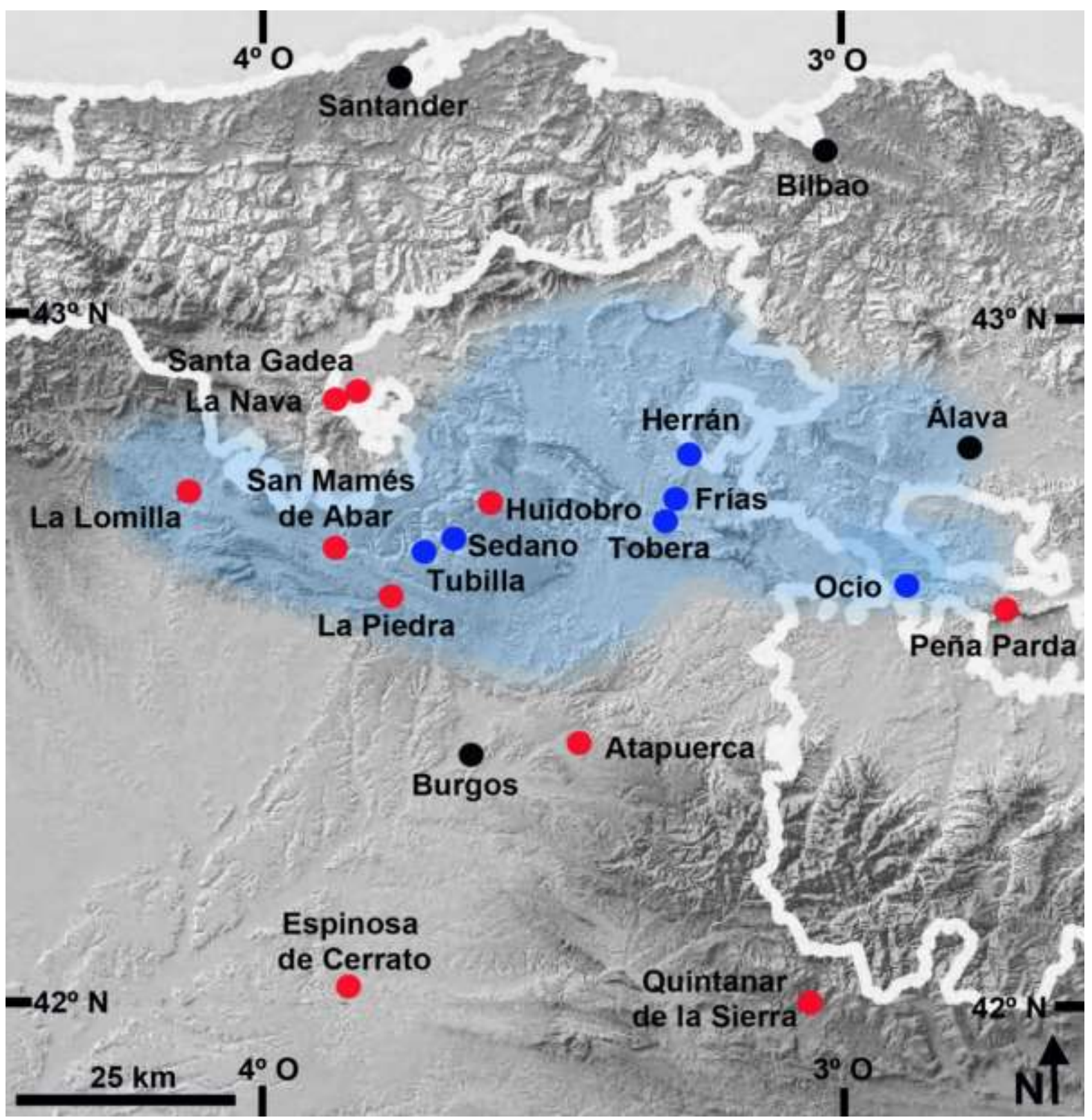

Figura 2. Yacimientos paleobotánicos relevantes para la reconstrucción de la vegetación finicuaternaria del sector Castellano Cantábrico —en rojo-y localidades en las que se encuentran los yacimientos tobáceos estudiados en esta Tesis Doctoral —en azul_. El sombreado azul representa el sector biogeográfico Castellano Cantábrico.

Cerca de la turbera de La Piedra se encuentra la de San Mamés de Abar, la cual abarca un rango temporal similar al de la anterior (Iriarte Chiapuso, et al., 2002) (Fig. 2). Los depósitos de San Mamés de Abar fueron datados a partir de dos muestras intermedias del sondeo, las cuales resultaron tener una antigüedad de 12.791-12572 cal BP y 9.401-9.030 cal BP. Los autores describen una secuencia que comienza en el Tardiglaciar con una fase arbolada en la que los componentes principales son Pinus y Betula. En menor medida 
aparece también polen de otras especies eurosiberianas como Fagus, Carpinus, Tilia L., Ulmus, Juglans y Fraxinus L. Tras una fase de regresión arbórea que se atribuye al Dryas Reciente, el comienzo del Holoceno registra la expansión de Pinus, Betula, Corylus y, en menor medida Quercus. Los depósitos de la última de las tres turberas situadas en el sector Castellano Cantábrico, la de Huidobro (Fig. 2), parecen ser muy recientes (Iriarte-Chiapusso, et al., 2003). Una única muestra datada mediante carbono-14 resultó tener menos de 500 años de antigüedad.

Por último, en el depósito higroturboso de La Lomilla —Aguilar de Campoo, Palencia— (Fig. 2) fueron encontradas 33 muestras de madera, 251 piñas, tres frutos y restos de corteza, los cuales han sido atribuidos a seis taxones -Pinus nigra, P. sylvestris, Betula, Fraxinus, Corylus y Salix - (Alcalde-Olivares, et al., 2001). La antigüedad del yacimiento, obtenida a partir de la datación por radiocarbono de 3 muestras, es de aproximadamente 8.500 años.

\subsection{Los depósitos tobáceos}

El término «toba» se usa en Geología para designar rocas porosas y de baja consistencia tanto de naturaleza volcánica como carbonática. El origen de las primeras está en la cementación de materiales piroclásticos, mientras que las tobas carbonatadas son el resultado de la precipitación del carbonato de calcio disuelto en el agua de fuentes, ríos y lagos (Ford \& Pedley, 1996; Pentecost, 2005)

También es habitual encontrar el término «travertino» usado como sinónimo de «toba» (Pentecost, 2005; González Martín \& González Amuchastegui, 2014a). No existe una norma estandarizada sobre la terminología más apropiada, aunque algunos autores reconocidos en este campo — p.e. Ford \& Pedley (1996) — han apuntado a la conveniencia de usar el término «toba calcárea» para la roca originada por precipitación química a temperatura ambiente de carbonato cálcico de aguas meteóricas, la cual, por lo general, contiene restos de micro y 
macrófitos, microorganismos e invertebrados. El nombre «travertino» quedaría reservado para los precipitados a partir de la actividad de bacterias y cianobacterias en aguas de origen hidrotermal; dado que las plantas no suelen desarrollarse en este tipo de ambientes de aguas calientes, los travertinos no presentan facies con impresiones de macrófitos. En esta esta memoria de Tesis Doctoral se sigue el criterio establecido por Ford \& Pedley (1996). Este concuerda con la forma por la que se conoce popularmente a la toba calcárea en la zona. Además, la palabra «toba» se encuentra, de forma más o menos alterada, en la raíz etimológica de muchos topónimos de la comarca y en el nombre de dos de las localidades de estudio: Tubilla del Agua y Tobera.

\subsubsection{Formación, factores implicados}

Los depósitos tobáceos son el resultado de un complejo conjunto de procesos interrelacionados y regulados por factores geológicos, morfo-estructurales, climáticos, hidrológicos y biológicos (González Martín \& González Amuchastegui, 2014a). La mayor parte de los depósitos tobáceos se forman a partir del carbonato cálcico disuelto en aguas meteóricas de origen kárstico. Estas aguas son el resultado de la disolución de la roca caliza, la cual tiene lugar cuando el agua de lluvia o escorrentía percola a través del suelo (Pentecost, 2005; Ordóñez \& García del Cura, 2014).

La atmósfera edáfica posee una concentración de $\mathrm{CO}_{2}$ hasta 100 veces superior a la atmosférica fruto de la degradación microbiana de la materia orgánica (Hem, 1985). Cuando el agua de lluvia entra en contacto con esa atmósfera, se acidifica, adquiriendo la capacidad de disolver el carbonato cálcico del que está compuesta la roca caliza (Pentecost, 2005; Ordóñez \& García del Cura, 2014). Este proceso ocurre en tres etapas:

1. Disolución del dióxido de carbono: $\mathrm{CO}_{2}+\mathrm{H}_{2} \mathrm{O} \leftrightarrow \mathrm{H}_{2} \mathrm{CO}_{3}$

2. Disociación acuosa del ácido carbónico: $\mathrm{H}_{2} \mathrm{CO}_{3}+\mathrm{H}_{2} \mathrm{O} \rightarrow \mathrm{H}_{3} \mathrm{O}^{+}+\mathrm{HCO}_{3}^{-}$ 
3. Ataque ácido de carbonatos calcáreos: $\mathrm{H}_{3} \mathrm{O}^{+}+\mathrm{CaCO}_{3} \leftrightarrow \mathrm{Ca}_{2}{ }^{+}+\mathrm{HCO}_{3}{ }^{-}+\mathrm{H}_{2} \mathrm{O}$

Dado que disolución y precipitación son los dos términos de una misma ecuación de balance, cuando se alteran las condiciones de equilibrio de la reacción se produce la precipitación de carbonato cálcico (Chen, et al., 2004):

$$
\mathrm{CO}_{2}+\mathrm{H}_{2} \mathrm{O}+\mathrm{CaCO}_{3} \leftrightarrow \mathrm{Ca}^{2+}+2 \mathrm{HCO}_{3}^{-}
$$

Tradicionalmente, se ha distinguido entre precipitación físico-química y bioquímica de toba, en función de la naturaleza de los factores implicados en el cambio en las condiciones de equilibrio de la disolución. Hoy en día existe cierto consenso en conceder a la precipitación físico-química un papel preponderante en el proceso de formación de tobas, frente a la precipitación bioquímica o biomediación, que tendría un papel secundario (Merz-Preiß \& Riding, 1999; Zhang, et al., 2001; Chen, et al., 2004).

De entre todos los factores físicos implicados, el régimen de flujo del agua parece ser el más determinante. De acuerdo con los resultados de las investigaciones llevadas a cabo en entornos controlados y al aire libre, las turbulencias y el incremento de la interfase aireagua propician la desgasificación de las aguas kársticas al reequilibrarse la presión parcial de $\mathrm{CO}_{2}$ con la atmosférica (Zhang, et al., 2001). Este proceso se ve favorecido por los efectos de aireación, debido al flujo a chorro «jet-flow» y a la baja presión que tienen lugar en las zonas en donde la velocidad de los cursos de agua se acelera, aumentando de esta forma el área de la interfase aire-agua (Chen, et al., 2004).

La temperatura parece incidir también en la precipitación de la toba, a través de dos mecanismos (Pedley, et al., 1996): (i) promoviendo la proliferación de microorganismos hidrófilos, lo que incrementa los efectos de la biomediación; (ii) aumentando la tasa de evaporación, lo que de forma indirecta hace aumentar la concentración de los iones disueltos y por lo tanto se incrementa su potencial de precipitación. Aunque se ha demostrado que la 
temperatura incide en la tasa de precipitación de carbonato, su contribución en términos absolutos al crecimiento de las formaciones calcáreas se considera residual (Chen, et al., 2004).

La biomineralización inducida por microorganismos, como cianobacterias y diatomeas, algas y plantas vasculares, puede ser debida tanto a efectos físicos como químicos (Chen, et al., 2004). Los físicos comprenden procesos como la nucleación, secreción, asimilación e incrustación del carbonato cálcico. Los químicos derivan de la fotosíntesis realizada por plantas y cianobacterias. A pesar de que la biomineralización puede ser realizada por diferentes tipos de organismos, se considera el biofilm microbiano, compuesto principalmente por cianobacterias que coloniza los sustratos subacuáticos, como el agente principal (Rogerson, et al., 2008). La biomediación inducida por el biofilm formado por velos cianobacterianos, bacterianos así como por hongos, diatomeas, etc., que recubren los elementos vegetales macroscópicos y los cementa con tapices calcíticos con bajo contenido en magnesio, genera unas estructuras características, los fitohermos (Pedley, 1990). Estos son formaciones tobáceas de tipología y tamaño variable, pero que se caracterizan por su notable porosidad como consecuencia de la intervención microbiana y los orificios dejados por los macrófitos que quedaron atrapados en su interior (Pedley, 1990; González Martín \& González Amuchastegui, 2014b).

Aunque la precipitación bioquímica contribuye en menor medida a la formación de toba que la desgasificación mecánica, el grado en que ambos mecanismos de precipitación —inorgánico y orgánico- participan en la formación de toba varía en función de las condiciones ambientales (Manzo, et al., 2012). Por ejemplo, cerca de las surgencias, o donde las condiciones físicas del agua cambian bruscamente, puede predominar la formación inorgánica, mientras que la biogénesis cobra más relevancia en zonas de aguas tranquilas (Merz-Preiß \& Riding, 1999). 


\subsubsection{Principales morfotipos de acumulaciones tobáceas}

Las formaciones tobáceas son sistemas autorregulados que tienden a acrecentarse a partir de la generación de su propio sedimento carbonatado (Ford \& Pedley, 1996). Esto ocurre porque la desgasificación tiene lugar principalmente en los lugares donde la corriente se acelera pasando a tener un régimen de flujo turbulento (Chen, et al., 2004; Zhang, et al., 2001). De esta forma, un salto de agua en una surgencia o un resalte en el lecho de un río que provoquen turbulencias, tiende a crecer, debido a que estos accidentes favorecen la precipitación de toba sobre ellos. Esta singularidad resulta notable si tenemos en cuenta que se desarrollan bajo la influencia de corrientes de agua, a veces, incluso en ríos de marcada estacionalidad y fuerte poder erosivo.

Los factores involucrados en la génesis de depósitos de toba son numerosos - la topografía del terreno, el clima, el régimen hidrológico, el grado de mineralización de las aguas, la cobertura vegetal, etc.- por lo que las estructuras resultantes pueden tener morfologías diversas y complejas (Ford \& Pedley, 1996). Sin embargo, se pueden observar ciertas tipologías básicas de construcciones tobáceas. A continuación, se describen los tres principales morfotipos, en una taxonomía de síntesis elaborada a partir de las publicadas por Pedley (1990) y Pentecost \& Viles (1994).
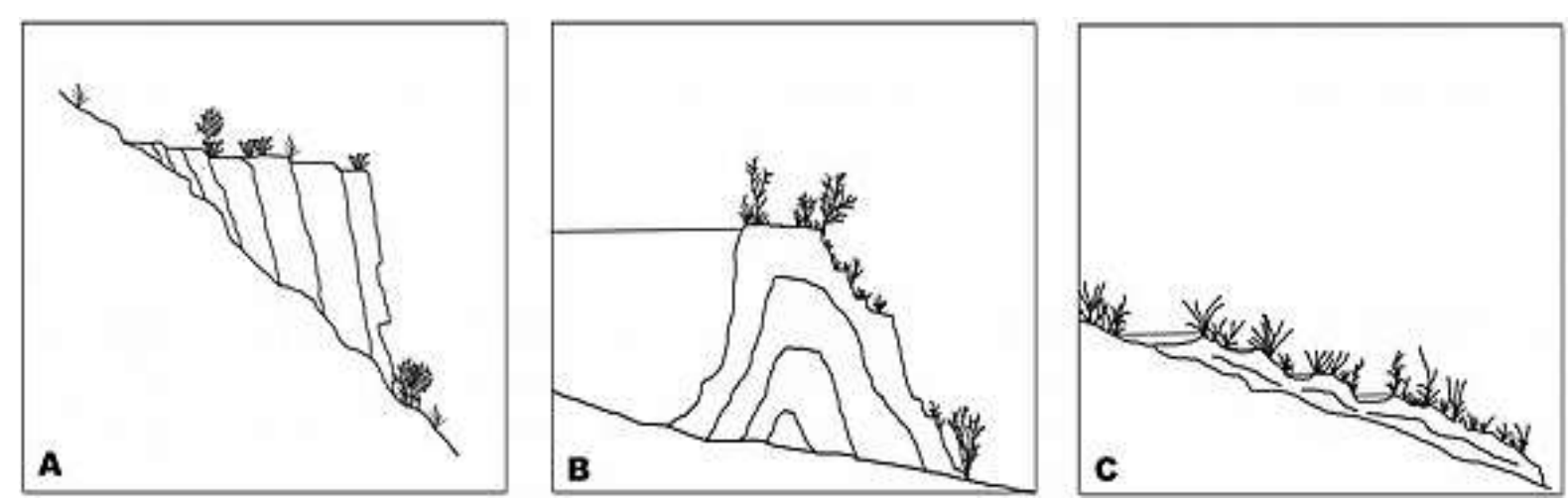

Figura 3. Tipos generales de formaciones tobáceas de carácter autóctono: A) Formación colgada en ladera B) Barrera C) Costra tobácea. Elaboración propia a partir de Pentecost \& Viles y (1994) y Pedley (1990). 


\subsubsection{Formaciones colgadas en ladera}

Este tipo de estructuras se corresponde con las formaciones denominadas «perched springline» por Pedley (1990) y las «cascades» de Pentecost \& Viles (1994). Se desarrollan en laderas, a partir de surgencias kársticas que pueden ser de régimen continuo o esporádico. En este caso, los depósitos carbonáticos pueden aparecer tanto en el punto de surgencia como aguas abajo. Su crecimiento se ve facilitado por la densa cobertura de musgos, hepáticas y otras plantas higrófilas propias de este ambiente húmedo, lo que ayuda a su estabilización.

Si la pendiente de la ladera es muy pronunciada, la toba crece adoptando un perfil de cascada, pudiendo llegar a desarrollar cuerpos colgados o en voladizo. Dada la fuerza erosiva del agua en estas condiciones, su crecimiento es lento (Pentecost \& Viles, 1994). Cuando el perfil de la ladera es más tendido y el caudal de agua más regular, la tasa de deposición llega a ser significativamente mayor que la de erosión y el edificio crece progradando hacia el valle. Un ejemplo de un depósito activo de este tipo dentro del área de estudio lo constituye la formación de El Tobazo — ver apartado 4.1—, la cual se desarrolla en las laderas del Cañón del Ebro, cerca de la localidad de Villaescusa de Ebro — Cantabria—.

\subsubsection{Barreras}

Las barreras tobáceas se corresponden con las denominadas «Barrages» por Pentecost \& Viles (1994) y Pedley (1990). Estas formaciones se originan a partir de los puntos de rotura del gradiente del lecho del río, donde emergen barreras embrionarias que dan lugar a estructuras transversales al cauce que crecen paulatinamente en altura (González Martín \& González Amuchastegui, 2014b). La sección de estos depósitos es variable, siendo habitual que sus paramentos interior y exterior presenten algún grado de inclinación (Fig. 3), aunque hay algunos ejemplos extraordinarios de barreras que pueden adoptar una morfología similar a la de una presa tipo muro, con paramentos verticales - p.e. Band-e-Amir, Afganistán (Lang \& Lucas, 1970)—. 
El cerramiento del curso de agua por la barrera genera aguas arriba del dique, una cubeta que da lugar a un ambiente lacustre (Fig. 21) o, si ha habido un aporte suficiente de sedimentos como para colmatarlo, palustre. Estos sedimentos de relleno pueden tener un origen aluvial, siendo en este caso la corriente fluvial que ha dado lugar al sistema el agente sedimentario principal. Por otro lado, si las laderas circundantes tienen una gran pendiente y no están fitoestabilizadas, puede haber un aporte de sedimento coluvionar a la cubeta de la formación. Este relleno puede estar también constituido por sedimento tobáceo detrítico alóctono (González Martín \& González Amuchastegui, 2014b) proveniente del desmantelamiento de depósitos de toba situados aguas arriba. En las orillas de algunas de estas cubetas lacustres de origen tobáceo pueden desarrollarse perfiles acantilados extraplomados asociados a replanos estromatolíticos. Estos constituyen formaciones tobáceas autóctonas compuestas de múltiples láminas desarrolladas a partir de microfilms cianobacterianos (Pedley, 1990; Pentecost \& Viles, 1994)

Las barreras de toba pueden aparecer excepcionalmente formando sistemas en los que varias de ellas se disponen de forma escalonada a lo largo del cauce del río, salvando en su conjunto desniveles de hasta varios centenares de metros. Ejemplos sobresalientes de estos sistemas de represas son los lagos de Plitvice —Croacia— (Roglic, 1977), Jiuzhaigou —China- (Florsheim, et al., 2013) y las Lagunas de Ruidera en España (González Martín, et al., 1987).

\subsubsection{Costras tobáceas}

Esta categoría engloba formaciones de extensión superficial variable, pero que nunca desarrollan volúmenes compactos en altura, sino que cubren el terreno como una costra de varios centímetros o decímetros de espesor (Fig. 3). Se pueden formar tanto en pequeñas corrientes de agua, a partir de surgencias kársticas en laderas, así como en el fondo de cursos fluviales. 
Las desarrolladas a partir surgencias kársticas se corresponderían con la categoría «paludal deposits» descrita por Pentecost \& Viles (1994) y Pedley (1990). Estos suelen aparecer en laderas de poca pendiente donde el sustrato, el crecimiento de la costra tobácea, la deposición de sedimentos finos y materia orgánica y la generación de toba intraclástica dificultan el drenaje, lo que a su vez favorece la instalación de pequeñas áreas palustres donde proliferan hidrófitos y macrófitos higrófilos. Las costras tobáceas fluviales — «braided fluvial model» sensu Pedley, (1990) o «Fluvial Crust» sensu Pentecost \& Villes, (1994)— se desarrollan en el fondo de ríos y arroyos permanentes o estacionales de poca profundidad. Se caracterizan por un relieve ondulado y/o nodular formado por cianolitos, oncoides y fitoclastos, así como por pequeños fitohermos marginales, en donde no están ausentes barros carbonatados microdetríticos y estromatolitos de origen bacteriano (Ford \& Pedley, 1996).

Las formaciones descritas anteriormente — colgadas en ladera, de barrera y costras tobáceas- constituyen, de acuerdo a la clasificación de Pedley (1990), depósitos autóctonos, por ser el resultado de la precipitación in situ del carbonato cálcico. Sin embargo, estas estructuras, una vez que se modifican las condiciones genéticas originales, pueden sufrir procesos de erosión y de transporte, dando lugar aguas abajo a acumulaciones carbonatadas alóctonas de naturaleza detrítica.

\subsubsection{Aspectos tafonómicos de los depósitos tobáceos}

El registro fósil se puede considerar como el resultado final de la transformación de una paleofitocenosis (Meléndez, 1998). Por lo general, este no representa de forma precisa la composición de las comunidades vegetales pretéritas, sino que ha sufrido una serie de sesgos tafonómicos (Behrensmeyer, et al., 2000). Por lo tanto, para poder reconstruir estas paleofitocenosis es necesario entender los procesos que dieron lugar tanto al conjunto de restos que produjeron como a los fósiles encontrados (Ochev, 1993). Los sesgos tafonómicos pueden ocurrir tanto en la fase bioestratinómica como durante la fosildiagenética. La primera 
de ellas comprende los procesos relacionados con la producción y/o acumulación de los restos, mientras que la segunda agrupa los que ocurren tras el enterramiento.

\subsubsection{Bioestratinomía}

Los procesos bioestratinómicos son los que afectan a los restos antes de ser enterrados (Meléndez, 1998). El conjunto de restos producidos por una biocenosis constituye una tanatocenosis, de estos, el grupo que es finalmente enterrado en el yacimiento forma la tafocenosis. Estos últimos, tras el proceso de fosildiagénesis, dan lugar a la orictocenosis (Ochev, 1993). A lo largo de las etapas citadas, diferentes sucesos van transformando la tanatocenosis, de tal forma que la orictocenosis final puede no representarla fielmente. A continuación, se describen las tres fases bioestratinómicas más importantes — dispersión, transporte y degradación-y los sesgos que se pueden producir en ellas.

\section{Dispersión}

El transporte por el aire es la primera etapa del viaje desde la biosfera a la geosfera para la mayoría de los restos vegetales, como hojas, frutos y semillas (Spicer, 1991). Sin la concurrencia del viento, la distancia horizontal que recorren estos restos desde su producción hasta llegar al suelo está relacionada con la altura desde la que caen, su forma y su peso por unidad de superficie. En términos generales, se puede decir que las hojas no suelen viajar una distancia mayor que la altura desde la que fueron liberadas (Ferguson, 1985).

Las hojas perennes suelen ser más pesadas, por lo que la distancia recorrida es menor que en el caso de las caducifolias. Entre estas últimas, las que más viajan son las que permanecen en el árbol después de la senescencia, debido a que al estar más secas presentan una densidad menor (Ferguson, 1985). Con respecto a las acículas de los pinos, se ha determinado que el $90 \%$ de ellas caen dentro de un cono de $20^{\circ}$ de inclinación proyectado desde la punta del árbol (Dunwiddie, 1987). El tamaño de la hoja no afecta mucho a la distancia de dispersión, salvo para hojas muy grandes y bosques cerrados, en los cuales 
las hojas pueden quedar atrapadas o verse frenadas por troncos y ramas (Ferguson, 1985).También ha sido comprobado que las hojas de la parte superior de la copa de los árboles dominantes son más propensas a viajar más lejos, por estar más expuestas a los vientos (Spicer, 1981).

\section{Transporte}

La vía de transporte más importante de restos vegetales hasta los depósitos de toba son las corrientes fluviales (Pentecost, 2005). El transporte por el agua está regulado por la velocidad a la que esos se empapan, sus características hidrodinámicas y la turbulencia de la corriente (Spicer, 1989). La mayoría de las hojas de especies caducas se hunden al cabo de pocos días, lo que reduce su movilidad, mientras que las hojas perennes con una cutícula más gruesa o revestimientos de ácidos grasos pueden permanecer en la superficie del agua durante semanas (Ferguson, 1985). Sin embargo, incluso las hojas que permanecen a flote en la corriente presentan una movilidad reducida. En un estudio realizado con hojas de Fagus sylvatica liberadas en una corriente de alta energía se comprobó que al cabo de 2 días tan solo el $0,2 \%$ de estas habían viajado más de $1,2 \mathrm{~km}$, mientras que el resto habían quedado atrapadas en las orillas y remansos (Spicer \& Greer, 1986). Es poco probable que los restos más ligeros sean retenidos en zonas en las que la corriente de agua posea una elevada energía, sin embargo, los remansos tras las barreras tobáceas constituyen lugares idóneos para su acumulación (Pentecost, 2005). En lo que respecta al viento, Ferguson (1985) demostró que la capacidad de transporte de las hojas caídas en el suelo del bosque es muy limitada, aunque los vientos fuertes pueden transportar las de las partes altas de los árboles a grandes distancias (Spicer, 1989). En cualquier caso, una vez que los restos llegan al suelo, la probabilidad de que pasen a formar parte del ambiente sedimentario acuático es reducida, sobre todo en cubiertas vegetales cerradas (Ferguson, 1985)

Las tanatocenosis pueden ser clasificadas en función de la relación entre el lugar donde vivían las plantas que produjeron los restos y el lugar en el que fueron fosilizados 
(Ochev, 1993). Si ambos coinciden, los restos son de carácter autóctono; si el lugar donde fueron preservados está en el hábitat o biotopo donde fueron producidos los restos vegetales, estos son parautóctonos; y cuando fueron transportados hasta el lugar donde fueron fosilizados se consideran alóctonos (Behrensmeyer \& Hook, 1992). En proceso de transporte de los elementos alóctonos, y en cierta medida en los parautóctonos, hasta su lugar de fosilización, el viento y el agua suelen ser los agentes principales (Ferguson, 1985).

\section{Degradación}

La velocidad de degradación de los restos vegetales depende del tipo de material y del ambiente al que están expuestos. Los restos leñosos son más resistentes a la degradación que otros tipos de restos con tejidos más blandos (Spicer, 1991). Debido a la reducida movilidad de las hojas en el suelo del bosque, estas se encuentran sujetas a una escasa degradación mecánica (Spicer, 1989). Sin embargo, estas pueden sufrir un proceso descomposición biológico mediado por bacterias y hongos, en el que la humedad, la temperatura, la naturaleza del sustrato y el tipo de resto son las variables más determinantes (Ferguson, 1985). En el caso de los depósitos tobáceos, las corrientes de agua son un agente de degradación importante. En este medio, las hojas de diversas especies presentan una diferente resistencia a su degradación (Ferguson, 1985), siendo generalmente las perennes las más resistentes (Willis \& McElwain, 2002).

\subsubsection{Composición de las tanatocenosis}

Además de los sesgos producidos durante la fase bioestratinómica, pueden darse otros relacionados con la producción de restos vegetales que deben ser tenidos en cuenta a la hora de reconstruir la vegetación del pasado. Por ejemplo, las especies caducas producen más hojas por año que las perennes y, dentro de la misma especie, los ejemplares de mayor tamaño producen más que los de menor porte (Willis \& McElwain, 2002). Sin embargo, se ha demostrado que, en términos generales, una muestra de hojas del suelo de un bosque 
templado de hoja caduca refleja la localización y abundancia relativa de las especies alrededor de la muestra (Burnham, 1989). Esto es debido a la aludida poca dispersión que sufren las hojas una vez que caen al suelo (Ferguson, 1985). Este hecho implica que existe una alta probabilidad de que una hipotética muestra del suelo contenga las especies de su entorno inmediato, pero difícilmente contendrá restos de las más alejadas. En este sentido, ha sido demostrado que para que una muestra contenga restos de la mayoría de las 25 especies de una hectárea de un bosque templado, esta debería tener un tamaño de entre 350 a 400 hojas (Burnham, 1989). Como consecuencia de todo lo argumentado, los estudios realizados en sedimentarios fluviales y lacustres suelen contener restos de la flora local — p.e. Demko, et al., (1998)—. En el caso de los ríos, la mayor parte de los restos proceden de los elementos riparios que crecen en las orillas, aunque la cubierta forestal de los terrenos adyacentes puede estar representada en cierta medida (Greenwood, 1991).

\subsubsection{Fosildiagénesis}

La precipitación de toba epigenética ocurre habitualmente a una gran velocidad, por lo que los restos vegetales atrapados en los depósitos son rápidamente cubiertos de carbonato cálcico (Pentecost, 2005). Los fósiles vegetales resultantes de este proceso pueden ser restos orgánicos, impresiones y encostramientos. Los tejidos orgánicos son degradados rápidamente por los microorganismos heterótrofos, por lo que no suelen conservarse durante mucho tiempo en los depósitos de toba. Las impresiones son el resultado de la descomposición de los tejidos vegetales, lo que deja como resultado el molde de toba que los contenía. Los encostramientos se generan también mediante la precipitación de toba sobre el resto vegetal, pero, en este caso, el precipitado no llega a cementarlos completamente en la matriz tobácea, ni el recubrimiento es excesivamente grueso, por lo que se puede identificar la forma exterior del resto fosilizado (Pentecost, 2005). A diferencia de los tejidos vegetales ordinarios, los tejidos previamente carbonizados son mucho más 
resistentes a la biodegradación (Meléndez, 1998), por lo que es habitual encontrarlos en este tipo de depósitos (Pentecost, 2005).

Como ha sido comentado anteriormente, la precipitación de toba está mediada por procesos tanto físicos como bioquímicos (González Martín \& González Amuchastegui, 2014a). El análisis petrográfico de las tobas permite determinar qué tipo de proceso ha prevalecido en su sedimentación. Una microestructura formada por cristales de esparita indica un predominio de la precipitación físico-química, mientras que si la estructura es micrítica, prevalecieron en su formación procesos de biomediación (García del Cura \& Ordóñez, 2014). El predominio de uno y otro tipo de precipitación está relacionado, con las condiciones hidrológicas de la corriente de agua. En zonas de mayor turbulencia predominan los encostramientos esparíticos, mientras que en aguas más tranquilas, donde se pueden desarrollar colonias microbianas, predominan los micríticos (Pedley, et al., 1996).

El análisis de los encostramientos alrededor de restos vegetales muestra que en la mayoría de los casos, estos constituyen estructuras micríticas porosas, por lo que su fosilización se considera principalmente resultado de la biomineralización de la calcita (Pavlović, et al., 2002). Esta toba biogénica, generada por la actividad de los seres vivos, puede ser el resultado tanto de sus efectos físicos como químicos (González Martín \& González Amuchastegui, 2014a). Por un lado, las algas, musgos y plantas superiores proporcionan un sustrato para la nucleación de la calcita, además de atrapar la micrita en suspensión, lo que acelera la formación de tobas (Zhang, et al., 2001). Por otro, la biomineralización puede ser debida a la acción de microorganismos que inducen, tanto activa como pasivamente, la nucleación de carbonatos sobre las paredes celulares de los organismos. Adicionalmente, la actividad fotosintética de macrófitos y microorganismos fotosintéticos requiere de la captura del $\mathrm{CO}_{2}$ disuelto en el agua, provocando la precipitación de $\mathrm{CaCO}_{3}$ (Pentecost \& Riding, 1986). Dentro de la biomediación, habitualmente se considera el agente más activo en la precipitación de tobas al biofilm compuesto por 
diatomeas, cianobacterias y bacterias heterótrofas (Rogerson, et al., 2008). La estructura concéntrica de los encostramientos, resultado del crecimiento estacional, revela la importancia que tienen en este biofilm las algas y cianobacterias (Pavlović, et al., 2002).

Dado el pequeño tamaño de los cristales de micrita $-<2 \mu \mathrm{m}-$, las impresiones de los tejidos vegetales presentan un alto grado de detalle, pudiéndose llegar a observar el algunas ocasiones las células epidérmicas (Pentecost, 2005). Adicionalmente, debido la rapidez con la que la toba precipita (Pentecost, 2005), muchas hojas son fosilizan antes de perder rigidez por lo que sus impresiones conservan su forma tridimensional original. Por último, en los depósitos tobáceos pueden tener lugar procesos de destrucción de fósiles, sobre todo relacionados con la disolución y recalcificación de las impresiones (Pavlović, et al., 2002). 
CAPÍTULO 2. ÁREA DE ESTUDIO 


\section{2. ÁREA DE ESTUDIO}

El sector biogeográfico Castellano Cantábrico abarca unos $4.500 \mathrm{~km}^{2}$ de la media montaña de la vertiente meridional del sector oriental de la Cordillera Cantábrica (Fig. 4). Desde el punto de vista administrativo se extiende por las provincias de Burgos, Palencia y Álava. De acuerdo con la última revisión de esta circunscripción biogeográfica (RivasMartinez, 2011b), este sector se divide en cuatro distritos: Parameño Burgalés, LosanoVillarcayense, Mirandano-Treviñés y Burebano. Su límite septentrional discurre unos kilómetros al norte de Aguilar de Campoo, siguiendo la frontera cántabro-burgalesa entre los páramos de la Lora y Valderredible, para continuar por el norte de la comarca de las Merindades, de la cual se excluye su extremo septentrional -las Machorras y el Valle de Mena-; ya en la provincia de Álava, continúa por Sierra Salvada y Sierra Badaya, hasta alcanzar su límite oriental en la cuenca de Miranda de Ebro y el extremo occidental de la Llanada Alavesa. La Sierra de Cantabria y los Montes de Vitoria quedan excluidas de este sector. El límite sur viene definido por las llanuras de las cuencas sedimentarias del Duero y el Ebro; de oeste a este, transcurre por los relieves orogénicos de la Banda Plegada elevaciones al sur de Aguilar de Campoo, Peña Amaya, Peña Ulaña, El Perul y Sierra de Ubierna- (Fig. 4), continuando por La Bureba hasta llegar en su límite oriental al Condado de Treviño (Loidi Arregui \& Fernández Prieto, 1986).

\subsection{Geología}

El área de estudio se sitúa sobre los dominios geomorfológicos meridionales del Surco Navarro-Cantábrico y la Plataforma Norcastellana -también conocida como plataforma estructural de los páramos o plataforma burgalesa- (Fig. 4), ambas pertenecientes al contexto paleogeográfico de la cuenca Vasco-Cantábrica (Vera, 2004). El Surco NavarroCantábrico y la Plataforma Norcastellana son el resultado del alzamiento tectónico producido durante la orogenia alpina; la deformación compresiva produjo el cabalgamiento profundo de 
la placa Euroasiática sobre la microplaca Ibérica, levantando el basamento paleozoico sobre el que estaba depositada una gruesa serie sedimentaria mesozoica (Vera, 2004).

El Surco Navarro-Cantábrico en este sector presenta un relieve plegado conforme formado por una sucesión de apretados anticlinales con curso noroeste-sureste — Sierra de Salvada, Sierra de Árcena, Sierra de la Tesla y Montes Obarenes- generados por un tectónica eyectiva que tuvo lugar principalmente a finales del Eoceno (Vera, 2004). Entre estas sierras aparecen sinclinales de gran radio, como los de Villarcayo y Miranda, y otros menores, como los de Ranera y Valdivielso, que constituyen relieves negativos concordantes donde se depositaron sedimentos terciarios producto de la erosión de las sierras colindantes (Carreras, et al., 1979; Ramírez, et al., 1979; Ramírez, et al., 1980). La parte del sector Castellano Cantábrico que se corresponde con el surco Navarro Cantábrico, es, por lo tanto, un territorio quebrado. Las altitudes medias de las sierras mencionadas se sitúan entre 1.000 y 1.200 msnm, siendo el punto de mayor altitud el Pico Humión, en los Montes Obarenes, con $1.435 \mathrm{msnm}$. Los fondos de los valles están situados entre los 500 y $650 \mathrm{msnm}$. La cota más baja de todo el sector se corresponde con el nivel del Ebro a su paso por las Conchas de Haro -450 msnm-.

En el dominio Norcastellano, las series carbonatadas cretácicas fueron sometidas a un plegamiento más suave. A consecuencia de ello, el relieve se presenta como una sucesión de altiplanicies morfológicamente casi planas y tectónicamente poco deformadas —las Loras— que, pese a su disposición elevada —800 y 1.000 msnm—, constituyen núcleos de sinclinales y anticlinales de alto radio y suaves buzamientos - entre $10-15^{\circ}$ - (Carreras, et al., 1979). El limite meridional de la Plataforma Norcastella lo constituye la Banda Plegada (Fig. 4); este subdominio, delimitado por las fallas de Ubierna y Becerril, se caracteriza por el alto grado de plegamiento de las series mesozoicas (Vera, 2004). 


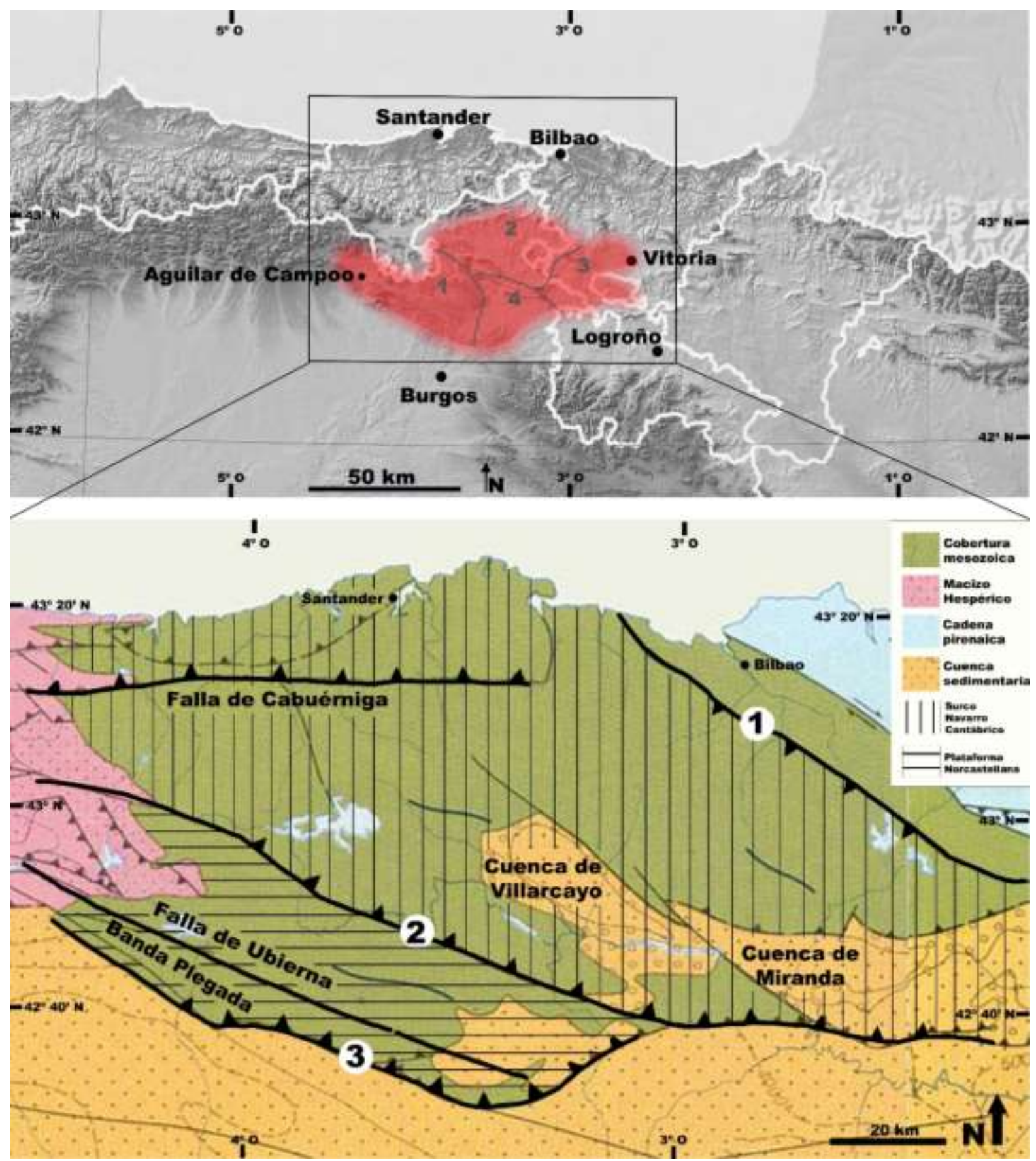

Figura 4. Mapa geológico y de ubicación del sector Castellano Cantábrico. Parte superior: Ubicación del sector Castellano Cantábrico — sombreado en rojo-. Parte inferior: Mapa geológico, (1) Falla de Bilbao-Alsasua; (2) Cabalgamiento frontal sobre la Cuenca del Ebro; (3) Cabalgamiento frontal sobre la Cuenca del Duero. Elaboración propia a partir del mapa de series, geoseries y geopermaseries de vegetación de España (RivasMartinez, 2007, 2011 a y 2011b), del mapa geológico 1:2.000.000 del Atlas Nacional de España (ANE, 2008) y del mapa geológico simplificado de la Cuenca Vasco-Cantábrica (Vera, 2004)

Si bien la tectónica es la causa primaria de los rasgos principales del relieve en este territorio, también la erosión fluvial ha sido un factor importante en su modelado (González Pellejero, 1986). El curso del río Ebro en el domino del Surco Navarro-Cantábrico se 
desarrolla a favor de los elementos geomorfológicos, discurriendo en dirección noroestesureste por los valles principales -Manzanedo, Valdivielso, Tobalina y Miranda- y excavando angostas cluses para salvar las barreras orográficas que se interponen en su recorrido hacia el Mediterráneo — Los Tornos, Desfiladero de los Hocinos, Desfiladero de la Horadada, Hoces del Sobrón y las Conchas de Haro-. Por el contrario, en su recorrido por las amplias parameras de La Lora —en el dominio geomorfológico Norcastellano—, entre los valles de Valderredible y Zamanzas, el río Ebro, y su principal afluente en este área, el Rudrón, discurren encajados formando un conjunto de profundos cañones fluvio-kársticos de hasta 300 m de profundidad (González Pellejero, 1986).

La naturaleza litológica de todo este conjunto se caracteriza por las series estratigráficas mesozoicas, siendo las calcáreas, margosas, y de areniscas cretácicas, las más representativas (Vera, 2004). Adicionalmente, las cubetas sinclinales de Villarcayo y Miranda de Ebro aparecen colmatadas por un potente relleno de facies terciarias detríticas de carácter aluvio-lacustre (Carreras, et al., 1978; Ramírez, et al., 1979).

\subsection{Fitoclima}

En este apartado se aborda la caracterización bioclimática de la zona de estudio con el objetivo de entender mejor la vegetación actual, lo cual es, a su vez, importante para trazar su evolución pretérita. Para ello se hace uso de la clasificación bioclimática descrita por RivasMartínez (2007) en el Mapa de series, geoseries y geopermaseries de vegetación de España.

Esta clasificación distingue cinco macrobioclimas presentes en el planeta: Tropical, Mediterráneo, Templado, Boreal y Polar. En cada bioclima, existen variantes bioclimáticas en función de los diferentes ritmos estacionales de precipitación y en los valores térmicos u ombrotérmicos — pisos bioclimáticos, termotipos y ombrotipos-. En el sector Castellano Cantábrico están presentes dos macrobioclimas, el Mediterráneo y el Templado. El primero 
de ellos queda definido por la existencia de sequía estival, esto es, al menos dos meses consecutivos durante el periodo más cálido del año en los que las precipitaciones, medidas en $\mathrm{mm}$, son inferiores al doble de la temperatura media mensual medida en ${ }^{\circ} \mathrm{C}$. El macrobioclima Templado corresponde a las localidades entre $23^{\circ} \mathrm{N}$ y $48^{\circ} \mathrm{N}$ a cualquier altitud y valor de continentalidad, en los que no existe o se compensa la sequía estival (RivasMartínez, 2007).

Dentro de los macrobioclimas Mediterráneo y Templado del área de estudio, en función de la continentalidad y del índice ombrotérmico se distinguen dos bioclimas, el Mediterráneo Pluviestacional-Oceánico y el Templado Oceánico, variante submediterránea —ver Anexo II-. La variante bioclimática submediterránea existe sólo en el macrobioclima Templado, y se caracteriza porque al menos durante un mes del estío la precipitación media en milímetros es dos veces y ocho décimas inferior a la temperatura media en grados centígrados de ese mismo período (Rivas-Martínez, 2007). A su vez, dentro de cada bioclima se diferencian diferentes pisos bioclimáticos en función de los factores termoclimáticos y ombroclimáticos que se suceden en una cliserie altitudinal o latitudinal. En el bioclima mediterráneo están representados los horizontes termotípicos Supramediterráneo Inferior y Superior, y los ombrotipos Subhúmedo Inferior y Húmedo inferior. En el Templado Oceánico aparecen los termotipos Mesotemplado Inferior y Superior, y Supratemplado Inferior, y los ombrotipos Subhúmedo Superior y Húmedo Inferior —ver Anexo II- (Rivas-Martínez, 2007).

Las temperaturas medias anuales de la zona de estudio varían entre los $9,3{ }^{\circ} \mathrm{C}$ registrados en la estación de Santa Cruz del Tozo —Burgos-y los $11,9^{\circ} \mathrm{C}$ de Berganzo Álava-, mientras que las precipitaciones medias anuales se sitúan entre los $621 \mathrm{~mm}$ recogidos en la estación de Berganzo, y los 877 mm de la de Vitoria —Álava- (RivasMartínez, 2007). Este es un territorio de moderada continentalidad, la cual se define como la diferencia en la temperatura media mensual de los meses más extremados del año (RivasMartínez, 2007). La amplitud térmica anual —-medida en ${ }^{\circ} \mathrm{C}$ — para las estaciones del área de 
estudio se sitúa entre $14^{\circ} \mathrm{C}$ y $17^{\circ} \mathrm{C}$, lo que se corresponde con el tipo de continentalidad Oceánico Euoceánico. La continentalidad se acentúa cuanto más alejado y aislado esté un territorio de la influencia atemperadora de las grandes masas de agua. En este caso, la barrera que supone la Cordillera Cantábrica a la influencia marina (Ortega Villazán \& Morales Rodríguez, 2015) provoca que existan grandes diferencias entre sus dos vertientes, de tal forma que los valores de continentalidad de la vertiente septentrional no pasan de $10^{\circ} \mathrm{C}$ (Loidi Arregui \& Fernández Prieto, 1986).

En resumen, el sector Castellano Cantábrico es, en lo climático, un territorio de transición entre los macroclimas Mediterráneo y Templado condicionado por el efecto barrera de la Cordillera Cantábrica (Ortega Villazán \& Morales Rodríguez, 2015). La menor altura de las elevaciones al oeste de este territorio permite que la influencia de Mar Cantábrico sea algo más intensa en esta zona, haciéndose notar en las sierras de Cantabria, Codes, Lokiz, Urbasa y Andía, que pese a estar situadas a la misma latitud, se encuadran desde el punto de vista biogeográfico en la región Eurosiberiana (Loidi Arregui \& Fernández Prieto, 1986).

\title{
2.3. Vegetación
}

Desde un punto de vista biogeográfico, la ubicación del sector Castellano Cantábrico es la siguiente (Rivas-Martínez, 2007):

\author{
Región Mediterránea \\ Subregión Mediterránea Occidental \\ Provincia Mediterránea Ibérica Central \\ Subprovincia Oroibérica \\ Sector Castellano Cantábrico
}

Esta unidad biogeográfica es fronteriza con la Provincia Atlántico Europea, perteneciente a la región biogeográfica Eurosiberiana, por el norte, y con la provincia 
Mediterránea Ibérica Occidental por el oeste. En la vegetación de este territorio se constata la influencia de las regiones vecinas, la cual penetra en el sector Castellano Cantábrico favorecida por su topografía irregular, la cual da lugar a estaciones diversas como consecuencia de la combinación de diferentes orientaciones, pendientes y sustratos (Alejandre, et al., 2006). Es por ello un territorio de gran riqueza y diversidad florística en el que las diferentes comunidades vegetales se distribuyen por el territorio subordinadas a la configuración topográfica (Loidi Arregui \& Fernández Prieto, 1986; Alejandre, et al., 2006; Loidi, et al., 2011).

Los sectores biogeográficos constituyen unidades territoriales homogéneas desde el punto de vista florístico y fitosociológico que se definen a partir de la distribución de endemismos infraespecíficos de distribución restringida o de determinados tipos de comunidades vegetales propios de un determinado territorio (Rivas-Martínez, 2007).

Como taxones endémicos o de óptimo castellano cantábrico se pueden citar Onobrychis reuteri Leresche, Endressia castellana Coincy, Genista eliassennenii UribeEchebarría \& Urrutia, Inula langeana G. Beck y Antirrhinum braun-blanquetii Rothm. (Loidi Arregui \& Fernández Prieto, 1986; Alejandre, et al., 2006). En lo que respecta a las comunidades vegetales que colonizan la zona de estudio, de acuerdo con el sistema sintaxonómico de Rivas-Martínez (2007, 2011b), el sector Castellano Cantábrico se caracteriza por la presencia de dos series de vegetación (Fig. 5): Spiraeo obovatae-Querceto fagineae, la cual se desarrolla preferentemente sobre los sustratos margosos, y SpiraeoQuercetum rotundifoliae, la cual se encuentra sobre los calizos duros. Estas asociaciones son comunidades dominadas por quejigos - Quercus faginea Lam. - y encinas — Quercus ilexrespectivamente.

El área potencial de los quejigares comprende los suelos profundos de sustratos margosos, aunque debido al valor agrícola de estos suelos hoy en día solo sobreviven en 
terrenos marginales donde este tipo de aprovechamiento no era posible, por su pendiente, pedregosidad, etc. (Loidi Arregui \& Fernández Prieto, 1986). Acompañan al quejigo en estas asociaciones árboles de porte mediano como Acer monspessulanum L., A. campestre L., $A$. pseudoplatanus L., Prunus avium L., y arbustos como Viburnum lantana L., Lonicera etrusca Santi, Prunus spinosa L., Crataegus monogyna L., Amelanchier ovalis Medik., Ligustrum vulgare L., Rosa canina L, Genista scorpius DC. y Erica vagans L. En el estrato herbáceo son habituales Bromus erectus Huds., Helleborus foetidus L., Primula veris L., Pulmonaria longifolia Boreau, Hepatica nobilis Mill. y Cephalanthera alba Simonk. entre otras (Loidi Arregui \& Fernández Prieto, 1986; García Mijangos, 1997; Loidi, et al., 2011).

La segunda formación forestal climatófila más importante del sector Castellano Cantábrico son los carrascales de la asociación Spiraeo-Quercetum rotundifoliae (Fig. 5). La encina, se desarrolla en este sector sobre sustratos calizos duros, y aparece acompañada de una cohorte florística similar a la de los quejigares anteriormente descritos (Loidi Arregui \& Fernández Prieto, 1986). Sobre suelos profundos mesoeútrofos de naturaleza silícea se asientan rebollares de la asociación —Festuco heterophyllae-Quercetum pyrenaicae-. Debido a litología predominantemente caliza del sector Castellano Cantábrico, este tipo de suelo es poco común, por lo que los rebollares ocupan una superficie reducida (Fig. 5) (Loidi Arregui \& Fernández Prieto, 1986).

También abundan en el sector Castellano Cantábrico los hayedos basófilos, que pueden pertenecer a la asociación Epipactido helleborines-Fagetum sylvicae los más xerófilos, termófilos y neutrobasófilos, o a Carici sylvaticae-Fagetum sylvicae los neutro basófilos y ombrófilos (Loidi Arregui \& Fernández Prieto, 1986; García Mijangos, 1997). En el área de estudio este tipo de bosque tiene carácter relíctico, y se instala en las umbrías de las sierras castellano cantábricas donde se produce una mayor permanencia de las nieblas (Loidi Arregui \& Fernández Prieto, 1986). En estos hayedos, el estrato arbóreo suele estar dominado por esta única especie, aunque no es infrecuente encontrar otras especies 
arbóreas como Tilia platyphyllos Scop., Fraxinus excelsior L. o Quercus faginea. En el estrato arbustivo, también pobre, están presentes Acer opalus Mill., Buxus sempervirens L., Corylus avellana, Crataegus laevigata (Poir.) DC., Crataegus monogyna, Daphne laureola L., Ilex aquifolium L., Hedera helix L. y Sorbus aria (L.) Crantz entre otras.

Otras comunidades vegetales importantes por su amplia distribución en el sector Castellano Cantábrico son las que se desarrollan en el fondo de los valles y barrancos, a veces asociadas a cursos de agua y zonas húmedas. García Mijangos (1997) ha caracterizado las asociaciones vegetales de este tipo presentes en los Montes Obarenes. La comunidad de Tilia platyphyllos habita el fondo de barrancos profundos, umbrosos y abruptos sobre suelos ricos en carbonatos. Junto con el tilo aparecen otras especies de carácter eurosiberiano como Fraxinus excelsior, Corylus avellana, Sorbus aria y otras submediterráneas como Buxus sempervirens y Quercus faginea. A lo largo del cauce del Ebro, sobre sustratos limosos y arenosos, se desarrolla un bosque de ribera — Humulo lupuliAlnetum glutinosae — dominado por alisos y otros grandes árboles propios de estos entornos como Fraxinus angustifolia Vahl y Populus alba L., además de sauces de las especies Salix alba L., S. fragilis L., S. atrocinerea Brot. y S. purpurea L., y arbustos edafohigrófilos como Cornus sanguinea L., Corylus avellana y Frangula alnus Mill.

En las riberas de cauces menores, como los ríos Oca o Molinar, García Mijangos (1997) ha descrito dos tipos de saucedas: comunidad de Salix atrocinerea y Sambucus nigra L. y Salicetum fragilis. La primera de ellas se puede encontrar en ríos y arroyos de acusado estiaje, no propicios para el establecimiento de alisedas. Está dominada por Salix atrocinerea y su híbrido con S. cantábrica Rech. F. - S. expectata- a los que acompañan Corylus avellana, Sambucus nigra, Cornus sanguinea, Fraxinus angustifolia, S. alba, y otras especies de requerimientos ecológicos similares. Salicetum fragilis son saucedas de porte arbustivo que colonizan el cauce menor de ríos de aguas calcáreas, sobre sustratos limosos, arenosos o de cantos rodados. Esta vegetación está formada por Salix purpurea L., junto al que 
aparecen también S. eleagnos Scop., S. triandra L., S. alba, S. neotricha Goerz y sus híbridos. Acompañando a estos sauces pueden aparecen Fraxinus angustifolia, Cornus sanguinea y Populus nigra L.

Por último, dentro de las especies arbóreas, debe señalarse la presencia dentro del área de estudio, de tres especies escasas y singulares por su significancia geobotánica: el alcornoque —Quercus suber L._, el pino silvestre —Pinus sylvestris L._y el orno —Fraxinus ornus L.- . El primero de ellos solo aparece en un pequeño enclave de los Montes Obarenes, en la localidad de Bozoó —Burgos—. Está población está situada en una solana, entre los 750 y 1000 msnm, sobre arenas silíceas (Alejandre, et al., 2006). Su interés reside en el carácter relativamente termófilo de esta especie y su aislamiento con respecto a sus poblaciones principales, que se encuentran fundamentalmente en la fachada atlántica de la Península Ibérica (López, 2007).

El pino silvestre se encuentra ampliamente distribuido por la zona de estudio debido a las repoblaciones forestales realizadas desde antaño. Sin embargo, a pesar de que algunos autores han considerado naturales buena parte de las masas de esta especie en el sector Castellano Cantábrico — p.e. Ceballos (1966) (Fig.5)—, hoy en día solo se consideran naturales algunas de las poblaciones de la Sierra de Árcena y de la parte suroccidental de la provincia de Álava (Barredo \& Barredo, 2002; Alejandre, et al., 2006). Estas son de carácter subesclerófilo y se desarrollan sobre sustratos calcáreos (López Leiva, et al., 2009). Por último, merece ser mencionada la cita reciente de Fraxinus ornus en las montañas de Oña Burgos- (Alejandre, et al., 2006). Este árbol, que se distribuye por el sur de Europa occidental, solo está presente en la Península lbérica en las montañas del este, especialmente en la Comunidad Valenciana. 


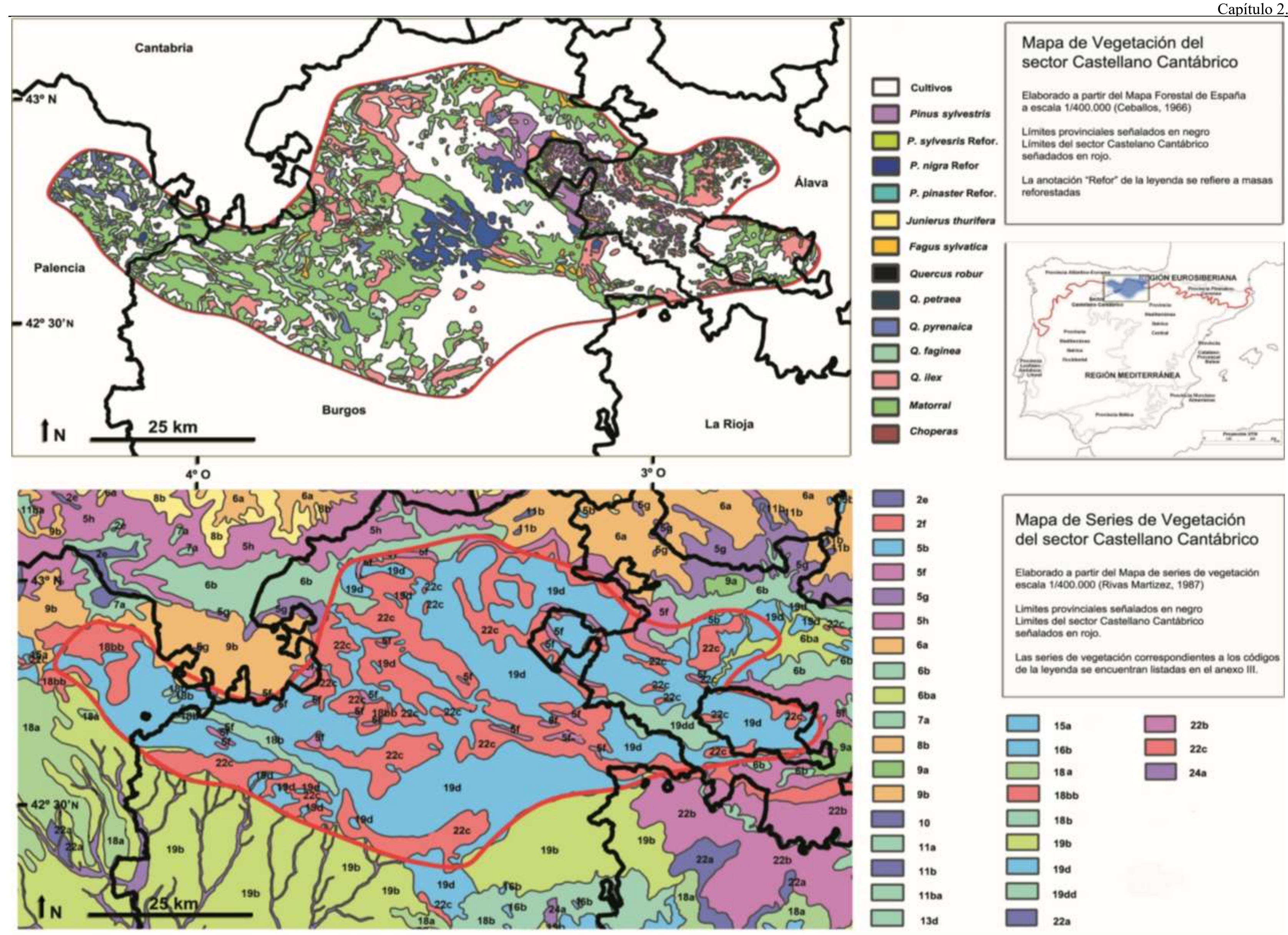

Figura 5. Mapa de vegetación y de series de vegetación del sector Castellano Cantábrico. Elaborado a parir del mapa forestal de España (Ceballos, 1966) y del Mapa de series de vegetación (Rivas Martínez, 1987) 
Con respecto a las comunidades vegetales descritas en este apartado, hay que señalar que, a pesar de estar bien representadas, ocupan en la actualidad una superficie reducida, ya que parte del territorio lo constituyen tierras de cultivo u otro tipo de cubierta forestal no arbolada, como eriales, pastizales y matorrales (Fig. 5) (Ceballos, 1966). Donde existen masas boscosas, estas suelen presentarse en forma de monte bajo. Esta estructura forestal es el resultado del aprovechamiento de los montes para la obtención de carbón y leña; las cortas «a hecho» en turnos cortos, de especies con capacidad de generar nuevos brotes a partir de la cepa -Quercus faginea, Q. pyrenaica, Q. ilex y Fagus sylvatica L.—, da como resultado una masa regular, monoespecífica y densa de chirpiales, apropiada para volver a realizar el mismo aprovechamiento (Gil Sánchez \& Torre Antón, 2007)

\subsection{Depósitos tobáceos estudiados}

En este apartado se describen, a partir de la información existente, los seis yacimientos estudiados en esta Tesis Doctoral, desde el punto de vista geomorfológico y geocronológico. Las localidades citadas pertenecen a tres comarcas diferentes: el Valle del Rudrón —yacimientos de Tubilla del Agua y Sedano—, el de Tobalina —yacimientos de Herrán, Tobera y Frías—y del Inglares —yacimiento de Ocio-.

\subsubsection{Valle del Rudrón}

El valle del Rudrón se encuentra en la comarca de La Lora, la cual desde el punto de vista geomorfológico se caracteriza por la existencia de amplias superficies tabulares elevadas -entre 900 y 1000 m- en niveles calcáreos cretácicos del Turoniense y del Santoniense (Carreras, et al., 1979). Este paquete calizo ha sido expuesto a la acción corrosiva del agua desde finales del terciario, lo que ha provocado el desarrollo de un karst de plataforma, actualmente disfuncional, y cuyo producto más destacado es el conjunto de cañones excavado por los Ebro y Rudrón (González Pellejero, 1986). 
Como testigos de unos procesos kársticos superficiales y subterráneos mucho más intensos en el pasado, aparecen dispersos por la comarca numerosos depósitos carbonatados exokársticos (González Pellejero, 1986). En las laderas de los valles y cañones, asociadas a los puntos de desagüe de la red hídrica del macizo calcáreo, se encuentran numerosas formaciones tobáceas colgadas en ladera (González Amuchastegui \& Serrano, 2013). Además de las formaciones asociadas a surgencias, también aparecen en esta comarca depósitos tobáceos en el fondo de los valles, originados a partir de la precipitación de carbonato cálcico ligada a corrientes fluviales. De este tipo son los de Tubilla del Agua y Sedano (González Pellejero, 1986; González Amuchastegui \& Serrano, 2010; González Pellejero, et al., 2012) que se describen a continuación.

\subsubsection{Complejo tobáceo de Tubilla del Agua}

Los depósitos que componen este complejo se presentan de forma escalonada a lo largo del valle del río Hornillo, desde su nacimiento en una serie de fuentes vauclusianas (González Amuchastegui \& Serrano, 2013) bajo los cantiles tobáceos de la Hornaceda, hasta su desembocadura en el Rudrón. La mayor parte del caudal de este río proviene de los depósitos cautivos en las dolomías campanienses, por lo que se mantiene bastante estable durante todo el año (González Pellejero, 1986), a pesar de su escaso recorrido — 1,5 km—.

Los estratos dolomíticos que contienen el acuífero se asientan sobre paquetes impermeables de margas santonienses grises-verdosas (Carreras, et al., 1979). Este hecho ha propiciado que la cota de desagüe de las surgencias del Hornillo $-780 \mathrm{msnm} —$ se haya mantenido invariable durante los últimos periodos del Cuaternario, lo que en última instancia es la causa de la gran cantidad de toba depositada desde el Pleistoceno en este complejo (González Pellejero, 1986).

Uno de los primeros estudios realizados sobre este conjunto de depósitos de toba fue el llevado a cabo por González Pellejero (1986). La autora identifica en este yacimiento cuatro 
terrazas escalonadas, las cuales tendrían su origen en diferentes surgencias y arroyos que se dan cita en el lugar. Resulta de interés en este trabajo la identificación de una terraza fluvial de cantos rodados que ha quedado fosilizada bajo una de las formaciones laterales, y que la autora asocia estos sedimentos con el antiguo cauce del río Rudrón.

Posteriormente han aparecido dos publicaciones sobre este yacimiento que incluyen los resultados de la datación de varias muestras de materia orgánica y carbonatos mediante diferentes técnicas — carbono-14, desequilibrio de las series del uranio y luminiscencia estimulada ópticamente (OSL)—: González Amuchastegui \& Serrano (2010) y González Pellejero et al. (2012). Los resultados del conjunto de dataciones de estas dos publicaciones se recogen en la Tabla 1.

\begin{tabular}{|c|c|c|c|c|}
\hline Muestra & Estructura & Técnica & Material & Edad \\
\hline GrA- $38017^{1}$ & TUAG-BH & Carbono-14 & Materia Orgánica & $4.290-4.450 \mathrm{cal} \mathrm{BP}$ \\
\hline GrA-38059 ${ }^{1}$ & TUAG-PS/TUAG-T3 & Carbono-14 & Materia Orgánica & $29.120-29.910 \mathrm{cal} \mathrm{BP}$ \\
\hline GrA-380291 & TUAG-PS/TUAG-T3 & Carbono-14 & Materia Orgánica & $26.570-27.760 \mathrm{cal} \mathrm{BP}$ \\
\hline TUB1 $^{2}$ & TUAG-PS & $\mathrm{U} / \mathrm{Th}$ & $\mathrm{CaCO} 3$ & $21.200 \pm 1.700$ \\
\hline TUB2 $^{2}$ & TUAG-VBH & $\mathrm{U} / \mathrm{Th}$ & $\mathrm{CaCO} 3$ & $1.950 \pm 290$ \\
\hline TUB-3 $(1)^{2}$ & TUAG-VBH & OSL & Detrítico & $6.488 \pm 631$ \\
\hline TUB-3(2) & TUAG-VBH & $\mathrm{U} / \mathrm{Th}$ & $\mathrm{CaCO} 3$ & $4.340 \pm 390$ \\
\hline TUB4 $^{2}$ & TUAG-T & $\mathrm{U} / \mathrm{Th}$ & $\mathrm{CaCO} 3$ & $5.520 \pm 670$ \\
\hline
\end{tabular}

Tabla 1. Dataciones del complejo Tobáceo de Tubilla del Agua recogidas en diferentes publicaciones. 1. González Amuchastegui \& Serrano, 2010. 2. González Pellejero et al., 2012. 3. El autor considera que TUAG-PS y TUAG$T$ forman parte de una única estructura - TB1-y no especifica el lugar de muestreo exacto, por lo que no se puede asignar la muestra a una formación concreta.

González Amuchastegui \& Serrano (2010) distinguen en este complejo tres unidades litológicas diferentes (Fig. 6); (i) el edificio superior, que se correspondería con los dos espolones tobáceos que sobresalen a ambos lados del valle, (ii) el edificio medio, que constituye todo el relleno tobáceo del valle y el edificio inferior, que estaría formado por las tobas activas que se depositan en el cauce actual del río Hornillo y, (iii) el edificio inferior, que se corresponde con tobas recientes a lo largo del cauce del río. Adicionalmente identifican 
otros depósitos «de fuente», siendo el de mayor entidad de todos ellos el asociado a la surgencia estacional de La Fuentona.

A partir de las dataciones obtenidas, ambos autores coinciden en identificar varias etapas constructivas. La primera de ellas habría tenido lugar a finales del Pleistoceno, en el Último Periodo Glacial, y durante esta fase se habría depositado el que González Amuchastegui \& Serrano (2013) llaman «edificio superior» (Fig. 6). A esta etapa constructiva le siguió otra en la que el edificio y el fondo del valle fueron erosionados. Los autores argumentan que el desmantelamiento de estas estructuras debió ocurrir durante el Último Máximo Glacial, dado que los depósitos holocenos, se asientan sobre derrubios ordenados de tipo periglaciar.

La segunda fase de construcción identificada habría tenido lugar en el Holoceno, durante el periodo cálido y húmedo del Atlántico —5.000 a 7.500 años (Salas, 1992)—y duró hasta el Subboreal —2.500-5000 años (Salas, 1992)—. Como resultado de ello, se depositó el «edificio intermedio» (Fig. 6), el de mayor extensión superficial de todo el complejo y que tapiza el fondo del valle del Hornillo. A esta fase constructiva le siguió otra en la que el río excavó su cauce en las tobas del fondo del valle. Esta etapa erosiva, que según los autores habría comenzado a finales del periodo Subboreal, ha sido identificada en otros depósitos del Alto Ebro y parece estar relacionada con el inicio del megalitismo en la zona y por lo tanto la acción antrópica (González Amuchastegui \& Serrano, 2013; González Amuchastegui \& Serrano, 2015). Por último, el «edificio intermedio» (Fig. 6) tendría su origen en la precipitación reciente de toba donde el complejo se mantiene activo.

González Pellejero et al. (2012) discrepan en otorgar una edad pleistocena al edifico superior» situado en la vertiente derecha del valle del Hornillo -TUAG-T_, el cual emplazan en la fase Atlántica, a partir de la datación de una muestra de $5.520 \pm 670$ años de antigüedad (Tabla 1). Por otro lado, los últimos autores citados alargan la etapa de sedimentación de toba 
Capítulo 2. Área de estudio

en el fondo del valle hasta el periodo Subatlántico —0-2.500 años (Salas, 1992)—, dado que una muestra obtenida de esta estructura fue datada en $1.950 \pm 290$ años (Tabla 1).
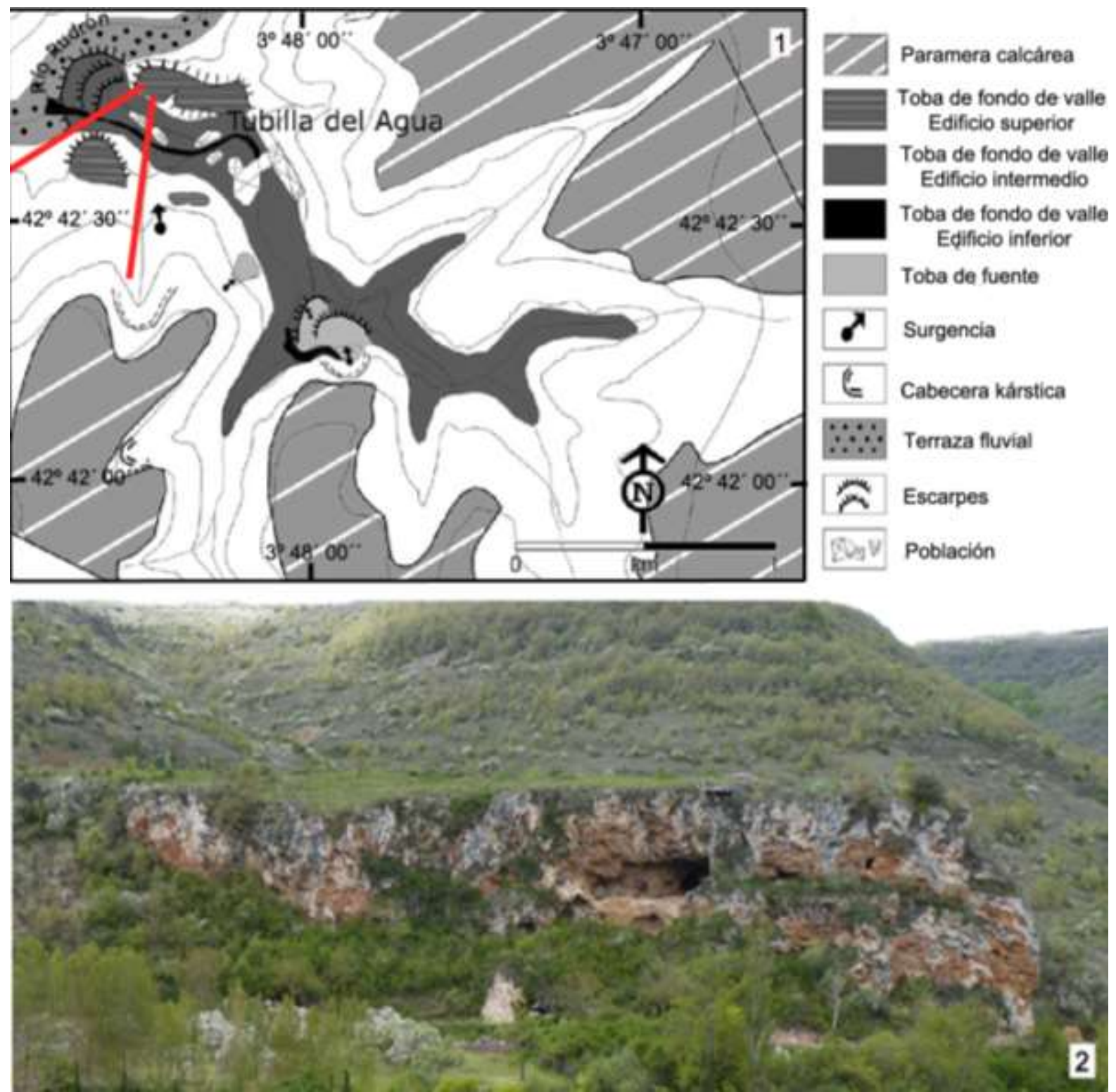

Figura 6. Complejo tobáceo de Tubilla del Agua. (1) Esquema geomorfológico; modificado de González Amuchastegui \& Serrano (2013). En rojo se ha marcado el punto desde el que se obtiene la perspectiva de uno de los dos edificios de toba superiores - TUAG-PS - mostrada en la foto 2.

\subsubsection{Barreras tobáceas de Sedano}

Las barreras tobáceas de Sedano se localizan en la cuenca del río Sedanillo tributario del Rudrón-, a la altura del barrio de Lagos, en la localidad de Sedano, provincia de Burgos. El sistema está compuesto por dos represas, en la actualidad disfuncionales, y un 
depósito sedimentario calcarenítico alóctono (Fig. 7). Este depósito, formado por dos niveles escalonados, está constituido por sedimentos estratificados con diferentes proporciones de limos, arcillas, arenas y materia orgánica (González Amuchastegui \& Serrano, 2013). Muestras tomadas en niveles medios de estas terrazas (Tabla 2) señalan que su génesis tuvo lugar principalmente durante los estadíos holocenos Atlántico y Subboreal —de 5.000 a 7.500 años y de 2.500 a 5.000 años respectivamente (Salas, 1992)— (González Amuchastegui \& Serrano, 2010). Adicionalmente, dentro del municipio, sobre unas casas situadas en la margen derecha del río, se halla la formación conocida como La Tobona, la cual constituye una formación de ladera asociada a una surgencia kárstica (González Amuchastegui \& Serrano, 2013). Con respecto a las barreras, los autores citados, hacen notar que el edificio superior se asienta sobre un depósito de derrubios ordenados cuya formación se atribuye a las fases frías el Último Periodo Glacial, por lo que su génesis ha debido tener lugar en el Holoceno.

\begin{tabular}{ccccc}
\hline Muestra & Posición en la formación & Técnica & Material & Edad cal BP \\
\hline Beta-271244 & Media & Carbono-14 & Materia Orgánica & $5.580-5.620$ \\
\hline Beta-271245 & Media & Carbono-14 & Materia Orgánica & $5.470-5.590$ \\
\hline Beta-271246 & Media-Alta & Carbono-14 & Materia Orgánica & $4.380-4.440$ \\
\hline
\end{tabular}

Tabla 2. Dataciones del depósito sedimentario calcarenítico de Sedano. González Amuchastegui y Serrano (2010) 
Capítulo 2. Área de estudio
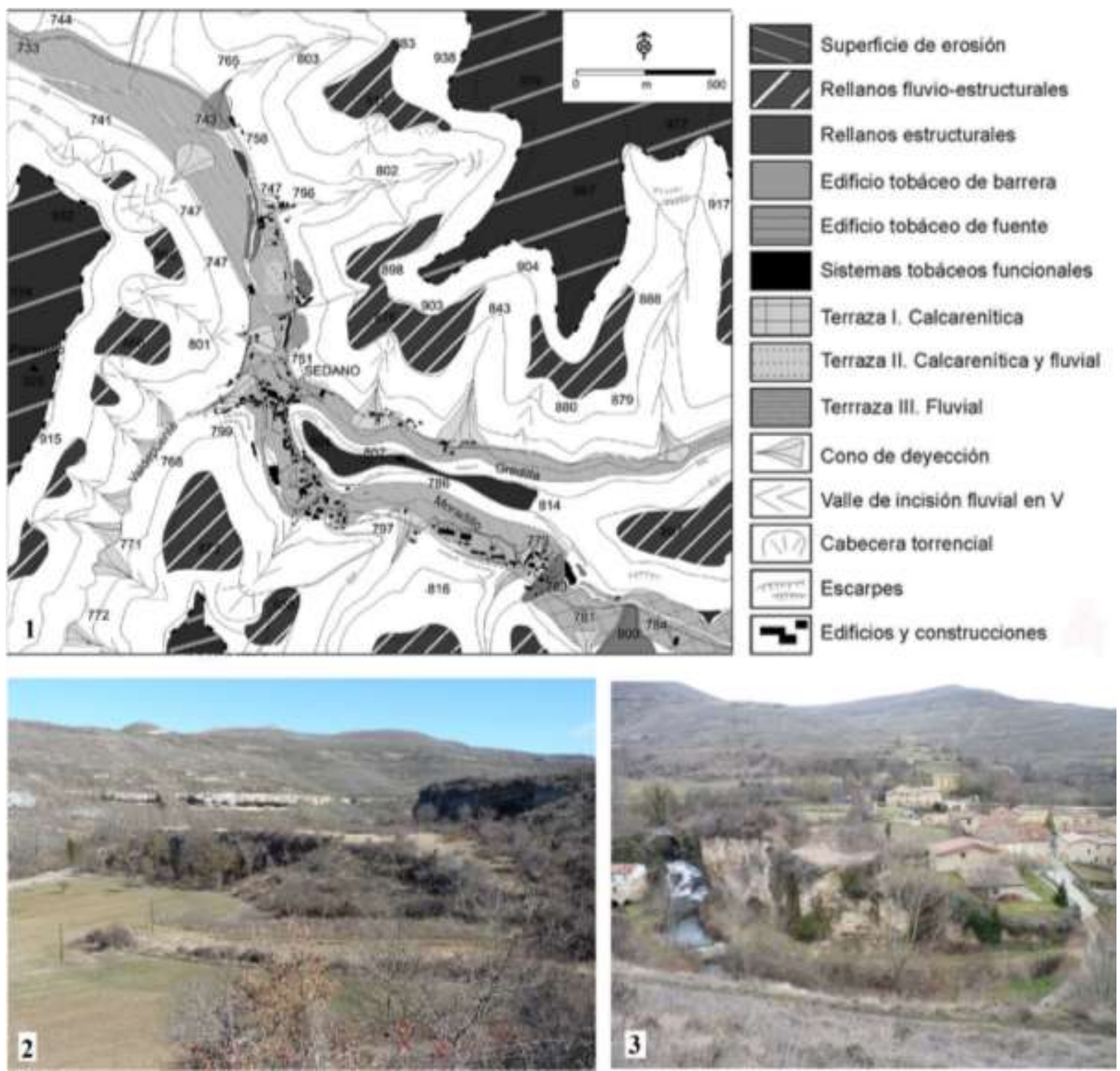

Figura 7. Barreras tobáceas de Sedano. (1) Esquema geomorfológico, modificado de González Amuchastegui \& Serrano (2013). (2) Perspectiva de la barrera superior -SD-BS-. (3) Perspectiva de la barrera inferior - SD$B I-$

\subsubsection{Valle de Tobalina}

El valle de Tobalina se encuentra en la provincia de Burgos, en el extremo sureste de la depresión estructural del Sinclinal de Villarcayo. Este valle está delimitado por los Montes Obarenes al sur, el río Jerea al oeste, la sierra de Árcena al norte y el cierre periclinal del sinclinal de Villarcayo por el este. El río Ebro discurre por el fondo del valle de Tobalina con curso meandriforme, hasta abandonarlo por la cluse de Las Hoces del Sobrón. En su recorrido, recoge las aguas de diferentes ríos y arroyos que tienen su origen en las sierras 
que enmarcan la depresión de Villarcayo, siendo el Purón y el Molinar, los más caudalosos de todos ellos.

El sinclinal de Villarcayo constituye una amplia depresión de carácter estructural rellena de materiales terciarios (Ramírez, et al., 1980), cuyo modelado actual es el resultado de la acción morfogenética del Ebro durante el Cuaternario (González Amuchastegui \& Serrano, 1996). Durante este periodo se sucedieron una serie de fases de acumulación e incisión que han generado formas fluviales y de ladera condicionadas en su desarrollo por los elementos morfoestructurales en los que se inscriben (González Amuchastegui \& Serrano, 1996). Formando parte de estas formas de modelado fluvial se incluyen los depósitos tobáceos, asociados a los cauces de los ríos Purón y Molinar y la formación de Frías que se describen a continuación.

\subsubsection{Complejo tobáceo del desfiladero del río Purón}

Este complejo tobáceo se localiza a lo largo de un tramo de 2,4 km del valle del río Purón, en la vertiente meridional de la sierra de Árcena, justo antes de su desembocadura en el valle del Ebro, a la altura de la localidad de Herrán. La sierra de Árcena constituye un apretado anticlinal que ha dejado expuestos una serie de materiales sedimentarios cretácicos, en la que se alternan rocas coherentes — calizas sobre todo- con menos consistentes -margas y areniscas— dispuestas en bandas de dirección noroeste-sureste (Ramírez, et al., 1979). La distinta dureza de estos materiales ha propiciado el desmantelamiento diferencial de las estructuras por lo que el relieve se presenta en forma de un conjunto de microcuestas sobre los niveles calizos, que se alternan con pasillos ortoclinales labrados en los sustratos más blandos (González Amuchastegui \& Serrano, 2007). El río Purón ha excavado su curso principalmente a favor de estos pasillos, orientados en dirección noreste-sureste de acuerdo al eje del anticlinal de Árcena, y horadado angostas cluses cataclinales entre ellos, por lo que su rumbo a través de esta sierra presenta un trazado zigzagueante (Fig. 8). 
Este complejo ha sido estudiado por González Amuchastegui \& Serrano (2007), quienes lo describen como un conjunto de depósitos tobáceos de tipología variada, con predominio de los de carácter alóctono. El origen de estos materiales alóctonos es el desmantelamiento de estructuras tobáceas situadas aguas arriba, cuyos sedimentos fueron transportados por el río hasta el lugar donde se produjo su precipitación. Esta acumulación se ha producido principalmente detrás de las barreras tobáceas generadas en las cluses (González Amuchastegui \& Serrano, 2007). Como ha sido comentado en el apartado 1.5., en los puntos de ruptura de la pendiente del río se forman saltos de agua que favorecen la precipitación de carbonato cálcico y la formación de barreras (Chen, et al., 2004). Muchas de las estructuras de este complejo aparecen mal definidas, presentando de forma local características típicas de formaciones tanto autóctonas como alóctonas, además de vestigios de otros procesos geomorfológicos erosivos, como material detrítico de las laderas o facies de gravas y arenas de origen fluvial (González Amuchastegui \& Serrano, 2007). González Amuchastegui \& Serrano (2007) dataron cuatro restos de materia orgánica extraídas de tres formaciones diferentes. Dos de las muestras fueron tomadas de la base y parte media de un mismo edificio calcarenítico, y las otras dos restantes de niveles próximos al techo de una formación de barrera y de un edificio tobáceo de relleno, respectivamente. Los resultados cronológicos (Tabla 3) indican que la sedimentación tobácea tuvo lugar entre las primeras etapas holocenas y mediados del periodo Subboreal -2.500-5.000 años (Salas, 1992)—. A partir de las edades de las dos primeras muestras, separadas $7 \mathrm{~m}$ en el mismo perfil, se infiere que las mayores tasas de sedimentación se dieron entre el Boreal y la mitad del periodo Atlántico —9.000 a 6.000 años—, con un crecimiento medio de 4,5 mm/año.

\begin{tabular}{cccccc}
\hline Muestra & Tipo de deposito & Posición en la formación & Técnica & Material & Edad cal BP \\
\hline GrN25977 & Calcarenítico & Media-baja & Carbono-14 & Materia Orgánica & $10.320-8.240$ \\
\hline GrN25978 & Calcarenítico & Central & Carbono-14 & Materia Orgánica & $7.700-7.580$ \\
\hline GrN25979 & Barrera & Próxima al techo & Carbono-14 & Materia Orgánica & $5.650-5.250$ \\
\hline GrN25980 & Barrera & Próxima al techo & Carbono-14 & Materia Orgánica & $6.810-6.330$ \\
\hline
\end{tabular}

Tabla 3. Dataciones del complejo tobáceo del desfiladero del río Purón publicadas por González Amuchastegui \& Serrano (2007). 
Capítulo 2. Área de estudio
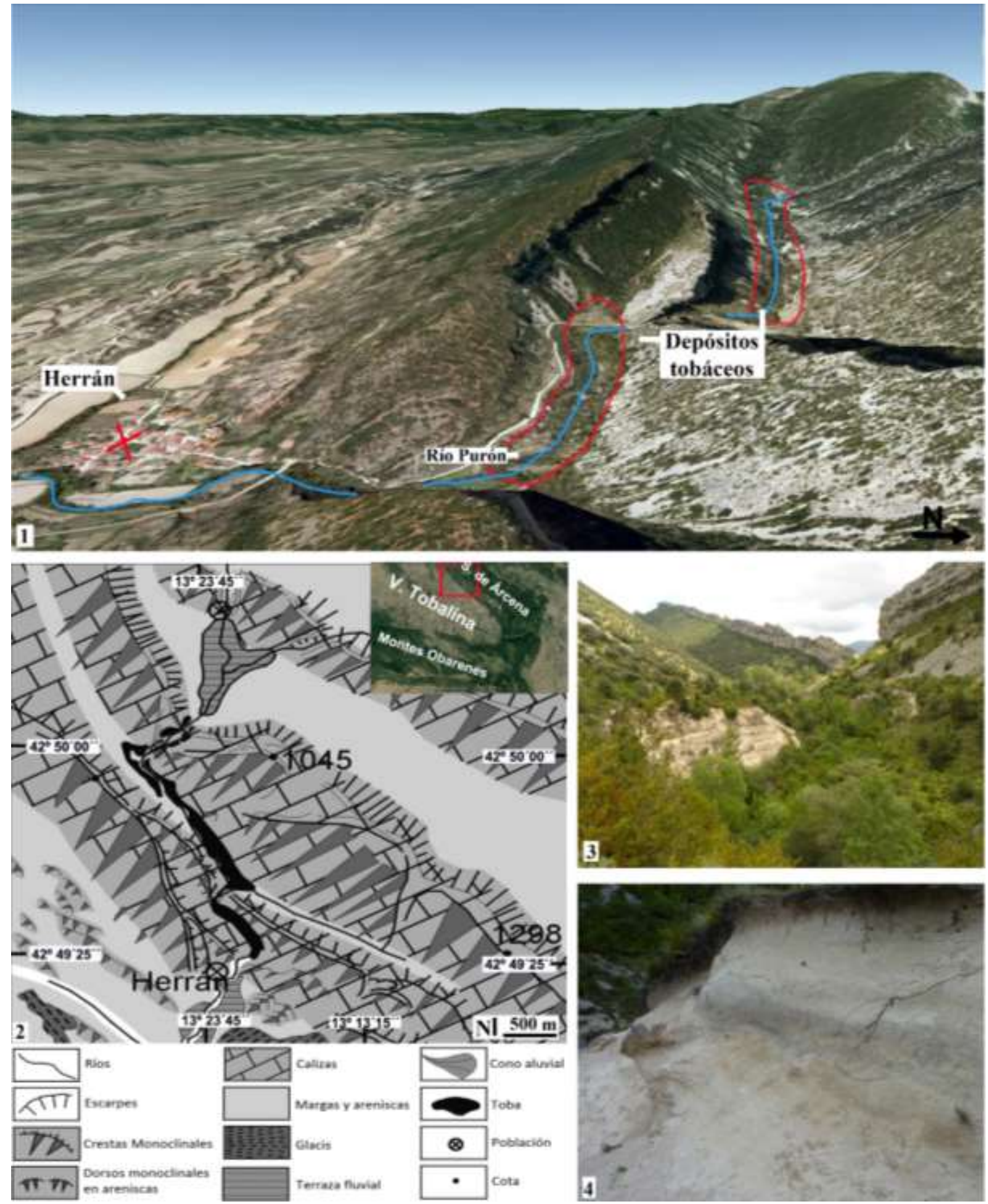

Figura 8. Complejo tobáceo del desfiladero del río Purón. (1) Perspectiva del yacimiento donde se representan la localidad de Herrán y la localización de los depósitos tobáceos - en rojo-. El aspa se corresponde con las coordenadas 42 $49^{\prime} 25^{\prime \prime} \mathrm{N}, 3^{\circ} 13^{\prime} 45^{\prime \prime} \mathrm{O}$. (2) Esquema geomorfológico del yacimiento, modificado de González Amuchastegui \& Serrano (2007). (3) Vista del desfiladero del río Purón donde se aprecia un depósito tobáceo alóctono. (4) Detalle de un afloramiento de sedimentos tobáceos calcareníticos en el río Purón 
A partir de hace unos 4.000 años la sedimentación se paralizó y comenzó una fase de incisión fluvial de las terrazas. Este periodo coincide con las primeras ocupaciones humanas capaces de intervenir sobre el paisaje, por lo que González Amuchastegui \& Serrano (2007) proponen que la evolución holocena del complejo tobáceo del río Purón corresponde a una secuencia climato-antrópica

\subsubsection{Complejo tobáceo del desfiladero del río Molinar}

El río Molinar, de tan solo $18,4 \mathrm{~km}$ de recorrido, drena las aguas de $54,2 \mathrm{~km}^{2}$ de la vertiente septentrional de los Montes Obarenes, desembocando en el Ebro cerca de la localidad de Frías, a 525 msnm (CHE, 2010). En su cuenca alta discurre por un pasillo tectónico ortoclinal en dirección noroeste-sureste sobre arcillas y conglomerados de edad oligocena-miocena (Ramírez, et al., 1979). En su parte baja realiza un quiebro para dirigirse en sentido norte hasta su desembocadura en la planicie del valle de Tobalina, a la altura de la localidad de Tobera. En este tramo el río discurre través de un desfiladero cataclinal labrado en las calizas cretácicas (Ramírez, et al., 1980).

A lo largo de esta garganta se localizan los dos depósitos tobáceos objeto de estudio de esta Tesis (Fig. 9). Su génesis se asocia a la existencia de pequeños saltos de agua en los estrechamientos del desfiladero, donde se habrían generado barreras embrionarias que fueron creciendo en altura como consecuencia de la precipitación carbonatada (González Amuchastegui \& Serrano, 2007). El primero de estos depósitos se localiza 360 m aguas arriba de la localidad de Tobera, en un ensanchamiento del desfiladero. Este se extiende a lo largo de unos $300 \mathrm{~m}$, alcanzando en algunos puntos los $150 \mathrm{~m}$ de anchura. Las tobas depositadas en el extremo inferior de esta formación presentan facies de cascada y biogénicas, lo que sugiere que en este estrechamiento se generó una barrera (González Amuchastegui \& Serrano, 2007). Aguas arriba de este punto, el edificio es mayoritariamente un depósito alóctono de sedimentos calcareníticos, con una superficie superior plana en la cota de los 660 msnm. Toda la formación ha sido incidida por el cauce del río Molinar y las obras de la 
carretera BU-520. Es en el talud de la carretera donde se aprecian mejor las series de sedimentos que, aunque estratificados, en su conjunto son bastante homogéneos. Intercalados entre los sedimentos detríticos aparecen pequeñas formaciones de toba autóctona, acumulaciones de gravas y arenas, y facies de paleocanales.

La segunda formación se encuentra 300 m aguas arriba de la anterior, también en un ensanchamiento del desfiladero (Fig. 9). Este depósito tiene 220 m de longitud por 120 de anchura y un espesor de unos $6 \mathrm{~m}$. Su techo se encuentra $30 \mathrm{~m}$ por encima del anterior depósito, a 690 msnm. La acumulación de sedimentos está también vinculada a la existencia de un salto de agua en un estrechamiento del desfiladero, lo cual facilita los procesos de precipitación carbonatada de origen físico-químico y la construcción de edificios de barrera (Zhang, et al., 2001; Chen, et al., 2004).

El estudio y datación de los depósitos calcareníticos del río Molinar, ha sido publicado en el mismo trabajo que los del río Purón a los que anteriormente se hace referencia González Amuchastegui \& Serrano, 2007-. A partir de los resultados radiométricos (Tabla 4), los autores establecen el comienzo de la fase precipitación de los depósitos hacia la mitad del periodo Atlántico —5.000 a 7.500 (Salas, 1992)—. Desde entonces y hasta el Subboreal -2.500-5.000 años (Salas, 1992)—, se depositaron $4 \mathrm{~m}$ de sedimentos en un tiempo de 1.700 años, lo que supone una tasa de acrecentamiento media para ese intervalo de 2,3 mm/año.

\begin{tabular}{cccccc}
\hline Muestra & Tipo de deposito & Posición & Técnica & Material & Edad cal BP \\
\hline GrN25975 & Calcarenítico & Media & Carbono-14 & Materia Orgánica & $5.950-5.630$ \\
\hline GrN-25976 & Calcarenítico & Base & Carbono-14 & Materia Orgánica & $7.680-7.480$ \\
\hline
\end{tabular}

Tabla 4. Resultados de las dataciones de muestras tomadas en el complejo tobáceo del río Molinar (González Amuchastegui \& Serrano 2007) 
Capítulo 2. Área de estudio
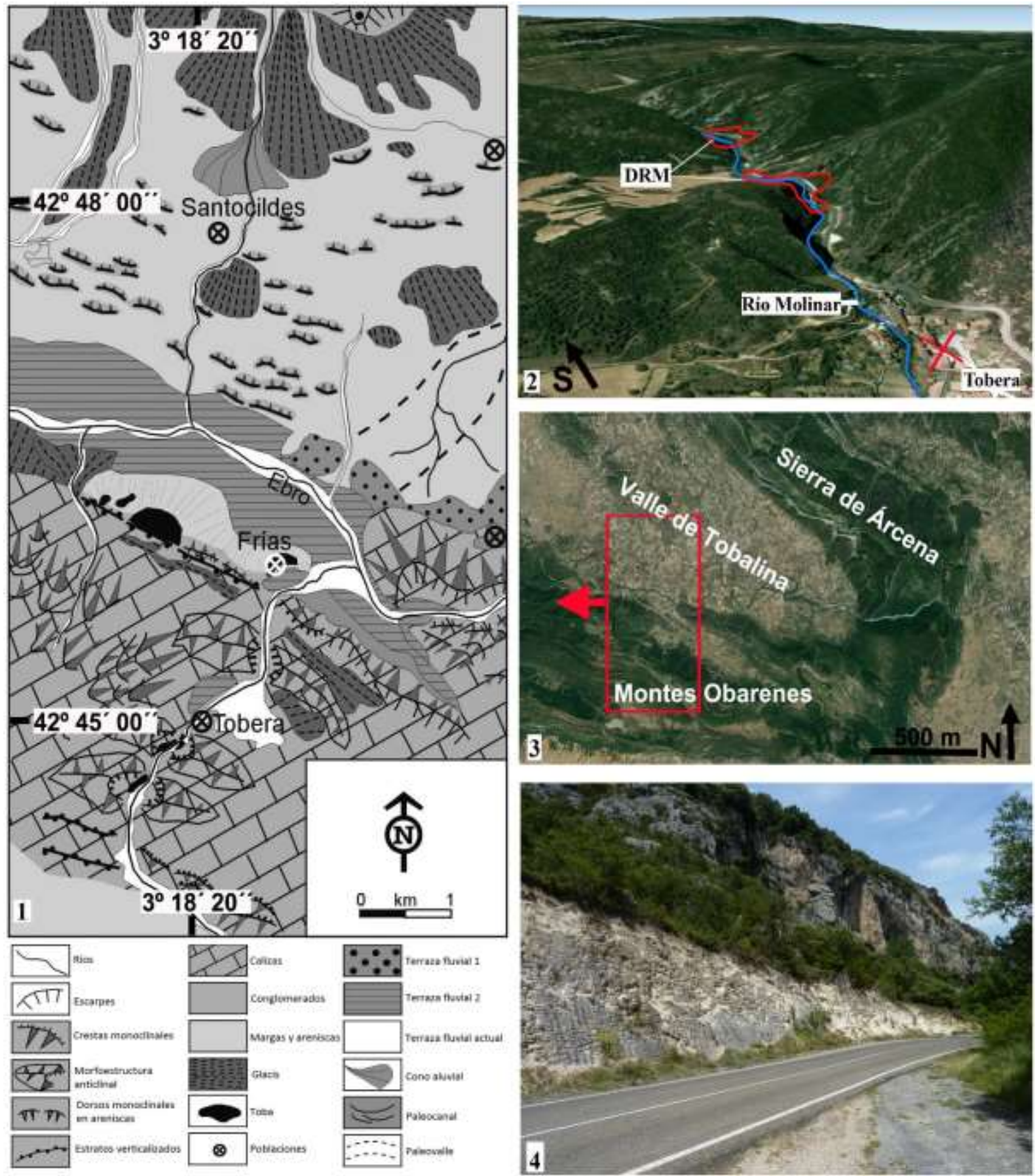

Figura 9. Complejo tobáceo del desfiladero del río Molinar. (1) Esquema geomorfológico del yacimiento. Modificado de González Amuchastegui \& Serrano (2007). (2) Perspectiva aérea donde se señala la ubicación de los depósitos tobáceos estudiados — en rojo-, el río Molinar y la localidad de Tobera. El aspa sobre la localidad se corresponde con las coordenadas $42^{\circ} 45^{\prime} 00^{\prime \prime} \mathrm{N}, 3^{\circ} 18^{\prime} 20^{\prime \prime} \mathrm{O}$. (3) Imagen cenital del valle de Tobalina donde se señala la zona ampliada en el esquema geomorfológico y los accidentes geográficos principales. (4) Talud de la carretera BU-504 donde se observan facies calcareniticas del depósito tobáceo. 


\subsubsection{Formación de Frías}

La formación de Frías constituye un promontorio de naturaleza tobácea situado en el borde meridional de la llanura del valle de Tobalina, entre el río Ebro y el piedemonte de los Montes Obarenes (Fig. 9). Esta estructura se asienta sobre un depósito fluvial colgado unos $30 \mathrm{~m}$ sobre el nivel actual del Ebro. Sobre su superficie se localiza el recinto amurallado y el castillo de la llustrísima ciudad de Frías.
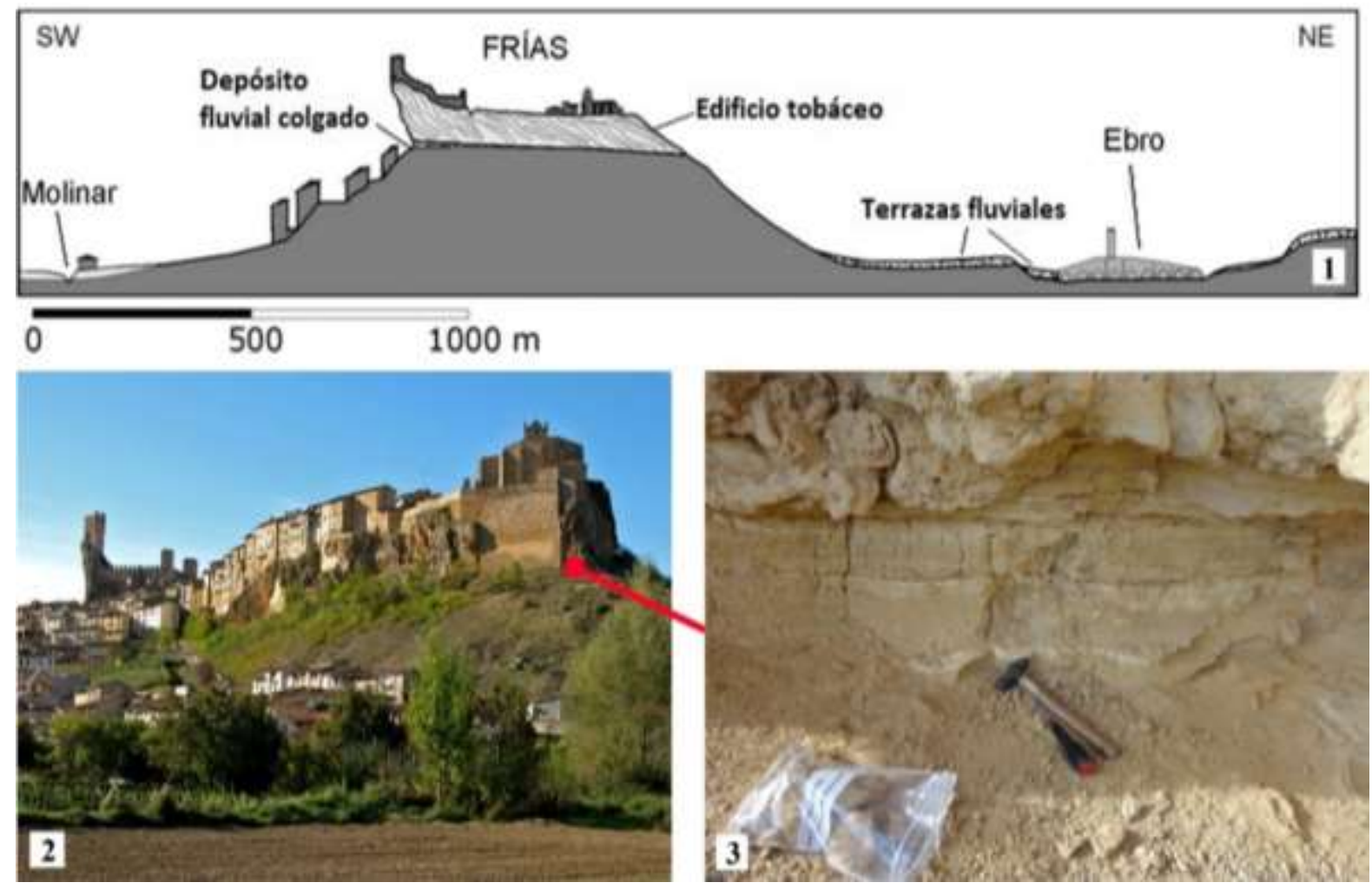

Figura 10. Formación tobácea de Frías. (1) Corte geológico de la formación de Frías (González Amuchastegui \& Serrano, 2014). (2) Perspectiva de la formación de Frías; el punto rojo representa el lugar en la base de la formación donde se tomaron las muestras para su datación mediante Racemización de Aminoácidos. (3) Lugar de la recogida de muestras.

La génesis del edificio tobáceo de Frías se asocia a la antigua dinámica del río Molinar, el cual debía salvar en el pasado un desnivel de $60 \mathrm{~m}$ en el acceso a la depresión del Valle de Tobalina (González Amuchastegui \& Serrano, 1996). Las facies de cascada y biogénicas que aparecen bajo la parte de la formación donde se encuentra el castillo, señalan que, en este punto, existía un salto de agua. La disposición de la toba indica la progresión del frente de terraza hacia el noreste. La datación mediante la técnica del Uranio-Torio de la muestra 
Cerak 738 de carbonato cálcico tomada por González Amuchastegui \& Serrano (2014) de una posición media de esta formación reveló una antigüedad de 163,3 +11,1/-9,9 ka.

\subsubsection{Barrera de Ocio, Valle del río Inglares}

El valle del río Inglares se encuentra en la vertiente septentrional de la Sierra de Cantabria, en la provincia de Álava. La cadena montañosa que forman la sierra de Cantabria y su prolongación al otro lado de la cluse de las Conchas de Haro — los Montes Obarenes, separan la depresión de Miranda de la cuenca sedimentaria del Ebro y la llanada de La Bureba (Fig. 11). La cuenca sedimentaria de Miranda constituye una cubeta sinclinal rellena de materiales terciarios de carácter continental, delimitada por elevaciones de origen tectónico. Los materiales pre-orogénicos plegados, son predominantemente mesozoicos y cenozoicos, y se depositaron en ambientes sedimentarios de transición, en el borde meridional de la cuenca Vasco-Cantábrica (Olivé Davó, et al., 1979).

El río Inglares discurre en sentido este-oeste, drenando la depresión situada entre la Sierra de Portilla y el Cerro Moraza al norte, y la Sierra de Toloño al sur. A lo largo de los últimos $15 \mathrm{~km}$ del valle del Inglares, desde la localidad de Peñacerrada hasta su desembocadura en el Ebro, se suceden una serie de depósitos tobáceos de carácter tanto autóctono como detrítico que se disponen en forma de amplias terrazas escalonadas de hasta $15 \mathrm{~m}$ de profundidad, colmatando el fondo del valle (Llanos, et al., 1998).

Sobre uno de estos depósitos sedimentarios, 600 metros al oeste de la localidad de Ocio, se localiza un edificio tobáceo de carácter autóctono y tipología de barrera (Fig. 11). Esta formación posee unas dimensiones de 620 m de longitud, 80 de anchura y entre 10 y 15 $\mathrm{m}$ de altura. Su planta tiene forma curva; su sección transversal es trapezoidal, con paramentos tendidos de unos $30^{\circ}$ el exterior y $15^{\circ}$ el interior; y su superficie superior es horizontal. El río Inglares ha incidido tanto la represa como en el depósito alóctono sobre el que se asienta, exponiendo los materiales de los que está constituida la barrera. Estos se 
presentan en forma de facies estromatolíticas y biogénicas con abundantes sedimentos calcareníticos intercalados.

En la actualidad la barrera aparece cubierta de vegetación herbácea, por lo que la toba solo aflora en las fracturas abiertas por el río y la carretera A-3126. Mientras que en la toba que ha expuesto la incisión del río predominan las facies detríticas calcareníticas, en los taludes de la carretera a su paso por la barrera abundan las biogénicas y estromatolíticas. El estudio del conjunto de depósitos tobáceos del río Inglares fue abordado por Llanos et al. (1998), quienes dataron una muestra recogida en la parte superior de la represa mediante la técnica del Uranio-Torio. Los resultados arrojaron una antigüedad de 10.900 años, que los autores dan por válida, aunque advierten de problemas de fiabilidad debidos a la baja relación isotópica ${ }^{230} \mathrm{Th} /{ }^{232} \mathrm{Th}$ (Tabla 5 ).

\begin{tabular}{ccccccc}
\hline Muestra & $\mathbf{U}(\mathbf{p p m})$ & ${ }^{234} \mathbf{U} /{ }^{238} \mathbf{U}$ & ${ }^{230} \mathbf{T h} /{ }^{234} \mathbf{U} /$ & ${ }^{230} \mathbf{T h} /{ }^{232} \mathbf{T h}$ & $\left.{ }^{234} \mathbf{U} /{ }^{238} \mathbf{U}\right]_{\mathbf{t}=\mathbf{0}}$ & Edad (Ka) \\
\hline PAY-6 & $0,264+/-0,010$ & $1,349+/-0,050$ & $0,096+/-0,007$ & $2,6+/-0,3$ & 1330 & $10,9+0,9 /-0,8$ \\
\hline
\end{tabular}

Tabla 5. Resultados Ocio publicados por Llanos et al. (1998) de la datación de toba de la barrera de Ocio 
Capítulo 2. Área de estudio
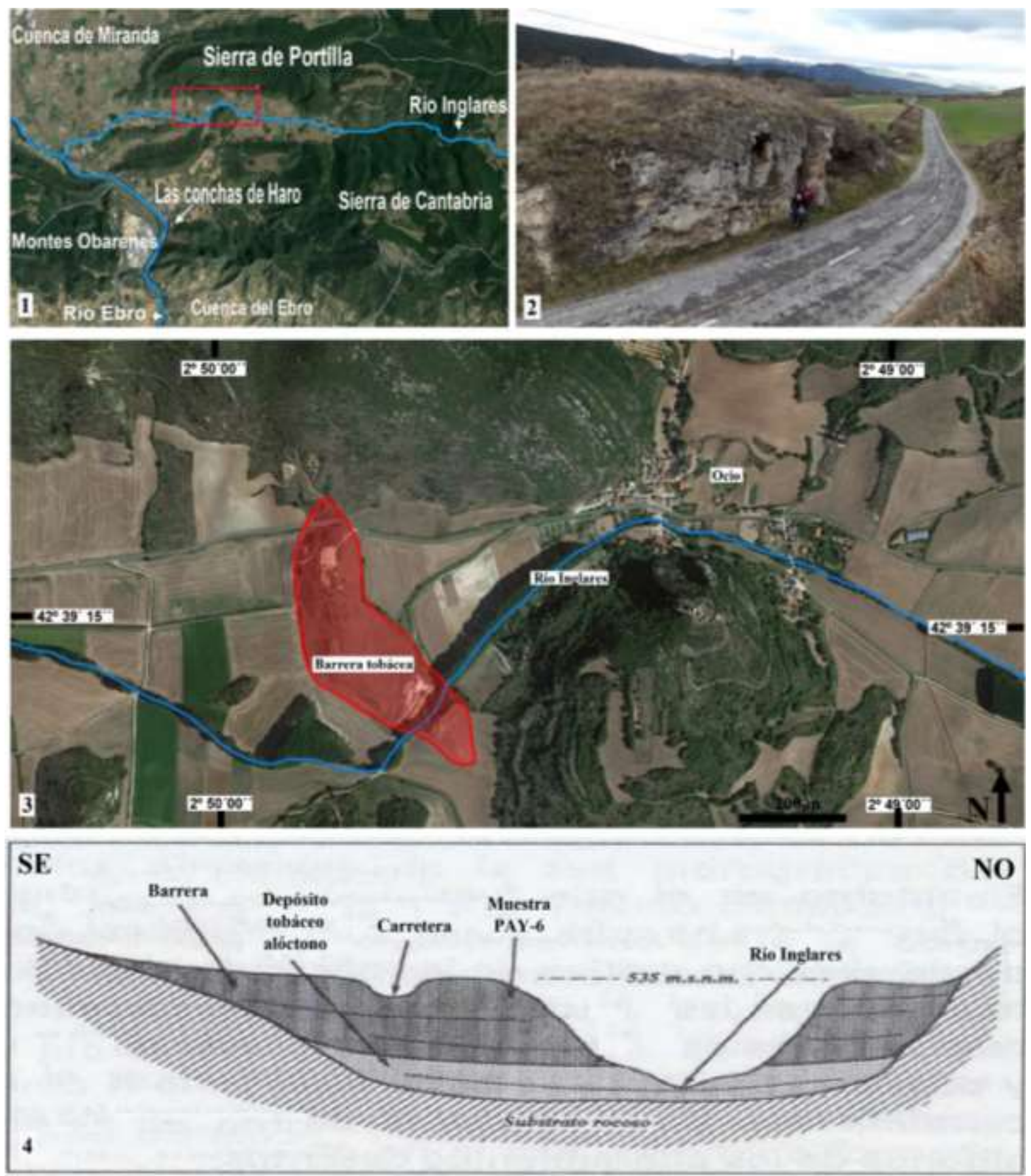

Figura 11. Barrera de Ocio. (1) Imagen aérea de la cuenca baja del río Inglares donde se señalan los accidentes geográficos principales y la zona ampliada de la imagen 3. (2) Afloramiento de tobas en el lugar donde la carretera atraviesa la formación. (3) Perspectiva aérea en donde se señala la ubicación de la barrera, la localidad de Ocio y el cauce del río Inglares. (4) Sección geomorfológica del yacimiento (Llanos, et al., 1998). 


\section{CAPÍTULO 3. MATERIAL Y MÉTODOS}




\section{MATERIAL Y MÉTODOS}

El proceso metodológico descrito en este capítulo comprende una serie de etapas diseñadas con el fin de alcanzar el objetivo de esta Tesis Doctoral: Contribuir al conocimiento de la evolución de la vegetación durante el Cuaternario Final en el sector biogeográfico Castellano Cantábrico a través del estudio del registro paleobotánico contenido en yacimientos tobáceos. En la Fig. 12 se recogen de forma esquemática las diferentes etapas seguidas en esta Tesis Doctoral que se describen a continuación.

\subsection{Selección de los yacimientos y determinación del área de estudio}

El hallazgo de una impresión de estróbilo femenino de Pinus nigra en el complejo tobáceo de Tubilla del Agua —ver Moreno Amat, et al. (2009) — nos condujo a explorar el interés paleobotánico del territorio del Alto Ebro. Sin embargo, dada la cantidad de depósitos de toba existentes en este territorio (González Amuchastegui \& Serrano, 2007; González Amuchastegui \& Serrano, 2010) y los recursos limitados para su estudio, fue necesario seleccionar aquellos de mayor interés paleobotánico. Para ello, primero se procedió a inventariar las formaciones existentes, lo cual se hizo a través de la consulta de bibliografía temática y el estudio de las hojas a escala 1:50.000 del Mapa Geológico de España —IGME. Posteriormente se evaluó la cantidad potencial de restos vegetales que podría contener y extraerse de cada yacimiento. No todas las formaciones de toba tienen el mismo interés paleobotánico. Algunas están asociadas a pequeñas surgencias, por lo que han generado un reducido volumen de toba y no tienen apenas materiales prospectables. Otras están constituidas mayoritariamente por material alóctono, por lo que lo que la cantidad de fósiles en buenas condiciones que contienen es muy escaso. Por último, en algunos depósitos, pese a ser fosilíferos, los restos son difícilmente extraíbles, al presentar poca toba expuesta o estar en lugares inalcanzables. La evaluación de su potencial se llevó a cabo examinando cada yacimiento in situ. 
Capítulo 3. Material y métodos

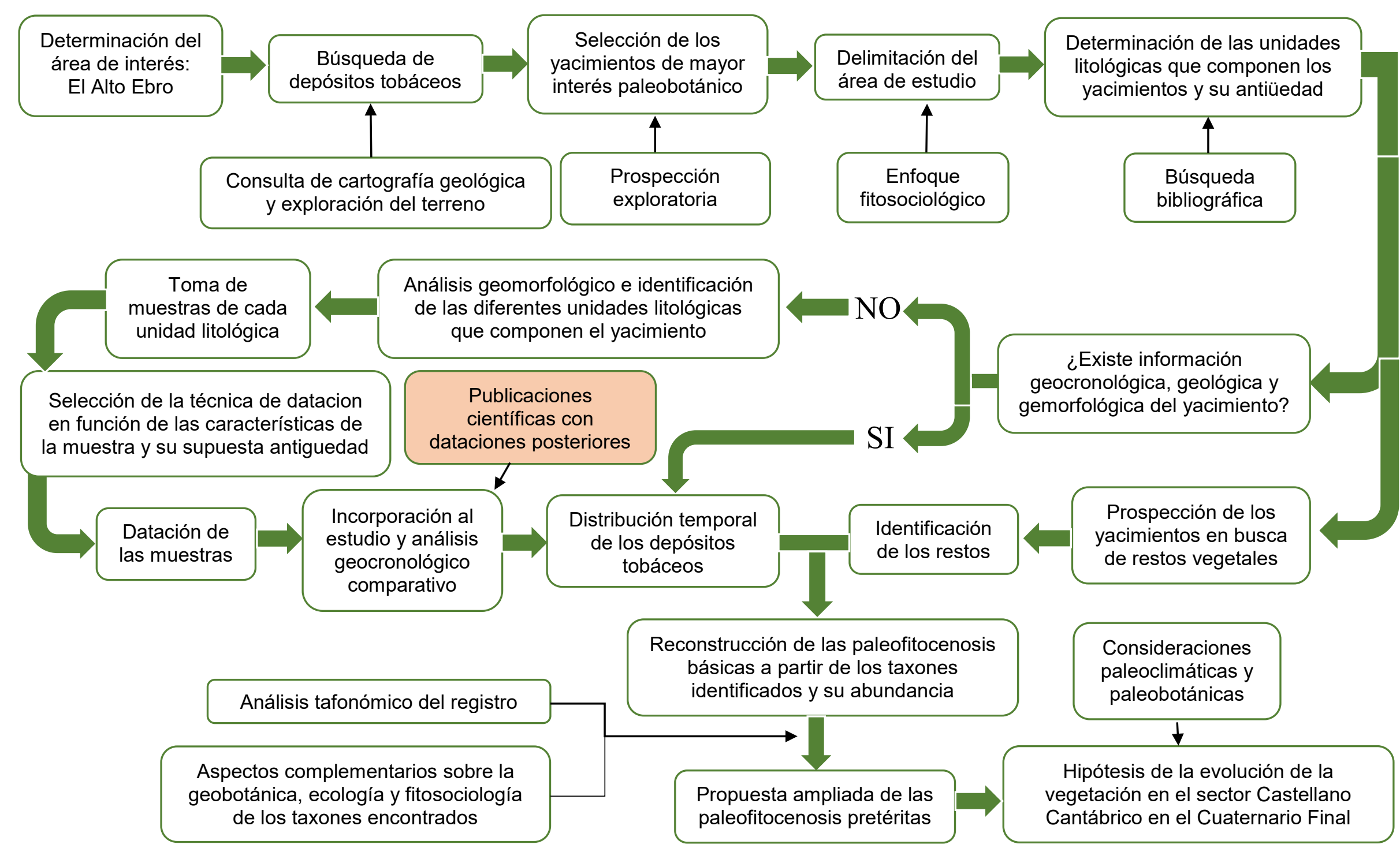

Figura 12. Diagrama del proceso metodológico de la Tesis Doctoral 
La delimitación del área de estudio se ha realizado bajo la premisa de que los resultados paleobotánicos obtenidos del conjunto de depósitos seleccionados debían ser representativos de ella. En este sentido, se descartó limitar el estudio al Alto Ebro, ya que, a pesar de que la búsqueda de formaciones de toba se llevó a cabo en este territorio, se consideró poco probable que el registro fósil fuera representativo de todo él. En efecto, existen en la cuenca alta del Ebro zonas montañosas del ámbito biogeográfico eurosiberiano —Sierra de Hijar, Las Machorras, etc.-, a las que difícilmente se podría extrapolar la flora encontrada en los depósitos tobáceos situados en el cauce bajo de los afluentes del Ebro. Adicionalmente, quedan fuera de la cuenca del alto Ebro zonas pertenecientes a la del Duero, muy similares desde el punto de vista fitogeográfico al territorio por el que se distribuyen los depósitos de toba en el Alto Ebro, específicamente a La Lora, a las que podrían extrapolarse los resultados paleobotánicos obtenidos.

Por lo tanto, para maximizar la representatividad de la muestra, la determinación del área de estudio se abordó desde un enfoque fitogeográfico, escogiéndose la unidad fitogeográfica de menor rango que englobaba todos los yacimientos paleobotánicos estudiados. En efecto, las unidades fitotogeográficas se definen a partir de criterios fitosociológicos, por lo que presentan un conjunto de comunidades vegetales particulares y características, diferentes de las vecinas, como resultado de compartir unas condiciones climáticas, edafológicas, litológicas y una paleohistoria comunes (Rivas-Martínez, 2007). Que la jerarquía de esta unidad fitogeográfica sea del menor rango posible pretende también garantizar que el registro fósil estudiado sea lo más representativo posible del área de estudio. La probabilidad de que un taxón esté representado en el yacimiento es directamente proporcional a la proximidad al lugar donde se produce la fosilización de los restos (Ferguson, 1985). Por lo tanto, se puede inferir que cuanto menor sea el territorio escogido, mejor representado estará en el registro. 


\subsection{Análisis geomorfológico}

En los yacimientos seleccionados de los que no existía información publicada fiable sobre su edad y composición —complejo tobáceo de Tubilla del Agua, barreras de Sedano y formación de Frías-, se abordó la identificación de las diferentes unidades litológicas que los forman. Para ello, se consultó la información publicada disponible y se exploraron los yacimientos sobre el terreno. Como ha sido comentado anteriormente, con posterioridad a la toma de muestras y datación de estos tres yacimientos fueron publicados varios trabajos sobre ellos -(González Amuchastegui \& Serrano, 2010; González Pellejero, et al., 2012; Amuchastegui \& Serrano (2013) — que incluyen el estudio geomorfológico y la datación de algunas de las estructuras de estos yacimientos.

Dado que los sistemas tobáceos pueden ser el resultado de una larga y compleja historia evolutiva en la que se suceden sucesivas fases de sedimentación y erosión de material carbonatado (González Martín \& González Amuchastegui, 2014a), las unidades litológicas resultantes de estos procesos no siempre se presentan como una única estructura diferenciada. Por el contrario, estas pueden aparecer en forma de depósitos complejos, formados por material de diferentes edades de difícil diferenciación, por lo que puede existir cierta incertidumbre de que la muestra sea representativa de toda la unidad litológica. Es por ello que en el apartado 5.1 del capítulo de Discusión se analizan los resultados geomorfológicos —apartado 4.2- y geocronológicos —apartado 4.3- obtenidos en esta Tesis Doctoral, en el marco de las edades posteriormente publicadas, otros indicios geológicos y geomorfológicos y la lógica evolutiva del complejo. Este análisis nos permite determinar la antigüedad de las distintas unidades litológicas identificadas y, en última instancia, elaborar un modelo evolutivo de estos yacimientos.

En los tres yacimientos restantes — complejos de los ríos Purón, Molinar, y la barrera de Ocio-, no se ha llevado a cabo ninguna datación que permita contrastar los resultados publicados, ni tampoco existen indicios que nos hagan dudar de su fiabilidad, por lo que la 
edad de las estructuras de estos yacimientos se infiere directamente a partir de las cronologías publicadas.

\subsection{Dataciones}

La datación de las muestras recogidas con el fin de determinar la edad de las unidades litológicas, así como la de algunos restos subfósiles encontrados, se ha realizado mediante diferentes métodos de datación absoluta. Estos métodos proporcionan un valor numérico que se corresponde con la edad estimada de la muestra. Por el contrario, las técnicas de cronología relativa — p.e. la Estratigrafía—, solo permiten ordenar el material en función de su antigüedad (Rodá, 1982). Para la datación de las muestras se han empleado dos técnicas radiométricas — radiocarbono y uranio-torio-, y una basada en el proceso físico-químico de la racemización de aminoácidos. La elección de la más adecuada en cada caso se ha hecho a partir de la edad inferida para cada estructura, el rango óptimo de aplicación de cada técnica, y el tipo de material disponible. A continuación se describen con más detalle los fundamentos de estas tres técnicas y los posibles inconvenientes en su aplicación sobre tobas.

\subsubsection{Radiocarbono}

Mediante esta técnica han sido datados tres conjuntos de restos vegetales subfósiles -TUAG-TRES-P, TUAG-P y TUAG-MR-P (Tabla 6)— encontrados durante los trabajos de prospección de material fosilífero en Tubilla del Agua. Una porción extraída de los dos primeros restos fue analizada en los laboratorios de Beta Analytic —Miami, Florida, EE.UU— , mientras que el tercero fue datado en el Centro Nacional de Aceleradores - Sevilla, España-. Adicionalmente, también fue analizado en los mismos laboratorios de Beta Analytic un fragmento de carbonato cálcico tomado de la impresión en toba de un estróbilo femenino encontrada en el yacimiento de Tubilla -TUAG.BU.01-. 
También se ha empleado el carbono-14 para determinar la edad de las barreras tobáceas de Sedano (Tabla 6). Para ello, se recogieron sendas muestras de carbonato cálcico del techo de SD-BI y base de SD-BS, así como un fragmento de madera carbonizada encontrado en el la base de la barrera SD-BI. Todas ellas fueron datadas en los mencionados laboratorios de Beta Analytic.

\subsubsection{Fundamentos de la datación por radiocarbono}

El carbono posee dos isótopos estables, el ${ }^{12} \mathrm{C}$ y ${ }^{13} \mathrm{C}$, y un isótopo inestable y débilmente radiactivo, el ${ }^{14} \mathrm{C}$. Este isótopo es producido de forma continua en la atmósfera como resultado del bombardeo de átomos de ${ }^{14} \mathrm{~N}$ por los neutrones de los rayos cósmicos (Libby, 1967). El ${ }^{14} \mathrm{C}$ se oxida rápidamente en el aire, pasando a formar dióxido de carbono y entrando así en el ciclo global del carbono (Sternberg, 1992). Como el ${ }^{14} \mathrm{C}$ es un isótopo inestable que se desintegra a una velocidad conocida, cualquier material inorgánico u orgánico que haya fijado en su estructura átomos de carbono es susceptible de ser datado midiendo la concentración de ${ }^{14} \mathrm{C}$ relativa a los isótopos estables ${ }^{12} \mathrm{C}$ y ${ }^{13} \mathrm{C}$. (Bowman, 1990). Dado el relativamente corto periodo de semidesintegración del ${ }^{14} \mathrm{C}-5.730 \pm 40$ años—, el uso de esta técnica queda limitado a los últimos 50.000-60.000 años. Después de este tiempo, la cantidad de ${ }^{14} \mathrm{C}$ remanente es tan pequeña que no es posible medirla con precisión (Bowman, 1990).

Existen tres técnicas diferentes para medir el contenido de ${ }^{14} \mathrm{C}$ de una muestra: recuento proporcional gaseoso, recuento de centelleo líquido, y espectrometría de masas AMS-. AMS es la técnica más moderna y, frente a las otras dos, ofrece las ventajas de su mayor sensibilidad y requerir menos material para su análisis. Esta ha sido la técnica empleada para la datación de las siete muestras analizadas mediante radiocarbono.

Dado que la concentración relativa de los isótopos de carbono varia ligeramente a lo largo del tiempo y de forma local (Sternberg, 1992), para realizar una estimación correcta de 
la edad de un material y obtener unos resultados precisos, se deben calibrar con las curvas obtenidas mediante interpolación de datos conocidos (Bowman, 1990). En esta memoria de Tesis se utilizan las edades radiocarbónicas calibradas, con un $95 \%$ de probabilidad, las cuales se denotan como «cal BP». Para simplificar su interpretación, en los casos en que las edades resultantes del proceso de calibración presenten más de un intervalo con un $95 \%$ de probabilidad, se darán las edades más extremas del conjunto de intervalos de confianza.

\subsubsection{Posibles fuentes de error}

A pesar de la precisión de esta técnica radiométrica, existen una serie de inconvenientes a la hora de datar toba que derivan de los numerosos procesos que pueden alterar la concentración isotópica del carbonato. Si esto ocurre, puede provocar que los resultados sean erróneos o imprecisos, ya que, como hemos visto, esta técnica se fundamenta en la medida de la concentración del isótopo ${ }^{14} \mathrm{C}$ y en el supuesto de que existe una relación isotópica inicial igual que la atmosférica. La alteración de la relación isotópica inicial puede provenir, por ejemplo, de la mezcla de proporciones variables del $\mathrm{CO}_{2}$ de las aguas meteogénicas con el procedente de la disolución de la caliza (Usdowski, et al., 1979). También puede tener lugar el intercambio de $\mathrm{CO}_{2}$ disuelto en el agua y el atmosférico, lo que tiene como efecto la sobreestimación de la edad del carbonato (Srdoc, et al., 1986a).

Otra fuente de error común que se debe tener en cuenta, es la presencia de carbonatos de diferente edad en una misma muestra. Si en las oquedades de la toba cristaliza material más moderno, se obtendrá una edad menor que la real (Hajdas, 2008). Dado el carácter poroso de la toba, y el hecho de que los depósitos tobáceos están habitualmente expuestos a las corrientes fluviales que las originaron y a las aguas de lluvia y escorrentía, esta es una fuente habitual de error. También puede ocurrir que la toba atrape en su estructura material alóctono carbonatado arrastrado por el agua que, si es de diferente edad, también afecta a la precisión de los resultados (Srdoc, et al., 1986b). En definitiva, aunque es posible datar tobas mediante radiocarbono, este no constituye el material más apropiado para 
el análisis mediante esta técnica. Si existe la posibilidad, es recomendable, para la datación de un depósito, analizar el material orgánico fósil contenido en su interior (Pentecost, 2005). Adicionalmente, se debe verificar que no existen recristalizaciones.

\subsubsection{Desequilibrio de las series del uranio}

La técnica elegida para la datación de las muestras de toba tomadas de las diferentes unidades litológicas del complejo tobáceo de Tubilla del Agua fue la de las series del uranio (Tabla 6). Para el muestreo se contó con la colaboración de los Dres. José Luis Pagés y Ángela Alonso Millán, quienes recomendaron el empleo esta técnica dado que el alto grado de karstificación de algunos depósitos de este complejo tobáceo sugería una edad preholocena.

Para minimizar el riesgo de contaminación, se evitó tomar muestras superficiales y se comprobó, observando con lupa, la ausencia de signos de recalcificación. Para garantizar su representatividad, las muestras fueron tomadas de partes claramente pertenecientes a las unidades de mayor entidad, evitando aquellos afloramientos menores, alterados o desconectados. En cada lugar de muestreo se recogieron aproximadamente unos $500 \mathrm{gr}$ de roca que fueron empaquetados en bolsas de plástico y rotulados con una sigla identificativa. Las muestras fueron enviadas para su datación al laboratorio de geocronología del Instituto de Ciencias de la Tierra Jaume Almera del Consejo Superior de Investigaciones Científicas -Barcelona-

\subsubsection{Fundamentos de la datación por uranio-torio}

La técnica de datación por desequilibrio de las series del uranio, o datación uraniotorio se fundamenta en la medición de la concentración de los elementos de la serie de desintegración radioactiva del ${ }^{238} \mathrm{U}$ atrapado en la calcita durante su formación. A diferencia del carbono-14, las series del uranio no miden la acumulación del producto de la 
desintegración del isótopo «padre», sino el grado en que el equilibrio radiactivo secular entre el producto de dicha desintegración —el isótopo inestable ${ }^{230} \mathrm{Th}-\mathrm{y}$ su isótopo «padre» ${ }^{234} \mathrm{U}$ - ha sido restaurado (Ivanovich \& Harmon, 1992). El tiempo transcurrido hasta que se alcanzan las condiciones de equilibrio secular es específico de cada serie par de isotopos padre-hijo, por lo que midiendo el grado en que este equilibrio ha sido restaurado, se pude determinar el tiempo transcurrido desde la formación de la muestra (Rodá, 1982).

Esta metodología únicamente es aplicable en muestras en las que solo existía el isótopo «padre» en las condiciones de partida. Este hecho tiene lugar en la formación de carbonatos de medios acuosos como, por ejemplo, en los espeleotemas y las tobas. La distinta solubilidad de los compuestos de uranio y de torio da lugar a que se produzcan procesos de fraccionamiento isotópico; el ${ }^{234} \mathrm{U}$, soluble en agua, queda retenido en la red cristalina de la calcita, mientras que el producto de su desintegración, el ${ }^{230} \mathrm{Th}$, que es insoluble, es excluido (Pentecost, 2005).

Dado que el periodo de semidesintegración del ${ }^{230}$ Th es de 75.380 años, la técnica de datación por desequilibrios de las series del uranio es aplicable para un rango de edades de entre un mínimo de 5.000 años hasta un máximo aproximado de 350.000 años (Rodá, 1982; Ivanovich \& Harmon, 1992).

\subsubsection{Posibles fuentes de error}

Al igual que en el caso de la datación por radiocarbono, un factor determinante de la fiabilidad de los resultados es la presencia de contaminación con uranio depositado posteriormente a la formación de la calcita (Pentecost, 2005). Idealmente, todo el ${ }^{230} \mathrm{Th}$ medido en una muestra debería provenir del decaimiento del ${ }^{234} \mathrm{U}$, sin embargo, si el sistema no es cerrado, puede haber un aporte externo de torio. Una forma de inferir si la muestra ha sido contaminada es medir la concentración de ${ }^{232}$ Th. Este isótopo no pertenece a la serie de desintegración del ${ }^{238} \mathrm{U}$, por lo que su presencia es un indicio de que ha habido aporte de 
terrígenos. Generalmente, se considera que la datación es analíticamente fiable cuando la relación ${ }^{230}$ Th $/ 232$ Th es superior a 10 (Livnat \& Kronfeld, 1985). Relaciones inferiores no invalidan los resultados, ya que se desconoce la cantidad real de ${ }^{230} \mathrm{Th}$ exógeno presente, aunque alertan de su posible imprecisión (Juliá, 2014).

Por otro lado, dado que el uranio es soluble, si las formaciones de toba sufren procesos de karstificación después de su formación, puede producirse el lixiviado de este elemento. En este caso, el ratio ${ }^{230} \mathrm{Th} /{ }^{234} \mathrm{U}$ aumentaría, lo que supone que la edad estimada sería superior a la real (Ordóñez, et al., 1990). Igualmente, dada la porosidad de la toba, los carbonatos disueltos pueden volver a cristalizar en las cavidades y orificios de la roca. Esto implicaría la existencia de material de dos edades diferentes en la misma muestra, por lo que la edad radiométrica obtenida no se correspondería con la real (Garnett, et al., 2004).

\subsubsection{Racemización de aminoácidos}

La datación por racemización de aminoácidos fue la técnica escogida para determinar la edad de cinco muestras de sedimento (Tabla 6) recogidas en la formación de Frías. La datación por radiocarbono fue descartada debido al alto grado de karstificación de este depósito y al hecho de que hoy en día se encuentra desconectada de cualquier surgencia o curso de agua, lo que sugiere una gran antigüedad. Las mismas evidencias de karstificación y recalcificación desaconsejaron emplear el método de datación por desequilibrio de las series del uranio, dado que, como ha sido comentado, afectan a la fiabilidad y precisión de los resultados (Ordóñez, et al., 1990).

Para la toma de muestras, se contó con el asesoramiento del Dr. José Eugenio Ortiz Menéndez, investigador titular de la E.T.S. de Ingenieros de Minas y Energías de la Universidad Politécnica de Madrid. Dado que la aplicación de esta técnica de datación requiere de la extracción de conchas de ostrácodos (Ortiz, et al., 2004), se tomaron muestras de sedimento disgregado, ya que el proceso de extracción se puede ver dificultado si los 
ostrácodos están embebidos en la matriz calcárea (Hortolà, 1998). El lugar escogido para el muestreo fueron unos sedimentos compuestos por arenas, arcillas y material calcarenítico, que afloran al pie de los escarpes del extremo noreste de la formación (Fig. 10). Para evitar su posible contaminación, se retiró una capa superficial de $5 \mathrm{~cm}$. A continuación, se recogieron unos $500 \mathrm{gr}$ de material que fue almacenado en bolsas estancas de plástico, las cuales fueron rotuladas con un código identificativo. El análisis de las muestras se realizó en el Laboratorio de Estratigrafía Biomolecular de la E.T.S.I. de la Escuela Superior de Ingenieros de Minas de la Universidad Politécnica de Madrid.

\subsubsection{Fundamentos de la datación por racemización de aminoácidos}

La datación por racemización de aminoácidos se fundamenta en la medición de la relación elantiomérica entre las formas dextrógiras y levógiras de los aminoácidos presentes en una muestra de material orgánico (Hortolà, 1998). Debido a la estereoespecificidad de las reacciones biológicas, la mayoría de las moléculas orgánicas que presentan isomería estereoquímica presentes en los seres vivos son levógiras. Tras la muerte del organismo, se inicia una lenta reacción de racemización por la cual los isómeros levógiros se van transformando en dextrógiros hasta alcanzarse la estabilidad de la mezcla racémica. Así pues, dado que la proporción D-aminoácidos/L-aminoácidos aumenta con la edad del ejemplar, conociendo la tasa de racemización de un aminoácido y las cantidades de formas L y $D$ presentes en una muestra, podremos determinar la edad cronométrica de esta (Hortolà, 1998).

La medición de la relación elantiomérica de las muestras datadas en esta Tesis Doctoral se llevó a cabo sobre conchas fósiles de ostrácodos de la especie Herpetocypris reptans Baird presentes en el sedimento recogido. Los ostrácodos son una clase de crustáceos bivalvos, generalmente de tamaño microscópico, que habitan en ecosistemas acuáticos, tanto de agua dulce como salada. Una vez que el animal muere, sus caparazones 
calcificados pasan a formar parte de los sedimentos, por lo que pueden ser utilizados como marcadores cronológicos para determinar la edad del depósito (Ortiz, et al., 2004).

\subsubsection{Posibles fuentes de error}

La velocidad de racemización depende de las condiciones biogeoquímicas del ambiente sedimentario donde se depositaron las muestras como, por ejemplo, la humedad, el $\mathrm{pH}$, la presión, etc. La temperatura es el factor más determinante de todos ellos (Hortolà, 1998). Debido al notable efecto que la temperatura causa en la velocidad de racemización, las edades deben ser calibradas con algoritmos establecidos a partir de muestras con una historia térmica similar (Ortiz, et al., 2004). En términos generales, una mayor temperatura media anual implica una mayor resolución temporal y un menor rango de datación. Para la temperatura del suelo de las latitudes medias, el equilibrio de racemización se alcanza aproximadamente en un millón de años, por lo que esta técnica puede ser empleada en la datación de materiales con una edad de entre 50.000 y 500.000 años (Wehmiller \& Miller, 2000)

Adicionalmente, puede darse problemas de fiabilidad de las mediciones si la muestra está contaminada con ostrácodos modernos. Este es un aspecto especialmente delicado en las muestras de toba, ya que, dada su porosidad y el ambiente húmedo en el que se suelen encontrar, pueden proliferar en sus oquedades diferentes especies de ostrácodos (Pentecost, 2005). 


\begin{tabular}{|c|c|c|c|c|c|c|c|c|c|}
\hline Código de muestra & Código de laboratorio & Localidad de recogida & Estructura & latitud & longitud & Altitud & Tipo de material & Técnica de datación & $\begin{array}{c}\text { Limite datación } \\
\text {-años- }\end{array}$ \\
\hline TUAG-UT-1 (C-4) ${ }^{1}$ & 910 & Tubilla del Agua & TUAG-VBH & $42^{\circ} 42^{\prime} 41^{\prime \prime}$ & $3^{\circ} 48^{\prime} 36^{\prime \prime}$ & 725 & $\mathrm{CaCO}^{3}$ & Series del uranio & 300.000 \\
\hline TUAG-UT-2 (P-1) $)^{1}$ & 1010 & Tubilla del Agua & TUAG-BH & $42^{\circ} 42^{\prime} 33^{\prime \prime}$ & $3^{\circ} 48^{\prime} 11^{\prime \prime}$ & 774 & $\mathrm{CaCO}^{3}$ & Series del uranio & 300.000 \\
\hline TUAG-UT-3 (TA-Media) ${ }^{1}$ & 310 & Tubilla del Agua & TUAG-TMM & $42^{\circ} 42^{\prime} 13^{\prime \prime}$ & $3^{\circ} 47^{\prime} 52^{\prime \prime}$ & 786 & $\mathrm{CaCO}^{3}$ & Series del uranio & 300.000 \\
\hline TUAG-UT-4 (TA-Baja) ${ }^{1}$ & 210 & Tubilla del Agua & TUAG-TBH & $42^{\circ} 42^{\prime} 15^{\prime \prime}$ & $3^{\circ} 47^{\prime} 59^{\prime \prime}$ & 775 & $\mathrm{CaCO}^{3}$ & Series del uranio & 300.000 \\
\hline TUAG-UT-5 (B-2) ${ }^{1}$ & 110 & Tubilla del Agua & TUAG-TP & $42^{\circ} 42^{\prime} 38^{\prime \prime}$ & $3^{\circ} 48^{\prime} 23^{\prime \prime}$ & 738 & $\mathrm{CaCO}^{3}$ & Series del uranio & 300.000 \\
\hline TUAG-UT-6 (B-3) ${ }^{1}$ & 410 & Tubilla del Agua & TUAG-T & $42^{\circ} 42^{\prime} 40^{\prime \prime}$ & $3^{\circ} 48^{\prime} 16^{\prime \prime}$ & 770 & $\mathrm{CaCO}^{3}$ & Series del uranio & 300.000 \\
\hline TUAG-UT-7 (A-2) $)^{1}$ & 510 & Tubilla del Agua & TUAG-PS & $42^{\circ} 42^{\prime} 33^{\prime \prime}$ & $3^{\circ} 48^{\prime} 31^{\prime \prime}$ & 765 & $\mathrm{CaCO}^{3}$ & Series del uranio & 300.000 \\
\hline A-1 & - & Tubilla del Agua & TUAG-PS & $42^{\circ} 42^{\prime} 37^{\prime \prime}$ & $3^{\circ} 48^{\prime} 31$ & 740 & $\mathrm{CaCO}^{3}$ & Series del uranio & 300.000 \\
\hline B-1 & - & Tubilla del Agua & TUAG-T & $42^{\circ} 42^{\prime} 41^{\prime \prime}$ & $3^{\circ} 48^{\prime} 29^{\prime \prime}$ & 742 & $\mathrm{CaCO}^{3}$ & Series del uranio & 300.000 \\
\hline TUAG-BU-01 & Beta-260006 & Tubilla del Agua & TUAG-VBH & $42^{\circ} 42^{\prime} 35^{\prime \prime}$ & $3^{\circ} 48^{\prime} 14^{\prime \prime}$ & 756 & $\mathrm{CaCO}^{3}$ & Radiocarbono- AMS & 40.000 \\
\hline TUAG-P & Beta-277713 & Tubilla del Agua & TUAG-PS & $42^{\circ} 42^{\prime} 37^{\prime \prime}$ & $3^{\circ} 48^{\prime} 31$ & 743 & Madera & Radiocarbono AMS & 40.000 \\
\hline TUAG-TRESP-1 & Beta-277714 & Tubilla del Agua & TUAG-T & $42^{\circ} 42^{\prime} 39^{\prime \prime}$ & $3^{\circ} 48^{\prime} 18^{\prime \prime}$ & 759 & Carbón & Radiocarbono AMS & 40.000 \\
\hline TUAG-MR-P & CNA1460 & Tubilla del Agua & TUAG-PS & $42^{\circ} 42^{\prime} 37^{\prime \prime}$ & $3^{\circ} 48^{\prime} 31$ & 743 & Madera & Radiocarbono AMS & 40.000 \\
\hline SD-BI-M & Beta -318668 & Sedano & SD-BI & $42^{\circ} 42^{\prime} 41^{\prime \prime}$ & $3^{\circ} 44^{\prime} 14^{\prime \prime}$ & 772 & Carbón & Radiocarbono AMS & 40.000 \\
\hline SD-BI-T & Beta - 318669 & Sedano & SD-BI & $42^{\circ} 42^{\prime} 41^{\prime \prime}$ & $3^{\circ} 44^{\prime} 14^{\prime \prime}$ & 782 & $\mathrm{CaCO}^{3}$ & Radiocarbono AMS & 40.000 \\
\hline SD-BS-M & Beta - 318670 & Sedano & SD-BS & $42^{\circ} 42^{\prime} 35^{\prime \prime}$ & $3^{\circ} 44^{\prime} 03^{\prime \prime}$ & 780 & $\mathrm{CaCO}^{3}$ & Radiocarbono AMS & 40.000 \\
\hline F-I-1 & $\begin{array}{l}\text { LEB-12230 a } 12231 \\
\quad(2 \text { muestras })\end{array}$ & Frías & FF & $42^{\circ} 45^{\prime} 46^{\prime \prime}$ & $3^{\circ} 17^{\prime} 31^{\prime \prime}$ & 551 & $\begin{array}{l}\text { Sedimento } \\
\text { detrítico }\end{array}$ & $\begin{array}{l}\text { Racemización de } \\
\text { aminoácidos }\end{array}$ & 500.000 \\
\hline F-I-2 & LEB-12232 & Frías & $\mathrm{FF}$ & $42^{\circ} 45^{\prime} 46^{\prime \prime}$ & $3^{\circ} 17^{\prime} 31^{\prime \prime}$ & 551 & $\begin{array}{l}\text { Sedimento } \\
\text { detrítico }\end{array}$ & $\begin{array}{l}\text { Racemización de } \\
\text { aminoácidos }\end{array}$ & 500.000 \\
\hline F-I-3 & $\begin{array}{l}\text { LEB-12233 a } 12236 \\
\text { (4 muestras) }\end{array}$ & Frías & $\mathrm{FF}$ & $42^{\circ} 45^{\prime} 46^{\prime \prime}$ & $3^{\circ} 17^{\prime} 31^{\prime \prime}$ & 551 & $\begin{array}{l}\text { Sedimento } \\
\text { detrítico }\end{array}$ & $\begin{array}{l}\text { Racemización de } \\
\text { aminoácidos }\end{array}$ & 500.000 \\
\hline F-I-4 & $\begin{array}{l}\text { LEB-12225 a } 11228 \\
\quad \text { (4 muestras) }\end{array}$ & Frías & $\mathrm{FF}$ & $42^{\circ} 45^{\prime} 46^{\prime \prime}$ & $3^{\circ} 17^{\prime} 31^{\prime \prime}$ & 551 & $\begin{array}{l}\text { Sedimento } \\
\text { detrítico }\end{array}$ & $\begin{array}{l}\text { Racemización de } \\
\text { aminoácidos }\end{array}$ & 500.000 \\
\hline F-I-5 & LEB-12229 & Frías & $\mathrm{FF}$ & $42^{\circ} 45^{\prime} 46^{\prime \prime}$ & $3^{\circ} 17^{\prime} 31^{\prime \prime}$ & 551 & $\begin{array}{l}\text { Sedimento } \\
\text { detrítico }\end{array}$ & $\begin{array}{l}\text { Racemización de } \\
\text { aminoácidos }\end{array}$ & 500.000 \\
\hline
\end{tabular}

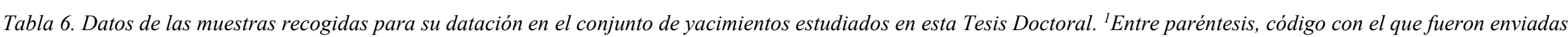
al laboratorio 


\subsection{Recogida e identificación de los restos vegetales}

La búsqueda de restos paleobotánicos se llevó a cabo examinando de forma sistemática los afloramientos de toba de las formaciones objeto de estudio de esta Tesis Doctoral. Los fósiles encontrados fueron extraídos con martillo y cincel. Tras retirar el material excedente in situ, se agruparon por unidad geomorfológica de origen y fueron empaquetados en cajas para el traslado al laboratorio. En algunos lugares aparecieron numerosos fósiles formando una amalgama. En estas ocasiones, se procuró extraer el bloque de toba que los contenía para ser llevado al laboratorio y poder realizar una extracción más cuidadosa de los restos. A continuación, todos los ejemplares fueron sometidos a una limpieza minuciosa. Con un punzón se retiró el carbonato adherido a su superficie para dejar expuestos sus rasgos morfológicos. Adicionalmente, se limpiaron con un cepillo y agua aquellos ejemplares que presentaban restos de sedimentos sueltos o suelo. Una vez limpios y secos, todos los ejemplares fueron etiquetados y fotografiados.

El primer paso para la identificación de los especímenes recogidos fue agruparlos en función de características morfológicas comunes. Los diferentes rasgos que exhibían los ejemplares de cada agrupación — p.e. ápice, borde foliar, envés, etc.— se integraron para componer el morfotipo. A continuación, fueron descritos todos los morfotipos identificados de acuerdo con los caracteres diagnósticos recogidos en la bibliografía consultada:

- La descripción de los briófitos se hizo a partir de las características macroscópicas recogidas en el glosario ilustrado del «Handbook of mosses of the Iberian Peninsula and the Balearic Islands» (Casas, et al., 2006); estas son: la forma de los filidios, de su base y ápice, su sección transversal y disposición en que los estos se encuentran organizados a lo largo del caulidio, y la presencia del nervio medio. 
- Para la descripción de las impresiones de estróbilos femeninos de coníferas se consideró la forma del borde externo de las apófisis, el grosor de estas, la posición del mucrón en el ombligo de las escamas y la depresión del ombligo (Morla, et al., 2004; Ruiz de la Torre, 2006).

- Las impresiones foliares se han descrito de acuerdo a los rasgos morfológicos propuestos por Hickey (1973), Dilcher (1974), Melville (1976), Stearn (1983) y, especialmente, los recogidos en el «Manual of Leaf Architecture» (Ash, 1999). Estos son:

$>$ Tamaño del limbo foliar.

$>$ Presencia de pecíolo.

$>$ Forma de la hoja.

$>$ Existencia de asimetría foliar

$>$ Forma del ápice.

$>$ Forma de la base.

$>$ Margen foliar.

$>$ Desarrollo o no de lobulaciones

$>$ Nerviación de primer orden.

$>$ Estructura de la nerviación de segundo orden.

$>$ Curso de los nervios de segundo orden.

$>$ Ángulo de incidencia con respecto al nervio de primer orden y si este ángulo varía a medida que nos alejamos de la base.

$>$ Espaciado entre los nervios de segundo orden.

$>$ Presencia de nervios intersecundarios.

$>$ Presencia de nervios agrofíticos.

$>$ Nerviación de tercer orden.

Disposición de los foliolos a lo largo del raquis en los ejemplares de hojas pinnaticompuestas. 
Una vez descritos los diferentes morfotipos, se procedió a la identificación de los diferentes taxones, la cual se realizó mediante morfología comparada con plantas actuales, ejemplares de herbario y bibliografía de referencia —p.e. López, 2007; López \& Allué, 2004; Ruiz de la Torre, 2006; Casas et al., 2006-.

Por último, los taxones identificados fueron clasificados taxonómicamente de acuerdo al sistema filogenético propuesto por Chase \& Reveal (2009). En este sistema se denomina equisetópsidas, a las plantas terrestres, anteriormente conocidas como embriofitas Endlicher, 1836, Emend. Lewis \& McCourt, 2004, grupo al que Chase y Reveal otorgan el rango de clase. De las 16 subclases que componen las equisetópsidas, cuatro están representadas en el registro fósil estudiado en esta Tesis Doctoral: Bryidae Engler, Polypodiidae Cronquist, Pinidae Cronquist, Takhtajan \& W. Zimmerman y Magnoliidae Novák ex Takhtajan. Por debajo del rango de subclase, los sistemas elegidos para la clasificación de los taxones son los publicados por Frey \& Stech (2008) para Bryidae, por Christenhusz, et al., (2011a) para Polypodiidae, por Christenhusz, et al., (2011b) para Pinidae y por el Angiosperm Phylogeny Group III, (2009) para la subclase Magnoliidae.

\subsection{Distribución temporal de las unidades litológicas identificadas}

Para poder trazar la evolución de la vegetación es necesario ordenar los depósitos estudiados, y por tanto su contenido paleobotánico, a lo largo de la escala temporal. Para ello, se ha partido de los resultados geocronológicos, tanto de los obtenidos de la datación de muestras de los yacimientos de Tubilla, Sedano y Frías, como de las edades publicadas para los yacimientos que no han sido datados en esta Tesis. Sin embargo, las dataciones disponibles no constituyen una medida de la antigüedad de todo depósito del que fueron tomadas, sino que tan solo representan un instante en el proceso de su formación. Adicionalmente, como ha sido comentado en el apartado 3.3. de este capítulo, las dataciones pueden presentar problemas de fiabilidad, así como tener un amplio intervalo de confianza. 
Por todo ello, y dado que la génesis de los depósitos de toba está relacionada con factores climáticos (Pedley, et al., 1996), se considera adecuado asignar cada unidad litológica identificada a estadíos climáticos determinados. Esto nos permite analizar de forma conjunta los depósitos de edad similar, con lo que su registro fósil gana en significancia, y facilita la sistematización del análisis de la evolución de la vegetación.

La asignación de las diferentes unidades litológicas a estadíos climáticos determinados se ha realizado combinado los intervalos de confianza de las dataciones disponibles con una escala temporal dividida en unidades climáticas. Adicionalmente, han sido tenidas en cuenta las consideraciones hechas en el apartado 5.1 del capítulo de Discusión sobre la fiabilidad de las dataciones y la edad de los depósitos. Con respecto a las unidades climáticas, en este trabajo se hace uso, para el Pleistoceno, de las Etapas Isotópicas Marinas -MIS- Estas han sido establecidas a partir del estudio de la concentración del isotopo de oxigeno $\delta^{18} \mathrm{O}$ contenido en los depósitos sedimentarios marinos (EPICA, 2004). Esta concentración está directamente relacionada con la temperatura atmosférica en el momento de la precipitación del sedimento, de tal forma que, a menor concentración, mayor temperatura media global, y viceversa. Las etapas identificadas se nombran con la serie de números naturales, empezando por el Holoceno -MIS 1-, y se asigna a las siguientes, números consecutivos (Fig. 1). Como resultado de ello, las etapas con número impar se corresponden con las fases cálidas y, las pares, con las glaciares (Shackleton \& Opdyke, 1973).

El conocimiento que se tiene sobre el cambio de la vegetación durante el Holoceno es más preciso que el de los periodos anteriores, por lo que para este periodo se usan unidades temporales más reducidas. Dado que mucha de la bibliografía consultada sobre los depósitos estudiados hace referencia a las cronozonas de Blytt-Sernander (Sernander, 1908), se ha decidido, por practicidad, emplear estas unidades climático-temporales en esta Memoria como los estadíos climáticos de referencia para la determinación de la edad de los 
depósitos holocenos y la evolución de la vegetación en este periodo. Las cronozonas de BlyttSernander fueron establecidas a partir del estudio estratigráfico de los sedimentos acumulados en las turberas en Dinamarca (Sernander, 1908). Esta escala divide el Holoceno en 5 estadíos, las cuales no poseen unos límites cronométricos estandarizados, pero que habitualmente se dividen de la siguiente forma: Subatlántica - 0-2.500 años—, Sub-boreal -2.500-5.000 años—, Atlántica -5.000-7.500 años—, Boreal -7.500-9.000 años—, y Preboreal —9.000-11.700 años— (Salas, 1992).

\subsection{Reconstrucción de las paleofitocenosis y de la evolución de la vegetación}

La reconstrucción de las paleofitocenosis se ha realizado a partir del conjunto de taxones encontrados en cada unidad litológica y su abundancia relativa. Para ello, se ha abordado el estudio del registro distinguiendo entre vegetación zonal, azonal y extrazonal, en función del papel que juega el bioclima general u otros factores - p.e. suelo, litología, orografía, etc.- en el establecimiento de esas comunidades vegetales (Walter, 1979). La vegetación zonal es aquella que está influenciada principalmente por factores climáticos. La extrazonal es la que se desarrolla en lugares donde el clima no es el más adecuado para sus requerimientos, por lo que su presencia se debe a factores microclimáticos. Por último, la vegetación azonal es aquella cuya distribución no guarda relación con el bioclima general, sino con aspectos edáficos, del relieve, orográficos, etc. De este último tipo son, por ejemplo, los bosques riparios, la vegetación de turbera, etc.

Mediante este proceso se pretende establecer de manera objetiva y mesurable un esbozo de la composición de las comunidades vegetales pretéritas. Sin embargo, como ha sido explicado en el apartado 1.5 de esta Memoria, además de que el registro es tan solo una muestra de los restos vegetales - fundamentalmente hojas - de las paleofitocenosis, este puede haber sufrido diversos sesgos tafonómicos, de tal forma que no refleja la composición 
de la vegetación en el pasado. Por ello, en el apartado 5.3. del capítulo de discusión se analiza el efecto que estos sesgos han podido tener en el registro estudiado. Con el objetivo de enriquecer las reconstrucciones de las paleofitocenosis y proponer una hipótesis sobre la vegetación del sector Castellano Cantábrico en cada estadío climático considerado, en el apartado 5.4. se discuten las consideraciones hechas sobre el posibles sesgo tafonómico del registro, en el contexto de la ecología, corología y fitosociología de los taxones y comunidades vegetales inferidas.

Las comunidades vegetales propuestas para cada periodo constituyen episodios aislados de la historia evolutiva de la vegetación del sector Castellano Cantábrico. Por ello, en el apartado 5.5. del capítulo de Discusión se analizan estos resultados en el contexto de la información paleobotánica y paleoclimática disponible para establecer la evolución de la vegetación en este territorio a lo largo del Cuaternario Final. 
CAPÍTULO 4. RESULTADOS 


\section{RESULTADOS}

En este capítulo se presentan los resultados de esta Tesis Doctoral organizados en cinco apartados: (i) en el primero se recogen los resultados del proceso de selección de los depósitos tobáceos estudiados y de la delimitación del área de estudio; (ii) en el segundo se expone el análisis morfoestructural de los yacimientos de Tubilla del Agua, Sedano y Frías; (iii) en el siguiente apartado se recogen los resultados de la datación de las muestras tomadas de los tres yacimientos anteriores; (iv) en el cuarto se muestran los resultados paleobotánicos, los cuales comprenden el análisis de las características morfológicas de los fósiles encontrados y su identificación taxonómica; (iv) y por último, en el quinto apartado se aborda la determinación de la antigüedad de los depósitos y su asignación a estadíos climáticos determinados, y la reconstrucción de las paleofitocenosis a partir del registro fósil.

\subsection{Selección de los depósitos a estudiar y determinación del área de estudio}

Para la selección de los seis yacimientos estudiados en esta Tesis Doctoral fueron visitados 14 afloramientos tobáceos del Alto Ebro (Fig. 13) (Tabla 7), que previamente habían sido identificados a partir de los mapas geológicos de este territorio y de la consulta de bibliografía temática. Durante la exploración se evaluó su interés paleobotánico en función de la presencia de restos vegetales visibles y de la cantidad de toba prospectable. A continuación se expone de forma resumida la valoración que se hizo del interés paleobotánico de cada afloramiento tras su exploración in situ.

\section{Complejo tobáceo de Tubilla del Agua}

Interés paleobotánico muy alto: Constituye un afloramiento de grandes dimensiones con mucha toba expuesta y accesible, la mayoría de carácter autóctono, en la que se aprecian numerosas impresiones de restos vegetales. Algunas de sus estructuras, colgadas en las laderas del valle y muy karstificadas, sugieren una gran antigüedad. 


\section{Formación de Frías}

Interés paleobotánico muy alto: Esta formación presenta mucha roca desnuda susceptible de ser prospectada aunque algunas de sus paredes son de gran altura lo que las hace inaccesibles. En ellas se aprecian numerosas impresiones foliares, de tallos, ramas y troncos, algunos de grandes dimensiones. Su alto grado de karstificación denota una gran antigüedad.

\section{Complejo tobáceo del desfiladero del río Purón}

Interés paleobotánico alto: Este complejo está formado por varios depósitos que en conjunto presentan mucha roca expuesta. Sin embargo, algunos de ellos son de naturaleza alóctona, por lo que no contiene impresiones. En los puntos donde aflora toba autóctona esta presenta numerosos restos.

\section{Barreras tobáceas de Sedano}

Interés paleobotánico alto: Este yacimiento está formado por dos edificios tobáceos de tamaño medio. Presentan bastante toba prospectable, aunque parte de ella es inaccesible debido a su altura. La mayoría es de carácter autóctono y muestra numerosas impresiones.

\section{Complejo tobáceo del río Molinar}

Interés paleobotánico medio: Está formado por dos depósitos independientes de tamaño medio. La mayor parte de ellos está constituye toba de carácter alóctono, pobre en fósiles, sin embargo, donde aflora toba autóctona aparecen numerosos restos vegetales.

\section{Barrera de Ocio}

Interés paleobotánico medio: Constituye una formación de carácter autóctono, de tamaño mediano grande. Sin embargo, presenta poca roca expuesta, excepto en el talud de la carretera que atraviesa la formación.

\section{Depósitos de Valdelateja}

Interés paleobotánico bajo: Están formados por varios afloramientos estratificados a lo largo del tramo final del río Rudrón antes de su desembocadura en el Ebro. Son de 
carácter autóctono y presentan roca expuesta donde aparecen impresiones foliares. Sin embargo, este yacimiento fue descartado por estar en su mayor parte cubierto por vegetación, lo que dificulta la prospección de fósiles.

\section{Depósitos de Orbaneja}

Interés paleobotánico bajo: Constituye una formación de ladera, de tamaño medio y naturaleza autóctona. A pesar de presentar impresiones foliares, su prospección fue descartada debido a que sobre estos depósitos se asienta el pueblo de Orbaneja, y mucha de la toba expuesta está dentro del casco urbano.

\section{La Tobona}

Interés paleobotánico bajo: Es una formación de ladera que presenta paredes desnudas en las que aparecen abundantes impresiones vegetales. La exploración de este depósito en profundidad fue descartada debido a que buena parte de la formación se encuentra dentro de una propiedad privada.

\section{Depósito de Valurcia}

Interés paleobotánico bajo: En este depósito aflora toba tanto de carácter autóctono como detrítico. Buena parte de la toba expuesta es inaccesible, por corresponderse con las pareces de un pequeño cañón que ha formado el arroyo que atraviesa este depósito.

\section{El Tobazo}

Interés paleobotánico bajo: Constituye una formación de ladera activa y, por lo tanto, aparece cubierta de agua y de abundante vegetación que dificulta la prospección de restos. Adicionalmente, la verticalidad de sus paredes y su altura hace difícil su exploración.

\section{Depósito de Berganzo}

Interés paleobotánico muy bajo: A pesar de su gran extensión, este depósito está formado por sedimentos calcareníticos de carácter detrítico no fosilíferos. 


\section{Depósito de Peñacerrada}

Interés paleobotánico muy bajo: Al igual que en el caso anterior, la mayor parte de los sedimentos de este afloramiento son de naturaleza detrítica y no presentan restos paleobotánicos. En algunos lugares existen depósitos de toba de naturaleza autóctona, pero inaccesibles, por encontrarse en el fondo de un estrecho desfiladero.

\section{Cuevas de los portugueses}

Interés paleobotánico muy bajo: Constituye un pequeño depósito de toba alóctona en el que no se encontró ninguna impresión de restos vegetales.

\section{Mesa de Frías}

Interés paleobotánico muy bajo: Este depósito parece ser muy antiguo y se encuentra tan karstificado que no se encuentran fósiles de ningún tipo.

Como ha sido expuesto en el capítulo de metodología, para la delimitación del área de estudio se ha seguido un enfoque fitogeográfico, de tal forma que esta área se corresponde con la unidad fitogeográfica de menor rango que engloba todos los yacimientos estudiados. La unidad tipológica elemental en fitogeografía es la tesela, la cual se define como un espacio geográfico homogéneo ecológicamente y de extensión variable (Rivas-Martínez, 2007). Un conjunto de teselas constituyen el elemento de paisaje. Este es el rango que tienen, por ejemplo, los valles fluviales. Los depósitos de toba contienen principalmente restos de la vegetación propia de los ecosistemas fluviales o lacustres donde estas estructuras habitualmente se generan, sin embargo, con frecuencia la muestra paleobotánica trasciende el biotopo ripario, conteniendo también restos de taxones de la vegetación de las laderas circundantes, que son transportados por el viento o el agua hasta el lugar donde se produce la precipitación de carbonato cálcico. En este caso, el registró tobáceo sería representativo de una unidad biogeográfica de rango superior de la que formarían parte tanto el biotopo ripario como otros existentes en el terreno circundante. 
Capítulo 4. Resultados

La comarca y el distrito son unidades fitogeográficas de rango superior a los elementos del paisaje (Rivas-Martínez, 2007), sin embargo, ninguna de ellas cumplen con la premisa de abarcar todos los depósitos estudiados. Los yacimientos seleccionados para su estudio paleobotánico se encuentran en los distritos Parameño Burgalés - Tubilla del Agua y Sedano-, Losano-Villarcayense —-Herrán, Tobera y Frías- y Mirandano-Treviñés — Ocio- Estos distritos se encuentran dentro del sector Castellano Cantábrico (RivasMartínez, 2007), el cual constituye el territorio florísticamente homogénea más pequeña que engloba todos los yacimientos, y por tanto el área de estudio considerado en este trabajo, y a la cual se puede extrapolar el registro fósil estudiado.

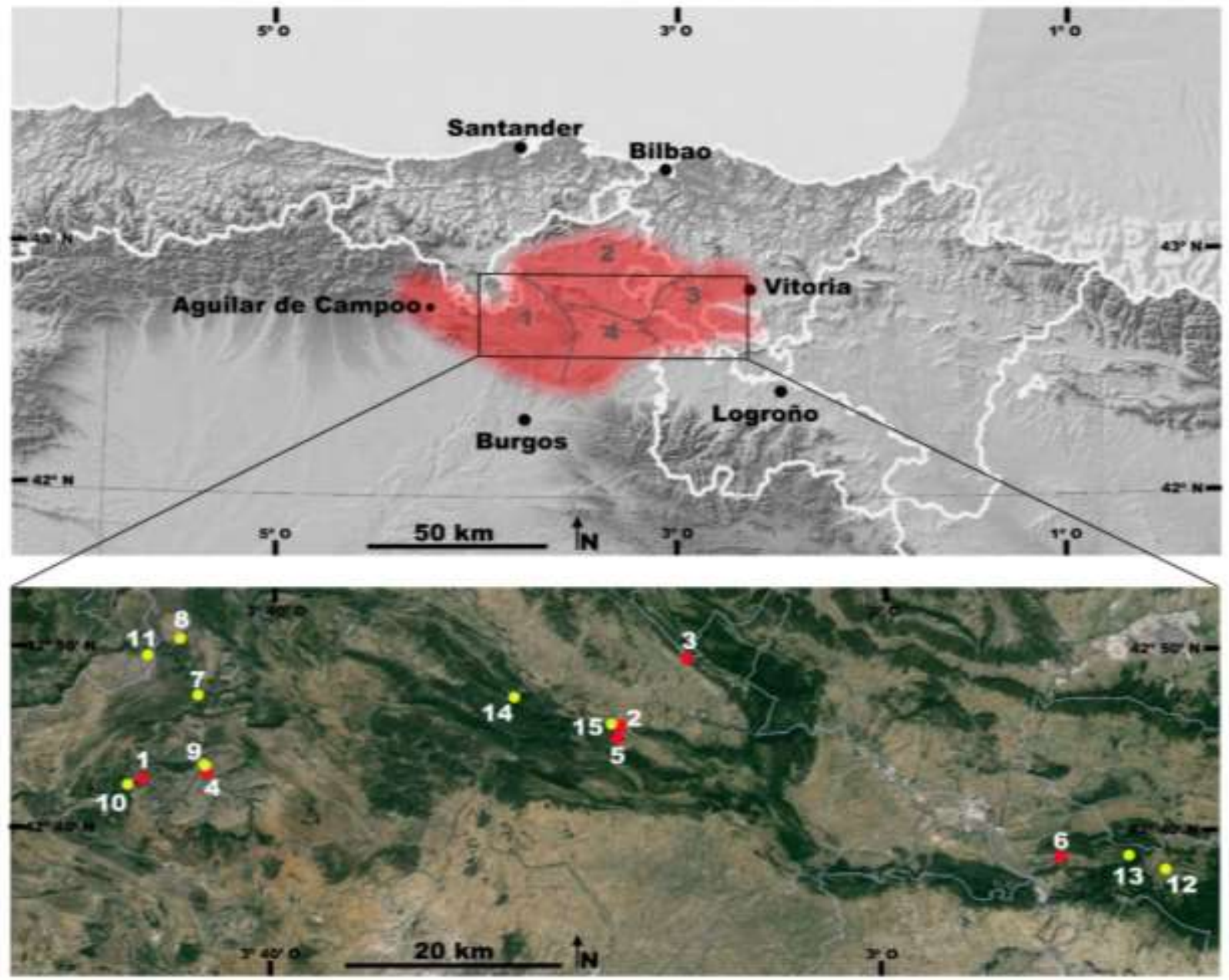

Figura 13. Afloramientos tobáceos del Alto Ebro. Parte superior: Ubicación del sector Castellano Cantábrico sombreado en rojo-y de los cuatro distritos fitogeográficos que lo forman, (1) Parameño Burgalés, (2) LosanoVillarcayense, (3) Mirandano-Treviñés y (4) Burebano. Parte inferior: Yacimientos explorados para determinar su interés paleobotánico: (1) complejo tobáceo de Tubilla del Agua, (2) formación de Frías, (3) complejo tobáceo del desfiladero del río Purón, (4) Barreras de Sedano, (5) complejo tobáceo del desfiladero del río Molinar, (6) barrera de Ocio, (7) depósitos de Valdelateja, (8) depósitos de Orbaneja, (9) La Tobona —Sedano-, (10) depósitos de Valurcia - Tubilla del Agua -, (11) El Tobazo —Villaescusa de Ebro -, (12) depósitos de Berganzo. (13) depósitos de Peñaderrada, (14) cuevas de los portugueses -Tartalés de Cilla-, (15) mesa de Frías 
Capítulo 4. Resultados

\begin{tabular}{|c|c|c|c|c|c|c|c|}
\hline$\#$ & Yacimiento & Localidad & Comarca & Provincia & Coordenadas & Altitud msnm & Interés paleobotánico \\
\hline 1 & $\begin{array}{l}\text { Complejo tobáceo de } \\
\text { Tubilla del Agua }\end{array}$ & Tubilla del Agua & Valle del Rudrón & Burgos & $\begin{array}{l}42^{\circ} 42^{\prime} 35^{\prime \prime} \mathrm{N} \\
3^{\circ} 48^{\prime} 18^{\prime \prime} \mathrm{W}\end{array}$ & $710-810$ & Muy alto \\
\hline 2 & Formación de Frías & Frías & Valle de Tobalina & Burgos & $\begin{array}{l}42^{\circ} 45^{\prime} 45^{\prime \prime} \mathrm{N} \\
3^{\circ} 17^{\prime} 39^{\prime \prime} \mathrm{W}\end{array}$ & $560-600$ & Muy alto \\
\hline 3 & $\begin{array}{l}\text { Complejo tobáceo del } \\
\text { desfiladero del río Purón }\end{array}$ & Herrán & Valle de Tobalina & Burgos & $\begin{array}{l}42^{\circ} 50^{\prime} 2^{\prime \prime} \mathrm{N} \\
3^{\circ} 13^{\prime} 47^{\prime \prime} \mathrm{W}\end{array}$ & $580-730$ & Alto \\
\hline 4 & $\begin{array}{l}\text { Barreras tobáceas de } \\
\text { Sedano }\end{array}$ & Sedano & Valle del Rudrón & Burgos & $\begin{array}{l}42^{\circ} 42^{\prime} 38^{\prime \prime} \mathrm{N} \\
3^{\circ} 44^{\prime} 15^{\prime \prime} \mathrm{W}\end{array}$ & $770-800$ & Alto \\
\hline 5 & $\begin{array}{c}\text { Complejo tobáceo del } \\
\text { Desfiladero del río Molinar }\end{array}$ & Tobera & Valle de Tobalina & Burgos & $\begin{array}{l}42^{\circ} 44^{\prime} 52^{\prime \prime} \mathrm{N} \\
3^{\circ} 18^{\prime} 26^{\prime \prime} \mathrm{W}\end{array}$ & $580-620$ & Medio \\
\hline 6 & Barrera de Ocio & Ocio & Valle del Inglares & Álava & $\begin{array}{l}42^{\circ} 39^{\prime} 7^{\prime \prime} \mathrm{N} \\
2^{\circ} 46^{\prime} 38^{\prime \prime} \mathrm{W}\end{array}$ & $540-710$ & Medio \\
\hline 7 & Depósitos de Valdelateja & Valdelateja & Valle del Rudrón & Burgos & $\begin{array}{l}42^{\circ} 46^{\prime} 43^{\prime \prime} \mathrm{N} \\
3^{\circ} 45^{\prime} 57^{\prime \prime} \mathrm{W}\end{array}$ & $670-675$ & Bajo \\
\hline 8 & Depósitos de Orbaneja & Orbaneja & Cañones del Ebro & Burgos & $\begin{array}{l}42^{\circ} 50^{\prime} 00^{\prime \prime} \mathrm{N} \\
3^{\circ} 47^{\prime} 33^{\prime \prime} \mathrm{W}\end{array}$ & $685-720$ & Bajo \\
\hline 9 & La Tobona & Sedano & Valle del Rudrón & Burgos & $\begin{array}{l}42^{\circ} 43^{\prime} 13^{\prime \prime} \mathrm{N} \\
3^{\circ} 44^{\prime} 56^{\prime \prime} \mathrm{W}\end{array}$ & $770-780$ & Bajo \\
\hline 10 & Depósito de Valurcia & Tubilla del Agua & Valle del Rudrón & Burgos & $\begin{array}{l}42^{\circ} 42^{\prime} 30^{\prime \prime} \mathrm{N} \\
3^{\circ} 49^{\prime} 32^{\prime \prime} \mathrm{W} \\
\end{array}$ & $723-727$ & Bajo \\
\hline 11 & El Tobazo & Villaescusa de Ebro & Cañones del Ebro & Cantabria & $\begin{array}{l}42^{\circ} 49^{\prime} 18^{\prime \prime} \mathrm{N} \\
3^{\circ} 49^{\prime} 40^{\prime \prime} \mathrm{W}\end{array}$ & $740-770$ & Bajo \\
\hline 12 & Depósitos de Berganzo & Berganzo & Valle del Inglares & Álava & $\begin{array}{l}42^{\circ} 39^{\prime} 00^{\prime \prime} \mathrm{N} \\
2^{\circ} 46^{\prime} 50^{\prime \prime} \mathrm{W}\end{array}$ & $560-600$ & Muy Bajo \\
\hline 13 & Depósitos de Peñacerrada & Peñacerrada & Valle del Inglares & Álava & $\begin{array}{l}42^{\circ} 38^{\prime} 50^{\prime \prime} \mathrm{N} \\
2^{\circ} 43^{\prime} 30^{\prime \prime} \mathrm{W}\end{array}$ & $700-720$ & Muy Bajo \\
\hline 14 & Cuevas de los portugueses & Tartalés de Cilla & $\begin{array}{l}\text { Desfiladero de la } \\
\text { Horadada }\end{array}$ & Burgos & $\begin{array}{l}42^{\circ} 47^{\prime} 58^{\prime \prime} \mathrm{N} \\
3^{\circ} 24^{\prime} 46^{\prime \prime} \mathrm{W} \\
\end{array}$ & $550-590$ & Muy Bajo \\
\hline 15 & Mesa de Frías & Frías & Valle de Tobalina & Burgos & $\begin{array}{l}42^{\circ} 45^{\prime} 56^{\prime \prime} \mathrm{N} \\
3^{\circ} 18^{\prime} 30^{\prime \prime} \mathrm{W}\end{array}$ & $665-690$ & Muy Bajo \\
\hline
\end{tabular}

Tabla 7. Ubicación de los afloramientos tobáceos del Alto Ebro explorados y resultado de la evaluación de su interés paleobotánico. Los seis primeros, sombreados en gris, fueron los seleccionados para ser prospectados en busca de restos vegetales fósiles. 


\subsection{Resultados del análisis geomorfológico de los yacimientos de Tubilla, Sedano y Frías}

En este apartado se aborda el análisis geomorfológico de los yacimientos de Tubilla del Agua, Sedano y Frías. Como ya ha sido comentado, estos son los únicos depósitos de los que no se había publicado información relevante sobre su antigüedad, estructura y composición cuando se diseñó el plan de investigación. A continuación se describen las tres formaciones citadas desde un punto de vista morfoestructural y se identifican las unidades litológicas que las componen.

\subsubsection{Complejo tobáceo de Tubilla del Agua}

Este complejo aparece en la actualidad como un conjunto de afloramientos de toba de diferente tipología situados a diferentes alturas a lo largo del valle del río Hornillo, entre las cotas 710 y 810 msnm. En él se han identificado siete unidades litológicas diferentes (Fig. 14), las cuales se describen a continuación:

\section{TUAG-PS}

Esta formación aparece como un espigón tobáceo flanqueando el valle en su vertiente izquierda. Tiene unas dimensiones de $250 \mathrm{~m}$ de longitud, por $130 \mathrm{~m}$ de anchura y 25 $\mathrm{m}$ de espesor. Sus flancos son verticales, excepto el occidental, que presenta unos $45^{\circ}$ de inclinación; la superficie superior es horizontal. Donde aflora la roca desnuda se observan principalmente facies de toba autóctona con abundancia de restos vegetales, desde hojas y tallos hasta troncos. También pueden aparecer, intercaladas entre las anteriores, facies de corrientes, formadas principalmente por sedimentos detríticos calcareníticos y aluviales. 


\section{TUAG-T}

TUAG-T se presenta enfrentada a TUAG-PS en la vertiente derecha del valle del Hornillo. Tiene unas dimensiones de $425 \mathrm{~m}$ de longitud, $175 \mathrm{~m}$ de anchura y $35 \mathrm{~m}$ de espesor. Su superficie superior está formada por varios niveles escalonados. La terraza de mayor superficie de todas ellas se encuentra a la misma cota que el techo de TUAG-PS -765 msnm-. En ambos edificios - TUAG-PS y TUAG-T- se observan indicios de haber sufrido una intensa karstificación, como pequeñas simas y cavidades con espeleotemas.

\section{TUAG-TP}

La unidad litológica TUAG-TP aflora en el fondo del valle, en su vertiente derecha, anexionada a TUAG-T. Constituye una pequeña terraza de $10 \mathrm{~m}$ de longitud por $4 \mathrm{~m}$ de anchura y $4 \mathrm{~m}$ de espesor. En su sección, muestra una serie de capas de toba tanto alóctona como autóctona, conteniendo esta última abundantes restos vegetales.

\section{TUAG-TBH}

TUAG-TBH se dispone en la cabecera del valle del Hornillo ocupando toda su anchura. Tiene unas dimensiones aproximadas de $320 \mathrm{~m}$ de longitud por $220 \mathrm{~m}$ de anchura y $12 \mathrm{~m}$ de espesor. Su superficie superior es plana, y termina abruptamente en un escarpe bajo el cual se encuentran las fuentes del río Hornillo. La formación ha sido incidida por un arroyo en forma de un pequeño cañón en cuyas paredes quedan expuestas facies detríticas de sedimentos carbonáticos detríticos. Sin embargo, en el escarpe comentado anteriormente abundan las facies biogénicas de musgos, tallos y otros restos vegetales. 


\section{TUAG-TMM}

Encima de la terraza anterior se encuentra la formación TUAG-TMM. Esta presenta estructura de formación en ladera, de dimensiones aproximadas de 160 por 120 m y un espesor de $4 \mathrm{~m}$, y flancos algo verticalizados. Su origen parece corresponderse con el manantial de La Fuentona, alrededor de la cual se dispone en forma de abanico. Esta surgencia es del tipo trop-plein ${ }^{1}$, funciona como rebosadero del sistema hídrico subterráneo en periodos de fuertes lluvias, cuando este no puede desaguar todo su caudal a través de las fuentes del Hornillo. El talud de esta formación está cubierto de vegetación, observándose en la poca toba desnuda existente, facies de salto de agua y biogénicas

\section{TUAG-BH}

TUAG-BH depósito se encuentra $600 \mathrm{~m}$ aguas abajo de las fuentes del Hornillo. Constituye una barrera de planta semicircular de $210 \mathrm{~m}$ de longitud, $30 \mathrm{~m}$ de anchura y $25 \mathrm{~m}$ de altura, que actualmente es disfuncional, ya que no retiene ninguna masa de agua. El río Hornillo atraviesa la formación a través de una incisión de unos $4 \mathrm{~m}$ de profundidad. El talud interior de la represa presenta en algunos puntos un perfil vertical extraplomado que recuerda a superficies estromatolíticas. Aguas arriba de TUAG-BH, hasta la base de TUAG-TBH, se extiende el vaso colmatado de sedimentos de la barrera; la perforación reciente de un pozo en este sector reveló la existencia de varios metros de sedimentos detríticos calcareníticos.

\section{TUAG-VBH}

TUAG-VBH cubre el fondo del valle y se extiende desde la base de la formación anterior hasta el río Rudrón. Esta unidad litológica, en su parte alta se presenta como

\footnotetext{
${ }^{1}$ Este tipo de surgencias son manantiales que funcionan como rebosaderos de acuíferos kársticos cuando se dan unas condiciones metereológicas determinadas, por ejemplo después de un periodo de fuertes lluvias (Rodriguez Estrella, et al., 2002)
} 
Capítulo 4. Resultados

un relleno calcarenítico estratificado en el cual se alternan capas de depósitos aluviales de distinta naturaleza -limos, arcillas, materia orgánica, etc.- y toba consolidada con facies de barrera. En su parte baja, esta estructura se ensancha hasta adoptar una tipología en abanico más propia de una formación colgada en ladera. Esta parte baja de TUAG-VBH parece estar formada por varios niveles escalonados. Donde la toba es visible, abundan las facies laminadas estromatolíticas, las cuales pueden llegar a tener más de dos metros de espesor.
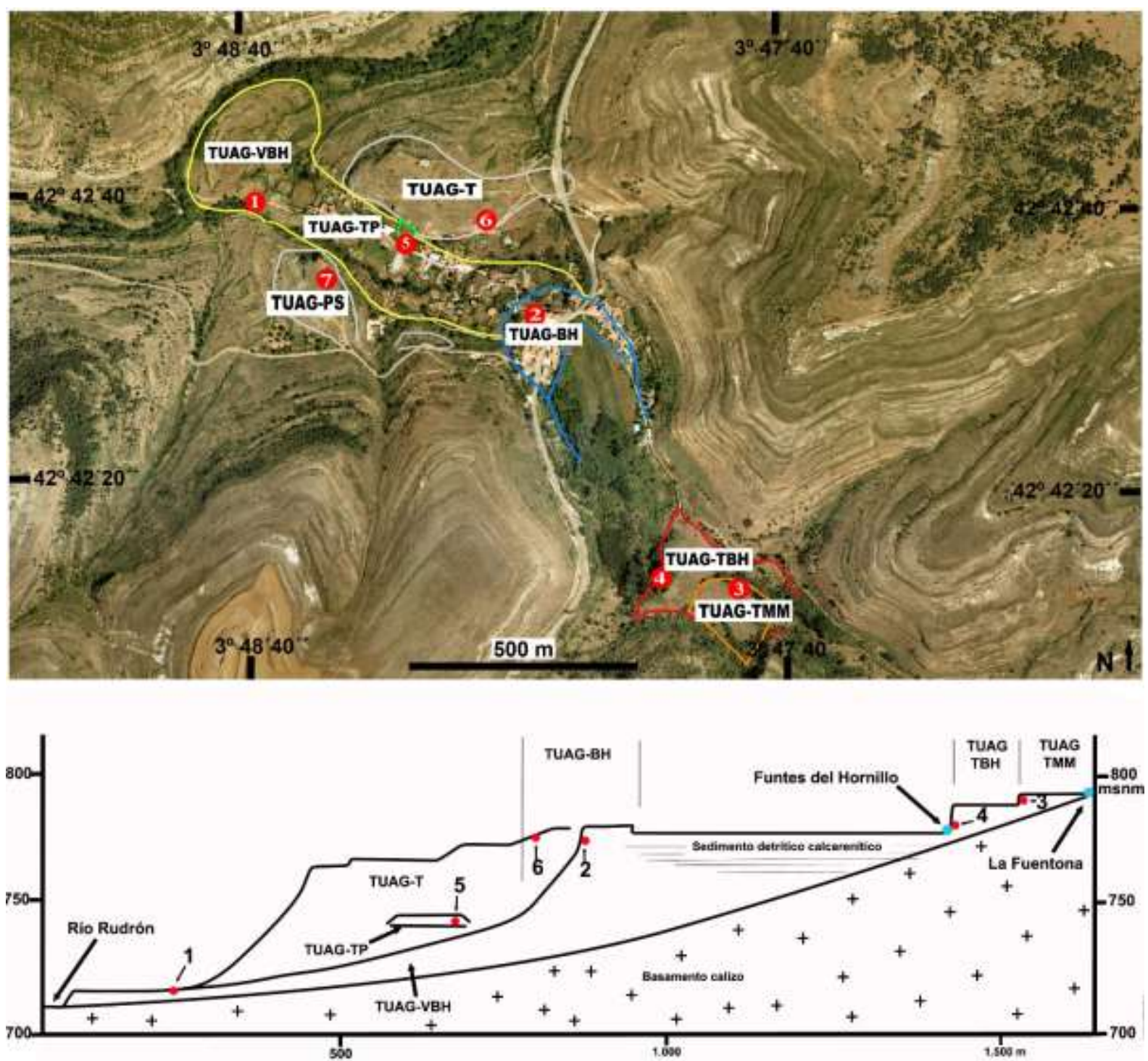

Figura 14. Complejo tobáceo de Tubilla del Agua. Parte superior: Imagen cenital del yacimiento donde se indican las estructuras identificadas y los lugares donde fueron tomadas las muestras TUAG-UT-1 a TUAG-UT-10 (Tabla 6). Parte inferior: Perfil geológico de complejo tobáceo. Los puntos en rojo indican los lugares de muestreo. La escala vertical esta exagerada cuatro veces con respecto a la horizontal. 


\subsubsection{Barreras tobáceas de Sedano}

En Sedano se encuentran una serie de depósitos de distinta naturaleza y morfología, constituidos por una formación en ladera — La Tobona-, depósitos calcareníticos de naturaleza alóctona que se disponen en el fondo del valle del río Sedanillo a lo largo de $2 \mathrm{~km}$, y dos formaciones de barrera, las cuales se localiza en la cabecera del depósito anterior (Fig. 15). En este trabajo solo se aborda el estudio paleontológico de las dos barreras superiores —SD-BI y SD-BS—, por constituir formaciones autóctonas de tipo fitohermo y presentar paredes desnudas adecuadas para la búsqueda de macrorrestos.

\section{SD-BI}

Esta formación de barrera se dispone perpendicular al curso del río y posee unas dimensiones aproximadas de $150 \mathrm{~m}$ de longitud, $50 \mathrm{~m}$ de anchura en su base y un espesor de 15 m (Fig. 15). Ha sido incidida por el curso del río Sedanillo, que en este punto forma una cascada donde se aprecian procesos activos de precipitación carbonatada. Esta brecha en la formación deja a la vista su sección transversal, la cual se asemeja al de una presa de gravedad, con una anchura en la base mayor que en su coronación, y un paramento aguas abajo de unos $30^{\circ}$ de pendiente; sobre esta vertiente se asientan algunas casas del barrio de Lagos. En la pared de toba que deja expuesta la incisión se aprecian facies biogénicas, de cascada, pequeños estromatolitos y lugares en donde se acumulan detritos y fitoclastos.

\section{SD-BS}

La barrera superior se sitúa 350 m aguas arriba de la formación anterior. Presenta unas dimensiones de $200 \mathrm{~m}$ de longitud, $60 \mathrm{~m}$ de anchura y $10 \mathrm{~m}$ de altura (Fig. 15). Desde la barrera SD-BI hasta la base de SD-BS se dispone el vaso, parcialmente colmatado de sedimentos, del espacio lagunar o palustre que formaba el cierre del curso fluvial por la barrera inferior. Por el contrario, la cubeta de la barrera superior - 
SD-BS—, a diferencia del caso anterior, se presenta vacía de sedimentos. Esta formación ha sido igualmente incidida por el río Sedanillo, que ha dejado expuesto un perfil transversal de paramentos casi verticales y superficie superior horizontal.
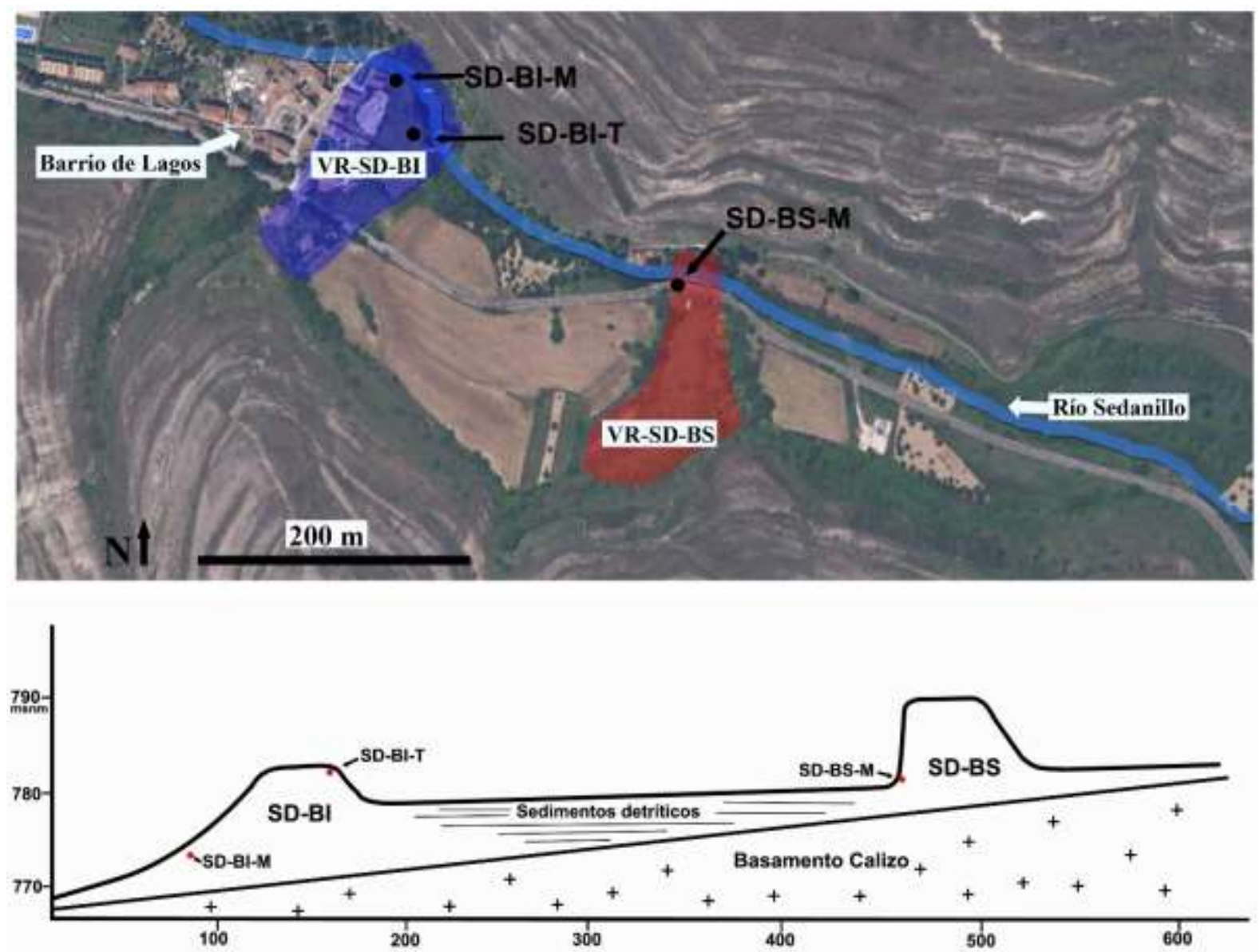

Figura 15. Barreras tobáceas de Sedano. Parte superior: Imagen cenital del yacimiento donde se muestra la ubicación de las dos formaciones estudidas - SD-BI y SD-BS-y los lugares donde fueron recogidas las muestras para su datación (Tabla 6). Parte inferior: Perfil geológico del yacimiento. La escala horizontal está exagerada 2 veces con respecto a la horizonatal.

\subsubsection{Formación de Frías}

La formación tobácea sobre la que se asienta el pueblo de Frías se presenta como una unidad litológica sin partes significativas diferenciables. Posee un perfil en planta de media luna y unas dimensiones de $270 \mathrm{~m}$ de longitud, $75 \mathrm{~m}$ de anchura y $40 \mathrm{~m}$ de altura. Se asienta sobre un basamento de sedimentos fluviales que constituyen una pequeña elevación con respecto al fondo del valle de Tobalina (Fig. 10). Los taludes de este basamento 
presentan una pendiente aproximada de $40^{\circ}$, mientras que el farallón tobáceo posee un perfil transversal de flancos verticales de 20-25 m de altura. Su superficie superior es horizontal, excepto en la parte sur, bajo la torre del castillo, donde emerge una elevación de unos $10 \mathrm{~m}$. En este mismo sector sur, pero entre el basamento calizo y la toba, aflora una acumulación de unos tres metros de espesor que se inicia con un nivel de 1,5 m de cantos homométricos, sobre el que reposa una acumulación tobácea muy diagenetizada y un nuevo nivel detrítico de cantos sub-redondeados y estructura caótica cubierto por una formación de bloques. En la actualidad, este edificio tobáceo se presenta muy karstificado.

\subsection{Resultados geocronológicos}

En este apartado se recogen los resultados de la datación del conjunto de 20 muestras recogidas de los yacimientos de Tubilla del Agua, Sedano y Frías (Tabla 6). El análisis de las cuatro muestras de Tubilla del Agua, datadas mediante carbono-14, dio resultados positivos, los cuales se muestran en la Tabla 8. La edad de la muestra TUAG-TRESP-1 está fuera del rango de calibración, por lo que en esta Memoria se indica su edad convencional, sin calibrar.

\begin{tabular}{|c|c|c|c|c|c|}
\hline Muestra & $\begin{array}{l}\text { Referencia } \\
\text { Laboratorio }\end{array}$ & Material & $\begin{array}{c}{ }^{13} \mathrm{C} /{ }^{12} \mathrm{C} \\
(\% \text { ) }\end{array}$ & $\begin{array}{c}\text { Edad convencional } \\
\text { años BP }\end{array}$ & $\begin{array}{l}\text { Edad calibrada.(cal BP) } \\
2 \sigma .95 \% \text { probabilidad }\end{array}$ \\
\hline TUAG-BU-01 & Beta-260006 & Carbonato Cálcico & $-9,6 \%$ & $2.650 \pm 40$ & $\begin{array}{l}2.840-2.820 \\
2.800-2.740\end{array}$ \\
\hline TUAG-P & Beta-277713 & Madera & $-21,0 \%$ & $1.570 \pm 40$ & $1.370-1.540$ \\
\hline TUAG-TRESP-1 & Beta-277714 & Carbón & $-23,2 \%$ & $37.870 \pm 370$ & $\begin{array}{l}\text { El resultado está fuera del rango } \\
\text { de calibración }\end{array}$ \\
\hline TUAG-MR-P & CNA1460 & Madera & $-32,47 \%$ & $2.170 \pm 30$ & $\begin{array}{l}2.311-2.321 \\
2.214-2.105 \\
2.085-2.065\end{array}$ \\
\hline
\end{tabular}

Tabla 8. Resultados de la datación mediante carbono-14 de las muestras del yacimiento de Tubilla del Agua. 
Las tres muestras tomadas de las barreras de Sedano, dos de carbonato cálcico y un carbón, también dieron resultados positivos. Estos se recogen en la Tabla 9.

\begin{tabular}{|c|c|c|c|c|c|}
\hline Muestra & $\begin{array}{c}\text { Referencia } \\
\text { Laboratorio }\end{array}$ & Material & $\begin{array}{c}{ }^{13} \mathrm{C} /{ }^{12} \mathrm{C} \\
(\% \mathrm{o})\end{array}$ & $\begin{array}{c}\text { Edad } \\
\text { convencional } \\
\text { años BP } \\
\end{array}$ & $\begin{array}{l}\text { Edad calibrada. cal BP } \\
2 \sigma .95 \% \text { probabilidad }\end{array}$ \\
\hline SD-BI-M & Beta-318668 & Carbón & $-26,0 \mathrm{o} / \mathrm{oo}$ & $5.410 \pm 30$ & $6.290-6.180$ \\
\hline SD-BI-T & Beta-318669 & Carbonato cálcico & $-8,3 \mathrm{o} / \mathrm{oo}$ & $4.090 \pm 30$ & $\begin{array}{c}4.810-4.760 \\
4.700-4.670 \\
4.650-4.520 \\
4.460-4.450\end{array}$ \\
\hline SD-BS-M & Beta- 318670 & Carbonato cálcico & $-7,4 \mathrm{o} / \mathrm{oo}$ & $5.200 \pm 30$ & $5.990-5.910$ \\
\hline
\end{tabular}

Tabla 9. Resultados de la datación mediante carbono-14 de las muestras del yacimiento de Sedano.

De las nueve muestras de toba que fueron enviadas para su datación mediante la técnica de uranio-torio, tan solo siete fueron analizadas. Las sigladas como A-1 y B-1, recogidas respectivamente de las estructuras TUAG-T y TUAG-PS, fueron descartadas por el laboratorio por presentar signos de recalcificación. La muestra TUAG-UT-7 se encontraba en equilibrio isotópico, por lo que su antigüedad se encuentra fuera del rango de esta técnica, —300-350 ka (Pentecost, 2005)—. Los resultados de estos análisis se recogen en la Tabla 10.

\begin{tabular}{ccccccccc}
\hline Muestra & Ref. lab. & Estructura & $\begin{array}{c}\text { U-238 } \\
\text { ppm }\end{array}$ & $\begin{array}{c}\text { Th-232 } \\
\mathbf{p p m}\end{array}$ & U-234/U-238 & Th-230/Th-232 & Th-230/U-234 & $\begin{array}{c}\text { Edad Nominal } \\
\text { ( años BP) }\end{array}$ \\
\hline TUAG-UT-1 & 910 & TUAG-VBH & 0,09 & 0,01 & $1,27 \pm 0,06$ & $2,298 \pm 0,322$ & $0,09 \pm 0,01$ & $10.241+929 /-922$ \\
\hline TUAG-UT-2 & 1010 & TUAG-BH & 0,12 & 1,72 & $1,27 \pm 0,05$ & $1,723 \pm 0,169$ & $0,11 \pm 0,01$ & $12.331+910 /-903$ \\
\hline TUAG-UT-3 & 310 & TUAG-TMM & 0,08 & 0,05 & $1,42 \pm 0,07$ & $1,328 \pm 0,114$ & $0,18 \pm 0,01$ & $20.891+1.607 /-1.586$ \\
\hline TUAG-UT-4 & 210 & TUAG-TBH & 0,12 & 0,22 & $1,22 \pm 0,04$ & $0,917 \pm 0,044$ & $0,43 \pm 0,02$ & $59.270+3.863 /-3.738$ \\
\hline TUAG-UT-5 & 110 & TUAG-TP & 0,14 & 0,02 & $1,30 \pm 0,05$ & $20,246 \pm 1,976$ & $0,60 \pm 0,03$ & $95.970+6.673 /-6.318$ \\
\hline TUAG-UT-6 & 410 & TUAG-T & 0,12 & 0,2 & $1,18 \pm 0,04$ & $2,058 \pm 0,108$ & $0,93 \pm 0,04$ & $245.261+47.470 /-33.755$ \\
\hline TUAG-UT-7 & 510 & TUAG-PS & 0,16 & 0,29 & $1,17 \pm 0,05$ & $2,557 \pm 0,083$ & $1,25 \pm 0,05$ & $>300.000$ \\
\hline
\end{tabular}

Tabla 10. Resultados de la datación mediante la técnica del uranio-torio de las muestras tomadas en el yacimiento de Tubilla del Agua. 
Como ha sido comentado en el apartado 3.3.2 del capítulo de Material y métodos, las dataciones por uranio-torio se suelen considerar analíticamente fiables cuando la relación ${ }^{230} \mathrm{Th} /{ }^{232} \mathrm{Th}$ es superior a 10 (Livnat \& Kronfeld, 1985). De las muestras analizadas para esta Tesis Doctoral, tan solo TUAG-UT-5 presenta una relación isotópica mayor de 10 -20,24-, mientras que las restantes tienen valores menores de 3 (Tabla 10). A pesar de que una relación de ${ }^{230} \mathrm{Th} /{ }^{232} \mathrm{Th}$ menor de 10 pone en duda la precisión del análisis, los resultados no tienen por qué ser descartados. Valores de ${ }^{230} \mathrm{Th} /{ }^{232} \mathrm{Th}$ bajos nos alertan de la presencia de material exterior al sistema, pero no de en qué medida la muestra está contaminada y, por lo tanto, del error existente en los resultados (Juliá, 2014). En este caso, para valorar la fiabilidad de los resultados, estos se deben valorar en combinación con otros indicios, como por ejemplo, otras dataciones disponibles o la lógica evolutiva del complejo, la cual tiene que ser coherente con la antigüedad de los depósitos.

Con respecto a las muestras tomadas de la formación de Frías, tres de las cinco enviadas para su datación fueron a su vez divididas en el laboratorio, hasta hacer un total de 12 (Tabla 11). De ellas, las provenientes de los sedimentos F-I-1, F-I-2, F-I-3 y F-I-5 presentaron una cantidad significativa de L-serina, lo cual es indicativo de contaminación por aminoácidos recientes (Kaufman \& Manley, 1998; Hearty, et al., 2004), por lo que fueron descartadas. La única considerada válida -F-I-4-, contenía caparazones de Herpetocypris reptans, sobre los que se midió la relación de racemización para el ácido aspártico y glutámico. La antigüedad de la muestra se ha determinado calibrando los valores $\mathrm{D} / \mathrm{L}$ de los ácidos aspártico y glutámico con los algoritmos de cálculo de edad establecido para ostrácodos de la zona central y meridional de la Península lbérica de Ortiz et al. (2004). 
Capítulo 4. Resultados

\begin{tabular}{ccccccc}
\hline Muestra & Referencia Laboratorio & Especie & Análisis & D/L Asp & D/L Glu & Edad (ka) \\
\hline F-I-1 & LEB-12230 a 12231 & Potamocypris spp. Brady & 2 & - & - & Contaminada \\
\hline F-I-2 & LEB-12232 & Potamocypris spp. & 1 & - & - & Contaminada \\
\hline F-I-3 & LEB-12233 a 12236 & $\begin{array}{c}\text { Candona neglecta Sars } \\
\text { Potamocypris spp. }\end{array}$ & 4 & - & - & Contaminada \\
\hline F-I-4 & LEB-12225 a 11228 & H. reptans & 2 & $0,465 \pm 0,024$ & $0,275 \pm 0,050$ & $277 \pm 61$ \\
\hline F-I-5 & LEB-12229 & Potamocypris spp. & 1 & - & - & Contaminada \\
\hline
\end{tabular}

Tabla 11. Relaciones de racemización medias para los ácidos aspártico y glutámico y edad de las muestras del yacimiento de Frías.

\subsection{Resultados paleobotánicos. Sistemática}

Como resultado de la prospección de los afloramientos tobáceos, fueron recogidos un total de 1.820 impresiones vegetales del conjunto de los seis yacimientos estudiados. El análisis morfológico de estos fósiles y su comparación con plantas actuales, ejemplares de herbario y bibliografía de referencia ha permitido identificar 28 taxones, los cuales pertenecen a cuatro subclases del Reino Plantae —sensu Chase \& Reveal (2009)—: Bryidae Engl., Polypodiidae Cronquist, Pinidae Cronquist, Takht. \& W. Zimm y Magnoliidae Novák ex Takht.

Por localidades, la más prolífica ha sido Tubilla del Agua, con 723 ejemplares, seguido de Sedano —478_, el desfiladero del río Purón —336—, el desfiladero del río Molinar — 162-, la formación de Frías -116 - y la barrera de Ocio -5- (Tabla 12). Considerando las localidades agrupadas por comarcas, el Valle del Rudrón aporta el $66 \%$ de los fósiles 1.201 ejemplares - frente al 33,72\% del Valle de Tobalina -614 ejemplares-y los 5 ejemplares del Valle del río Inglares. Además de las impresiones en toba, también fueron hallados en el yacimiento de Tubilla 42 restos vegetales subfósiles. Estos consisten en un estróbilo femenino casi completo, 17 ejes de estróbilo femenino, 22 brácteas sueltas y un conjunto de carbones vegetales (Lám. 2). A continuación, se describen estos 28 taxones conforme a los caracteres diagnósticos indicados en el apartado 3.4. del capítulo de Metodología. 


\subsubsection{Subclase Bryidae Engler, 1892}

La subclase Bryidae sensu Chase \& Reveal (2009) se corresponde con la clase Bryopsida de algunas clasificaciones anteriores, p.e. Engler, (1903). Sus integrantes se caracterizan por presentar en sus esporofitos cápsulas artrodontas, —con dientes separados y articulados- (Buck \& Goffinet, 2000). El orden Hypnales, al cual pertenece la única especie identificada de esta subclase, incluye los musgos ramificados de forma pinnada. Se trata del orden de briofitos más diverso, con más de 40 familias y 4.000 especies (Goffinet, et al., 2008).

\section{Orden HYPNALES (M. Fleisch.) W. R. Buck \& Vitt, 1986 \\ Familia FONTINALACEAE W. P. Schimper, 1856 \\ Género Fontinalis J. Hedwig, 1801}

Fontinalis antipyretica J. Hedwig, 1801

(Lám. 1, Figs. 1-2)

\section{Material estudiado}

Se han recogido seis ejemplares (Anexo IV), dos en cada una de las estructuras TUAG-TBH y TUAG-PS del yacimiento de Tubilla del Agua, y otros dos en SD-BS del yacimiento de Sedano (Tabla 12).

\section{Descripción}

Fragmentos de caulidios de hasta $8 \mathrm{~cm}$ de longitud y 6-8 $\mathrm{mm}$ de diámetro. Filidios de $3 \mathrm{~mm}$ de longitud, con forma elíptica o lanceolada, ápice agudo y sección aquillada. Se insertan a lo largo del caulidio en tres o cuatro filas, de forma erecto-patente, con un ángulo de divergencia variable de entre 40 y $60^{\circ}$, separados unos de otros entre sí alrededor de 1 mm. Los ejemplares estudiados aparecieron fosilizados en posición de vida dentro de oquedades del sustrato calcáreo en conjuntos de entre 8 y 20 caulidios, dispuestos verticalmente o ligeramente curvados. 


\section{Observaciones}

F. antipyretica crece sumergida en cursos de aguas tanto rápidas como lentas, así como en estanques, canales y lagunas (Peñuelas \& Comelles, 1984). Tolera un amplio rango de tipos de agua, pero es sustituida por $F$. squamosa Hedw. en las más ácidas o pobres en nutrientes (Atherton, et al., 2010). A veces, esta especie se observa creciendo suspendida en voladizos tobáceos de saltos de agua permanente, lo que concuerda con la disposición vertical de los ejemplares descritos.

Actualmente, F. antipyretica se distribuye por casi todo el Hemisferio Norte, incluyendo Norte América, Europa, Asia y el Norte de África (FNAEC, 2014). En el Hemisferio Sur se encuentra en Sudáfrica, en donde fue introducida por el hombre (Richards, 1946). Esta especie ha sido citada en el Último Máximo Glacial a partir de restos hallados en depósitos turbosos y en los yacimientos de Hawk Tor — condado de Cornwal, Inglaterra - (Conolly, et al., 1950), Kirkmichael —Isla de Man— (Dickson, et al., 1970) y el condado de Dunshaughlin, -Irlanda- (Mitchel, 1940).

\subsubsection{Subclase Polypodiidae Cronquist, Takhtajan \& W. Zimmermam, 1966}

Incluye a los helechos leptosporangiados, que poseen un esporangio con espesor de pared de una única célula, denominado leptosporangio. Dentro de Polypodiidae, el orden Polypodiales, al que pertenece el ejemplar estudiado, se distingue por poseer en el esporangio una estructura especializada en la dehiscencia llamada estomio. Con cerca de 10.000 especies, este orden engloba el $80 \%$ de las especies de helechos actuales (Cracraft \& Donoghue, 2004). 


\section{Orden POLYPODIALES Link, 1833}

Familia ASPLENIACEAE Newman, 1840

Género Asplenium Linné, 1753

Asplenium scolopendrium Linné, 1753

(Lám. 1, Fig. 3)

\section{Material estudiado}

Se describe un único ejemplar —FF-21- encontrado en la formación de Frías. La impresión del fronde apareció completa, pero dadas sus dimensiones y la consistencia de la toba que lo contenía, que era bastante deleznable, se decidió no extraerlo para evitar que se fragmentara. Por lo tanto, fue medido y fotografiado in situ.

\section{Descripción}

Impresión del haz de un fronde con forma linear-lanceolada, de 19,5 cm de longitud por 4,6 cm de anchura con ápice agudo, base lobulada y pecíolo de $2,4 \mathrm{~cm}$ de longitud. Presenta la lámina pinnada y, en su base, algo aquillada hacia el haz. Raquis de 0,8 mm de anchura en su parte basal que se atenúa y deprime hacia el ápice. Posee numerosos nervios de segundo orden, paralelos, de curso recto, que se unen al raquis con un ángulo de divergencia de $50^{\circ}$, y terminan en el margen, que es entero y ondulado.

\section{Observaciones}

Asplenium scolopendrium es un helecho que en su fase esporofítica presenta un conjunto de frondes que emergen en roseta de un rizoma. Se trata de una planta calcícola que requiere cierta humedad ambiental y suelos ricos en humus (Bremer \& Jongejans, 2010).

Se distribuye por el Hemisferio Norte —Norteamérica, Macaronesia, Europa, el Norte de África, el Cáucaso y el este de Asia- aunque sus poblaciones más numerosas se encuentran en Europa, en la región Eurosiberiana. En la zona de estudio es una especie 
común (Loidi Arregui \& Fernández Prieto, 1986; Barredo \& Barredo, 2002; Alejandre, et al., 2006; Loidi, et al., 2011; Uribe-Echebarría, 2012), aunque está restringida a zonas sombrías. En este ámbito geográfico tiene predilección por paredes y roquedos que se encuentran en las orillas de corrientes de aguas turbulentas, en donde siempre existe una elevada humedad ambiental.

Un fronde de esta especie ha sido citado en el yacimiento tobáceo francés del Pleistoceno Medio de La Roquette — Valle de Tarn, Millau—, en el Macizo Central (Ambert, et al., 1992). También se ha encontrado en la flora Eemiense de Burgtonna —Alemania(Vent, 1978).

\subsubsection{Subclase Pinidae Cronquist, Takhtajan \& W. Zimmermam, 1966}

Pinidae sensu Chase \& Reveal (2009) aparece representada en el registro estudiado por dos taxones pertenecientes al orden Pinales. Este se corresponde con las gimnospermas que desarrollan conos ovulíferos compactos formado por megaesporofilas compuestas por brácteas sencillas, más o menos fusionadas, pero con el extremo libre. Las escamas ovulíferas se presentan no enteras y con uno o más óvulos. Son plantas vasculares leñosas de porte arbustivo o arbóreo, con canales resiníferos y hojas aciculares (Anderson, et al., 2007). 
Capítulo 4. Resultados
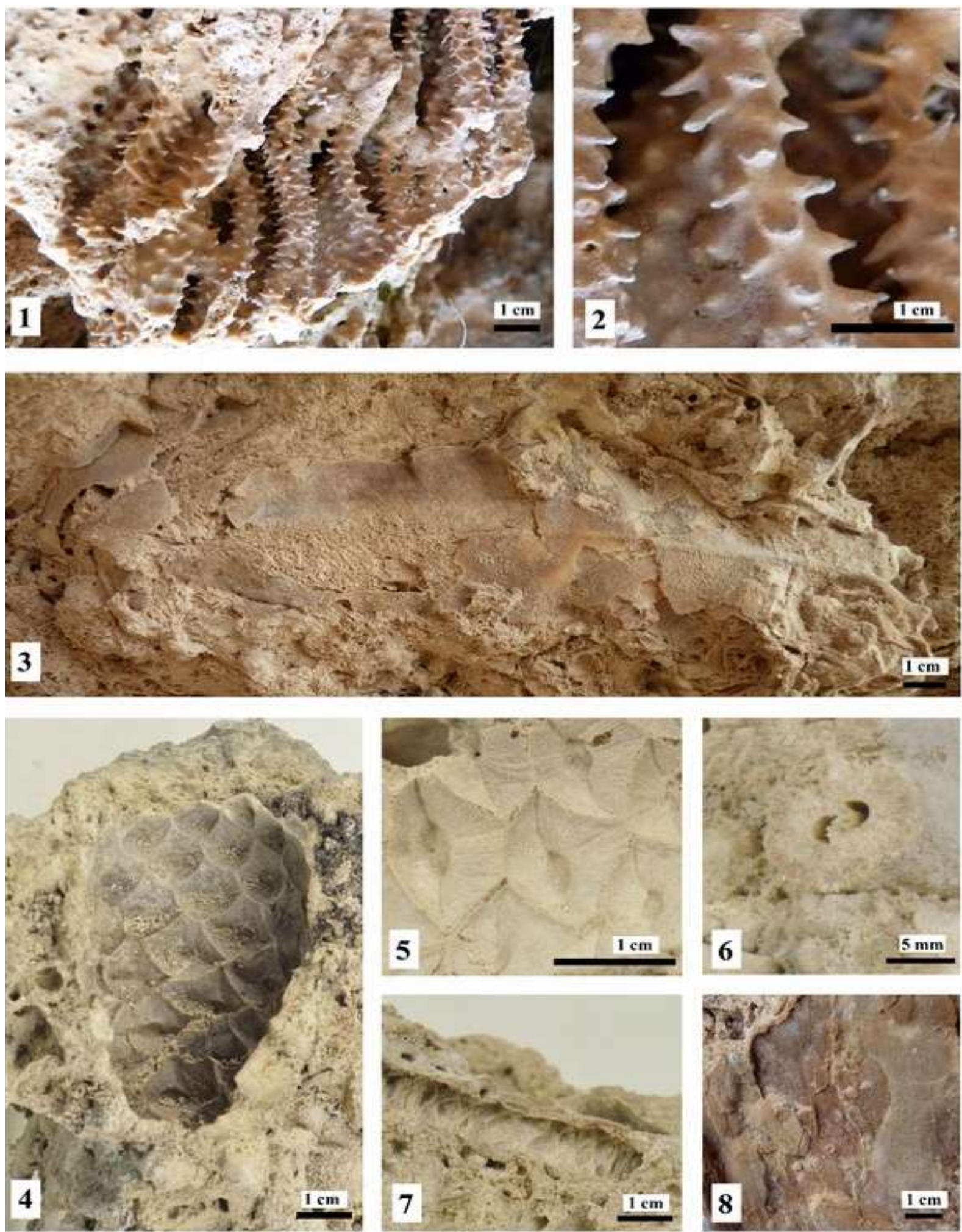

Lámina 1. Figs.1-2. Fontinalis antipyretica Hedw., TUAG-PS-125, Tubilla del Agua; Fig. 3. Asplenium scolopendrium L., haz, FF-21, Frías; Figs. 4-5. Pinus nigra J.F. Arnold, (4) Estróbilo. DRP-62, Herrán, (5) Detalle de las brácteas. DRP-61, Herrán; Figs. 6-7-8. Pinus sp. (6) Secciones de acículas. DRP-82, Herrán, (7) Rama, DRM-152, Tobera, (8) Corteza, TUAG-T-7, Tubilla del Agua. 


\section{Orden PINALES Gorozhankin, 1904 \\ Familia PINACEAE Sprengel ex Rudolphi, 1830 \\ Género Pinus Linné, 1753}

Pinus nigra J. F. Arnold, 1885

(Lám. 1, Figs. 4-5 y Lám. 2, Figs. 1, 4-5)

\section{Material estudiado}

Se han estudiado 37 impresiones de estróbilos femeninos cerrados (Anexo IV) que aparecieron en 11 de los 13 depósitos prospectados (Tabla 12). La proporción de los conos que aparece impresa varía de unos fósiles a otros, desde algunos casos en los que se aprecia la mitad hasta otros que solo conservan la impresión de varias brácteas. En las impresiones de la parte distal de los conos se podía observar el pedúnculo. Los 37 ejemplares recogidos suponen el 2,07\% de todo el registro fósil. Además de los restos anteriores, que están asociados a la génesis de las formaciones tobáceas, durante la prospección de las formaciones tobáceas fue hallado un conjunto de macrorrestos vegetales en una oquedad de la TUAG-PS, pero depositados después de la formación de los edificios tobáceos. Este conjunto incluye 16 ejes de piña 22 brácteas y una piña casi completa -TUAG-MR-P-. En la misma oquedad aparecieron restos de frutos y semillas de otras especies - Juglans regia L., Corylus avellana, Fagus sylvatica, Prunus sp., etc.- lo que indica que estos restos pudieron haber sido acumulados por algún roedor.

\section{Descripción}

Conos femeninos de 4,7-6,9 cm de longitud por $(2,2) 3,4-5,2 \mathrm{~cm}$ de anchura, subsésiles —algunos ejemplares conservan un corto pedúnculo, de menos de $1 \mathrm{~cm}$ de longitud-. Tienen forma ovoideo-cónica, son simétricos y presentan la parte proximal y distal redondeada. Las escamas muestran un borde redondeado y convexo. La apófisis son por lo general casi planas —aunque hay ejemplares con el centro hendido o pronunciado—, más anchas que largas, y están recorridas por una costilla horizontal prominente. Están rematadas 
en su zona central por un ombligo abultado de forma romboidal que está deprimido en su zona central, y del que sobresale el mucrón, el cual se presenta centrado en el ombligo.

\section{Observaciones}

Los estróbilos femeninos estudiados presentan también una gran similitud con los de las especies $P$. sylvestris y Pinus halepensis Miller. Estos últimos se diferencian claramente de los de $P$. nigra por ser de mayor tamaño -5 a $12 \mathrm{~cm}$ de longitud - y tener un pedúnculo curvado más largo — de 2 a $5 \mathrm{~cm}-$ y grueso $-1-2 \mathrm{~cm}-$. Con respecto a las piñas de $P$. sylvestris, estas se distinguen por su apófisis, que tiene una forma romboidal y es más alargada y protuberante.

$P$. nigra es una especie de carácter submediterráneo orófilo, de tendencia fríoesteparia pero que por compensaciones litológicas y geomorfológicas puede vivir bajo un mayor rango de condiciones climáticas (Regato, et al., 1991). Habita en el entorno de la Cuenca Mediterránea, donde muestra una clara preferencia por sustratos de carácter calcáreo o dolomítico (Sánchez Palomares, et al., 1990). En la Península Ibérica, se distribuye de forma natural por el Pirineo, Cordilleras Catalanas, Sistema Ibérico, Sierras Béticas y núcleos relictos en el Sistema Central y cuenca del río Cega — Lastras de Cuellar, Segovia— (Fig. 25) (Rubio Sancho, et al., 2009). No aparece en la actualidad de forma natural en el área de estudio, aunque existen numerosas repoblaciones de la subespecie austriaca $-P$. nigra var. austriaca-. Las poblaciones naturales más cercanas son las existentes en el cañón del Río Lobos, entre las provincias de Burgos y Soria (Fig. 25) (Ceballos, 1966; Catalán, et al., 1991).

Esta especie ha sido citada en el Pleistoceno -MIS 6 - en la Provenza francesa — Meyrargues-, a partir de impresiones de estróbilos coincidentes en edad con la glaciación del Riss (Magnin, et al., 1990). También se ha mencionado en Francia, en el yacimiento del Pleistoceno Medio — entre $75 \pm 10$ y $74 \pm 9$ ka- de La Roquette —Valle de Tarn, Millau- 
(Vernet, et al., 1984; Ambert, et al., 1992), aunque su identificación no es segura y los conos encontrados podrían también corresponderse con los de $P$. sylvestris. En el MIS 3, P. nigra formaba parte de la flora de los yacimientos del Vallée du Lez — Herault- (Farizier, 1980; Ambert, et al., 1995) y el depósito de Roquevaire, en el Valle de Huveaune, región de Provenza (D’Anna, et al., 1988). En Alemania, ha sido citado en el interglacial Riss-Würn en la localidad de Weimar-Ebringsdorf (Vent, 1955). También en Francia apareció en el Último Periodo Glacial en el Vallée du Gardon (Bazile-Robert, 1979), y en los depósitos holocenos de Saint Guilhem-le-Désert —l'Herault- (Lecoeuvre, et al., 2008; Ali, et al., 2008).

En la Península Ibérica, se han encontrado impresiones de piñas de $P$. nigra en Beceite —Teruel—, en depósitos tobáceos del Último Periodo Interglacial (Martínez-Tudela, et al., 1986; Badía-Gimeno \& Muñoz-Bertomeu, 1999); y restos de estróbilos con unos 35.800 años de antigüedad, en San Juan de Mozarrifar -Zaragoza- (Postigo, 2003). En el Holoceno se tiene constancia de la presencia de esta especie en la localidad soriana de Fuentetoba, a partir de unas impresiones en toba con una antigüedad 9.400-9.020 cal BP (García-Amorena, et al., 2011). También, a partir de restos de estróbilos ha sido citada en las turberas de Cevico Navero —Palencia; 5.583-5.085 cal BP_ (Roig, et al., 1997), La Lomilla —Palencia; 9.890-9.501 cal BP_ (Alcalde-Olivares, et al., 2001) y Tubilla del Lago —Burgos; 4.233-3.836 cal BP y 3.556-3.209 cal BP- (Moreno Amat, et al., 2009).

\section{Pinus sp.}

\section{(Lám. 1, Figs. 6-8 y Lám. 2, Figs. 2-3)}

\section{Material estudiado}

Se han recogido 152 restos de toba con encostramientos o impresiones de acículas, 12 moldes de ramas de pequeño diámetro y 8 impresiones de corteza. Además, han sido hallados dos restos vegetales subfósiles no coetáneos con las formaciones tobáceas en las que aparecieron. En un talud de la estructura TUAG-T fue hallado un grupo de maderas 
carbonizadas -TUAG-TRESP-1- que formaban parte de un paleosuelo, bajo una costra calcárea que los ha preservado de la erosión. Adicionalmente, apareció un eje de estróbilo -TUAG-P- en una oquedad del afloramiento TUAG-PS.

\section{Descripción}

Las acículas halladas son rectas, de $8-15 \mathrm{~cm}$ de longitud y 1,5-2,4 $\mathrm{mm}$ de anchura reunidas de dos en dos, de sección exterior e interior cóncava, con braquiblastos cilíndricos de 6-12 mm de longitud y 1,5-2 mm de anchura (Lám. 1, Fig. 6). Las impresiones de ramas pequeñas y corteza atribuidas a Pinus sp. aparecen como el molde de una estructura linear de entre 3 y $12 \mathrm{~cm}$ de longitud por 0,6-1,2 cm de diámetro (Lám. 1, Fig. 7). Su superficie está cubierta por pequeñas protuberancias de $4 \mathrm{~mm}$ de longitud, por $2 \mathrm{~mm}$ de anchura y forma elíptica que se distribuyen de acuerdo a un patrón regular y se corresponden con el lugar de inserción de los braquiblastos. También se observan los nudos de crecimiento anual, separados entre sí de 2 a $4 \mathrm{~cm}$. Las impresiones de fragmentos de corteza, de hasta 12 × 10 $\mathrm{cm}$, se presentan divididas en placas de tamaños diversos y formas irregulares, bordes redondeados $\mathrm{u}$ ondulantes y superficie plana. Algunas placas aparecen recorridas por grietas uniformemente curvadas (Lám. 1, Fig. 8). Por otro lado, las maderas carbonizadas presentan anillos anuales de crecimiento bien demarcados y canales resiníferos fisiológicos homogéneamente distribuidos en la madera tardía, visibles en el corte transversal, característicos de Pinus (Schweingruber, 1990).

\section{Observaciones}

Los restos descritos anteriormente no han podido ser adscritos a ninguna especie de pino en particular, sin embargo, muchos de ellos aparecieron cerca de impresiones de estróbilos de Pinus nigra, lo que podría indicar que pertenecieron a la misma especie. 


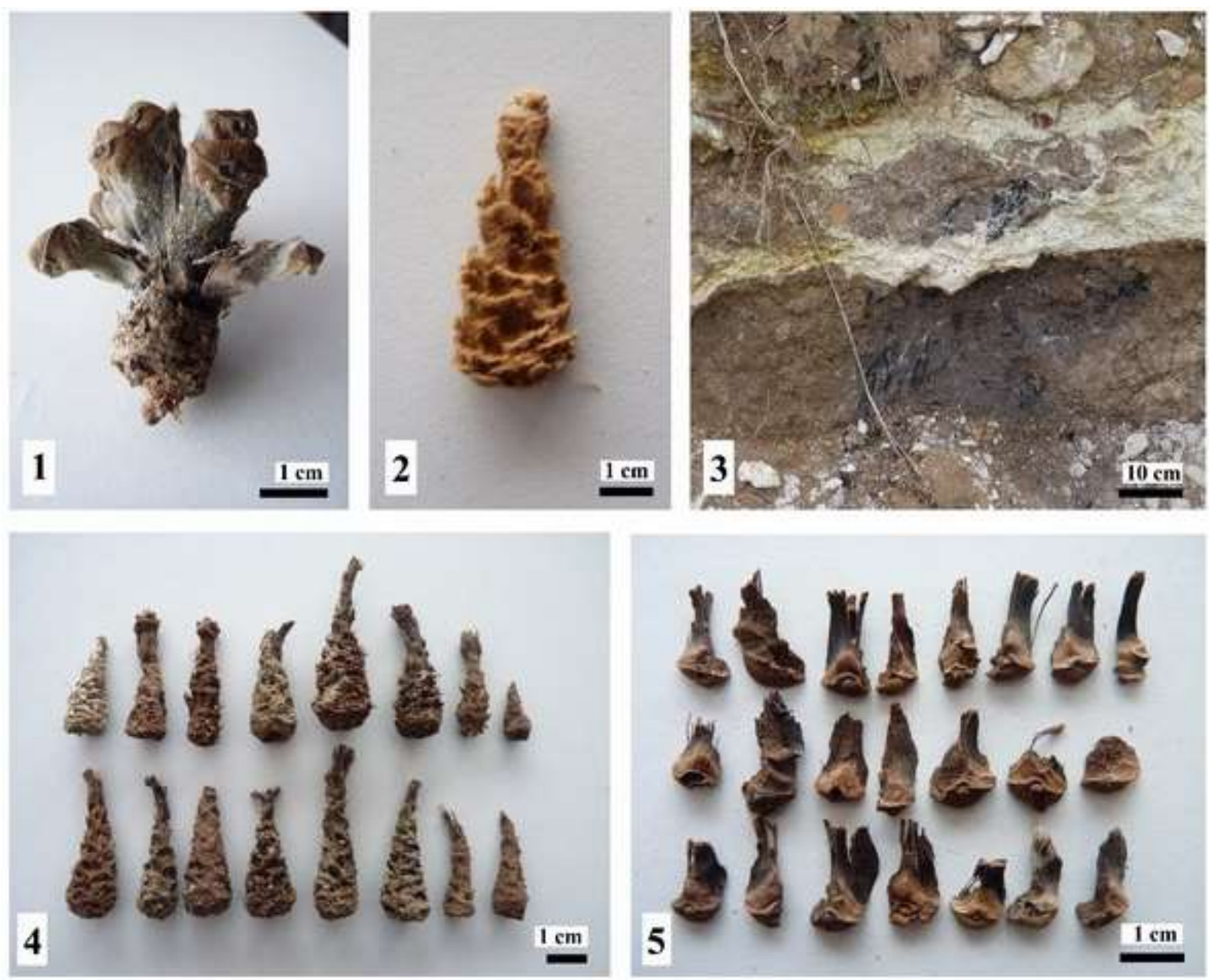

Lámina 2. Restos subfósiles encontrados en Tubilla del Agua. Figs. 1, 4-5. Pinus nigra J.F. Arnold, (1) TUAGMR-P, estróbilo femenino, (4-5) Ejes y brácteas de P. nigra hallados en una oquedad de TUAG-PS; Figs. 2-3. Pinus sp. (2) TUAG-P, Eje de estróbilo femenino, (3) TUAG-TRESP-1, madera carbonizada.

\subsubsection{Subclase Magnoliidae Novák ex Takhtajan, 1967}

La subclase Magnoliidae sensu Chase \& Reveal (2009) se corresponde con el grupo de las angiospermas, o plantas con flores. El sistema de clasificación del Angiosperm Phylogeny Group III que se ha seguido en este trabajo, se fundamenta en las relaciones filogenéticas de los diferentes taxones, inferidas a partir de datos moleculares. En función de ello, ha establecido la existencia de 59 órdenes y 413 familias (Haston, et al., 2009). Por otro lado, este sistema no categoriza los taxones por encima de orden, sino que los denomina con nombres «informales» no sujetos a las normas del Código Internacional de Nomenclatura Botánica. Con 24 taxones, Magnoliidae es la subclase mejor representada en el registro 
estudiado, en su conjunto sus restos suponen el $88,15 \%$ de todos los ejemplares recogidos. De estos, el grupo de las dicotiledóneas es el más abundante, con 20 taxones, frente a los 3 asignados a las monocotiledóneas.

\title{
Orden POALES Small, 1903
}

Poales incertae sedis 1

\author{
(Lám. 3, Fig. 1)
}

\section{Material estudiado}

Se han analizado 100 ejemplares (Anexo IV), que suponen el 5,49\% de todo el registro estudiado. Estos han sido recogidos en 11 de las 13 unidades litológicas estudiadas, faltando solo en la estructura TUAG-TMM de Tubilla del Agua y en la barrera de Ocio (Tabla 12).

\section{Descripción}

Fragmentos de limbos foliares, de entre 0,5 y $1 \mathrm{~cm}$ de anchura y hasta $20 \mathrm{~cm}$ de longitud, con forma linear, margen entero y venación paralelinervia. Los nervios paralelos se encuentran separados entre ellos con una distancia de entre 1 y $3 \mathrm{~mm}$.

\section{Observaciones}

Poales abarca un gran número de taxones capaces de desarrollarse de forma natural en una gran variedad de ecosistemas, por lo que sus especies se distribuyen por casi todo el planeta. (Wilson \& Morrison, 1998). Dado el gran número de especies pertenecientes a este orden que poseen limbos como el descrito, no resulta posible relacionar los especímenes estudiados con ninguna especie en concreto, por lo que en esta Memoria se atribuyen a este orden sin poder especificar ni la familia, ni el género, ni la especie a la que pertenecieron.

Impresiones como las descritas halladas en el depósito tobáceo del interglacial RissWürn en Beceite - Teruel—, fueron identificadas como cf. Sparganium L. por MartínezTudela, et al. (1986) y Badía-Gimeno \& Muñoz-Bertomeu (1999). Sparganium es un taxón 
propio de lugares húmedos e inundables como los ambientes en los que se forman los fitohermos. Sin embargo, otras poáceas más generalistas poseen también una nerviación similar. Por otro lado, Ollivier, et al., (2009) identificaron de forma genérica como "monocotiledóneas" unos restos similares hallados en un travertino de aguas termales en Armenia.

En la actualidad, existen un gran número de especies herbáceas de este orden presentes en la zona de estudio. También se puede constatar la abundancia de algunas familias de este género en el pasado a partir del estudio de los registros polínicos. Por ejemplo, polen de la familia Poaceae aparece a lo largo de toda la serie polínica de los yacimientos de la cercana sierra de Atapuerca, que en su conjunto abarcan el periodo comprendido entre 1,2 Ma y 240 ka (Rodríguez, et al., 2011), así como en la turbera del La Piedra, situada dentro del árela de estudio, la cual registra porcentajes de polen de poáceas que varían entre 10 y $60 \%$ a lo largo buena parte del Holoceno.

\section{Poales incertae sedis 2}

\section{(Lám. 3, Fig. 2)}

\section{Material estudiado}

Este taxón solo se ha encontrado en la localidad de Sedano, en la estructura SD-BS. En este trabajo se ha estudiado un único ejemplar en detalle - SD-BS-22-, si bien en el yacimiento aparecen numerosos restos similares por toda la parte superior de la formación, en lo que supondría el paramento interior de la represa. Algunos de estos restos aparecen en posición vertical, de vida, embebidos en un sustrato calcáreo poco consolidado de naturaleza detrítica. 


\section{Descripción}

Fragmentos de tallos de sección transversal cilíndrica de hasta $15 \mathrm{~cm}$ de longitud y 2$4 \mathrm{~cm}$ de diámetro, huecos, con una pared de $5 \mathrm{~mm}$ de grosor de pared. Alrededor de ellos pueden aparecer también restos de tallos dispuestos en capas concéntricas.

\section{Observaciones}

Este tipo macrorresto se interpreta como un fragmento del tallo de una «caña, espadaña o carrizo» alrededor de la cual se conservan los tallos de años anteriores nacidos del mismo rizoma. Especies habituales que comparten las características descritas son Typha latifolia L. o Phragmites australis (Cav.) Trin. ex Steud., entre otras, siendo imposible concretar la especie a partir de los restos descritos.

Las especies citadas y otras Poales palustres con tallos similares, son plantas emergentes, robustas, perennes y rizomatosas. Habitan en humedales cubiertos permanentemente por aguas no muy profundas, o en zonas encharcadas, en donde forman habitualmente densas colonias. Ambas especies citadas están presentes en la zona de estudio, pero restringidas a los medios en donde existen cuerpos de aguas retenidas o de circulación lenta sobre sustratos arcillosos suficientemente profundos como para que se desarrolle su amplio sistema rizomatoso de estas plantas. Typha sp. y $P$. australis han sido citados en Alemania, en el depósito tobáceo del Pleistoceno Superior de Ehringsdorf (Mania, 2006). También aparece en el mismo país formando parte de la flora eemiense de Burgtonna (Vent, 1978). En el Holoceno, Phragmites spp. ha sido citado a partir de impresiones tobáceas en las localidades francesas de St-Antonin —Bouches-du-Rhone- (Ali, et al., 2003c) y Valle de Mouresse (Roiron, et al., 2006). 
Familia JUNCACEAE Jussieu, 1789

Género Juncus Linné, 1753

Juncus sp.

(Lám. 3, Fig. 3)

\section{Material estudiado}

Esta especie se describe a partir de 11 ejemplares (Anexo IV) recogidos en siete estructuras diferentes de los yacimientos de Tubilla del Agua, Sedano, Tobera y Frías. En conjunto suponen el $0,60 \%$ del registro fósil estudiado (Tabla 12). A pesar de que solo se han recogido 11 ejemplares, los restos de este taxón podrían ser mucho más numerosos, ya que es difícil discernir las oquedades que se corresponden a tallos de esta planta de los de ramas de otras especies leñosas.

\section{Descripción}

Fragmentos de tallos cilíndricos de hasta $6 \mathrm{~cm}$ de longitud, 8-10 mm de diámetro y 2 $\mathrm{mm}$ de espesor de pared, recorridos longitudinalmente en su cara exterior por acanaladuras de $0,5 \mathrm{~mm}$ de grosor. Uno de los ejemplares encontrado en TUAG-TMM -TUAG-TMM-12posee el molde de la cara interior de la hoja, la cual presenta para los tallos acanaladuras similares a las indicadas, posiblemente, al envolver parte de los entrenudos.

\section{Observaciones}

De todas las especies pertenecientes al género Juncus solo las de la sección Juncotypus se caracterizan por sus tallos cilíndricos y alargados, en los que la única hoja se dispone a modo de envoltura en la base del tallo (Kirschner, et al., 1999). Existen numerosas especies de este género en el área de estudio (Loidi Arregui \& Fernández Prieto, 1986; Barredo \& Barredo, 2002; Alejandre, et al., 2006; Loidi, et al., 2011; Uribe-Echebarría, 2012), la mayoría de las cuales habitan en zonas húmedas o temporalmente inundadas. Los fósiles descritos son muy similares a los encontrados por Martínez-Tudela, et al. (1986) y Badía- 
Gimeno \& Muñoz-Bertomeu (1999) en el yacimiento del interglacial Riss-Würn de El Prat, — Beceite, Teruel-, los cuales fueron identificados como cf. Juncus sp. y Juncaceae respectivamente.

\title{
Orden RANUNCULALES jussieu ex Bercht. \& J.Presl, 1820
}

Familia BERBERIDACEAE Jussieu, 1789

\author{
Género Berberis Linné, 1753
}

Berberis vulgaris Linné, 1753

(Lám. 3, Fig. 4)

\section{Material estudiado}

Se han recogido 24 ejemplares (Anexo IV), en las estructuras TUAG-VBH y TUAGBH de Tubilla del Agua y SD-BI y SD-BS de la localidad de Sedano. En total suponen el 1,31\% de todo el registro estudiado (Tabla 12).

\section{Descripción}

Hojas obovadas de 4,9-6,2 $\mathrm{cm}$ de longitud por 2,8-3,7 cm de anchura; ápice redondeado, base cuneada y margen entero o ampliamente aserrado. Limbo pinnado, con nerviación de segundo orden broquidódroma festoneada. Nervio medio percurrente, de curso recto o ligeramente zigzagueante. Los nervios secundarios - de 4 a 7 pares - se disponen de forma opuesta o ligeramente alternos, con una distancia entre ellos decreciente hacia el ápice, por lo que los lazos que forman son cada vez más pequeños en esa dirección. El curso abrupto y ramificado de los nervios de segundo orden da a los lazos un aspecto reticulado. El ángulo de divergencia varía de unos a otros ejemplares dentro de un margen -de $30^{\circ}$ a $50^{\circ}-$, pero no se observa ninguna tendencia a aumentar o disminuir conforme nos alejamos de la base. La nerviación terciaria forma una retícula ortogonal de areolas bien desarrolladas, dentro de las cuales se puede llegar a observar la nerviación de cuarto orden que también sigue un patrón reticulado similar. 
La nerviación descrita se observa tanto en las impresiones del haz de la hoja como en las del envés. En el haz, todos los nervios, tanto de primero como de segundo y tercer orden se presentan igualmente prominentes, mientras que en el envés, el nervio medio es mucho más grueso que el resto de la nerviación, sobretodo en su parte basal.

\section{Observaciones}

B. vulgaris es un arbusto caducifolio espinoso, ramificado y denso que puede llegar a los $2 \mathrm{~m}$ de altura. Crece en bosques aclarados y terrenos abiertos de carácter continental o submediterráneo, sobre suelos preferentemente calizos y pedregosos. Su área de distribución abarca casi toda Europa, el oeste de Asia y algunos puntos del norte de África (López, 2007). Es una especie abundante en el área de estudio, apareciendo especialmente en pendientes pedregosas y soleadas (Loidi Arregui \& Fernández Prieto, 1986; Barredo \& Barredo, 2002; Alejandre, et al., 2006; Loidi, et al., 2011; Uribe-Echebarría, 2012).

Impresiones foliares asignadas al género Berberis han sido halladas en el Pleistoceno Inferior de Crespià -Gerona- (Villalta \& Vicente, 1972; Roiron, 1983) y en el Pleistoceno Medio de Bilzingsleben Alemania- (Harmon, et al., 1980; Mania, 2006). B. vulgaris también ha sido encontrado en el yacimiento francés de Serre de Montdenier, en los Alpes Marítimos de la región de Provenza. El nivel del depósito tobáceo donde apareció esta especie fue datado en aproximadamente 8.500-9.000 años (Roiron, et al., 2006). 
Capítulo 4. Resultados
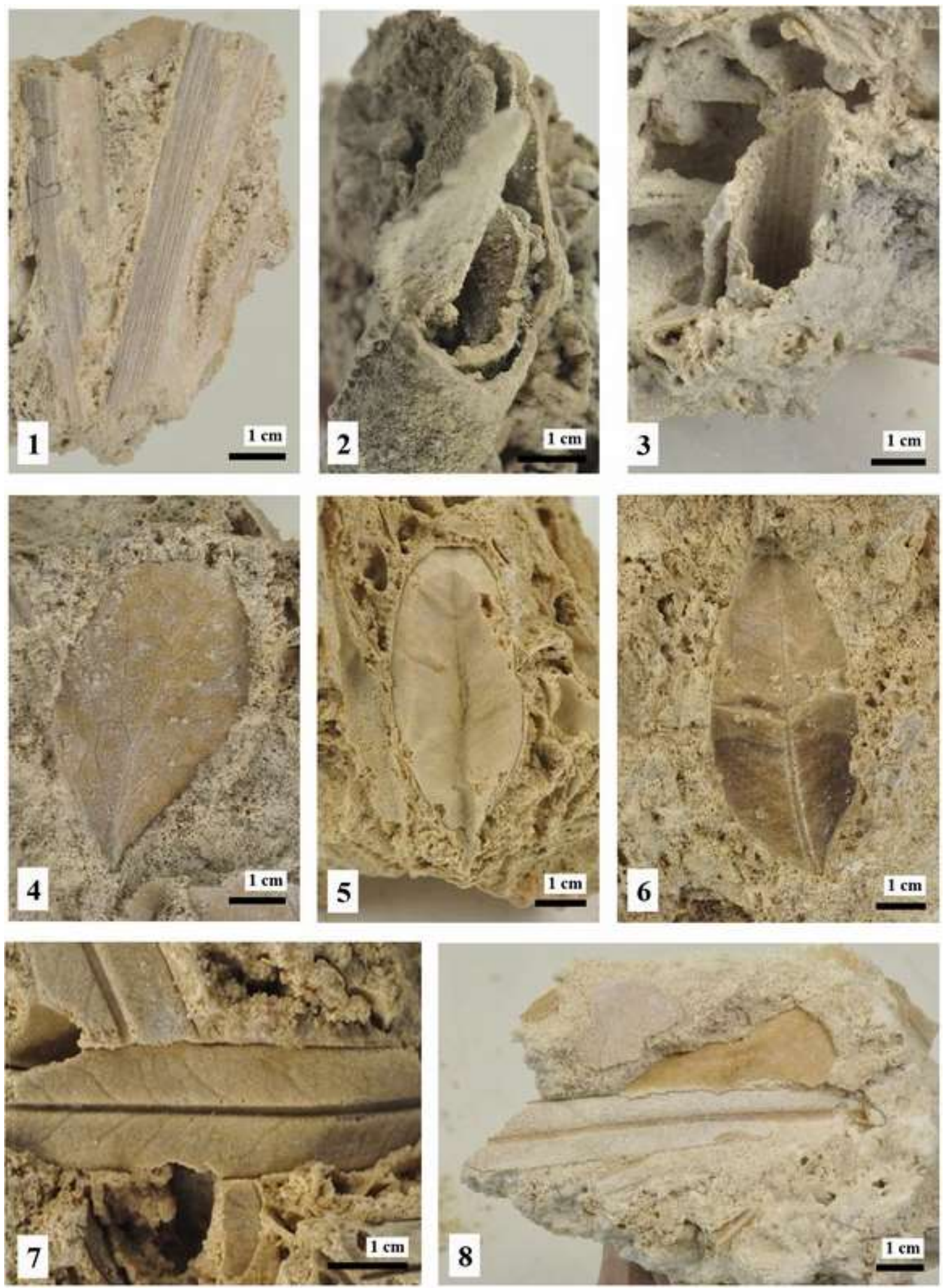

Lámina 3. Fig. 1. Poales incertae sedis 1, DRP-263, Herrán; Fig. 2. Poales incertae sedis 2, SD-BS-51, Sedano; Fig. 3. Juncus sp., DRM-69, Tobera; Fig. 4. Berberis vulgaris L. (Haz), SD-BI-216, Sedano; Figs. 5-6. Buxus sempervirens L., (5) Haz, TUAG-PS-157, Tubilla del Agua, (6) Envés, TUAG-PS-198, Tubilla del Agua; Figs. 78. Salix eleagnos Scop. (7) Detalle de la nerviación, (Envés), TUAG-PS-46, Tubilla del Agua, (8) Envés, DRP306, Herrán. 


\section{Orden BUXALES Takhtajan ex Reveal, 1996 \\ Familia BUXACEAE Dumortier, 1822 \\ Género Buxus Linné, 1753 \\ Buxus sempervirens Linné, 1753 \\ (Lám. 3, Figs. 5-6)}

\section{Material estudiado}

Se han recogido 76 ejemplares (Anexo IV) en el afloramiento TUAG-PS de Tubilla del Agua y 34 en el desfiladero del río Purón. En conjunto suponen el 6,04\% de todo el registro estudiado (Tabla 12).

\section{Descripción}

Hojas micrófilas, pecíoladas, de 0,9-1,7 cm de longitud y 1,8-3,5 cm de anchura, con forma generalmente elíptica y, a veces, ovada. Ápice redondeado o, en algunas ocasiones, ligeramente acuminado o retuso; base cuneada y margen entero revoluto.

Nerviación pinnada paxilada ${ }^{2}$ con el nervio medio robusto, de curso recto, y numerosos pares de nervios de segundo orden alternos, poco aparentes en los ejemplares estudiados, que se desarrollan rectos y paralelos, con un ángulo de divergencia de $40^{\circ}$ a $50^{\circ}$. La nerviación terciaria no es visible en los fósiles estudiados.

La lámina de muchos ejemplares está aquillada hacia el haz a lo largo del eje mayor y presentan un nervio medio prominente en el envés y ligeramente deprimido en el haz. La superficie de los ejemplares es suave por ambos lados o estriada, si la nerviación de segundo orden es patente.

\footnotetext{
${ }^{2}$ nervios secundarios numerosos, cercanamente paralelos entre ellos y más o menos derechos, excepto cerca del margen donde se curvan más o menos abruptamente en una vena submarginal (Barrón, 1996; Barrón \& Dieguez, 2005).
} 


\section{Observaciones}

El boj es un arbusto perenne de hasta $3 \mathrm{~m}$ que crece preferentemente en terrenos calcáreos, ocupando los claros de los bosques, roquedos y laderas escarpadas. Habita en la Cuenca Mediterránea, llegando por el norte hasta las Islas Británicas y Centroeuropa, y por el este hasta el Himalaya. En la Península Ibérica es especialmente abundante en el cuadrante noreste, siendo raro en la Iberia silícea y el sur peninsular (López González, 2006). Se encuentra en la zona de estudio, aunque es más abundante en la mitad occidental que en el dominio geomorfológico de la Plataforma Norcastellana, donde su presencia es testimonial (Loidi Arregui \& Fernández Prieto, 1986; Barredo \& Barredo, 2002; Alejandre, et al., 2006; Loidi, et al., 2011; Uribe-Echebarría, 2012).

Esta especie ha sido encontrada en el Pleistoceno Medio-Superior de los depósitos italianos de Piànico-Sèllere (Sordelli, 1873; Moscariello, et al., 2000) y Lazio (Clerici, 1887; Manfra, et al., 1976). El boj forma parte también de la flora del interglacial MIS 7 de Bilzingsleben (Harmon, et al., 1980; Mania, 2006). En Francia, ha sido citada en el Pleistoceno Medio del Macizo Central, en el yacimiento tobáceo de La Roquette — Valle de Tarn, Millau— datado en el MIS 7 y en el depósito de Peyre I, del MIS 5 (Vernet, et al., 1984; Ambert, et al., 1992; Vernet, et al., 2008). En este mismo país, se ha hallado en el MIS 3 en la flora de Castelnau-le-Lez y en el Holoceno, en St-Antonin —Bouches-du-Rhone; Francia— (Ali, et al., 2003c) y Saint Guilhem-le-Désert —l'Herault— (Lecoeuvre, et al., 2008; Ali, et al., 2008).

En la Península Ibérica $B$. sempervirens está presente en el yacimiento tobáceo del interglacial Riss-Würn de Beceite -Teruel— (Martínez-Tudela, et al., 1986; Badía-Gimeno \& Muñoz-Bertomeu, 1999). Adicionalmente, el polen del boj se encuentra en numerosos depósitos peninsulares. Así, en el Pleistoceno, Buxus aparece en torno a hace 400 ka en el Estadío Isotópico Marino 11, en el sondeo marino MD01-2447 realizado en las costas de Galicia(Desprat, et al., 2005), y puntualmente, en los niveles II y III del yacimiento de La Galería, en la Sierra de Atapuerca -Burgos- (García-Antón \& Sainz-Ollero, 1991). 
En el Holoceno, ha sido identificado a partir de carbones en el yacimiento arqueológico de Balma del Gai —Barcelona; 9.000 a 12.000 años de antigüedad— (Allué, et al., 2007). Además, su polen aparece en numerosos sondeos del Tardiglaciar y el Holoceno, p.e. Cueva de Ekain —Guipúzcoa; 9.500 a 15.500 años de antigüedad- (Dupré, 1984), Aizpea — Navarra, $\sim 5.000$ a 8500 años de antigüedad- (Zapata, 2001), La Mota —Valladolid; >2.600 años— (Mariscal, 1995) y el yacimiento de Peña Parda —Álava; 4.000 años— (Ruiz-Zapata, et al., 2002; Pérez Díaz, et al., 2007), situado en la vertiente meridional de la Sierra de Cantabria.

\section{Orden MALPIGHIALES Jussieu ex Bercht. \& J.Presl, 1820 \\ Familia SALICACEAE Mirbel, 1815}

Género Salix Linné, 1753

\section{Salix eleagnos Scopolli, 1772}

(Lám. 3, Figs. 7-8)

\section{Material estudiado}

Se han hallado 36 impresiones foliares (Anexo IV): 15 en el afloramiento TUAG-PS de Tubilla del Agua, 16 en el complejo tobáceo del río Purón y cinco en la formación de Frías (Tabla 12).

\section{Descripción}

Hojas lineares o linear-lanceoladas, de tamaño bastante variable: $4,0-8,8 \mathrm{~cm}$ de longitud y 0,7-2,4 cm de anchura. Ápice y base cuneadas y margen entero revoluto. Lámina pinnada, con el nervio medio robusto, de curso recto y prominente en el envés.

Nerviación pinnada, posiblemente semicraspedódroma, con numerosos pares de nervios secundarios, visibles solo en las impresiones del envés, que se disponen con un ángulo de divergencia de entre $30^{\circ}$ y $50^{\circ}$ de manera no uniforme a lo largo del nervio principal. Estos nervios secundarios no siguen un curso curvado, pero tampoco totalmente recto, 
llegándose algunos de ellos a ahorquillar. Presencia de nervios intersecundarios. En el haz, solo se observa el nervio medio, que está profundamente deprimido. La lámina foliar de algunos especímenes aparece curvada, especialmente en su parte basal, y el margen se observa claramente curvado hacia el envés.

\section{Observaciones}

S. eleagnos se presenta habitualmente como un arbusto muy ramificado, de hasta 6 $\mathrm{m}$ de altura. Crece en la ribera de ríos y arroyos, preferentemente sobre terrenos aluviales. Habita en la cuenca del mar Mediterráneo, Europa Central y Asia Menor (López, 2007). En la Península Ibérica, aunque está restringido a los ecosistemas riparios o con cierta humedad edáfica y terreno suelto, es una especie frecuente, sobre todo en las regiones calizas, aunque escasea en el sur peninsular.

Esta especie ha sido citada a partir de impresiones foliares en toba en el yacimiento de del interglacial Riss-Würn de Beceite, donde se cita junto con S. purpurea (MartínezTudela, et al., 1986; Badía-Gimeno \& Muñoz-Bertomeu, 1999). También en el mismo periodo interglacial, en torno a hace 110 ka (Sanders \& Ostermann, 2006), aparece en la flora de Hötling, —Insbruck; Austria- (Murr, 1926). En el periodo Boreal del Holoceno -7.500-9.000 años (Salas, 1992) - se cita en la Sierra de Montdenier, en la región de Provenza Francia- (Roiron, et al., 2006). 


\section{Salix sp. 1}

\section{(Lám. 4, Figs. 1-3)}

\section{Material estudiado}

Con 160 impresiones foliares recogidas (Anexo IV), es el quinto taxón más abundante, lo que supone el $8,78 \%$ de todo el registro (Tabla 12). Ha sido hallado en 7 de las 13 unidades litológicas identificadas.

\section{Descripción}

Láminas foliares pecíoladas con forma elíptica u ovada, de 5,3-8,1 cm de longitud por 2,8-3,8 cm de anchura, ápice agudo y base cuneada, margen espaciadamente aserrado. Lámina pinnada, con un nervio medio grueso, prominente que recorre la hoja con curso recto, sin reducir su grosor. De 6 a 10 pares de nervios secundarios que aparentemente se disponen en forma broquidódroma, aunque en los ejemplares estudiados no se llega a apreciar que los nervios se unan formando arcos. Estos nervios de segundo orden se distribuyen de forma alterna y no uniforme a lo largo del nervio medio, existiendo una gran variación en la distancia entre ellos. Presentan un curso curvado, pero con un radio de curvatura variable, de tal forma que, en la parte proximal tienen un ángulo de divergencia de $80^{\circ}$ a $60^{\circ}$, en su parte medial presentan una curvatura de unos $45^{\circ}$, y cerca del borde, se curvan hacia el ápice. Nerviación de tercer orden no preservada.

La nerviación, tanto de primer como de segundo orden se presenta prominente en el envés, especialmente el nervio medio que sobresale homogéneamente a lo largo de todo su recorrido. Los nervios secundarios son estrechos, pero también prominentes, apareciendo marcados casi hasta el borde. En el haz de la hoja, a diferencia del envés, los secundarios se presentan tan deprimidos como el nervio medio, aunque su impronta se atenúa hacia el borde. 


\section{Observaciones}

El conjunto de impresiones foliares estudiadas presenta similitudes con las hojas de S. salviifolia Brot. Sin embargo, algunos rasgos específicos de las hojas de este sauce, como el hecho de que las hojas suelan presentar formas más alargadas y que su nerviación terciaria sea algo patente en el envés, no permite asegurar una identificación positiva. Por otro lado S. salviifolia, especie endémica de la Península Ibérica, ocupa con predilección terrenos silíceos, por lo que solo aparece testimonialmente en algunas localidades del área de estudio (Alejandre, et al., 2006). Otra especies de sauces también tienen ciertas semejanzas con los fósiles descritos, por ejemplo S. cantabrica Rech. fil., endemismo de la montaña cantábrica y especie común en la mitad occidental del área de estudio (Alejandre, et al., 2006).

La dificultad de identificar con precisión las impresiones estudiadas es resultado del polimorfismo y la anisofília ${ }^{3}$ que se da en muchas de las especies del género Salix. Una de las razones de esto es su tendencia a hibridar y producir poblaciones con caracteres intermedios (Alejandre, et al., 2006).

\footnotetext{
${ }^{3}$ Dimorfismo foliar que se manifiesta en la hojas de una misma planta
} 
Capítulo 4. Resultados
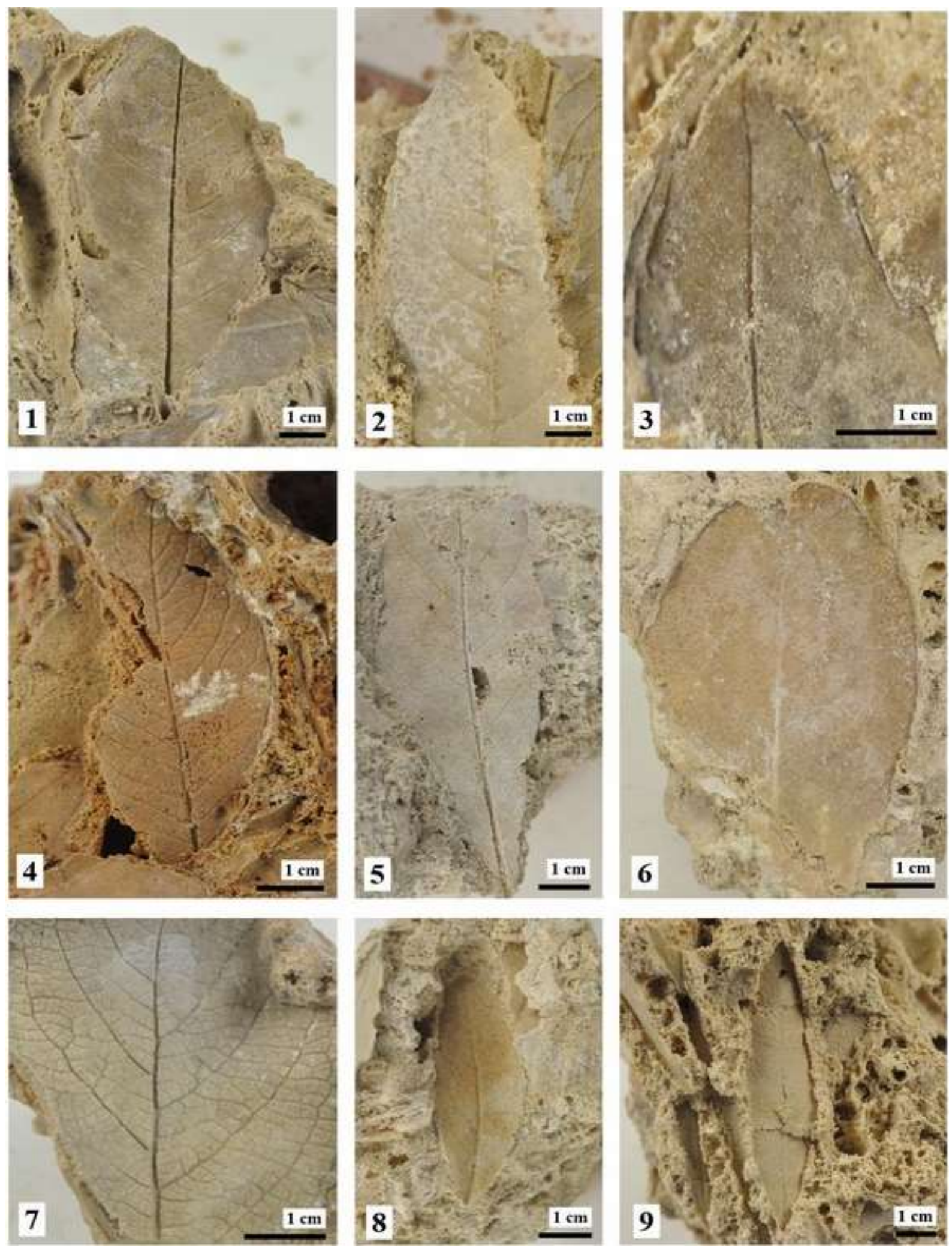

Lámina 4. Figs. 1-3. Salix sp. 1, (1) Envés, TUAG-PS-80, Tubilla del Agua, (2) Haz, TUAG-PS-96, Tubilla del Agua, (3), Detalles del ápice y del borde aserrado, (Envés), TUAG-PS-78, Tubilla del Agua; Figs. 4-7. Salix sp. 2, (4) Envés, TUAG-PS-26, Tubilla del Agua, (5) Envés, SD-BS-22, Sedano, (6) Haz, DRP-323, Herrán, (7), Detalles de la nerviación, (Envés), TUAG-TMM-21, Tubilla del Agua; Figs. 8-9. Salix sp. 3, (8) Envés, TUAGTP-18, Tubilla del Agua, (9) Haz, TUAG-TP-24, Tubilla del Agua. 


\section{Salix sp. 2}

\section{(Lám. 4, Figs. 4-7)}

\section{Material estudiado}

Este taxón aparece en ocho de las 13 estructuras tobáceas estudiadas (Tabla 12). Con 68 ejemplares (Anexo IV), supone el 3,73\% de todos los fósiles recogidos.

\section{Descripción}

Hojas pecíoladas, con forma elíptica u obovada, de 6,0-7,4 cm de longitud por 3,2-4,8 cm de anchura, ápice acuminado, base convexa y margen entre entero y festoneado. Nerviación pinnada broquidódroma, con nervios secundarios que se unen entre ellos formando lazos cerca del margen. Nervio medio de curso recto y muy prominente por el envés, aunque disminuye progresivamente de grosor al alejarse de la base.

De 6 a 10 pares de nervios de segundo orden —ocasionalmente, presencia de algún nervio intersecundario-, uniformemente curvados hacia el ápice y con curso algo zigzagueante. Se disponen tanto de forma opuesta como alterna y están desigualmente distribuidos a lo largo del nervio medio. Se observa una equivalencia en cuanto al ángulo de divergencia -unos $45^{\circ}$ - Estos nervios son prominentes por el envés, aunque menos que el principal, y, a diferencia de este, mantienen su grosor a lo largo su recorrido hacia el borde de la hoja.

La nerviación terciaria, —casi tan prominente en el envés como los nervios de segundo orden-, es una mezcla de alterna y opuesta percurrente. Se observa la tendencia de los nervios de tercer orden, de curso recto, a orientarse de forma perpendicular a los nervios secundarios en la parte basal y con un ángulo más perpendicular al nervio medio en la parte media. En la parte apical de la hoja casi todos los nervios de tercer orden están 
ahorquillados, por lo que no se aprecia ninguna orientación específica, sino que conforman una retícula ortogonal.

Toda la nerviación de primer, segundo y tercer orden es muy prominente por el envés, observándose profundamente impresa en los fósiles de ese lado de la hoja. Es mucho menos perceptibles en el haz, donde, si son visibles, aparecen gruesos - especialmente el nervio medio en su base- pero ligeramente patentes.

\section{Observaciones}

Las características de los fósiles descritos son compartidas por algunas especies de sauces de hoja ancha, como por ejemplo S. caprea L. y S. atrocinerea. Estos, además de la similitud comentada, presentan una gran heterofilia foliar, lo que impide su identificación a nivel específico a partir de las impresiones foliares estudiadas. De las dos especies citadas, S. atrocinerea es actualmente la más abundante en el área de estudio (Loidi Arregui \& Fernández Prieto, 1986; Barredo \& Barredo, 2002; Alejandre, et al., 2006; Loidi, et al., 2011; Uribe-Echebarría, 2012). Este sauce tiene una gran capacidad para colonizar espacios riparios alterados por la fuerza de las aguas, terrenos encharcados y la orilla de masas de agua retenidas (López González, 2006).

S. caprea, ha sido citada en el yacimiento del Interglacial Riss-Würn de Hötling Insbruck, Austria- (Murr, 1926; Sanders \& Ostermann, 2006). Impresiones foliares del mismo taxón, junto con S. cinerea L., S. purpurea y $S$. fragilis han sido encontradas en materiales de la región francesa de La Provenza, de hace aproximadamente 8.500-9.000 años (Roiron, et al., 2006). 


\section{Salix sp. 3}

\section{(Lám. 4, Figs. 8-9)}

\section{Material estudiado}

Esta especie solo se ha encontrado en las estructuras TUAG-VBH y TUAG-TP de Tubilla del agua (Tabla 12), con dos y 23 ejemplares respectivamente en cada una (Anexo IV).

\section{Descripción}

Hojas micrófilas, pecíoladas, de 3-5,5 cm de longitud por 1,1-2,6 cm de anchura; forma elíptica; ápice y base cuneados, y margen entero revoluto. Lámina pinnada, recorrida por un nervio medio con curso recto hasta el ápice. Nerviación de segundo orden apenas visible; en algunos ejemplares se intuyen en las impresiones del haz de la hoja unos nervios de segundo orden zigzagueantes, curvados hacia el ápice y con un ángulo de divergencia de unos $45^{\circ}$. El aspecto del haz es liso, salvo si se observan el nervio medio y los secundarios que se presentan ligeramente deprimidos. En el envés sobresale el nervio central, que es robusto. En muchos de los especímenes, la lámina foliar está combada hacia el haz.

\section{Observaciones}

Los impresiones foliares descritas presentan similitudes con las hojas estrechas de algunos sauces como S. alba L. o S. fragilis Ambas especies están hoy en día presentes en el sector biogeográfico Castellano Cantábrico, pero restringidas a ambientes riparios y zonas deprimidas con nivel freático superficial (Loidi Arregui \& Fernández Prieto, 1986; Barredo \& Barredo, 2002; Alejandre, et al., 2006; Loidi, et al., 2011; Uribe-Echebarría, 2012). Debido a la comentada variabilidad morfológica intra e interespecífica del género, los especímenes estudiados no pueden ser adscritos a ninguna especie en concreto, por lo que se citan en nomenclatura abierta como Salix sp. 3. 


\section{Orden ROSALES Berchtold \& J. Presl, 1820 \\ Familia ROSACEAE Jussieu, 1789 \\ Género Amelanchier Medikus, 1789 \\ Amelanchier ovalis Medikus, 1793}

(Lám. 5, Figs. 1-3)

\section{Material estudiado}

A. ovalis es el segundo taxón más abundante de esta Memoria, habiéndose encontrado 210 ejemplares (Anexo IV), el 11,53\% de los restos estudiados. Apareció en siete de las 13 estructuras estudiadas (Tabla 12).

\section{Descripción}

Hojas micrófilas -2,8-4,2 x 1,9-2,6 cm-, de forma elíptica o redondeada; àpice redondeado, base ligeramente lobulada y margen finamente aserrado. Nerviación pinnada semicraspedódroma. Nervios de segundo orden en número de 8 a 12 pares, que se disponen opuestos en la zona proximal pero que suelen presentarse alternos conforme nos alejamos de la base. Se observa una tendencia a incrementarse su curvatura, pudiendo presentar un curso recto o ligeramente curvado cerca de la base, y pronunciadamente curvado en la zona apical de la hoja. El ángulo de divergencia es uniforme a lo largo del nervio medio, de unos $45^{\circ}$. La distancia entre los nervios de segundo orden es variable, aunque se observa la tendencia a aumentar conforme nos alejamos de la base; en unos pocos especímenes se observan nervios intersecundarios. Nerviación de tercer orden ortogonalmente reticulada, pero con un patrón que sugiere cierta orientación perpendicular al nervio medio

En muchos de los fósiles estudiados el limbo de la hoja está ligeramente plegado o combado sobre el nervio medio hacia el haz. El nervio principal se aquilla hacia el envés, donde aparece prominente con casi el mismo grosor a lo largo de todo su recorrido. En el haz aparece ligeramente deprimido, o no visible. La nerviación de segundo orden es también más 
aparente en las impresiones del envés, aunque es levemente prominente en el haz. La nerviación de tercer orden, si es visible, lo es en el haz, en donde se muestra ligeramente abultada.

\section{Observaciones}

A. ovalis es un arbusto caducifolio de hasta $3 \mathrm{~m}$ de altura, de ramas largas y flexibles, que crece en bosques, en sus orlas y en matorrales poco densos, sobre todo en terrenos pedregosos, preferentemente sobre calizas. Habita en toda la Cuenca Mediterránea, llegando por el este hasta el Cáucaso (Castroviejo, et al., 1998). Es una especie extendida por toda la Península Ibérica, pero escasea en la mitad sudoccidental, de naturaleza silícea. Se encuentra repartida por todo el área de estudio en donde muestra predilección por las laderas soleadas y suelos pobres y pedregosos (Loidi Arregui \& Fernández Prieto, 1986; Barredo \& Barredo, 2002; Alejandre, et al., 2006; Loidi, et al., 2011; Uribe-Echebarría, 2012).

Esta especie ha sido citada en el afloramiento del Pleistoceno Medio-Superior probables Estadíos Isotópicos Marinos 5, 7 ó 9- de Piànico-Sèllere, al norte de Italia (Emmert-Straubinger, 1991; Moscariello, et al., 2000). En el Holoceno se ha hallado en los yacimientos tobáceos de La Provenza —Francia— en las localidades de Sierra de Montdenier (Roiron, et al., 2006) y St-Antonin —Bouches-du-Rhone- (Ali, et al., 2003c).

Género Sorbus Linné, 1753

Sorbus aria (L.) Crantz, 1763

(Lám. 5, Figs. 4, 5, 6 y 7)

\section{Material estudiado}

S. aria es la especie más abundante de todas los identificadas; se han recogido 211 impresiones foliares (Anexo IV) en 11 de las 13 unidades litológicas prospectadas (Tabla 12). 
Los especímenes estudiados representan el $12,13 \%$ de todo el registro de esta Tesis Doctoral.

\section{Descripción}

Hojas pecíoladas con forma elíptica o ancho-elíptica, de 6,2-10,4 cm de longitud y 4,17,3 cm de anchura, ápice convexo o redondeado, ligeramente acuminado, base de cuneada a convexa y margen aserrado con una denticulación compuesta por dientes de primer y segundo orden. Nerviación pinnada craspedódroma con 9-13 pares de nervios secundarios, rectos o ligera y uniformemente curvados que se disponen de forma alterna u opuesta al nervio medio y se distribuyen de forma uniforme a lo largo de él. El ángulo de divergencia desciende ligera y progresivamente desde la base hacia el ápice, de $45^{\circ}$ a $35^{\circ}$. Presencia de varios pares de nervios agrofíticos y ausencia de nervios intersecundarios. Nerviación de tercer orden percurrente que tan solo se aprecia ligeramente en el envés de algunos ejemplares; esta se dispone uniendo directamente los nervios de segundo orden o ahorquillándose previamente, observándose una tendencia a presentarse de forma perpendicular al nervio medio, sobre todo en la parte media de la hoja.

Tanto la nerviación de primero como de segundo orden son prominentes en el envés, apareciendo en el haz ligeramente deprimidas. En las impresiones del haz de las hojas estudiadas se observa una fina costilla prominente que recorre el centro de la hendidura del nervio medio. En el envés, tanto los nervios de segundo orden como el medio destacan, pero este último lo hace en mayor medida cuanto más cerca de la base. Los nervios de segundo orden, por el contrario, se presentan igualmente prominentes a lo largo de todo su recorrido. 
Capítulo 4. Resultados
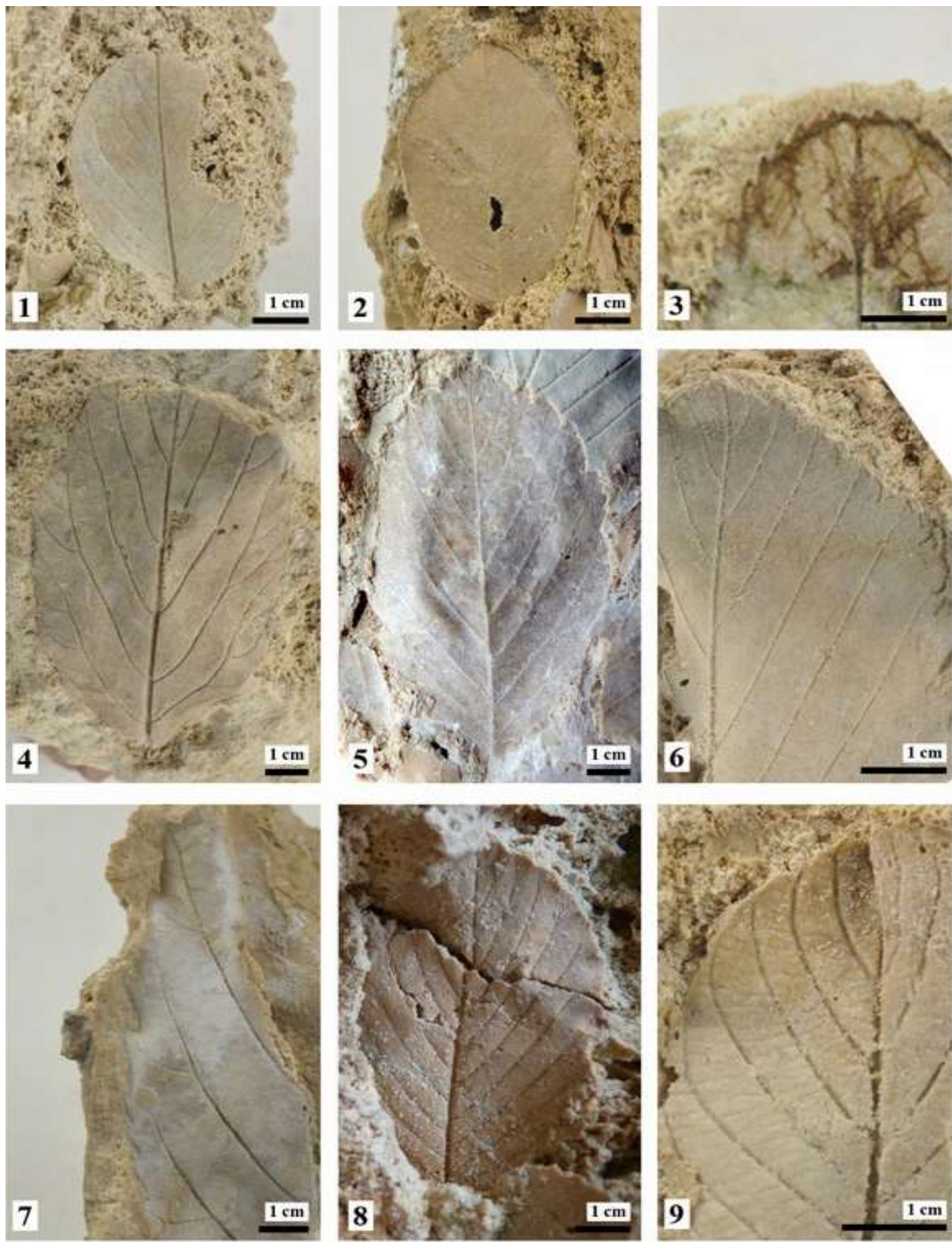

Lámina 5. Figs. 1-3. Amelanchier ovalis Medik., (1) Envés, SD-BI-242, Sedano, (2) Haz, TUAG-BH-3, Tubilla del Agua, (3) Detalles del ápice y borde, (Haz), TUAG-VBH-139, Tubilla del Agua; Figs. 4-7. Sorbus aria (L.) Crantz, (4) Envés, TUAG-VBH-35, Tubilla del Agua, (5) Haz, SD-BI-125, Sedano, (6) Detalles del ápice, nerviación y margen, (Envés), TUAG-VBH-43, Tubilla del Agua, (7) Detalles de los dientes basales, (Envés), TUAG-TMM-42, Tubilla del Agua; Figs. 8-9. Rhamnus alpina L., (8) Envés, TUAG-BH-31, Tubilla del Agua, (9) detalles de la nerviación, borde, margen y ápice (Envés), TUAG-BVH-38, Tubilla del Agua. 


\section{Observaciones}

S. aria es un árbol caducifolio de pequeño porte, aunque en condiciones excepcionales puede alcanzar los $20 \mathrm{~m}$ de altura. Crece en el sotobosque y orlas de los bosques de una gran variedad de formaciones forestales: hayedos, quejigares, pinares, etc. (Castroviejo, et al., 1998). A pesar de su amplia valencia ecológica, tiene cierta preferencia por los terrenos calizos y los bosques frescos de montaña. Se distribuye por Europa Central y Meridional, y Macaronesia; existen también algunas pequeñas poblaciones en el Norte de África. Se puede encontrar en prácticamente toda la Península lbérica, aunque falta del cuadrante sudoccidental (López, 2007). Esta especie también es común en el área de estudio (Loidi Arregui \& Fernández Prieto, 1986; Barredo \& Barredo, 2002; Alejandre, et al., 2006; Loidi, et al., 2011; Uribe-Echebarría, 2012), creciendo en las orlas de los bosques frescos de la zona, a veces al pie de cantiles.

S. aria ha sido citada a partir de impresiones foliares en el Pleistoceno Medio-Superior del norte del Italia, (Amsler, 1900; Maffei, 1924; Moscariello, et al., 2000), y en el interglacial Riss-Würn de los Alpes septentrionales -Hötling, Austria- (Murr, 1926; Sanders \& Ostermann, 2006). En el mismo periodo interglacial aparece en la Península Ibérica en el yacimiento de Beceite -Teruel— (Martínez-Tudela, et al., 1986). En el Holoceno, S. aria se ha hallado en un depósito tobáceo de la sierra de Montdenier, al sur de Francia (Roiron, et al., 2006). 


\title{
Familia RHAMNACEAE Jussieu, 1789
}

Género Rhamnus Linné, 1753

Rhamnus alpina Linné, 1753

\author{
(Lám. 5, Figs. 8-9)
}

\section{Material estudiado}

Esta especie ha sido encontrada únicamente en dos afloramientos, en TUAG-BH de Tubilla del Agua y en SB-BI y SD-BS de Sedano (Tabla 12). Los 21 ejemplares hallados (Anexo IV) constituyen el 1,15\% de todos los fósiles estudiados.

\section{Descripción}

Hojas pecíoladas, de forma ovalada, de $6,0-8,2 \mathrm{~cm}$ de longitud y $3,8-4,8 \mathrm{~cm}$ de anchura, ápice redondeado o acuminado, base cuneada y margen finamente aserrado. Nerviación pinnada semicraspedódroma; nervio medio de curso recto; de 10 a 14 nervios secundarios, alternos u opuestos, de curso recto o ligeramente curvados hasta cerca del margen, donde se bifurcan en dos o más nervios. La primera ramificación sigue un curso perpendicular al nervio medio hasta unirse con el nervio secundario adyacente, mientras que las demás terminan en el margen. Los nervios de segundo orden se disponen a una distancia uniforme a lo largo del nervio medio, mientras que el ángulo de divergencia disminuye progresivamente, de unos $45^{\circ}$ hasta $35^{\circ}$, de la base al ápice, y la curvatura de estos se incrementa. Nerviación terciaria no visible en los especímenes estudiados.

Toda la nerviación se presenta prominente en el envés de la hoja, especialmente el nervio medio, el cual muestra un grosor atenuado hacia el ápice, algo que no ocurre con los nervios de segundo orden, los cuales presentan un grosor uniforme. En el haz todos aparecen deprimidos. Es característico de los fósiles estudiados que el espacio que existe entre dos nervios se presente combado hacia el haz. 


\section{Observaciones}

La forma y tamaño de las hojas y, sobre todo, la disposición de los nervios de segundo orden, relativamente juntos, paralelos y rectos hace que los fósiles de $R$. alpina sean muy similares a los de Sorbus aria descritos anteriormente. Cuando algunos pequeños detalles, como el tipo de margen, no son visibles, el extremo ramificado de los nervios secundarios permite diferenciar las impresiones de $S$. aria.

Esta especie caducifolia suele presentar un porte arbustivo o de pequeño árbol de hasta $3 \circ 4 \mathrm{~m}$ de altura. $R$. alpina muestra una tendencia calcícola, heliófila, montana y rupícola siendo habitual en laderas empinadas, cornisas, canchales, etc. (Castroviejo, et al., 1998). Habita en las montañas del este de Europa y norte de África. En la Península Ibérica es habitual en las montañas del norte peninsular, escaseando hacia el sur y faltando en Andalucía y Portugal (López, 2007). Está también ampliamente distribuido por el área de estudio (Loidi Arregui \& Fernández Prieto, 1986; Barredo \& Barredo, 2002; Alejandre, et al., 2006; Loidi, et al., 2011; Uribe-Echebarría, 2012), donde debido a que necesita suelos algo húmedos, se encuentra preferentemente en las laderas de umbría, de cañones y barrancos.

Restos foliares de esta especie han aparecido en el norte de Italia en el yacimiento Pleistoceno de Piànico-Sèllere (Amsler, 1900; Maffei, 1924; Rytz, 1953; Moscariello, et al., 2000). En Francia, se encontró en el Pleistoceno Medio del Macizo Central, en el yacimiento de La Roquette —Valle de Tarn, Millau—(Vernet, et al., 1984; Ambert, et al., 1992). También en Francia se recogieron carbones de esta especie en el yacimiento arqueológico del Último Máximo Glacial de Abri Pataud —Dordogña- (Marquer, et al., 2010) e impresiones foliares en el depósito tobáceo holoceno de Serre de Montdenier —Provenza- (Roiron, et al., 2006). 


\section{Rhamnus frangula Linné, 1753}

\section{(Lám. 6, Figs. 1-2)}

\section{Material estudiado}

$R$. frangula aparece en la estructura TUAG-PS de Tubilla del Agua y en el desfiladero del río Purón, en el Valle de Tobalina con cuatro y siete ejemplares recogidos respectivamente (Anexo IV).

\section{Descripción}

Hojas elípticas de 4,1-8,2 cm de longitud por 2,3-5,8 cm de anchura; ápice de redondeado a acuminado, base de cuneada a convexa y margen entero. Limbo pinnado; nerviación de segundo orden broquidódroma débil, con 6-9 pares de nervios secundarios que se disponen de tanto de forma alterna como opuesta. Su curso es ligeramente curvado hasta cerca del margen de la hoja, donde se ramifican y curvan abruptamente formando lazos con los nervios adyacentes. Tanto el ángulo de divergencia $-\sim 45^{\circ}-$ como la distancia entre los nervios de segundo orden se mantiene uniforme a lo largo del limbo, mientras que la curvatura de los mismos aumenta algo conforme nos alejamos de la base.

Presencia en algunos ejemplares de nervios intersecundarios. La nerviación de tercer orden es tan solo visible en un ejemplar de pequeñas dimensiones —DRP-51—; se dispone uniendo los nervios de segundo orden, en algunos casos, de forma percurrente y, en otros, ahorquillándose previamente. En su conjunto, la nerviación de tercer orden tiende a orientarse de forma perpendicular al nervio central, excepto en la parte basal de la hoja, en donde se orienta perpendicular a la base. Tanto el nervio medio como la nerviación de segundo orden son prominentes en el envés. 


\section{Observaciones}

Esta especie caducifolia crece habitualmente hasta alcanzar el porte de un pequeño árbol de 4 ó $5 \mathrm{~m}$ de altura. Prefiere los suelos frescos, húmedos y ricos en nutrientes del fondo barrancos, orillas de arroyos, humedales y bosques de galería. Se distribuye por Europa, Asia y norte de África, incluyendo toda la Península Ibérica. Aquí, resulta más abundante en su mitad septentrional y occidental (López, 2007). R. frangula está presente en el área de estudio (Loidi Arregui \& Fernández Prieto, 1986; Barredo \& Barredo, 2002; Alejandre, et al., 2006; Loidi, et al., 2011; Uribe-Echebarría, 2012), donde suele encontrarse en suelos cercanos a humedales, vaguadas con aguas freáticas o rezumaderos de aguas montanas.

Esta especie forma parte de la flora pleistocena de la vertiente meridional de los Alpes de Hötling —Insbruck, Austria- (Murr, 1926; Sanders \& Ostermann, 2006). También se ha citado en Francia, en los depósitos del Pleistoceno Medio y Superior del Vallée du Lez (Farizier, 1980; Ambert, et al., 1995) y al sur del país, en los Alpes Marítimos, en el depósito holoceno del Valle de Mouresse (Roiron, et al., 2006).

\section{Orden FAGALES Engler, 1892}

Familia BETULACEAE Gray, 1822

Género Betula Linné, 1753

Betula sp.

(Lám. 6, Figs. 3-4)

\section{Material estudiado}

Se han estudiado nueve ejemplares (Anexo IV), todos ellos proceden del afloramiento TUAG-PS de Tubilla del Agua. Ninguno de los especímenes es una impresión foliar completa, por lo que este taxón ha sido identificado a partir de varios fragmentos parciales. 


\section{Descripción}

Hojas simétricas, notófilas de 5,8-7,5 cm de longitud y 4,4-6,1 cm de anchura, con forma ovada, ápice agudo y base truncada, redondeada o convexa. El margen, si bien no se conserva en estado óptimo en los ejemplares estudiados, parece estar aserrado, excepto en la parte basal de la hoja. El nervio medio presenta un curso recto o ligeramente ondulado y su grosor disminuye conforme nos alejamos de la base, siendo en todo caso más prominente por el envés que por el haz.

Nerviación pinnada craspedódroma, con 5-6 pares de nervios secundarios que nacen de forma opuesta en el nervio medio, aunque en algunos ejemplares se observa que puede existir una separación creciente entre nervios secundarios sucesivos conforme nos alejamos de la base. Por lo general, la distancia entre los diferentes pares de nervios a lo largo del nervio medio se mantiene uniforme. El ángulo de divergencia entre el nervio medio y los secundarios disminuye de la base hacia el ápice, oscilando entre los $50^{\circ}$ de los nervios basales —en los ejemplares con lámina de base truncada - y los $30^{\circ}$ de los nervios apicales. Su curso es recto, excepto en el primer par de nervios basales que en algunas impresiones se presentan ligeramente curvados hacia el ápice. En los ejemplares estudiados la nerviación secundaria es claramente visible en las impresiones del envés de las hojas, y apenas en el haz. La nerviación terciaria no se ha podido observar en ningún espécimen.

\section{Observaciones}

La descripción construida a partir de los ejemplares fósiles recogidos coincide con más de una especie del género Betula - p.e. B. pubescens Ehrh., B. pendula Roth-. Además, no se puede distinguir entre ellas en función de su morfología foliar. Su forma y tamaño también recuerdan a Populus nigra y $P$. tremula L., pero estas especies se distinguen fácilmente por la nerviación curvipinnada que presentan sus hojas. 
Los abedules son árboles caducifolios, raramente arbustos, cuyos ejemplares presentan una gran variabilidad morfológica. Se caracterizan por su predilección por los suelos ácidos y su carácter pionero, siendo una de las primeras especies arbóreas en colonizar terrenos despoblados tras un incendio o un periodo glacial (Castroviejo, et al., 1990). Las especies Ibéricas - B. pendula y $B$. pubescens - está ampliamente distribuidas por Europa y el norte de Asia, pero en la Península son comunes solo en el ámbito eurosiberiano, de litología silícea, quedando restringidas al piso montano en localidades más meridionales (López, 2007). Crecen en los márgenes de turberas y arroyos sobre suelos silíceos, sueltos y frescos. Ambas especies están presentes hoy en día en el área de estudio, aunque son muy escasas. Se han citado pequeñas poblaciones $B$. pendula en la Sierra de Árcena y el valle del río Inglares, y de $B$. alba en el Páramo de Masa, Basconcillos del Tozo, Sierra de Árcena y Montes Obarenes (Loidi Arregui \& Fernández Prieto, 1986; Barredo \& Barredo, 2002; Alejandre, et al., 2006; Loidi, et al., 2011; Uribe-Echebarría, 2012).

Se han hallado impresiones foliares de $B$. pubescens en el yacimiento tobáceo del Pleistoceno Medio —interglacial MIS 7- de Bilzingsleben (Harmon, et al., 1980; Mania, 2006). La misma especie se ha citado en los Alpes franceses, a una altitud de $2.200 \mathrm{msnm}$ en una toba de hace 9.800 años (Ali, et al., 2003a). Por otro lado, Betula es un taxón habitual en muchas series polínicas estudiadas en la Península Ibérica. Aparece, por ejemplo, de forma intermitente en los cercanos depósitos pleistocenos de Atapuerca —Burgos- (GarcíaAntón \& Sainz-Ollero, 1991), los cuales abarcan casi ininterrumpidamente el periodo comprendido entre 1.2 Ma y 240 ka (Rodríguez, et al., 2011). Dentro del área de estudio, también se encuentra en las series polínicas holocenas de la turbera de La Piedra, sobre todo en la primera parte del Holoceno (Muñoz Sobrino, et al., 1996). 
Capítulo 4. Resultados
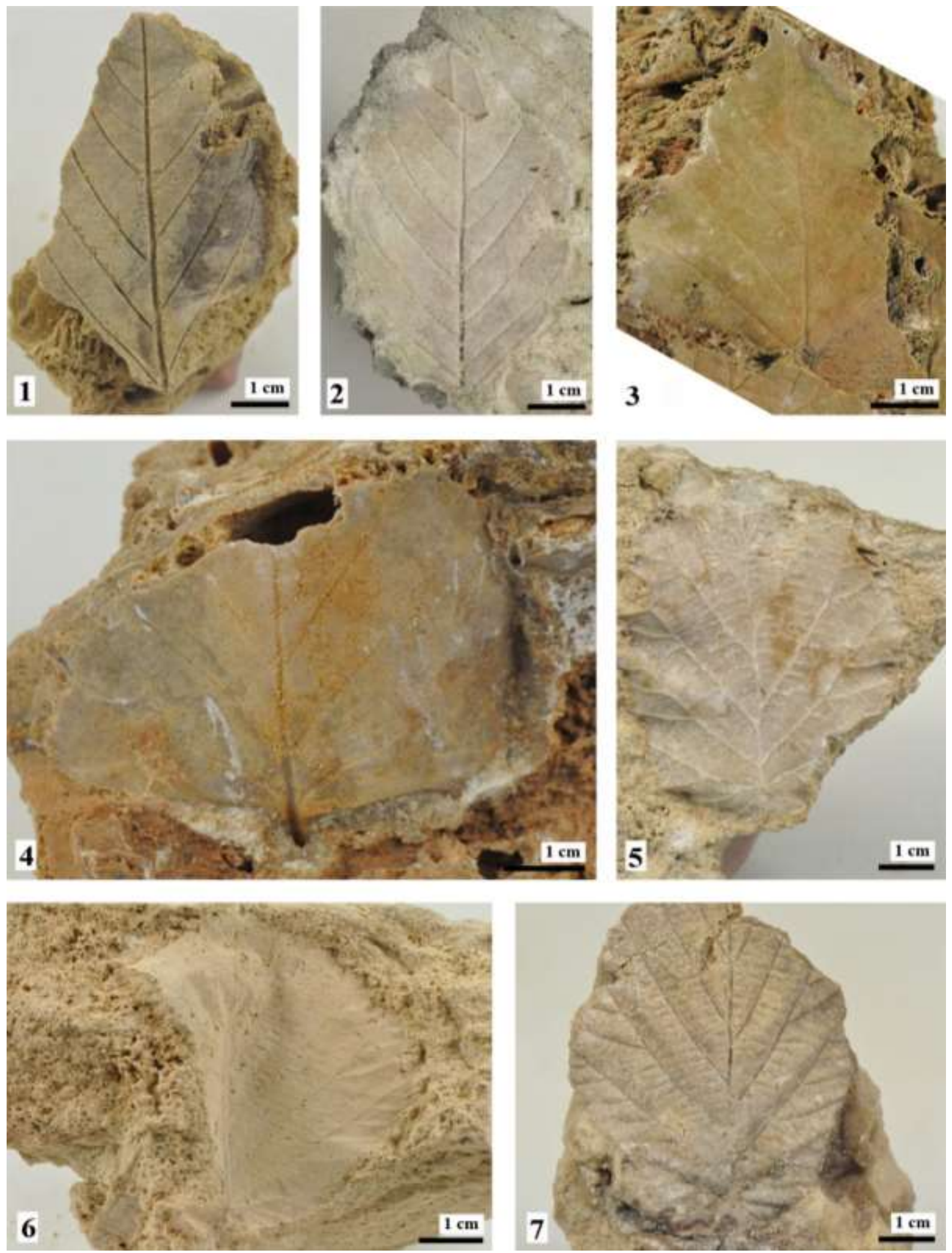

Lámina 6. Figs. 1-2. Rhamnus frangula L., (1) Envés, TUAG-PS-256, Tubilla del Agua, (2) Envés, DRP-56, Herrán; Figs. 3-4. Betula sp., (3) Envés, TUAG-PS-55, Tubilla del Agua, (4) Envés, TUAG-PS-60, Tubilla del Agua; Figs. 5-7. Corylus avellana L., (5) Haz, FF-71, Frías, (6) Haz, TUAG-TBH-35, Tubilla del Agua, (7) Envés, FF-68, Frías. 


\section{Género Corylus Linné, 1753 \\ Corylus avellana Linné, 1753}

(Lám. 6, Figs. 5-7)

\section{Material estudiado}

Este taxón aparece en seis de los afloramientos estudiados (Tabla 12). Con 106 ejemplares (Anexo IV) supone el 5,82\% de todos los encontrados.

\section{Descripción}

Hojas notófilas y mesófilas de 5,2-10,3 cm de longitud por 4,0-7,1 cm de anchura. Limbo pecíolado, simétrico, con forma orbicular u ovada, ápice acuminado, base cordada, lobulada o convexa y margen aserrado con dientes marginales. Nervio medio percurrente, prominente en el envés; más sobresaliente cuanto más cerca de la base. Nerviación pinnada craspedódroma, con los nervios secundarios -5 ó 6 pares- opuestos o alternos, uniformemente distribuidos a lo largo del nervio medio y ligeramente curvados hacia el ápice. Ángulo de divergencia decreciente de la base hacia el ápice —de $50^{\circ}$ a $35^{\circ}$ - Los primeros dos o tres pares de nervios basales pueden presentar ramificaciones —nerviación agrofítica-. Los nervios secundarios se presentan prominentes en el envés y algo deprimidos en el haz de las hojas.

Nerviación terciaria mezcla de opuesta y alterna percurrente, de curso recto o ahorquillado y con tendencia a disponerse de forma perpendicular al nervio medio. En los ejemplares estudiados, los nervios de tercer orden son muy visibles, tanto por el haz, donde se presentan deprimidos, como en el envés, donde son prominentes. Esto da un aspecto rugoso a la hoja por ambos lados. Sin embargo, la nerviación terciaria tiende a estar menos marcada en la parte media del espacio que existe entre los nervios secundarios. 


\section{Observaciones}

El avellano es un arbusto o arbolillo caduco y de bajo porte que rara vez alcanza más de 6 metros de altura. Suele desarrollar varios tallos que brotan desde la cepa. Requiere cierto grado de humedad edáfica, por lo que en el ámbito mediterráneo crece en el fondo de barrancos y umbrías. En la región Eurosiberiana se le puede encontrar formando parte de la orla arbustiva de bosques de hoja caduca. Habita en toda Europa y Asia occidental. En la Península Ibérica está principalmente presente en la mitad septentrional, siendo especialmente abundante en la Cornisa Cantábrica y Pirineos (López, 2007). Esta especie se encuentra distribuida por toda el área de estudio, pero está restringida a zonas con suelos frescos y poco soleadas, como valles cerrados, bosques de ribera, laderas en umbría, etc. (Loidi Arregui \& Fernández Prieto, 1986; Barredo \& Barredo, 2002; Alejandre, et al., 2006; Loidi, et al., 2011; Uribe-Echebarría, 2012).

Impresiones foliares de esta especie han sido encontradas de los niveles superiores del complejo tobáceo de Jorox, en la Serranía de Ronda —Málaga- Con respecto a la antigüedad de estos depósitos, solo se sabe que superan el límite de edad de la técnica empleada para su datación, por lo que tendrían más de 350 ka de antigüedad (Delannoy, et al., 1993). Se han encontrado también hojas de avellano en el yacimiento tobáceo del Pleistoceno Medio de La Roquette — Valle de Tarn, Millau, Macizo Central, Francia— (Vernet, et al., 1984). También, en el Pleistoceno Medio -MIS 7-, se ha hallado en el yacimiento tobáceo de Bilzingsleben -Turingia, Alemania- (Harmon, et al., 1980; Mania, 2006). En el interglacial Riss-Würn, aparece en los yacimientos de Hötling —Austria- (Murr, 1926), Beceite -Teruel— (Martínez-Tudela, et al., 1986), Burgtonna —Alemania- (Vent, 1978) y Millau —Francia—. Por último, han sido encontradas en el Holoceno impresiones de hojas de avellano en el yacimiento tobáceo de St-Antonin —Bouches-du-Rhone, Francia— (Ali, et al., 2003c) y en niveles datados en el periodo Boreal —7500-9000 años (Salas, 1992)— de los depósitos de Jorox —Málaga- (Delannoy, et al., 1993). 
El polen de Corylus, aunque en poca cantidad, aparece en muchos yacimientos tanto dentro del área de estudio como en las comarcas circundantes. Se ha citado, por ejemplo, en el Pleistoceno de los yacimientos de Atapuerca -Burgos- (García-Antón \& Sainz-Ollero, 1991)_ y Torralba —Soria_ (Ruiz-Zapata, et al., 2005) y en los del Holoceno de La Piedra —Burgos- (Muñoz Sobrino, et al., 1996)—, Lomilla —Palencia- (Alcalde-Olivares, et al., 2001)—, Quintanar de la Sierra —Burgos_(Ruiz-Zapata, et al., 2002), Peña Parda —Álava— (Ruiz Alonso \& Zapata, 2003), Arenaza —Álava- (Uzquiano \& Zapata, 2000) y Alsa Cantabria- (Mariscal, 1995).

\section{Familia FAGACEAE Dumortier, 1829 \\ Género Fagus Linné, 1753 \\ Fagus sylvatica Linné, 1753}

(Lám. 7, Figs. 1-3)

\section{Material estudiado}

Han sido estudiados 50 ejemplares (Anexo IV) que fueron recogidos de las estructuras TUAG-BH y TUAG-TBH de Tubilla del Agua. La mayoría de los especímenes —49-, proceden de la segunda de ellas y solo 1 de la primera (Tabla 12). En total suponen el 2,74\% de todo el registro fósil estudiado.

\section{Descripción}

Láminas foliares notófilas, pecíoladas, de 6,6-9,1 cm de longitud por 4,6-7,4 cm de anchura, forma elíptica, ápice acuminado y base convexa o redondeada. El margen es entero, aunque en algunos ejemplares se observan bordes ligeramente ondulados o ampliamente crenados.

Venación pinnada craspedódroma; el nervio medio sigue un curso ligeramente ondulado en aquellos ejemplares con nervios secundarios que están dispuestos de forma alterna. Otras impresiones foliares muestran todos los nervios de segundo orden opuestos, y 
en este caso el nervio medio sigue un curso recto. Los nervios secundarios — de 5 a 8 pares— siguen un curso recto hasta el margen. Se observa una disminución del ángulo de divergencia de la base $-50^{\circ}$ - hacia el ápice $-35^{\circ}-$, y una distribución homogénea de estos a lo largo del nervio medio.

En cuanto a la forma tridimensional, la lámina foliar suele aparecer de forma plana, con los nervios prominentes en el envés, aunque sobre ellos existe una costilla que los recorre, ligeramente sobresaliente en el haz. Los nervios de segundo orden son tan finos y prominentes como el principal y mantienen su grosor hasta el borde de la hoja. En algunos ejemplares, estos nervios se presentan más deprimidos de lo normal hacia el haz y el espacio entre dos nervios consecutivos está recorrido por una tenue nervadura que, a modo de bisagra, divide en dos planos oblicuos, dando a la hoja un aspecto ondulado. La nerviación terciaria no es visible en ningún ejemplar, presentando la lámina una superficie suave y lisa por ambos lados.

\section{Observaciones}

El haya es un árbol caducifolio que puede alcanzar hasta $35 \mathrm{~m}$ de altura. Crece sobre suelos frescos y ricos, preferentemente calizos. Habita en Europa central y occidental. En la Península Ibérica es una especie común en el tercio norte, haciéndose más rara hacia el sur o el oeste, de tal manera que las poblaciones más meridionales de esta especie se encuentran en el Sistema Central; no está presente en Portugal (López, 2007). Es una especie ampliamente distribuida por el sector Castellano Cantábrico, donde debido a su poca tolerancia a la sequía estival y las heladas tardías, busca las umbrías y terrenos no muy soleados o venteados (Loidi Arregui \& Fernández Prieto, 1986; Barredo \& Barredo, 2002; Alejandre, et al., 2006; Loidi, et al., 2011; Uribe-Echebarría, 2012). Si la estación es buena, acostumbra a formar bosques puros. Hojas de haya han sido encontradas en la flora del Interglacial Riss-Würn de Hötling, en los Alpes septentrionales —Austria- (Murr, 1926). 
Capítulo 4. Resultados
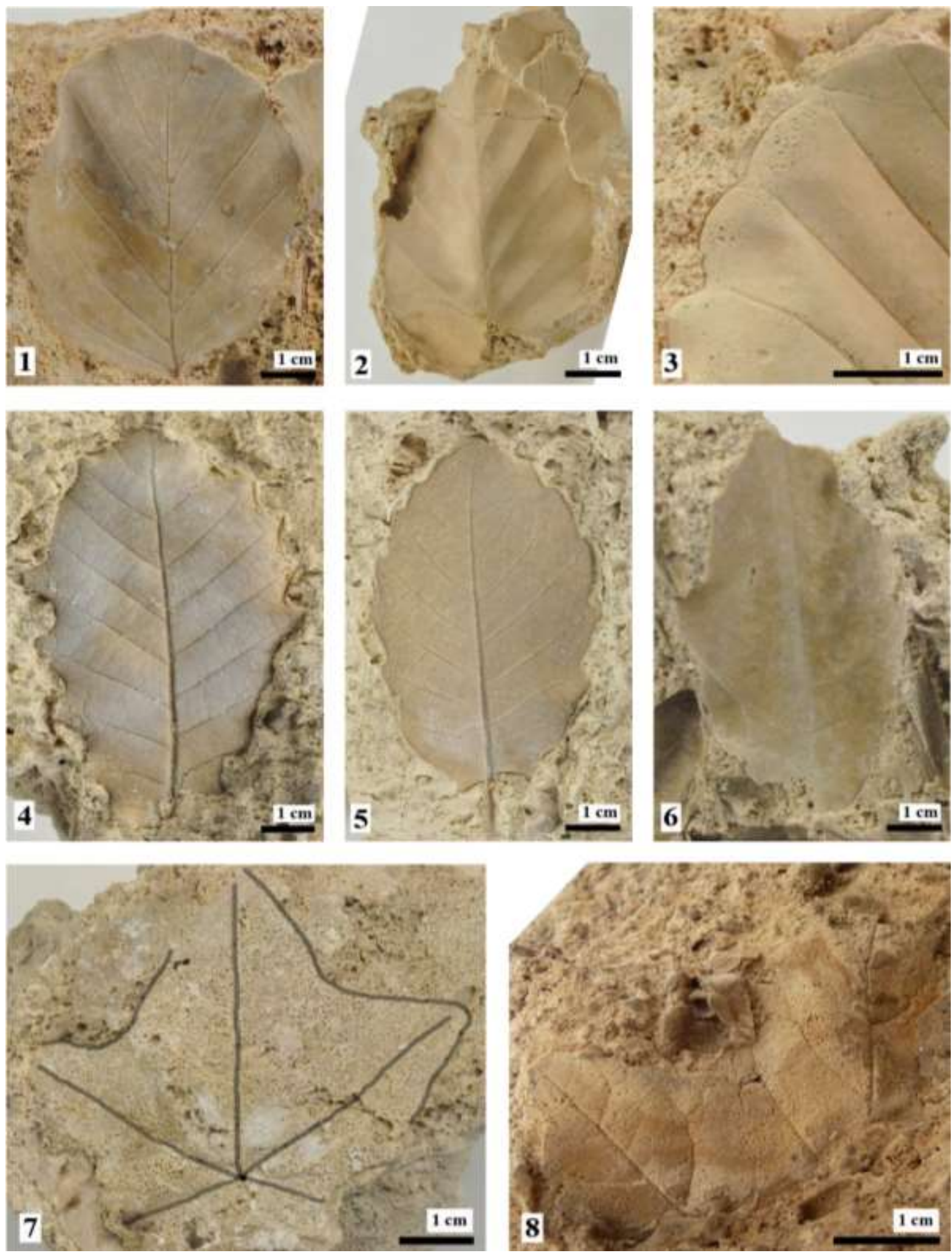

Lámina 7. Figs. 1-3. Fagus sylvatica L., (1) Envés, TUAG-TBH-22, Tubilla del Agua, (2) Haz, TUAG-TBH-38, Tubilla del Agua, (3) Detalle del margen, (Envés), TUAG-TBH-54, Tubilla del Agua; Fig. 6-8. Quercus faginea Lam. (6) Envés, TUAG-TP-93, Tubilla del Agua, (7), Envés, TUAG-TP-82, Tubilla del Agua, (8) Haz, SD-BI139, Sedano; Figs. 7-8. Acer campestre L., (7) Envés, se ha marcado en negro el limbo de la hoja y los nervios de primer orden. FF-106, Frías, (8) Detalle de la nerviación y márgen, (Envés), FF-99, Frías. 


\section{Género Quercus Linné, 1753}

\section{Quercus faginea Lamarck, 1785}

(Lám. 7, Fig. 4-6)

\section{Material estudiado}

Q. faginea, con 204 ejemplares (Anexo IV), es el cuarto taxón más abundante y representa el $11,20 \%$ de todos los fósiles recogidos. Fue encontrado en 10 de los 13 yacimientos estudiados (Tabla 12).

\section{Descripción}

Hojas notófilas de 4,7-7,8 cm de longitud y 2,6-3,9 cm de anchura, pecíoladas, con forma obovada o elíptica, ápice redondeado, base desde ligeramente lobulada hasta cuneada y margen lobulado o lobulado-dentado. Nerviación pinnada craspedódroma, toda ella prominente en el envés. El haz aparece plano y liso, aunque si el fósil está bien conservado, se pueden apreciar los nervios de primer, segundo y tercer orden ligeramente impresos. Nervio medio robusto y prominente en el envés, que se hace cada vez más delgado conforme discurre hacia el ápice. Lo mismo ocurre con los nervios de segundo orden que son más gruesos cerca del nervio medio - aunque no tanto como este- y se atenúan cerca del margen, llegando incluso a no ser visibles en algunos casos cerca del borde. El nervio medio sigue un curso recto o ligeramente ondulado. Los nervios de segundo orden se insertan con el mismo ángulo en el nervio medio —unos $45^{\circ}$ - curvándose después para seguir un curso recto en los nervios más basales — de hasta $0^{\circ}$ - y curvado hacia el ápice los más apicales - de hasta $20^{\circ}$ - Los pares de nervios de segundo orden se pueden encontrar opuestos o alternos, y tienden a estar distribuidos a lo largo del nervio medio de forma homogénea.

La nerviación de tercer orden, que es percurrente, se orienta de forma perpendicular a los nervios de segundo orden, a veces uniéndolos directamente $\mathrm{y}$, otras veces, bifurcándose. En unos pocos ejemplares se conserva la nerviación de cuarto orden, que 
forma una retícula ortogonal bien desarrollada. En las impresiones que conservan la forma tridimensional de la lámina, los lóbulos del margen, sobre todo los que se encuentran en las zonas media y apical de las hojas, están ligeramente recurvados. Esto se da en mayor medida en los ejemplares de margen lobulado-dentado.

\section{Observaciones}

El quejigo es un árbol caducifolio, marcescente, de tamaño medio que no suele sobrepasar los $20 \mathrm{~m}$ de altura. Se desarrolla en zonas de clima mediterráneo o mediterráneo continental, sobre todo tipo de suelos pudiendo llegar a en sustratos muy pobres. Q. faginea habita en la región mediterránea occidental. Está presente en toda la Península lbérica excepto en Asturias y Galicia (López, 2007). En concreto, se encuentra ampliamente distribuida por el sector Castellano Cantábrico, donde forma bosques puros - quejigares—o mixtos junto con encinas, otros robles o pinos de repoblación (Loidi Arregui \& Fernández Prieto, 1986; Barredo \& Barredo, 2002; Alejandre, et al., 2006; Loidi, et al., 2011; UribeEchebarría, 2012).

Q. faginea ha sido citada en el Pleistoceno Inferior de Crespià en Gerona (Roiron, 1983). En la Serranía de Ronda —Málaga - aparece en los depósitos del Pleistoceno Superior de Yunquera y en Tolox y Jorox, en el último interglacial (Delannoy, et al., 1993). También han sido encontradas impresiones de esta especie en el yacimiento del interglacial Riss-Würn del yacimiento de Beceite -Teruel— (Martínez-Tudela, et al., 1986; BadíaGimeno \& Muñoz-Bertomeu, 1999). 
Orden SAPINDALES Jussieu ex Bercht. \& J. Presl, 1820

Familia SAPINDACEAE Jussieu, 1789

Genero Acer Linné, 1753

Acer campestre Linné, 1753

(Lám. 7, Figs. 7-8)

\section{Material estudiado}

Se han recogido 23 ejemplares (Anexo IV), lo que supone el $1,26 \%$ del total del registro fósil estudiado (Tabla 12). Todos ellos proceden del yacimiento de Frías.

\section{Descripción}

Hojas notófilas, de 5,2-8,4 cm de longitud por 4,3-7,5 cm de anchura con forma palmada pentalobulada. El lóbulo central es siempre de mayor tamaño que los laterales, y estos a su vez mayores que los basales. Lámina pecíolada con el ápice redondeado, la base lobulada y el margen entero o ampliamente lobulado. El pecíolo se dispone perpendicular al plano de la hoja.

Nerviación de primer orden actinódroma basal, con 5 nervios originados en un mismo punto de la base, y de curso recto. Nerviación secundaria broquidódroma. Nervios secundarios algo curvados hacia el ápice pero uniformemente arqueados a lo largo de su recorrido, que se presentan alternos, con un ángulo de divergencia de unos $45^{\circ}$ y se encuentran separados por una distancia variable a lo largo del nervio medio. Presentan ramificaciones a lo largo de todo su recorrido pero, sobre todo, cerca del margen, en donde una mayoría de ellos se bifurcan en dos ramas. Nerviación primaria y secundaria prominente en el envés; los nervios de primer orden disminuyen de grosor progresivamente a lo largo de su recorrido hasta casi desaparecer cerca el ápice. Nerviación terciaria no conservada en los fósiles estudiados. 


\section{Observaciones}

A. campestre es un árbol caducifolio de pequeño porte, que no supera los $20 \mathrm{~m}$ de altura. Suele encontrarse de forma aislada o en pequeños grupos como especie secundaria en bosques de hoja caduca o formaciones de ribera, preferentemente sobre suelos naturaleza caliza, aunque puede crecer casi sobre cualquier tipo de sustrato. Habita en Europa, Asia y el Norte de África. En la Península Ibérica se encuentra solo en su mitad septentrional y especialmente en el cuadrante nororiental (López, 2007). Está ampliamente distribuida en el área de estudio, pero es escasa en número (Loidi Arregui \& Fernández Prieto, 1986; Barredo \& Barredo, 2002; Alejandre, et al., 2006; Loidi, et al., 2011; Uribe-Echebarría, 2012).

El arce campestre forma parte de la flora del yacimiento tobáceo del Pleistoceno Medio de Lazio —Italia — (Clerici, 1887; Manfra, et al., 1976). En Alemania, se ha encontrado en tobas en el estado de Turingia, en el afloramiento del Pleistoceno Medio de Bilzingsleben, (Harmon, et al., 1980; Mania, 2006). En el mismo periodo, ha sido hallada en el Macizo Central, en Francia, en los yacimientos de La Roquette - Millau- (Vernet, et al., 2008) y Meyrargues —La Provenza- (Magnin, et al., 1990). Así mismo, este taxón ha sido encontrado en materiales del interglacial Riss-Würn en Hötling, Alpes septentrionales — Austria- (Murr, 1926). También se ha recogido en el intergalcial Eemiense de Burgtonna Alemania- (Vent, 1978). Por último, vuelve a ser citada en el Holoceno de La Provenza francesa, en los yacimientos de Serre de Montdenier (Roiron, et al., 2006) y en St-Antonin Bouches-du-Rhone- (Ali, et al., 2003c).

\section{Acer cf. platanoides Linné, 1753}

\section{(Lám. 8, Fig. 1-2)}

\section{Material estudiado}

Se han encontrado dos únicos ejemplares (Anexo IV), ambos en la formación TUAGPS de Tubilla del Agua. Uno de ellos -TUAG-PS-261_, está fragmentado y solo conserva 
la parte media de una hoja. El segundo -TUAG-PS-262—se corresponde con el extremo de un lóbulo de una lámina de pequeñas dimensiones.

\section{Descripción}

Fragmentos de hojas, de $7,3 \times 7,8 \mathrm{~cm}$ el mayor y $3,2 \times 4 \mathrm{~cm}$ el menor. Lámina posiblemente palmada, con al menos 3 lóbulos; margen aserrado, con dos pares de dientes a cada lado del lóbulo, que son grandes y apuntados hacia el ápice. Nerviación actinódroma, con nervios de primer orden de curso recto o ligeramente curvado en su parte terminal. Nerviación de segundo orden craspedódroma. Algunos nervios secundarios terminan en los dientes marginales y otros parecen ramificarse sin llegar al margen. Nervios secundarios curvos, alternos y con un ángulo de divergencia de $40-50^{\circ}$. Nervios de tercer orden no preservados. Tanto la nerviación de primer orden como la de segundo aparecen de manera prominente en el envés de la hoja.

\section{Observaciones}

Las características principales que nos ha llevado a la identificación de los ejemplares descritos como $A$. cf. platanoides son la forma palmada, el característico margen ampliamente aserrado —exclusivo de A. platanoides entre las especies de distribución ibérica-y el patrón de nerviación secundaria. Sin embargo, algunas características de los fósiles sugieren un limbo de margen lobulado-dentado, como ocurre en la variedad $A$. platanoides var dissectum o en la especie americana Acer saccharum Marshall. Es por ello que tenemos ciertas reservas acerca de la verdadera identidad de este taxón por lo que se cita con duda —cf.—.

A. platanoides es un árbol caducifolio de hasta 30 metros de altura, de amplia copa y ramas gruesas. Crece en bosques umbrosos y de ribera sobre suelos frescos y fértiles. Ocupa buena parte de Europa Central llegando por el este hasta el Cáucaso e irán. En la Península Ibérica habita principalmente en los Pirineos oriental y Navarra (López, 2007). Esta especie no está presente en el área de estudio. 
Integró la flora del interglacial Riss-Würn de Hötling — Insbruck, Austria- (Murr, 1926). También ha aparecido en el Eemiense en la localidad alemana de Burgtonna (Vent, 1978)

\title{
Orden MALVALES Jussieu, 1820
}

Familia MALVACEAE Jussieu, 1789

\section{Género Tilia Linné, 1753}

\author{
cf. Tilia sp.
}

(Lám. 8, Figs. 4-5)

\section{Material estudiado}

Se han recogido un total de 19 ejemplares (Anexo IV), 16 en la estructura TUAG-PS de Tubilla del Agua y tres en el desfiladero del río Molinar (Tabla 12). Todos los fósiles estudiados se encuentran fragmentados.

\section{Descripción}

Hojas mesófilas, de 6,4-8,5 x 5,2-6,3 cm, pecíoladas, con forma ovada, ápice acuminado, base lobulada o cordada y margen aserrado. Nerviación pinnada craspedódodroma; los nervios secundarios — de 5 a 7 pares— se presentan casi siempre opuestos, algo arqueados hacia el ápice y con un ángulo de divergencia uniforme a lo largo del nervio medio, de unos $35^{\circ}-40^{\circ}$. La separación entre los distintos pares de nervios secundarios se reduce hacia el ápice. Presencia de varios pares de nervios agrofíticos; el primer par de ellos se origina en el centro de la base de la hoja y dan origen a un sistema relativamente extenso de nervios con curso perpendicular al nervio medio.

Los nervios de tercer orden se disponen generalmente de forma perpendicular a los de segundo orden, uniéndolos entre sí, de forma escalariforme. Algunos de ellos sin embargo se bifurcan, conformando una retícula mixta entre opuesta y alterna percurrente. Tanto la nerviación de segundo como de tercer orden se presentan prominentes en el envés. 


\section{Observaciones}

Los fósiles recogidos de Corylus avellana y cf. Tilia sp. presentan una apariencia similar y característica, tanto por el haz como por el envés. Los rasgos identificativos que permiten diferenciar $C$. avellana son la distancia uniforme y el ángulo divergente decreciente de los nervios de segundo orden a lo largo del nervio medio en $C$. avellana Además de esto, es característico de Tilia sp. el carácter opuesto de los nervios de segundo orden y el presentar un primer par de nervios agrofíticos bien desarrollado con origen en la base, y curso perpendicular al nervio medio, si bien ambas características pueden darse excepcionalmente en hojas de C. avellana.

El género Tilia comprende unas 30 especies de árboles caducifolios repartidos por las regiones templadas del Hemisferio Norte. Este género presenta problemas taxonómicos, derivados de su propensión a la hibridación interespecífica y la introgresión genética (Castroviejo, et al., 1993). Por lo tanto, existen individuos que combinan caracteres de dos especies diferentes, difíciles de clasificar taxonómicamente. En la Península Ibérica aparecen de forma natural dos especies T. platyphyllos y T. cordata Mill. Ambas son árboles robustos de tronco recto y copa amplia y ramosa. En condiciones favorables pueden llegar a medir más de $30 \mathrm{~m}$ y vivir cientos de años. Estas pueden aparecer juntas formando parte de bosques frescos y algo umbrosos, preferentemente sobre sustratos calizos. En el ámbito mediterráneo encuentran estas condiciones en el fondo de hoces, barrancos y al pie de cantiles rocosos (López, 2007).

El área de distribución de $T$. platyphyllos en la Península Ibérica comprende las montañas la mitad septentrional, principalmente del cuadrante nordeste, llegando por el sur hasta la serranía de Cuenca. T. cordata está presente en la Cordillera Cantábrica, País Vasco y Pirineos Orientales (López, 2007). T. platyphyllos, aunque no de forma abundante, se encuentra ampliamente distribuida por el sector biogeográfico Castellano Cantábrico, mientras que $T$. cordata únicamente ha sido citada en unas pocas localidades (Loidi Arregui 
\& Fernández Prieto, 1986; Barredo \& Barredo, 2002; Alejandre, et al., 2006; Loidi, et al., 2011; Uribe-Echebarría, 2012).

Ambas especies, forman parte de la flora pleistocena de Piànico-Sèllere, al norte de Italia (Maffei, 1924; Emmert-Straubinger, 1991). En este mismo depósito, que parece haber sido formado durante los Estadíos Isotópicos Marinos interglaciares 5, 7 ó 9 (Moscariello, et al., 2000), se han encontrado las especies del mismo género, T. caucásica Rupr. (Rytz, 1953) y T. tomentosa Moench. (Emmert-Straubinger, 1991). T. platyphyllos también aparece en el yacimiento de tobáceo del Pleistoceno Medio -MIS 7- de Bilzingsleben -Turingia, Alemania- (Harmon, et al., 1980; Mania, 2006). Así mismo, ha sido encontrada en el interglacial Riss-Würn de los Alpes septentrionales —Hötling, Austria— (Murr, 1926; Sanders \& Ostermann, 2006). En la Península Ibérica, se ha hallado el taxón Tilia aff T.platyphyllos en el yacimiento del Pleistoceno Inferior de Crespià —Gerona- (Villalta \& Vicente, 1972). En el Holoceno, Tilia ha aparecido en la Sierra de Montdenier — Sur de Francia- (Roiron, et al., 2006) y en Weilheim —Bavaria, Alemania— (Herrmann, 1957).

Por otro lado, el polen de este género ha sido identificado en numerosos sondeos de la Península Ibérica, fundamentalmente del tercio norte y noreste peninsular. Por ejemplo, aparece de forma testimonial en las secuencias pleistocenas de la Sierra de Atapuerca Burgos - y en muchas otras del Holoceno de las provincias que circundan la zona de estudio —p.e. Los Tornos (Muñoz-Sobrino, et al., 2005) y Alsa (Mariscal, 1993) en Cantabria, Peña Parda en Guipúzcoa (Pérez Díaz, et al., 2007) y Quintanar de la Sierra (Ruiz-Zapata, et al., 2002) en Burgos-. 


\section{Orden CORNALES Link, 1829 \\ Familia CORNACEAE Berchtold ex J.Presl, 1825 \\ Genero Cornus Linné, 1753 \\ Cornus sanguinea Linné, 1753}

(Lám. 8, Fig. 3)

\section{Material estudiado}

Han sido recogidos 11 ejemplares (Anexo IV) en las estructuras TUAG-VBH y TUAGPS de Tubilla del Agua y en la formación de Frías (Tabla 12).

\section{Descripción}

Hojas con forma elíptica, de 6,1-7,5 cm de longitud por 4,3-5,8 cm de anchura, ápice acuminado, base convexa o redondeada y margen entero. Limbo asimétrico en la parte terminal de la hoja, ya que por lo general un lado puede estar más desarrollado que el opuesto. Nerviación curvipinnada eucamptódroma, con el nervio central robusto y 4 ó 5 pares de nervios secundarios, opuestos los basales y alternos los distales. La distancia entre ellos aumenta en sentido apical. La curvatura es similar en todos los nervios y se mantiene uniforme a lo largo de ellos, siendo el ángulo de divergencia de los nervios de segundo orden es de unos $30^{\circ}$.

La nerviación de tercer orden se dispone percurrente entre los nervios secundarios. Es más aparente entre los primeros pares de nervios donde, de forma característica pueden presentarse algunos nervios terciarios tan gruesos como los secundarios, formando retículas y alterando el curso curvo de los de segundo orden. La nerviación de primer y segundo orden se presenta prominente hacia el envés, tanto, que en algunos de los ejemplares estudiados se observa combado el espacio entre los nervios secundarios. 


\section{Observaciones}

Las hojas de $C$. sanguinea se asemejan a las de la especie Rhamnus cathartica L., que también presenta una nerviación eucamptódroma. El rasgo diferencial que se ha considerado para la identificación de los ejemplares estudiados ha sido el número de nervios secundarios, ya que en $R$. cathartica no suelen aparecer más de 3 pares.

Esta especie, caducifolia, posee un porte de no más de $5 \mathrm{~m}$. Forma parte de la orla arbustiva de bosques caducifolios, donde crece preferentemente sobre suelos frescos, profundos y ricos. Habita en toda Europa y el sudoeste de Asia. En la Península Ibérica se encuentra principalmente en la mitad septentrional (López González, 2006). Es habitual en el área de estudio (Loidi Arregui \& Fernández Prieto, 1986; Barredo \& Barredo, 2002; Alejandre, et al., 2006; Loidi, et al., 2011; Uribe-Echebarría, 2012).

C. sanguínea ha sido citada en el interglacial Eemiense de los Alpes septentrionales —Insbruck, Austria — (Murr, 1926) y en el yacimiento Pleistoceno de Piànico-Sèllere, al norte de Italia (Amsler, 1900; Maffei, 1924; Rytz, 1953; Moscariello, et al., 2000). También ha sido encontrada en Francia, en el MIS 3, en la flora de los afloramientos de Roquevaire (D'Anna, et al., 1988) y Castelnau-le-Lez (Ambert, et al., 1995). En el Holoceno se cita en La Provenza francesa, en la localidad de St-Antonin —Bouches-du-Rhone- (Ali, et al., 2003c). 
Capítulo 4. Resultados

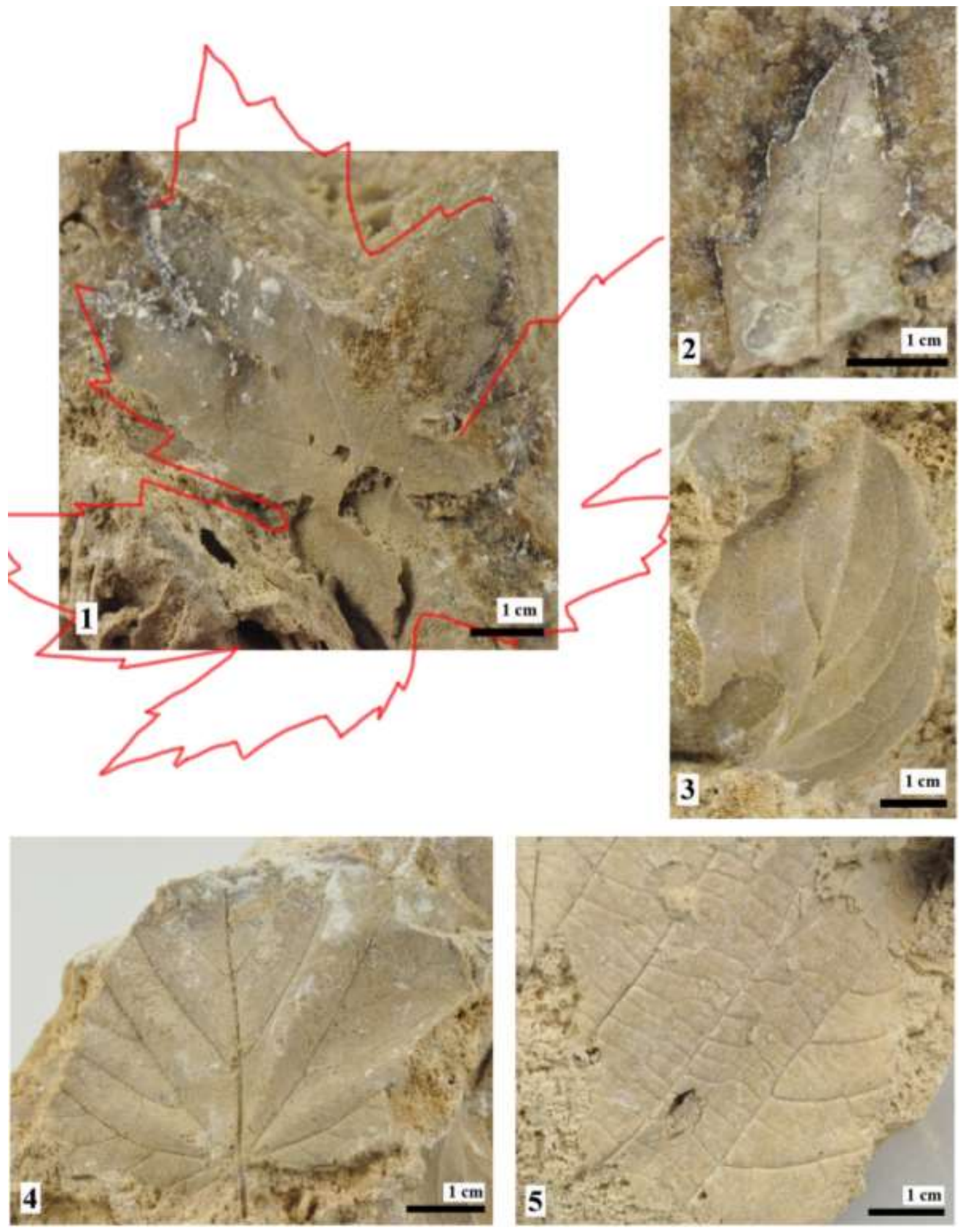

Lámina 8. Figs. 1-2. Acer cf. platanoides, (1) Envés, se ha marcado en rojo la silueta del limbo completo. TUAGPS-261, Tubilla del Agua, (2) Detalle de un lóbulo (Envés), TUAG-PS-262, Tubilla del Agua; Fig. 5. Cornus sanguinea L. (Envés). TUAG-PS-221, Tubilla del Agua; Figs. 4-5. cf. Tilia sp., (4) Envés, TUAG-PS-239, Tubilla del Agua (5) Detalle del márgen y la nerviación (Envés), DRM-106, Tobera. 
Orden LAMIALES Bromhead, 1838

Familia OLEACEAE Hoffmannsegg. \& Link, 1809

Género Fraxinus L., 1753

Fraxinus sp.

(Lám. 9, Figs. 1-2)

\section{Material estudiado}

Este taxón solo ha sido encontrado en el yacimiento del desfiladero del río Purón, en el que se han recogido 49 ejemplares (Anexo IV), lo que supone el 2,9\% del registro fósil estudiado (Tabla 12).

\section{Descripción}

Fragmentos de hojas imparipinnadas con folíolos opuestos de 4,5-6,6 cm de longitud por 2,3-3,8 cm de anchura, con forma elíptica, ápice acuminado, base cuneada y margen aserrado. Folíolos pinnados, con un nervio medio robusto de curso recto. Nerviación secundaria aparentemente semicraspedódroma; los nervios de segundo orden — de 8 a 12— se disponen alternos, uniformemente curvados, con una separación variable entre ellos y un ángulo de divergencia similar para todos ellos, de unos $50^{\circ}$. Tanto la nerviación de primer como de la de segundo orden se presentan prominentes en el envés; el nervio medio es especialmente visible, aunque es cada vez menos patente conforme se aleja de la base, hasta casi desaparecer cerca del ápice. La nerviación secundaria, aunque visible, es mucho más fina. Las impresiones del haz aparecen lisas, tan solo están recorridas por la acanaladura correspondiente a la hendidura del nervio medio de los folíolos. No se observa nerviación de menor rango. 


\section{Observaciones}

El género Fraxinus comprende unas 45 especies distribuidas por el Hemisferio Norte. De las 5 que habitan en Europa, tres de ellas -F. excelsior, F. angustifolia y $F$. ornus- lo hacen en la Península Ibérica (López González, 2006). Las tres tienen porte arbóreo, siendo F. excelsior la de mayor porte —hasta $40 \mathrm{~m}$ - y F. ornus el de menor — no más de $20 \mathrm{~m}$ Sus hojas, compuestas, pueden llegar ser similares, por lo que no es posible identificar una especie concreta a partir de los folíolos descritos. Las tres se desarrollan sobre suelos profundos y frescos, pudiendo formar parte de los bosques de ribera. Mientras que $F$. excelsior y $F$. angustifolia están distribuidas por casi toda la península, $F$. ornus está habita principalmente en las montañas del este peninsular (López González, 2006). Las tres se encuentran representadas en el sector Castellano Cantábrico, pero mientras que $F$. excelsior y $F$. angustifolia, sin ser abundantes, están bien distribuidas, $F$. ornus solo cuenta con una población en los montes de Oña (Loidi Arregui \& Fernández Prieto, 1986; Barredo \& Barredo, 2002; Alejandre, et al., 2006; Loidi, et al., 2011; Uribe-Echebarría, 2012).

El género Fraxinus ha sido citado en la Península Ibérica en el yacimiento del Pleistoceno Inferior de Crespià -Gerona- (Roiron, 1983), y las especies F. excelsior y $F$. angustifolia en los depósitos tobáceos del interglacial Riss-Würn de Beceite -Teruel— (Martínez-Tudela, et al., 1986; Badía-Gimeno \& Muñoz-Bertomeu, 1999).

Fuera de la Península Ibérica, en afloramientos del Pleistoceno Medio, han sido también citados F. excelsior y F. ornus: la primera de ellas en La Roquette — Valle de Tarn, Millau, Francia- (Ambert, et al., 1992) y en las localidades alemanas del Pleistoceno Medio de Bilzingsleben, (Harmon, et al., 1980; Mania, 2006), y Burgtonna (Vent, 1978). Por su parte, F. ornus, se ha citado como integrante de la flora del yacimiento tobáceo de Fiano Romano —Lazio, Italia— (Clerici, 1887; Manfra, et al., 1976). 
Capítulo 4. Resultados
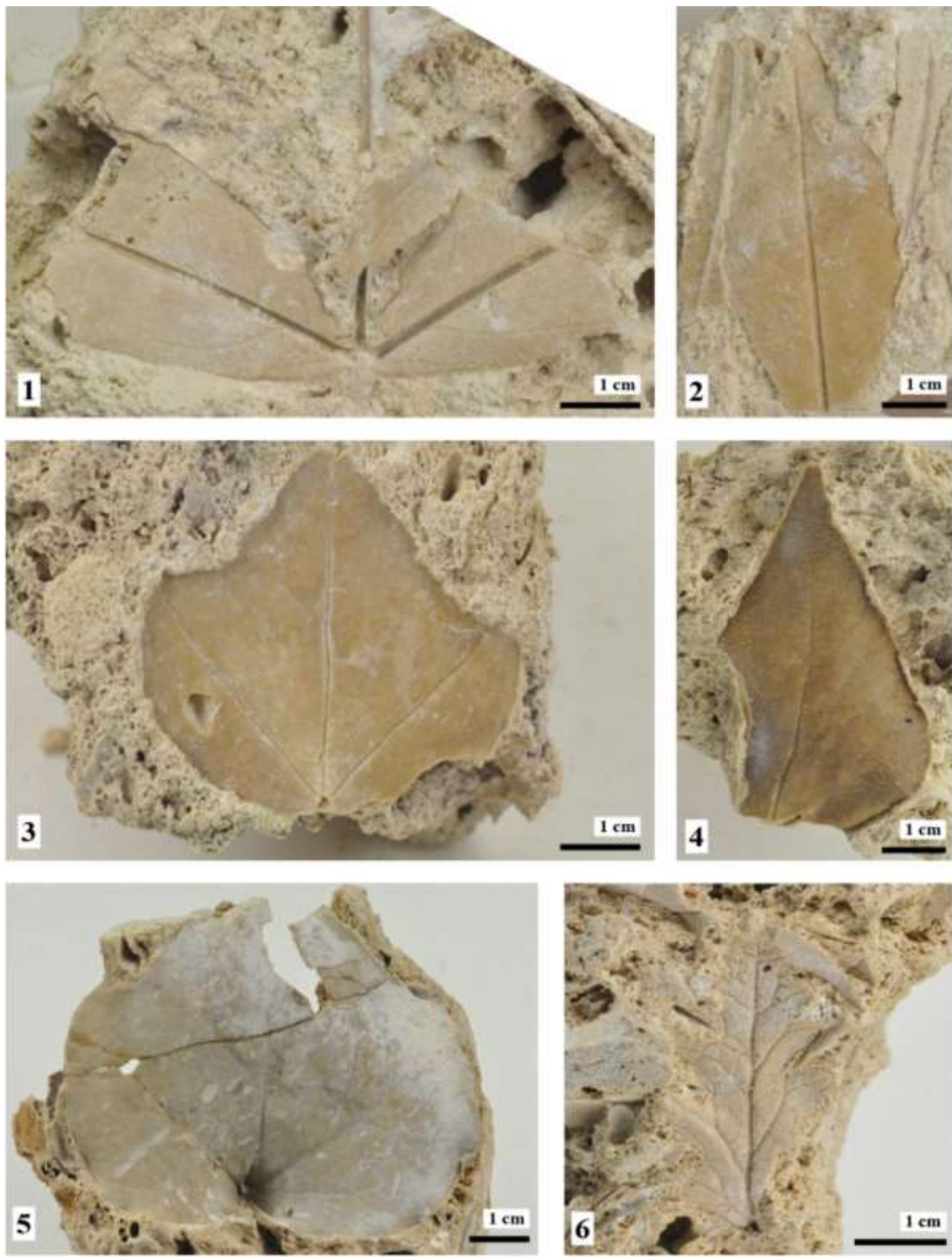

Lámina 9. Fig. 1-2. Fraxinus sp., (1) Envés, fragmentos de dos foliolos opuestos y sentados, DRP-159, Herrán, (2) Envés, foliolo aislado, DRP-162, Herrán; Figs. 3-5. Hedera sp. L., (1) Haz, SD-BI-25, Sedano, (4) Envés, TUAG-TP-55, Tubilla del Agua, (5) Envés, TUAG-TMM-34, Tubilla del Agua; Fig. 6. Dicotyphyllum sp. 1, Envés, TUAG-BH-12, Tubilla del Agua. 


\section{Orden APIALES Nakai, 1930 \\ Familia ARALIACEAE Jussieu, 1789 \\ Género Hedera Linné, 1753 \\ Hedera sp. \\ (Lám. 9, Figs. 3-5)}

\section{Material estudiado}

Este taxón ha aparecido en 10 de los 13 afloramientos que se estudian en esta memoria (Tabla 12). Se han recogido 133 fósiles (Anexo IV), lo que supone el 7,30\% del total.

\section{Descripción}

Hojas de tamaño variable, de 4,6-8,7 cm de longitud por 3,3-5,7 cm de anchura con limbo simétrico y pecíolado de margen entero que en algunos ejemplares se puede presentar algo revoluto. Presentan una morfología foliar variable; la lámina puede ser desde orbicular u ovada a palmada, el ápice acuminado, agudo o redondeado y la base aguda, truncada o lobada. La nerviación varía de acuerdo con la forma de la hoja. Las pinnadas presentan una nerviación broquidódroma mientras los ejemplares palmados tienen una nerviación actinódroma basal, encontrándose limbos con 3 ó 5 lóbulos que pueden estar más o menos hendidos. En ambos casos, pueden existir entre 3 y 6 pares de nervios de segundo orden y nervios intersecundarios, que adoptan una estructura broquidódroma. Estos se disponen de forma irregular en cuando a la orientación, curso y ángulo de divergencia con respecto al nervio medio, mientras que disminuye la separación entre los nervios secundarios conforme nos alejamos de la base. La nerviación de tercer orden forma una retícula ortogonal sin seguir un patrón regular.

La superficie de los ejemplares estudiados presenta la nerviación de forma patente en ambas caras del limbo, pero resalta de forma más patente en el envés. También se observa que tanto la nerviación de primer orden como la de segundo se hace menos prominente 
conforme se acerca al margen. Muchos de los ejemplares estudiados están combados hacia la base, con el pecíolo casi perpendicular al limbo.

\section{Observaciones}

La gran diversidad de formas de hojas descritas a partir de los especímenes estudiados concuerda con la heterofilia foliar de Hedera, en la que las hojas de las ramas fructíferas son pinnadas, mientras que las de las ramas vegetativas tienen formas palmadas (López, 2007). En la Península Ibérica habitan dos hiedras. $H$. helix L. y $H$. hibernica (G.Kirchn.) Carrière, ambas muy similares entre sí (López, 2007). La gran variabilidad intra e interespecífica de estos dos taxones, además del hecho de que pueden hibridarse allí donde sus áreas de distribución entran en contacto, hace difícil su identificación a partir de impresiones foliares.

Las hiedras son plantas perennes, leñosas, trepadoras, que pueden alcanzar hasta los $30 \mathrm{~m}$ de altura. Crecen en ambientes húmedos, como los que se encuentran en bosques de ribera, barrancos y umbrías, trepando tanto por árboles como por rocas, y pudiendo ser rastreras sino tienen a qué encaramarse. $H$. helix habita en toda Europa, hasta el Cáucaso y en toda la Península lbérica e Islas Baleares, mientras que $H$. hibernica se distribuye por la fachada atlántica del continente europeo, desde Escocia a Portugal (López, 2007). De ambas hiedras, solo $H$. helix habita en el sector Castellano Cantábrico, donde se encuentra en bosques umbrosos y frescos (Loidi Arregui \& Fernández Prieto, 1986; Barredo \& Barredo, 2002; Alejandre, et al., 2006; Loidi, et al., 2011; Uribe-Echebarría, 2012).

Se han hallado fósiles de $H$. helix en Italia, en el yacimiento pleistoceno de PiànicoSèllere, (Amsler, 1900; Maffei, 1924; Rytz, 1953; Moscariello, et al., 2000), así como en el Pleistoceno Medio del depósito de Lazio (Clerici, 1887; Manfra, et al., 1976). En Alemania forma parte de la flora del Pleistoceno Medio -MIS 7- de Bilzingsleben (Harmon, et al., 1980; Mania, 2006) y de la del interglacial Eemiense de Burgtonna (Vent, 1978). 
En el interglacial Riss-Würn se ha citado en Insbruck, Austria (Murr, 1926) y Beceite -Teruel- (Martínez-Tudela et al., 1986; Badía-Gimeno and Muñoz-Bertomeu, 1999). En Francia, han sido encontradas impresiones foliares de hiedra en los depósitos del Pleistoceno Superior del Vallée du Lez —MIS 3 y 4- (Farizier, 1980; Ambert, et al., 1995) y en el de Huveaune -MIS 3 - (Ambert, et al., 1995). En este mismo país aparece en el Holoceno en las localidades de St-Antonin —Bouches-du-Rhone- (Ali, et al., 2003c) y Saint Guilhem-leDésert —l'Herault— (Lecoeuvre, et al., 2008; Ali, et al., 2008). También se ha hallado en los depósitos holocenos del yacimiento tobáceo de Jorox, en la Serranía de Ronda —Málaga— (Delannoy, et al., 1993)

\section{Dicotylophyllum sp 1.}

(Lám. 9, Fig. 6)

\section{Material estudiado}

Este taxón, del que se han recogido únicamente tres ejemplares (Anexo IV), solo ha sido encontrado en la estructura TUAG-BH de Tubilla del Agua (Tabla 12).

\section{Descripción}

Hojas micrófilas, de 2,4-3 cm de longitud por 1-1,5 cm de anchura, con forma elíptica, ápice redondeado, base cuneada y margen lobulado. Lámina pinnada, con un nervio medio robusto de curso algo ondulado del que salen 4-6 pares de nervios secundarios, alternos y de curso ligeramente ondulado. Presentan un ángulo de divergencia de entre $35^{\circ}$ y $50^{\circ}$. Los nervios secundarios están separados entre ellos por una distancia variable, bifurcándose cerca del margen y terminando uno de los ramales en el ápice del lóbulo y, el otro, en la zona hendida entre dos lóbulos. Aparecen también nervios intersecundarios, y otras ramificaciones en los nervios de segundo orden que recorren el margen de la hoja o enlazan las distintas nervaduras formando una cuadrícula heterogénea en cuanto a la forma y tamaño de las 
areolas. Todos los especímenes estudiados se corresponden a impresiones del envés de la hoja, donde la nerviación es prominente, especialmente el nervio medio.

\section{Observaciones}

Los fósiles descritos presentan cierta similitud con hojas de plantas herbáceas anuales ligadas a terrenos húmedos y frescos de las familias Apiaceae, Ranunculaceae, Asteraceae etc., sin poder concretar más a partir de los restos encontrados. 
Capítulo 4. Resultados

\begin{tabular}{|c|c|c|c|c|c|c|c|c|c|c|c|c|c|c|}
\hline Comarca & \multicolumn{9}{|c|}{ Valle del Rudrón } & \multicolumn{3}{|c|}{ Valle de Tobalina } & \multirow{3}{*}{$\begin{array}{c}\text { V. I. } \\
\text { Ocio } \\
\text { Bo }\end{array}$} & \\
\hline Localidad & \multicolumn{7}{|c|}{ Tubilla del Agua } & \multicolumn{2}{|c|}{ Sedano } & \multirow{2}{*}{$\begin{array}{c}\text { Herr } \\
\text { án } \\
\text { DRP }\end{array}$} & \multirow{2}{*}{$\begin{array}{l}\text { Tob } \\
\text { era }\end{array}$} & \multirow{2}{*}{$\begin{array}{c}\text { Frías } \\
\mathrm{FF}\end{array}$} & & \\
\hline Taxón & VBH & BH & TMM & TBH & TP & $\mathrm{T}$ & PS & BS & BI & & & & & \\
\hline Fontinalis antipyretica & & & & 1 & & & 1 & 2 & & & & & & $4(0,16)$ \\
\hline $\begin{array}{c}\text { Asplenium } \\
\text { scolopendrium }\end{array}$ & & & & & & & & & & & & 1 & & $1(0,05)$ \\
\hline Pinus nigra & 3 & 2 & 2 & 2 & 3 & & 6 & & 4 & 5 & 3 & 2 & 5 & $37(2,03)$ \\
\hline Pinus sp. & 26 & 13 & & 5 & 8 & 2 & 19 & & 6 & 62 & 20 & 11 & & $172(9,45)$ \\
\hline Poales incertae sedis 1 & 17 & 1 & & 2 & 2 & 5 & 1 & 1 & 23 & 35 & 12 & 1 & & $100(5,49)$ \\
\hline Poales incertae sedis 2 & & & & & & & & 1 & & & & & & $1(0,05)$ \\
\hline Juncus sp. & & & 2 & & 1 & & 2 & 2 & 2 & & 1 & 1 & & $11(0,60)$ \\
\hline Berberis vulgaris & 3 & 1 & & & & & & 1 & 19 & & & & & $24(1,32)$ \\
\hline Buxus sempervirens & & & & & & & 76 & & & 34 & & & & $110(6,04)$ \\
\hline Salix eleagnos & & & & & & & 15 & & & 16 & & 5 & & $36(1,98)$ \\
\hline Salix sp. 1 & & 1 & & 1 & 1 & & 82 & 49 & 12 & & 14 & & & $160(8,79)$ \\
\hline Salix sp. 2 & & & 20 & & & 2 & 10 & 2 & 11 & 16 & 3 & 4 & & $68(3,73)$ \\
\hline Salix sp. 3 & 2 & & & & 23 & & & & & & & & & $25(1,37)$ \\
\hline Amelanchier ovalis & 10 & 10 & & & & & & 26 & 128 & 33 & 2 & & & $209(11,53)$ \\
\hline Sorbus aria & 42 & 7 & 10 & 5 & 1 & & 7 & 8 & 81 & 16 & 41 & 3 & & $221(12,14)$ \\
\hline Rhamnus alpina & & 7 & & & & & & 4 & 10 & & & & & $21(1,15)$ \\
\hline Rhamnus frangula & & & & & & & 4 & & & 7 & & & & $11(0,60)$ \\
\hline Betula sp. & & & & & & & 9 & & & & & & & $9(0,49)$ \\
\hline Corylus avellana & 11 & & & 8 & & & 3 & & & 13 & 15 & 56 & & $106(5,82)$ \\
\hline Fagus sylvatica & & 1 & & 49 & & & & & & & & & & $50(2,75)$ \\
\hline Quercus faginea & 30 & 1 & & & 54 & 1 & 13 & 9 & 33 & 27 & 32 & 4 & & $204(11,20)$ \\
\hline Acer campestre & & & & & & & & & & & & 23 & & $23(1,26)$ \\
\hline Acer ef. platanoides & & & & & & & 2 & & & & & & & $2(0,11)$ \\
\hline cf. Tilia sp. & & & & & & & 16 & & & & 3 & & & $19(1,04)$ \\
\hline Cornus sanguínea & 1 & & & & & & 9 & & & & & 1 & & $11(0,60)$ \\
\hline Fraxinus sp. & & & & & & & & & & 49 & & & & $49(2,69)$ \\
\hline Hedera sp. & & 6 & 17 & 9 & 13 & 1 & & 22 & 22 & 24 & 15 & 4 & & $133(7,30)$ \\
\hline Dicotylophyllum sp. 1 & & 3 & & & & & & & & & & & & $3(0,16)$ \\
\hline № / afloramiento & 145 & 53 & 51 & 82 & 106 & 11 & 275 & 127 & 351 & 336 & 162 & 116 & 5 & 1820 \\
\hline$\%$ / afloramiento & 7,96 & 2,91 & 2,8 & 4,56 & 5,82 & 0,6 & 15,1 & 6,97 & 19,3 & 18,5 & 8,9 & 6,37 & 0,27 & \\
\hline $\begin{array}{c}\text { № / localidad } \\
\text { (\%) }\end{array}$ & & & & $\begin{array}{l}723 \\
9,76)\end{array}$ & & & & & & $\begin{array}{r}336 \\
18,5\end{array}$ & $\begin{array}{l}162 \\
8,9\end{array}$ & $\begin{array}{l}116 \\
6,37\end{array}$ & $\begin{array}{c}5 \\
0,27\end{array}$ & \\
\hline $\begin{array}{c}\text { № / comarca } \\
\text { (\%) }\end{array}$ & & & & & $\begin{array}{l}1201 \\
66,01)\end{array}$ & & & & & & $\begin{array}{c}614 \\
(33,72\end{array}$ & & $\begin{array}{c}5 \\
0,27\end{array}$ & \\
\hline
\end{tabular}

Tabla 12. Número de ejemplares fósiles de toba recogidos en los 6 yacimientos estudiados en esta Tesis, contabilizados por taxón, afloramiento, localidad y comarca. 


\subsection{Distribución temporal de los depósitos tobáceos y reconstrucción de las paleofitocenosis}

La asignación de las 13 unidades litológicas que componen los seis yacimientos estudiados a diferentes estadíos climáticos es el resultado de combinar los intervalos de confianza de las 31 dataciones disponibles con la escala temporal de unidades climáticas establecida en el capítulo de metodología. De todas estas dataciones, 15 de ellas han sido obtenidas ex profeso para la elaboración de esta Tesis Doctoral (Tablas 8-11), y las 16 restantes fueron tomadas de diferentes publicaciones consultadas (Tablas 1-5). Durante este proceso se han tenido en cuenta las consideraciones hechas en el apartado 5.1. del capítulo de Discusión sobre la fiabilidad de los resultados de las muestras datadas y la edad los depósitos. Por ejemplo, los resultados las muestras TUAG-UT-1, TUAG-UT-2 y CERAK-7835 han sido excluidos del análisis por problemas de fiabilidad y los de TUB1, GrA38029 y GrA38059 por considerar que no representan el depósito del que supuestamente fueron tomadas. La asignación de las distintas unidades litológicas a un estadío climático determinado nos permite establecer la presencia en ese periodo de los taxones de su registro fósil -Tabla 12-.

Como puede observarse en la Fig. 16, la cual recoge de forma sintética el resultado del proceso descrito anteriormente, el conjunto de unidades litológicas consideradas abarca buena parte del Cuaternario Final. Únicamente no están representados los MIS 3 y 6 , aunque en el primero de ellos se consigna la presencia de Pinus sp. a partir de la madera carbonizada -TUAG-TRESP-1 - aparecida en un paleosuelo de TUAG-T (Lám 2, Fig. 3) y datada en $37.870 \pm 370$ años $\mathrm{BP}^{4}$ (Tabla 8).

\footnotetext{
${ }^{4}$ La antigüedad de esta muestra se expresa en edad radiocarbónica convencional por encontrarse fuera del rango de calibración.
} 


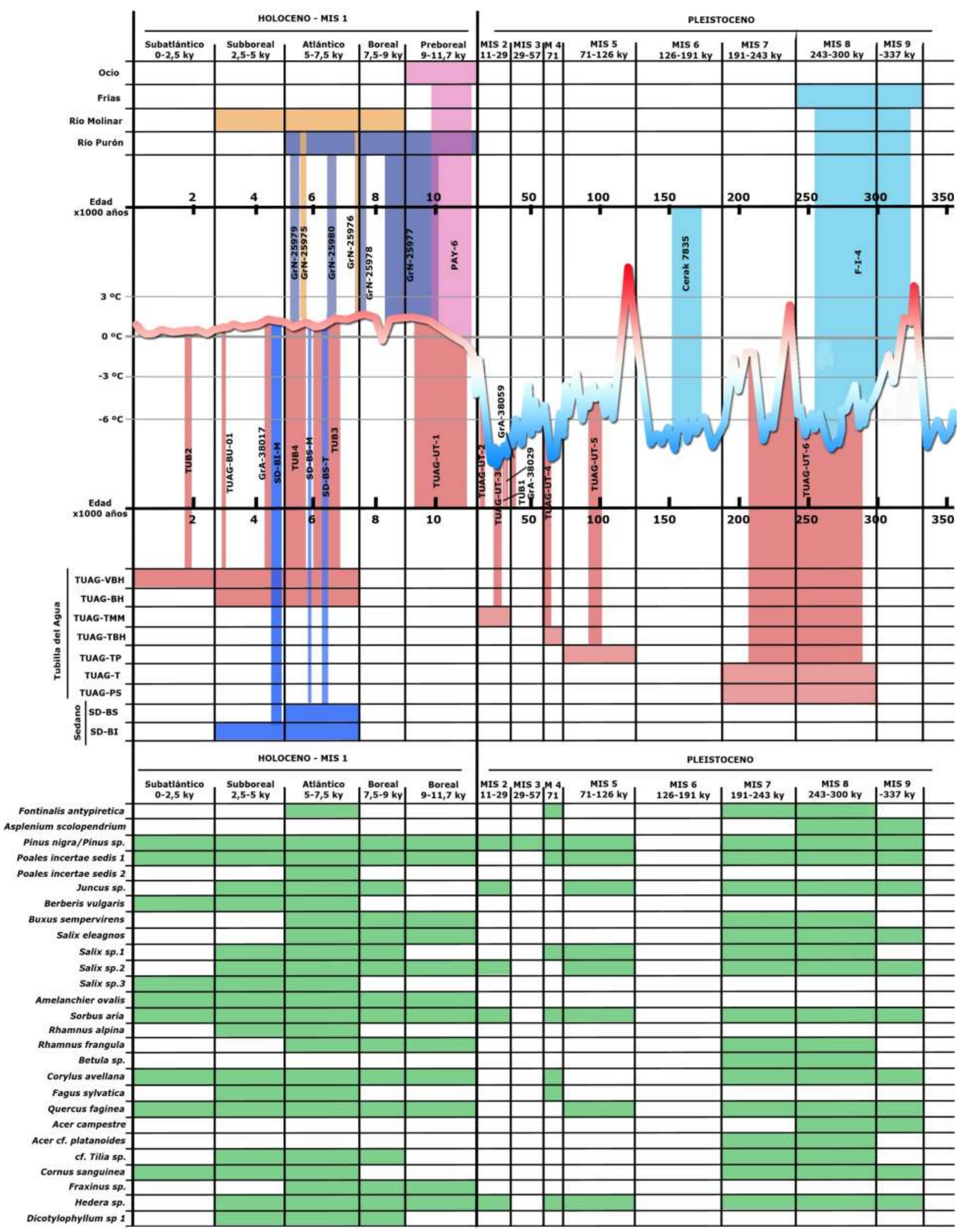

Figura 16. Diagrama sintético de los resultados del análisis geocronológico y paleobotánico. En la parte central se representa la gráfica de anomalía de la temperatura de los últimos $800 \mathrm{ka}$ con respecto a la temperatura del último milenio, elaborada a partir de los registros de deuterio del sondeo EPICA Dome C (Luthi, et al., 2008), y la curva de anomalía de la temperatura en el Holoceno, modificada de Marcott, et al. (2013). Las barras verticales representan los intervalos de confianza —95\%- de las muestras datadas en esta Tesis Doctoral, y de las publicadas para los yacimientos de Tubilla del Agua (González Amuchastegui \& Serrano, 2010; González Pellejero, et al., 2012), Sedano (González Amuchastegui \& Serrano, 2010), desfiladeros de los ríos Purón y Molinar (González Amuchastegui \& Serrano, 2007), formación de Frías (González Amuchastegui \& Serrano, 2015) y barrera de Ocio (Llanos, et al., 1998). Las casillas coloreadas junto a la curva de temperatura representan el estadio climático para el cual se infiere que las formaciones fueron depositadas. Nótese que las barras que no se prolongan hasta ninguna casilla, es porque existen dudas sobre esas dataciones. En la parte inferior se representan los taxones identificados en cada una de las unidades litológicas datadas. La presencia de Pinus sp en el MIS 3 proviene de la datación de la muestra TUAG-TRESP-1, la cuál no formaba parte de ninguna estructura tobácea. 
Para la reconstrucción de las comunidades vegetales que habitaban en el entorno de los yacimientos de toba cuando estos se formaron se han clasificado los taxones del registro en tres categorías: flora zonal, extrazonal y azonal. La definición de estos tipos de vegetación se recoge en el apartado 3.6. del capítulo de Material y métodos. Esta clasificación nos permite sistematizar el estudio del registro, y distinguir entre los taxones que formaban parte de las comunidades asociadas al entorno húmedo donde estos depósitos se generan, de los que componen las paleofitocenosis circundantes.

Las floras de las unidades litológicas coetáneas de una misma localidad son analizadas en conjunto. Este es el caso de los edificios TUAG-PS y TUAG-T de Tubilla del Agua y de las barreras SD-BS y SD-BI de Sedano. La determinación de la coetaneidad de estas estructuras se discute en el apartado 5.1., y se ha fundamentado en el análisis de las dataciones obtenidas en combinación con la cronología publicada por otros autores y el análisis geomorfológico realizado en el apartado 4.3. de este capítulo.

La clasificación de los taxones en zonales, extrazonales y azonales se ha realizado en función de sus requerimientos ecológicos, los cuales han sido brevemente descritos para cada taxón en el apartado 4.4. de resultados paleobotánicos. Los que se considera que forman parte de las fitocenosis azonales son: Fontinalis antypiretica, Asplenium scolopendrium, Juncus sp., Poales incertae sedis 1 , Poales incertae sedis 2, los sauces Salix eleagnos, Salix sp. 1, Salix sp. 2 y Salix sp. 3-y Rhamnus frangula.

Poales incertae sedis 1 aparece en la mayoría de los depósitos estudiados y se ha incluido entre la vegetación zonal porque, como ha sido señalado en el apartado del capítulo de Resultados donde se describen sus restos, estos podrían corresponderse con especies hidrófilas que habitualmente se encuentran en este tipo de biotopos, tales como Carex elata, C. acutiformis, Cyperus longus, Glyceria fluitans, Agrostis stolonifera, etc. Igualmente, Poales 
incertae sedis 2 presenta similitudes con geófitos rizomatosos propios de suelos inundados, como Phragmites australis, Typha domingensis o Scirpus lacustris L.

Fontinalis antypiretica es el único hidrófito del registro. Asplenium scolopendrium, Poales incertae sedis 1, Poales incertae sedis 2 y Juncus sp. se pueden considerar hemicriptófitos, por pasar la estación desfavorable en forma de yemas invernantes en el suelo (Raunkiær, 1934). El resto de taxones de esta flora zonal tiene un porte de pequeño árbol o arbusto, excepto Hedera sp., que es una planta leñosa trepadora.

Los taxones arbóreos que se considera que formaban parte tanto de la vegetación azonal como de la extrazonal son: Sorbus aria, Rhamnus alpina, Betula sp., Corylus avellana, Fagus sylvatica, Acer cf. platanoides, cf. Tilia sp., Cornus sanguinea y Fraxinus sp. Todos ellos, excepto Acer cf. platanoides, habitan hoy en día de forma natural en el sector Castellano Cantábrico, donde forman parte de las comunidades vegetales que habitualmente se desarrollan en terrenos de suelos frescos, con cierta humedad edáfica o umbrías (Loidi Arregui \& Fernández Prieto, 1986; García Mijangos, 1997; Alejandre, et al., 2006). Sin embargo, algunas estas especies pueden también formar parte de la vegetación zonal en aquellos territorios donde se dan las condiciones climáticas adecuadas. El significado ambiental de la presencia en el registro de algunas de ellas es analizado en el apartado 5.4. del capítulo de Discusión.

Por último, las especies que integrarían las comunidades vegetales zonales son: Pinus nigra, Pinus sp., Berberis vulgaris, Buxus sempervirens, Amelanchier ovalis, Quercus faginea, Acer campestre y Hedera sp. El taxón Dycotylophyllum sp. 1 no ha sido incluido en ninguno de estos grupos debido a que no ha podido ser identificado taxonómicamente. Algunas especies de la vegetación zonal, como Pinus nigra, Quercus faginea o Hedera sp., tienen una gran amplitud ecológica, por lo que suelen formar parte de la vegetación zonal en un amplio rango de condiciones ambientales (Blanco, et al., 1997; López, 2007). Otros, sin embargo, 
son más exigentes, por lo que los factores ambientales pueden restringir su área de distribución más que en los anteriores.

La Fig. 17 recoge de forma sintetizada la composición de los tres tipos de comunidades vegetales —zonal, extrazonal y azonal- para cada afloramiento. Como ya ha sido comentado en el apartado 1.5.3. del capítulo de Introducción, durante las fases bioestratinómica y fosildiagénica pueden tener lugar una serie de sesgos tafonómicos que causan que el registro fósil no refleje de forma precisa la composición de las paleofitocenosis. La presencia y abundancia relativa de cada taxon debe ser analizada teniendo en cuenta estos posibles sesgos, así como otros aspectos, como por ejemplo, su corología, ecología y fitosociología para reconstruir de la forma más precisa posible las paleofitocesis. Esto es analizado en los apartados 5.3. y 5.4. del capítulo de Discusón.

Con respecto a la abundancia de los diferentes taxones identificados, se debe puntualizar que esta no representa de forma precisa el número de restos encontrados. Esto es debido a que algunos de los ejemplares presentaban varias impresiones foliares incompletas, o amalgamas de ellas (Fig. 19), pero fueron contabilizados como un único especimen, dada la imposibilidad de determinar el número total de restos presentes. Sin embargo, la cantidad de impresiones recogidas, consignadas en la Tabla 12, está próxima a la real, ya que la gran mayoría de los fósiles contenía restos de un solo ejemplar. En otros casos, dada la gran cantidad de restos de algunos taxones, solo se tomó uno para su descripción y su identificación. Este es el caso de Poales incertae sedis 2, el cual aparece en la formación SD-BS de Sedano, y de las acículas de pino encontradas en la mayoría de los depósitos prospectados. En este último caso, solo se recogieron los ejemplares más completos, aunque se comprobó que muchos de los pequeños orificios de la toba se corresponden con acículas, los cuales es posible reconocer por la sección característica que presentan. 


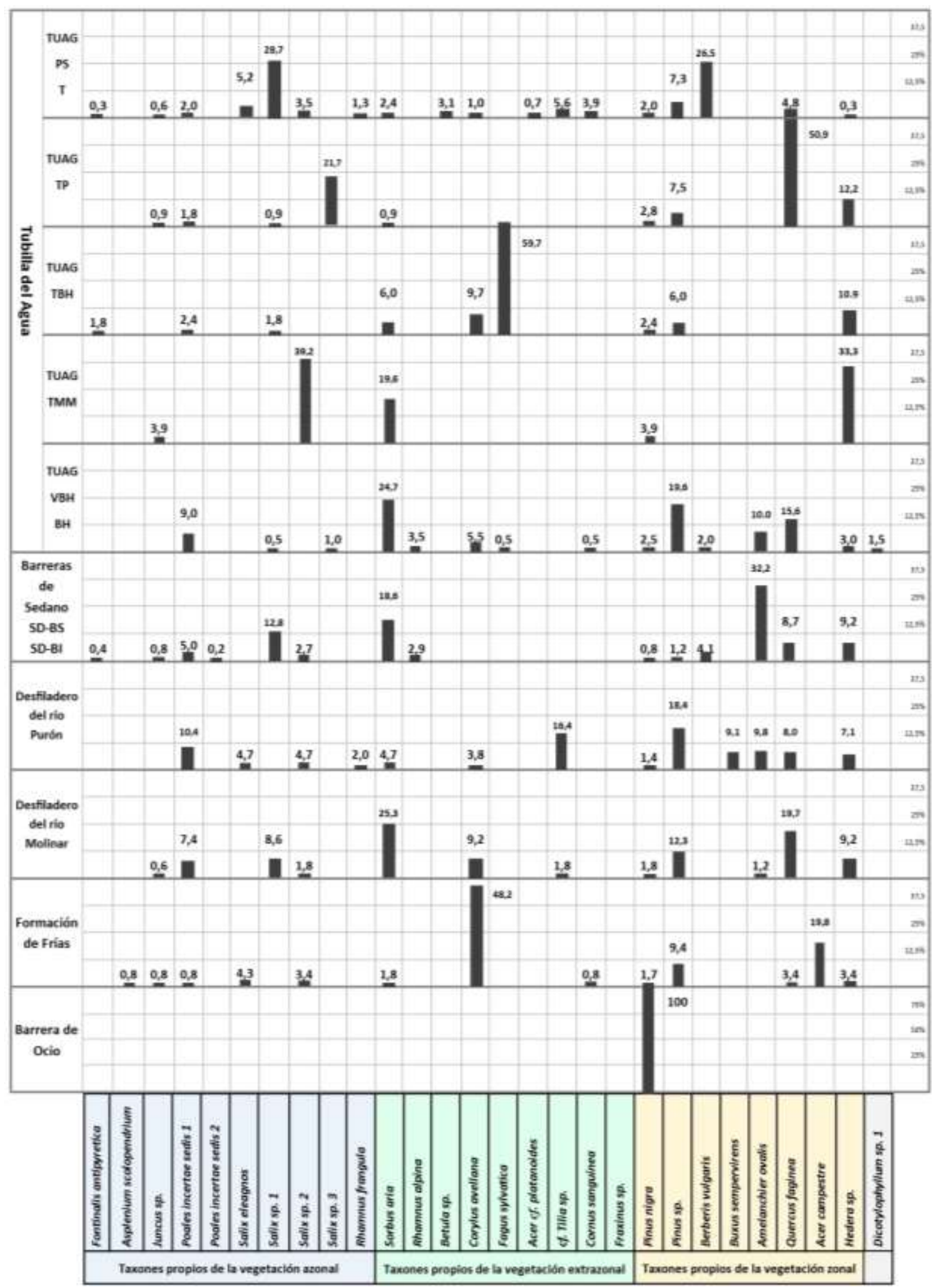

Figura 17. Reconstrucción de las paleofitocenosis. Las barras verticales y los valores anotados sobre ellas representan el porcentaje relativo de ejemplares recogidos de cada taxón con respecto al total de especímenes de todos los taxones encontrados en el depósito. 
CAPÍTULO 5. DISCUSIÓN 


\section{DISCUSIÓN}

La discusión de los resultados de esta Tesis Doctoral se ha estructurado de la siguiente forma: (i) primero se realiza un análisis geocronológico del complejo tobáceo de Tubilla del Agua, las barreras de Sedano y la formación de Frías, con la finalidad de contrastar los resultados expuestos en los apartados 4.2 y 4.3 del capítulo anterior, con los procedentes de otras fuentes; (ii) a continuación se discuten algunos aspectos relativos a la distribución temporal de los depósitos de toba estudiados y su relación con el clima; (iii) en el apartado 5.3 se analizan los diferentes factores que afectan al proceso de fosilización y cuál es el sesgo que ha podido producir en las asociaciones vegetales fósiles estudiadas; (iv) a continuación, se reconstruye la paleoflora encontrada en los diferentes yacimientos, considerando la corología y ecología de los taxones identificados, y las comunidades vegetales de las que habitualmente forman parte; (v) en el apartado 5.6. se integran los resultados de la reconstrucción de las paleofitocenosis con la información paleobotánica y paleoclimática disponible, para trazar la evolución de la vegetación en el sector Castellano Cantábrico a lo largo del intervalo Pleistoceno Medio-Holoceno; (v) para concluir, en el último apartado se discute el posible papel del sector Castellano Cantábrico como refugio glacial.

\subsection{Análisis de la geocronología y evolución de los yacimientos de Tubilla del Agua, Sedano y Frías}

Los resultados de esta Tesis Doctoral incluyen un análisis gemorfológico y la datación de varias muestras tomadas de tres de los seis yacimientos estudiados: el complejo tobáceo de Tubilla del Agua, las barreras de Sedano y la formación de Frías — ver apartados 4.2. y 4.3- Como ya ha sido comentado anteriormente, se ha abordado el estudio en detalle de estos tres yacimientos debido a la falta de información acerca de ellos en el momento en el que fue diseñado el proyecto de investigación de esta Tesis. A continuación se discuten 
algunos aspectos relacionados con la cronología, estructura y evolución de estos yacimientos.

\subsubsection{Complejo tobáceo de Tubilla del Agua.}

En este complejo han sido identificadas siete unidades litológicas diferentes (Fig. 14) —ver apartado 4.2.1.—. Las muestras TUAG-UT-6 y TUAG-UT-7 tomadas de las estructuras TUAG-T y TUAG-PS resultaron tener una antigüedad de $245.261+47.470 /-33.755$ años y más de 300 ka respectivamente (Tabla 10), lo que las sitúa como las más antiguas del complejo. En los trabajos publicados por González Amuchastegui \& Serrano (2010) y González Pellejero et al. (2012) sobre este afloramiento tobáceo, también se señala a TUAGPS como la más antigua de todas las estructuras, aunque emplazan su formación en el Último Máximo Glacial (Tabla 1). Con respecto a TUAG-T, tan solo fue datada por González Pellejero et al. (2012), y sus resultados sugieren que se habría formado hacia mediados del Holoceno $-5.520 \pm 670-($ Tabla 1).

A pesar de los resultados obtenidos por los autores citados anteriormente, en esta Tesis se propone que ambas unidades litológicas - TUAG-T y TUAG-PS — son coetáneas y que su formación tuvo lugar en el loniense, durante los Estadíos Isotópicos Marinos 7 y/u 8. Ambas unidades debían formar en el pasado una única estructura, la cual consistía en una formación de barrera que cerraba el valle del río Hornillo. Esta hipótesis se ve avalada por una serie de indicios:

- La forma y posición de ambas formaciones, que se presentan de forma casi simétrica a ambos lados del valle.

- La coincidencia de las cotas de la base y el techo en la parte más próxima de ambas formaciones. 
- La falta de evidencias sobre la existencia en el pasado de surgencias que hubiesen dado origen de forma independiente a sendas formaciones de ladera.

- La aparición de sedimentos detríticos carbonatados colgados en diferentes puntos del valle, aguas arriba de la represa, y a una cota similar al techo de ambas formaciones, los cuales se podrían atribuir a un hipotético relleno de la cubeta de la barrera.

A pesar de estas evidencias, los resultados geocronológicos no son totalmente consecuentes con la supuesta coetaneidad de ambas formaciones. Aun asumiendo que la edad real de TUAG-UT-6 estuviese cerca del límite superior de su intervalo de confianza, y la de TUAG-UT-7 próxima al límite de datación de la técnica de uranio-torio $-300-350 \mathrm{ka}$ (Pentecost, 2005)—, existiría entre ambas una diferencia de edad del orden de decenas de miles de años. Esta diferencia podría explicarse por la falta de precisión de los resultados como consecuencia de la baja concentración del marcador cronológico U-234 y la presencia de terrígenos en la muestra (Tabla 10) —ver apartado 4.3.— (Livnat \& Kronfeld, 1985; Juliá, 2014).

La hipótesis de que TUAG-PS y TUAG-T se formaron en el Pleistoceno Medio se ve también respaldada por dos indicios. Por un lado, (i) ambas estructuras se encuentran muy karstificadas, de forma similar al depósito pleistoceno de Frías, datado en 163,3 +11,1/-9,9 ka (González Amuchastegui \& Serrano, 2015). Por otro, (ii) bajo TUAG-PS aparece un depósito de sedimentos fluviales asociado a un antiguo nivel de base del río Rudrón (González Pellejero, 1986). Esta antigua terraza fluvial se encuentra en la actualidad colgada unos $43 \mathrm{~m}$ sobre el nivel actual del cauce del río. Desniveles similares, entre 35 y $60 \mathrm{~m}$ sobre el talweg del río, han sido medidos en depósitos tobáceos del Pleistoceno Medio en el Alto Tajo (González Amuchastegui, 2014), e incluso en la formación del Pleistoceno Superior de Frías, la cual se encuentra $30 \mathrm{~m}$ por encima de la actual cota del cauce del Ebro (Fig. 10) (González Amuchastegui \& Serrano, 2014). 
La coincidencia en las edades de las muestras de GrA-38029, GrA-38059 y TUB1 (Tabla 1) obtenida por González Amuchastegui \& Serrano (2010) y González Pellejero et al., (2012), de la formación TUAG-PS parece indicar que la discrepancia en la antigüedad de este depósito no estaría relacionada con su fiabilidad, si no con su representatividad. La explicación que aquí se propone es que estas muestras no se corresponderían con el cuerpo principal de la formación, sino con sedimentos más modernos. En efecto, en el flanco interior de TUAG-PS aparecen colgados unos depósitos de poca entidad de tobas autóctonas y alóctonas de aspecto más moderno, menos karstificados, que podrían haber sido los muestreados por los citados autores.

Estos depósitos, datados en el Último Periodo Glacial, se habrían acumulado después de que el río incidiese la barrera TUAG-PS/T y vaciado la cubeta de sedimentos. Está hipótesis se ve reforzada por la existencia en la cabecera del valle del Hornillo del depósito TUAG-TMM (Fig. 14), datada por nosotros en 20.891+1.607/-1.586 años (Tabla 10) y, por lo tanto, coetánea de estos hipotéticos depósitos del Último Máximo Glacial.

Una segunda discrepancia entre las edades publicadas por Amuchastegui \& Serrano (2010) y González Pellejero et al. (2012) y las obtenidas en esta Tesis Doctoral se da en las dataciones del conjunto de depósitos que tapizan el fondo del valle -TUSG-BH y TUAGVBH- (Fig. 14). Para los autores mencionados, estos se habrían depositado durante el Óptimo Climático Holoceno, mientras que las muestras tomadas de la parte superior de estas estructuras -TUAG-UT-1 y TUAG-UT-2 (Tabla 10)— sugieren que su construcción finalizó entre el final del Pleistoceno y el comienzo del Holoceno. El resultado de la datación mediante carbono-14 de la muestra de toba TUAG-BU-01 (Tabla 8), tomada en la base de TUAG-BH (Fig. 14), indica que es más moderna que las anteriores, lo que sugiere, como apuntan los autores citados, que la génesis de TUAG-BH y TUAG-VBH pudo haber comenzado más tardíamente, durante el Óptimo Climático Holoceno. En este caso, la falta de coincidencia entre los resultados de las muestras se podría achacar a problemas de precisión en la 
medida, dada la baja concentración de U-234 y baja relación Th-230/Th-232 de las muestras TUAG-UT-1 y TUAG-UT-2 (Tabla 10). A partir de estas consideraciones sobre la edad de los depósitos se propone un modelo evolutivo para este complejo tobáceo.

\section{Modelo evolutivo}

La formación más antigua de la que se tiene evidencia sería la gran barrera formada por TUAG-PS y TUAG-T, la cual se habría depositado entre 250 y $300 \mathrm{ka}$. El vaso de la represa estaría colmatado de sedimentos detríticos, de los que tan solo quedan como testigos algunos depósitos situados a la misma cota que el techo de TUAG-PS/T. Posteriormente, el río incidió la barrera y vació la cubeta. Este vaciado debió ser casi completo, como demuestra la existencia de la estructura TUAG-TP (Fig. 14), la cual se depositó en el fondo del vaso vacío de la represa, hace alrededor de 95 ka (Tabla 10).

La siguiente fase de acumulación de toba de la que se tiene constancia tuvo lugar hace unos $60 \mathrm{ka}$. La terraza TUAG-TBH es la única estructura formada en este periodo. La formación que se asiente sobre ella, TUAG-TMM (Fig. 14), se depositó durante el Último Máximo Glacial. Si bien esta es la única formación identificable de esta fase, los carbones y carbonatos de edad similar encontrados por Amuchastegui \& Serrano (2010) y González Pellejero et al., (2012) aguas debajo de esta formación, sugieren la existencia en el mismo periodo de otros depósitos, hoy desaparecidos.

Las unidades litológicas TUAG-BH y TUAG-VBH se levantan sobre el basamento calizo y sedimentos formados por derrubios de ladera, lo que indica que previamente a su acumulación el río excavó el fondo del valle, desmantelando otras posibles formaciones tobáceas más antiguas que pudieran existir en su cauce. Este proceso erosivo pudo haber tenido lugar durante el Último Máximo Glacial, coincidiendo con la etapa de erosión identificada por González Amuchastegui \& Serrano (2010) en Sedano. 
El sistema pudo mantenerse activo durante el inicio del Subatlántico $-0-2.500$ años (Salas, 1992)—, como prueban las muestras TUB2 —1.950 \pm 290 años de antigüedad (Tabla 1)—y TUAG-BU-01 -2.840-2.740 cal BP (Tabla 8)—. Una vez que cesó la precipitación de toba, el río comenzó a excavar su cauce en los depósitos tobáceos holocenos, aunque sin desmantelar todas las estructuras. La barrera TUAG-BH parece haber permanecido funcional, reteniendo una masa de agua tras de sí hasta tiempos históricos. Así lo atestigua la toponimia menor alrededor de esta formación, la cual hace referencia a la existencia de un lago —Sobre el lago; La Toba del Campo al Lago; Lago; Laguna (ADPBU.CE.; AHPB.PN)— hoy desaparecido. También podría hacer referencia a esta masa de agua el antiguo nombre de la población, la cual hasta el año 1.663, se llamó Tubilla del Lago (Cidad, 1988).

\subsubsection{Barreras tobáceas de Sedano}

La antigüedad del conjunto de depósitos tobáceos de Sedano (Tablas 2 y 9) revela una historia evolutiva más breve, reciente y sencilla que la del de complejo de Tubilla del Agua. Las edades de la base de las dos barreras estudiadas - SD-BI y SD-BS - son coincidentes, y emplazan el comienzo de su formación hace unos 6.000 años. La muestra SD-BI-T, tomada del techo de la barrera inferior - SD-BI-, indica que su crecimiento tuvo lugar durante los 1.500 años siguientes al inicio de su formación, y que se detuvo hace unos 4.500 años (Tabla 9). A partir de estos datos se puede deducir una tasa de precipitación media de 6,66 mm/año en la barrera SD-BI y de 5,33 mm/año en la barrera superior —SDBS- Estas velocidades de crecimiento están en consonancia con las estimadas por González Amuchastegui \& Serrano (2007) para los depósitos de los ríos Purón $-4,5$ mm/año— y Molinar — 2,3 mm/año—.

Las dataciones de los sedimentos detríticos de carácter tobáceo que cubren el fondo del valle del río Sedanillo, aguas abajo de las barreras descritas, realizadas por González Amuchastegui \& Serrano, (2010) (Tabla 2) muestran que el periodo de mayor actividad del 
sistema coincidió con la formación de las dos barreras estudiadas en este trabajo. La naturaleza alóctona de estos sedimentos carbonatados pone de manifiesto que, además de las barreras señaladas, debieron de existir otras formaciones que fueron erosionadas, y cuyos detritos se acumularon donde la pendiente del río se suaviza. Estos debieron de estar situadas aguas abajo de SD-BI, en tanto que el vaso de la represa superior —SD-BS— está vacía de cualquier sedimento carbonatado y el de la inferior se encuentra ligeramente relleno de lo que parecen ser derrubios de ladera.

Si bien el desarrollo del sistema se detuvo hace 4.500 años, la toponimia, al igual que en el caso de Tubilla, sugiere que las barreras pudieron haber permanecido funcionales hasta tiempos históricos. El pequeño núcleo de población que se ubica sobre de SD-BI recibe el nombre de «Lagos», lo que podría hacer referencia a las masas de agua que debían retener las barreras cuando se estableció el asentamiento. Hoy en día, el río Sedanillo discurre libremente a través de sendas brechas en las represas, las cuales han debido ser incididas en tiempos relativamente recientes.

\subsubsection{Formación de Frías}

La formación del depósito tobáceo de Frías parece estar asociada con el antiguo nivel de desagüe del río Molinar sobre el Ebro (González Amuchastegui \& Serrano, 1996). Esta hipótesis es consistente con las facies en cascada que se aprecian en su flanco noreste, y que indican el sentido de progradación de la formación, hacia el interior del valle.

A pesar de la sencillez morfoestructural de este yacimiento, la discrepancia entre las diferentes dataciones disponibles complica su análisis y la determinación de su edad. Mientras que los ostrácodos contenidos en un nivel de sedimentos calcareníticos que afloran en la fase de la formación, datados en testa Tesis Doctoral, resultaron tener $277 \pm 61$ ka de antigüedad (Tabla 11), los carbonatos fechados mediante uranio torio por González 
Amuchastegui \& Serrano (2014) indican que el edificio tobáceo fue formado hace 163,3 $+11,1 /-9,9$ ka.

Aun considerando que las edades reales de las muestras se encuentran en los extremos más próximos de ambos intervalos de confianza, estas estarían todavía separadas por un espacio de unos 50.000 años. La hipótesis de que la formación creció tan lentamente durante un periodo tan largo de tiempo no parece muy probable. Por un lado, el río Molinar drena una buena parte de la fachada septentrional de los Montes Obarenes, por lo que posee un caudal considerable, acorde con las tasas de precipitación medias observadas por González Amuchastegui \& Serrano (2007) en los depósitos holocenos del mismo río, en los que se acumularon más de $7 \mathrm{~m}$ de espesor de sedimentos en tan solo 1.500 años. Por otro lado, tampoco parece factible un escenario en el que la formación creció en diferentes etapas a lo largo del Pleistoceno Medio, dado que se presenta como una estructura continua, sin partes diferenciadas.

Por lo tanto, parece que, en este caso, la discrepancia entre los resultados geocronológicos disponibles puede estar relacionada con su fiabilidad. Como ya ha sido comentado anteriormente —ver apartado 3.3.2.2.—, la datación de carbonatos mediante uranio-torio puede presentar una serie de inconvenientes relacionados con el aporte de ${ }^{230} \mathrm{Th}$ exterior al sistema, el lixiviado de Uranio y la recalcificación de calcita (Ordóñez, et al., 1990). En efecto, la formación de Frías se encuentra muy karstificada, apreciándose síntomas de disolución y rekarstificación a lo largo de toda ella. Este, fue de hecho, el motivo por el cual se optó por su datación mediante la técnica de racemización por aminoácidos.

Por otro lado, existen también factores difíciles de controlar que pueden afectar a la precisión de la datación por racemización de aminoácidos. Ya ha sido comentado que se descartaron las muestras contaminadas con aminoácidos modernos — ver apartado 3.3.3.— , pero se desconocen cómo han afectado las condiciones geoquímicas y ambientales del 
depósito a la reacción de racemización. En definitiva, existe cierta incertidumbre sobre la precisión de ambas dataciones, pero el alto grado de karstificación del depósito nos hace desconfiar en mayor medida de la obtenida por uranio-torio. En consecuencia, en este trabajo se asume la cronología obtenida mediante racemización de aminoácidos $-277 \pm 61$ ka—.

\subsection{Consideraciones sobre la distribución temporal de los depósitos tobáceos estudiados}

La distribución temporal de los depósitos tobáceos cuaternarios ha sido reiteradamente asociada a las variables climáticas, como las precipitaciones, que juegan un papel clave (Ford \& Pedley, 1996; Pedley, et al., 1996). Su importancia estriba no tanto en el volumen de las corrientes de agua, como en la regularidad de los flujos (González Martín \& González Amuchastegui, 2014a). Un régimen regular favorece la biomediación, al asegurar la pervivencia del biofilm microbiano, a la vez que previene contra el efecto destructor de fuertes riadas. Adicionalmente, las precipitaciones, junto con la temperatura, influyen en el desarrollo de la cubierta vegetal, la cual protege las formaciones frente a la erosión. Este efecto protector lo ejerce tanto de forma directa, fitoestabilizando los depósitos sobre los que se desarrolla, como indirecta, al retener los sedimentos de las laderas y evitando así que lleguen a los cauces, lo que incrementa su capacidad erosiva (González Martín \& Fidalgo, 2014c)

Como consecuencia de la relación entre la precipitación de toba y un flujo de agua abundante y regular, la proliferación de depósitos de toba está asociada a periodos climáticos húmedos. En concreto, se ha constatado para las latitudes medias, una mayor abundancia de depósitos de toba en los estadíos climáticos interglaciares, especialmente en los MIS 1 y 5 (Durán Valsero \& López Martínez, 1989) (Fig. 18). Los periodos fríos fueron menos favorables al desarrollo de estas formaciones geológicas, no tanto por las bajas temperaturas, sino por las condiciones de aridez que caracterizaron las épocas glaciares (Pentecost, 2005). 
La naturaleza poco consistente de la toba no favorece la conservación de los las estructuras que forma, por lo que los formados en el Holoceno son mucho más comunes que los de épocas anteriores (Henning, et al., 1983). La abundancia de depósitos holocenos ha permitido abordar el estudio en profundidad de estas formaciones, y hoy en día se conoce con precisión la antigüedad de muchos de ellos. Este hecho ha permitido establecer un patrón evolutivo general para la época holocena, según el cual la sedimentación tobácea comenzó en el Preboreal —de 11,7 a 9 ka (Salas, 1992)—y se aceleró durante el Boreal y Atlántico — de 9 a 7,5 ka y de 7,5 a 5 ka respectivamente (Salas, 1992)—. Después de este periodo se constata una paulatina ralentización en el crecimiento de estos depósitos hasta el periodo Subatlántico — de 2,5 ka hasta la actualidad (Salas, 1992)—, en el cual la precipitación de toba en los ríos europeos ha sido residual (Ford \& Pedley, 1996).

Esta dinámica está ligada principalmente a las variaciones climáticas holocenas y la acción del hombre. El inicio de la precipitación coincide con el fin de la era glacial, y las mayores tasas de crecimiento se dan durante el Óptimo Climático del Holoceno (Ford \& Pedley, 1996), periodo sensiblemente más húmedo que el actual, que tuvo lugar entre 7 y 5 ka (Salas, 1992). La ralentización posterior de la sedimentación carbonatada se achaca a unas condiciones ambientales más xéricas (Brochier, 1988), pero también a la actividad antrópica, que empezó a ser determinante para este tipo de sistemas a partir del Neolítico (Vaudour, 1986; González Amuchastegui \& Serrano, 2007; González Amuchastegui \& Serrano, 2015). Por último, durante el Subatlántico se ha producido la destrucción de muchos depósitos de toba debido a las actividades humanas, principalmente a la deforestación, la agricultura, la captación de agua y la extracción de piedra (González, et al., 2014).

Los depósitos estudiados en esta Tesis Doctoral presentan un patrón de distribución temporal similar al descrito anteriormente (Fig. 18). Si bien las dudas existentes sobre la edad de los afloramientos del Pleistoceno Medio — TUAG-T, TUAG-PS y FF— no permite precisar cuándo se depositaron, resulta plausible que al menos las dos primeras pudieron formarse 
durante el interglacial MIS 7. Mayor certidumbre existe sobre la edad de TUAG-TP, que se habría formado en un periodo de gran actividad sedimentaria, el interglacial MIS 5 (Pentecost, 2005; Peña, et al., 2014). Por el contrario, TUAG-TBH y TUAG-TMM se generaron durante el Último Periodo Glacial, un estadío climático que, pese a que no es incompatible con la existencia de este tipo de depósitos (Ford \& Pedley, 1996), es uno de los periodos en los que menos formaciones tobáceas se contabilizan (Henning, et al., 1983; Durán Valsero \& López Martínez, 1989). Su existencia se achaca en este caso a la ya comentada regularidad de caudal y estabilidad de la cota de desagüe a lo largo del Cuaternario, del acuífero que da lugar al río Hornillo (González Pellejero, 1986).

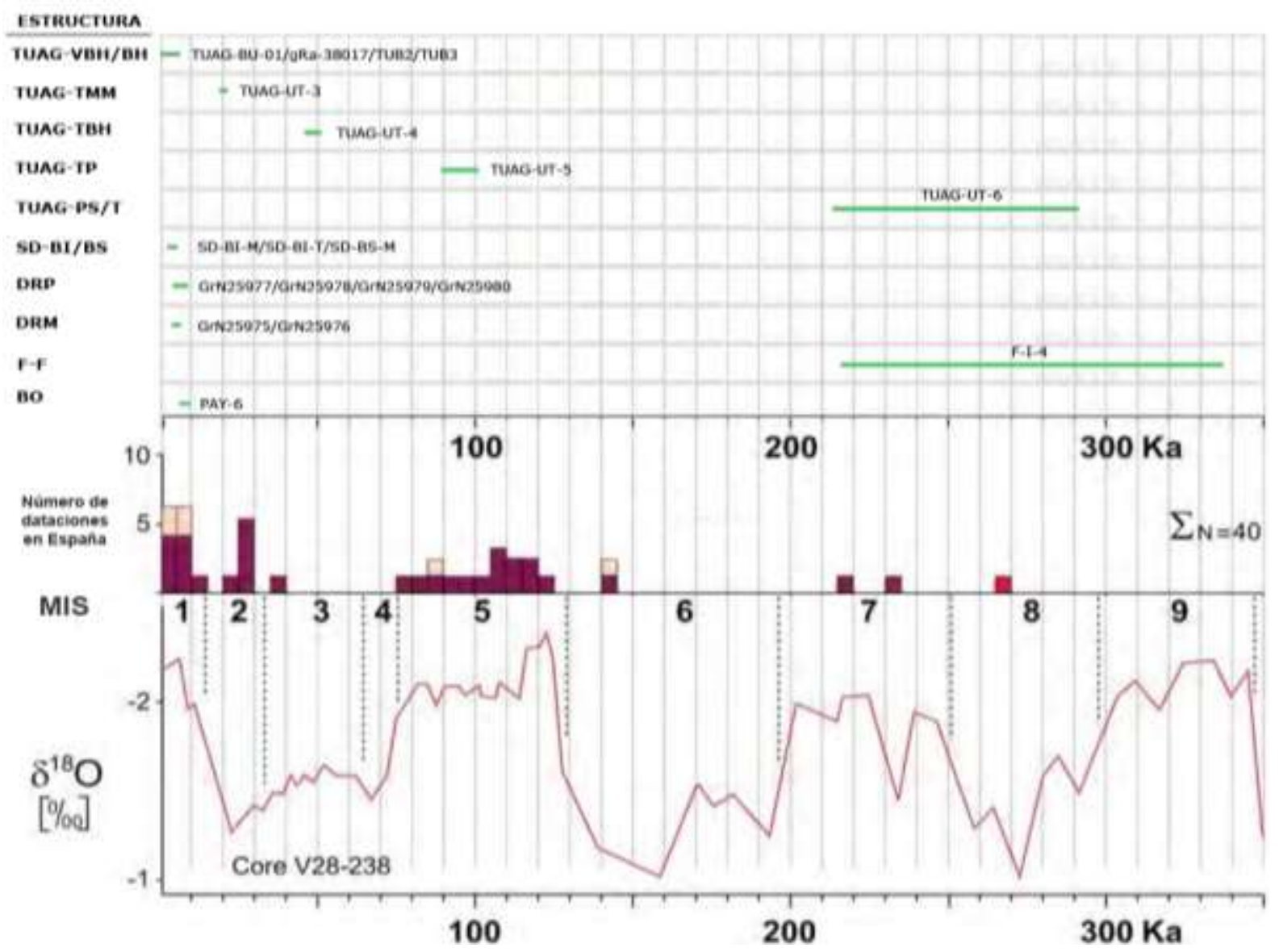

Figura 18. Distribución temporal de los depósitos tobáceos estudiados. Parte superior: distribución cronológica de las muestras datadas por depósito. Se han agrupado las dataciones de las formaciones coetáneas de un mismo yacimiento. Las barras se corresponden con los intervalos de confianza de las muestras datadas. Parte media: frecuencia de tobas en ambientes mediterráneos en España (Henning, et al., 1983). Parte inferior: curva de $\delta^{18} O$ obtenida a partir del sondeo oceánico V28-238 y Estadios Isotópicos Marinos (Shackleton \& Opdyke, 1973). Modificado de Peña, et al. (2014) 
Todos los depósitos estudiados, excepto la barrera de Ocio, se asientan sobre el sustrato rocoso o sedimentario, y no sobre estructuras tobáceas anteriores. Esto sugiere que, con anterioridad a su formación, tuvo lugar una fase en la que prevalecieron de forma generalizada unas condiciones erosivas en los ríos que barrió de su cauce estructuras más antiguas. La existencia de derrubios de ladera ordenados bajo los depósitos tobáceos holocenos de Tubilla del Agua, Sedano (González Amuchastegui \& Serrano, 2010), y de Tobera y Herrán (González Amuchastegui \& Serrano, 2007) sugieren que esta etapa erosiva coincidió con el Último Máximo Glacial o el Tardiglaciar.

Hacia mediados del Holoceno se constata en los yacimientos estudiados un incremento de la precipitación de carbonatos, coincidiendo con el Óptimo Climático. Las estructuras TUAG-BH y TUAG-VBH de Tubilla del Agua, SD-BS y SD-SI de Sedano, los depósitos del río Purón y los del río Molinar fueron depositados en esta fase. Por último, en ninguna de las localidades estudiadas se observa hoy en día una precipitación de toba significativa, sino que prevalecen los procesos erosivos, hasta tal punto que todas se encuentran incididas por los cursos de agua que las generaron.

\subsection{Análisis tafonómico del registro fósil}

El registro fósil estudiado en Tesis Doctoral está formado en su mayoría por impresiones de restos de plantas, principalmente láminas foliares, aunque también se han encontrado algunos encostramientos como, por ejemplo, los caulidios de Fontinalis antypiretica (Lám.1, Fig. 1-2), los tallos de Poales incertae sedis 2 (Lám.3, Fig. 2), y algunas acículas de Pinus sp (Fig. 19). Además de estas impresiones, también han sido hallados restos subfósiles de Pinus sp. y P. nigra (Lám. 2). Estos no son contemporáneos de las formaciones de toba en las cuales se encontraron, sino que se depositaron una vez que estas se habían formado. El análisis de las características de este registro y los sesgos tafonómicos que ha sufrido, es de interés a la hora de inferir las comunidades vegetales que representa. 
En los dos apartados siguientes se aborda el estudio del origen de los restos encontrados y los sesgos tafonómicos que han sufrido.

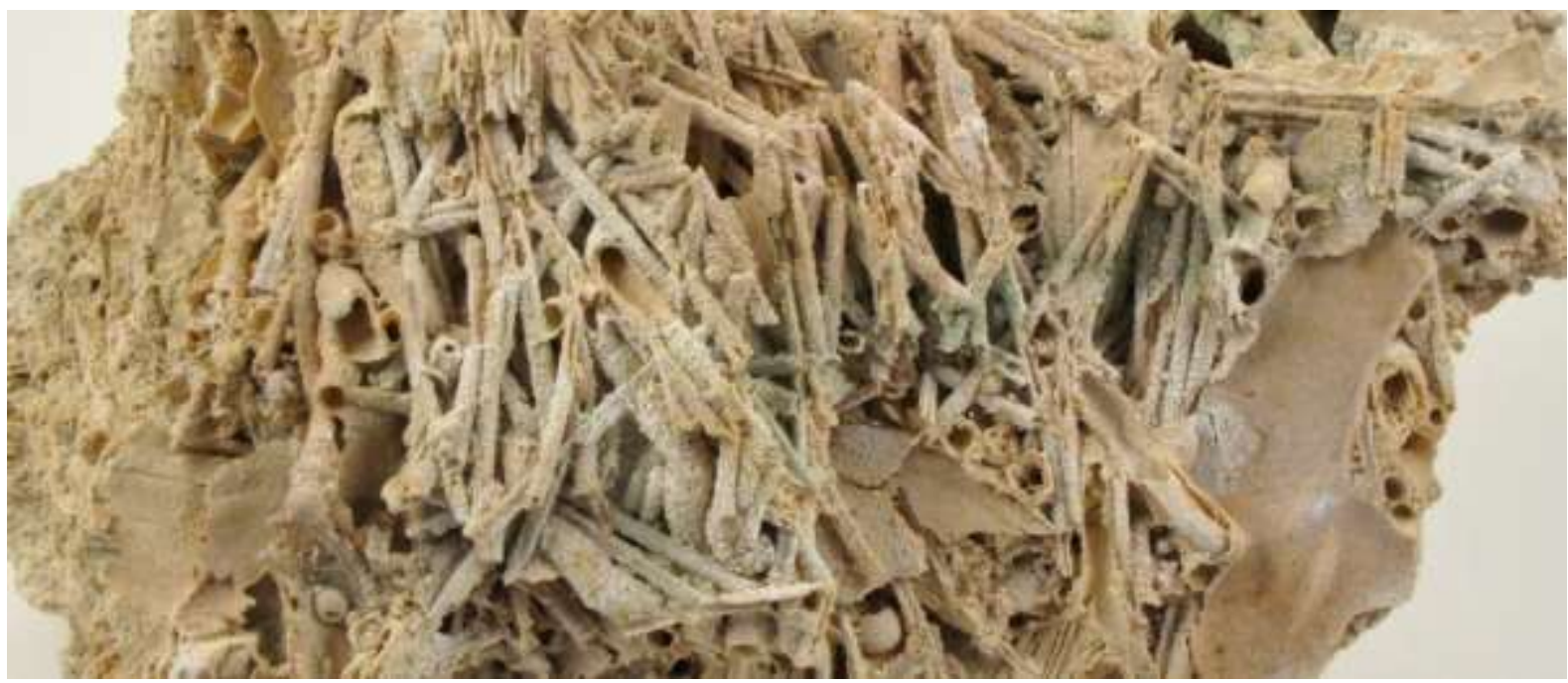

Figura 19. Encostramientos de toba sobre acículas de pino halladas en el desfiladero del río Purón —Herrán-

\subsubsection{Autoctonía/aloctonía del registro}

Como ha sido explicado en el apartado 1.5.3 del capítulo de Introducción, los restos hallados en yacimientos fosilíferos pueden catalogarse como autóctonos, parautóctonos y alóctonos en función de su procedencia. En el caso particular de los depósitos tobáceos estudiado en esta Tesis, el grupo de restos autóctonos lo componen los que se produjeron en la comunidad vegetal que se desarrollaba sobre el fitohermo. Este está formado por los encostramientos de caulidios de Fontinalis antypiretica, aparecidos en posición de vida, y por restos de otros vegetales que, a pesar de que no se tiene constancia de que creciesen sobre la formación activa, habitualmente forman parte de estas comunidades. Este es el caso de las impresiones de limbos de herbáceas —Poales incertae sedis 1- que, dada la limitada capacidad de dispersión de los restos de las plantas de pequeño porte (Ferguson, 1985), es probable que fueran generados por plantas hidrófilas que colonizaban el fitohermo. Los restos encontrados podrían corresponderse con algunas especies del orden Poales - p.e. Carex elata All., C. acutiformis Ehrh., Cyperus longus L., Glyceria fluitans (L.) R. Br., Agrostis stolonifera L., etc. - que hoy en día son habituales de este tipo de entornos húmedos en el 
sector Castellano Cantábrico (García Mijangos, 1997; Alejandre, et al., 2006). También se consideran fósiles autóctonos los encostramientos de tallos -Poales incertae sedis 2-, los cuales pueden estar relacionados con geófitos rizomatosos como Phragmites australis y Typha spp., así como los moldes de tallos de Juncus sp. y el fronde de Asplenium scolopendrium. Por último, es habitual encontrar en este biotopo árboles y arbustos edafohigrófilos como sauces —Salix eleagnos, Salix sp 1, Salix sp 2 y Salix sp 3-y Rhamnus frangula, por lo que los restos de estos taxones podrían ser también considerados como autóctonos.

Cuando el transporte de los restos fósiles desde el lugar en que fueron producidos hasta donde se produjo su fosilización ha tenido lugar dentro de los límites del hábitat en el que habitan las plantas parentales, se consideran parautóctonos (Behrensmeyer \& Hook, 1992). Este podría ser también el caso de las impresiones de los árboles y arbustos edafohigrófilos mencionados anteriormente, los cuales, además de desarrollarse sobre los fitohermos, se encuentran habitualmente formando parte del bosque de ribera que puebla las orillas de los ecosistemas fluvio-lacustres en los que estos edificios se desarrollaron.

También podrían incluirse en este grupo Sorbus aria, Rhamnus alpina, Acer cf. platanoides, Corylus avellana, Betula sp., cf. Tilia sp., Cornus sanguinea y Fraxinus sp., que, en el clima submediterráneo del sector biogeográfico Castellano Cantábrico, se encuentran habitualmente formando parte de los bosques de ribera (Loidi Arregui \& Fernández Prieto, 1986; García Mijangos, 1997; Alejandre, et al., 2006; Loidi, et al., 2011).

El grupo de fósiles de Pinus nigra, Quercus faginea, Fagus sylvatica, Berberis vulgaris, Buxus sempervirens, Amelanchier ovalis, Acer campestre, y Hedera sp. se consideran alóctonos, en tanto que estas especies no suelen formar parte de la vegetación de la orilla de las corrientes fluviales o cuerpos de aguas retenidas, sino de las comunidades vegetales circundantes. 


\subsubsection{Análisis de los sesgos tafonómicos}

Como ha sido expuesto en el apartado 1.5.3, durante las fases bioestratinómica y fosildiagénica del proceso de fosilización, se puede producir una selección de los restos, de tal forma que la muestra paleobotánica no refleje de forma precisa las biocenosis del pasado (Behrensmeyer, et al., 2000). En este apartado se analiza cómo este sesgo tafonómico ha podido afectar al registro fósil estudiado.

Los 28 taxones identificados en esta Tesis Doctoral pertenecen a 4 subclases: Bryidae, Polypodiidae, Pinidae y Magnoliidae. Las tres primeras están representadas cada una por un solo taxón, mientras que los 24 restantes pertenecen a la subclase Magnoliidae. En términos porcentuales, Bryidae y Polypodiidae representan respectivamente, el 3,5\% de todos los taxones, mientras que Pinidae supone el 7,1\% y Magnoliidae el $85,7 \%$ restante.

Con respecto a los briófitos, parecen estar infrarrepresentados en el registro si se les compara con la vegetación actual. Por ejemplo, en la comarca de La Lora se han identificado 171 especies de este grupo —34 hepáticas y 137 musgos (Casas, et al., 1992)— frente a las 942 especies de plantas espermatofitas (Alejandre, et al., 2006), por lo que suponen el 15,3\% de las especies vegetales de este territorio. La infrarrepresentación de los musgos obedece al hecho de que su estudio requiere de técnicas microscópicas. Algunos fósiles de agrupaciones de briófitos tienen dimensiones macroscópicas y son fácilmente identificables en los depósitos tobáceos (Pavlović, et al., 2002). Sin embargo, la observación de algunos de los rasgos que permiten identificarlos taxonómicamente —p.e. la forma de las células de la los filidios, el tipo de peristoma, etc.- debe ser realizada al microscopio (Casas, et al., 2006). Este aspecto no ha sido abordado en este trabajo, por lo que durante la fase de exploración de los yacimientos solo se recogieron aquellos en los que se apreciaban sus rasgos macroscópicos. 
La proporción de las restantes subclases se asemeja algo más a la encontrada en algunas comunidades naturales. Por ejemplo, Polypodiidae, Pinidae y Magnoliidae representan respectivamente el 2,4\%, 0,6\% y $97 \%$ de la flora actual de la provincia de Burgos (Alejandre, et al., 2006). Entre las angiospermas, las monocotiledóneas suponen, con tres taxones, el $13 \%$, mientras que las dicotiledóneas comprenden el $87 \%$ restante; en la flora de la provincia de Burgos las proporciones de estos grupos son del $21 \%$ y $79 \%$, respectivamente (Alejandre, et al., 2006).

Con respecto al origen de los restos recogidos, un 22,9\% son de origen autóctono, un 24\% parautóctono y un 52,8\% son alóctonos (Fig. 20). Si consideramos toda la superficie del sector Castellano Cantábrico, la proporción del territorio que potencialmente ocuparía la vegetación riparia, es muy reducida (Fig. 5). Sin embargo, los restos correspondientes a taxones que habitan en este tipo de ecosistemas suponen en conjunto el $46,9 \%$ de todos los encontrados. La abundancia de restos autóctonos y parautóctonos es consecuencia de la forma en la que ocurre la fosilización de los restos vegetales en este tipo de depósitos. Esta tiene lugar en los puntos donde se está depositando activamente toba, por lo que para ser fosilizados deben ser transportados hasta este lugar. Dada la escasa dispersión que sufren las hojas en el bosque (Ferguson, 1985), las pocas probabilidades de que estos restos pasen a formar parte del ambiente sedimentario acuático (Ferguson, 1985) y la limitada capacidad de transporte de este tipo de restos por las corrientes fluviales (Spicer \& Greer, 1986), la mayoría de los vestigios contenido en los depósitos de toba provienen de un radio de unas decenas o cientos de metros alrededor del fitohermo (Pentecost, 2005). 


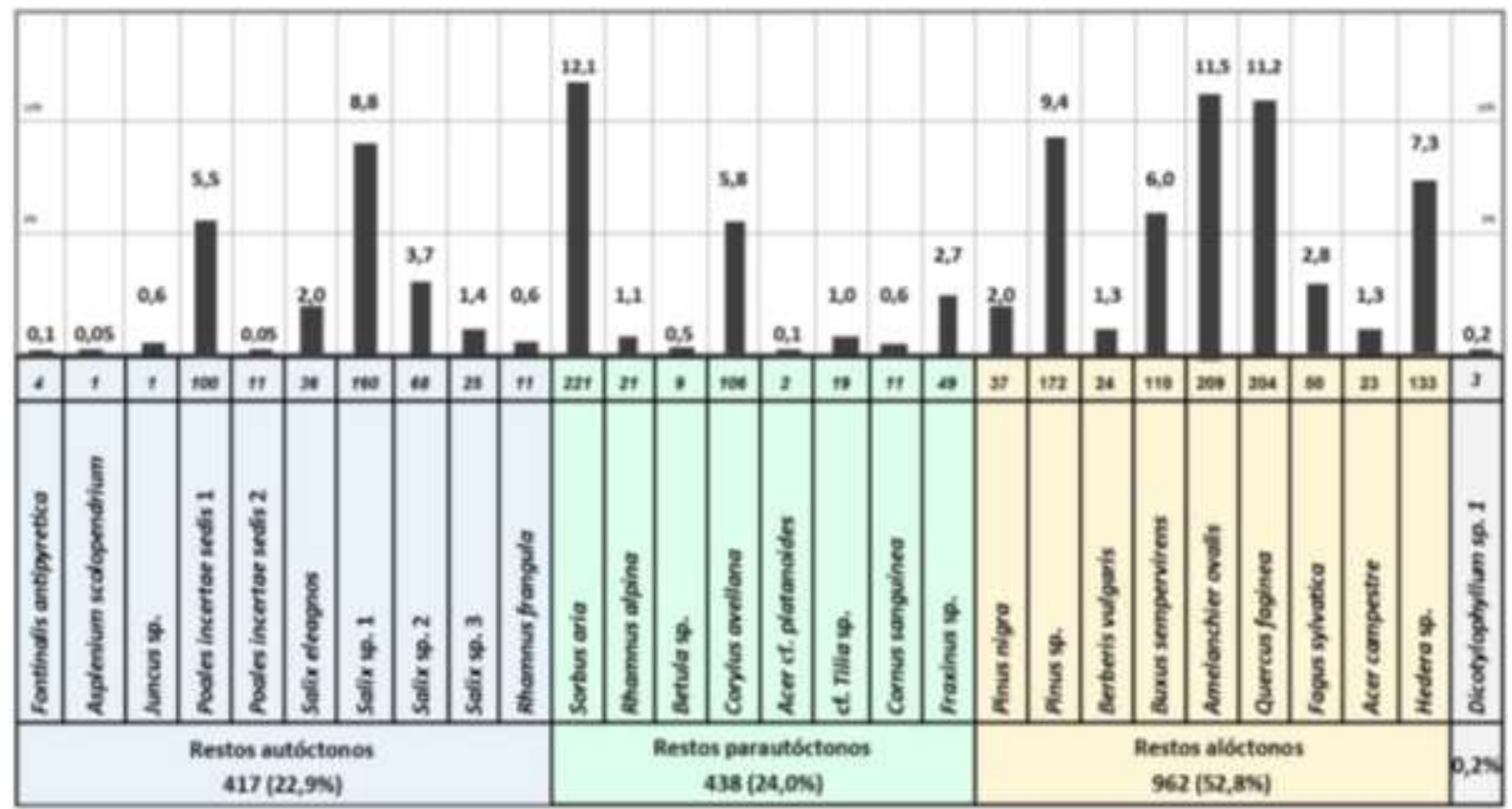

Figura 20. Porcentaje de cada taxón sobre el total de fósiles recogidos, agrupados por procedencia de los restos. El valor sobre las barras indica el porcentaje sobre el total y el número en la casilla debajo de cada barra indica el número de ejemplares recogidos.

Con respecto a los diferentes biotipos de la clasificación de Raunkiær (1934), de los 27 taxones identificados — se ha excluido Dicotylophyllum sp. 1-, 4 de ellos se pueden considerar hemicriptófitos —Asplenium scolopendrium, Juncus sp., Poales incertae sedis 1 y Poales incertae sedis 2-, uno hidrófito -Fontinalis antipyretica- y los 22 restantes fanerófitos. Estos últimos se corresponden con las plantas leñosas o herbáceas vivaces cuyas yemas de reemplazo se encuentran en vástagos por encima de los $20-50 \mathrm{~cm}$ del nivel del suelo o del arranque del tallo en las formas reptantes. En términos porcentuales, los fanerófitos constituyen el $93,4 \%$ del todos los restos recogidos, y el $78,5 \%$ de los taxones identificados. Este grupo podría estar sobrerrepresentado frente a los demás, si se compara con, por ejemplo, el $7,4 \%$ de especies que adoptan este biotipo entre las plantas vasculares de la provincia de Burgos (Alejandre, et al., 2006).

La sobrerrepresentación de los fanerofitos podría deberse al hecho de que a este grupo pertenecen las plantas de mayores dimensiones -árboles y arbustos-, que como hemos visto, producen un mayor número de hojas (Willis \& McElwain, 2002). Adicionalmente, 
debido a su talla, las plantas de mayor porte dispersan sus hojas por una superficie mayor, por lo que tienen más probabilidades de ser fosilizados (Ferguson, 1985). Esto ha podido favorecer la presencia en el registro de especies arbóreas como Q. faginea, F. sylvatica, cf. Tilia sp. Betula sp., Fraxinus sp., etc. (Fig. 20). Frente a las hojas de estas especies, las acículas de los pinos sufren una dispersión menor, lo que unido al hecho de que las plantas perennifolias producen menos hojas que las caducifolias (Dunwiddie, 1987), podría haber afectado a su representación en el registro. Por el contrario, el hecho de que las acículas y las hojas coriáceas son más resistentes a la degradación (Ferguson, 1985), podría haber favorecido la presencia de Pinus y Buxus sempervirens, frente a las caducifolias. Entre estas últimas, la mayor resistencia de las hojas del quejigo y el haya puede haber influido en la alta representación de ambas especies (Fig. 20), especialmente en la primera. En cualquier caso, la degradación no parece ser un sesgo tafonómico determinante, ya que la mayoría de las impresiones foliares recogidas no muestran signos de degradación mecánica o microbiana. Esto puede ser debido a la rapidez con la que el carbonato cálcico precipita sobre los restos (Pentecost, 2005), lo que por otro lado ha permitido que algunas impresiones hayan conservado su forma tridimensional. Esto ha ayudado en la identificación taxonómica de algunos taxones, sobre todo de las especies con las hojas más coriáceas, como por ejemplo B. sempervirens, —Lám. 3, Fig. 5- o Hedera sp —Lám. 9, Fig. 5—.

El registro estudiado en esta Tesis es equiparable al de otros yacimientos tobáceos en algunos aspectos. Por ejemplo, el número de fósiles encontrados y taxones identificados es similar al de algunos estudios de este tipo llevados a cabo en otros yacimientos. En lo que respecta al número de taxones identificados, este suele ser del orden de unas pocas decenas, mientras que la cantidad de fósiles recuperados suele variar entre unos pocos ejemplares, hasta los varios centenares en los yacimientos de mayores dimensiones en pequeños yacimientos. Por ejemplo en el depósito de Tioures -Francia-, Ali, et al. (2003a) contabilizan 35 fósiles pertenecientes a 6 taxones, mientras que en el yacimiento de St- 
Antonin -Bouches-du-Rhone; Francia- se citan 31 taxones a partir de 926 ejemplares (Ali, et al., 2003c).

Estos valores están en consonancia con la cantidad de fósiles rencontrados y los taxones identificados en los yacimientos estudiados en esta Tesis. Por ejemplo, en Tubilla del Agua, el más prolífico de todos, se han identificado 23 taxones a partir de 723 ejemplares (Tabla 12). Estos valores no están muy alejados de los resultados experimentales obtenidos por Burnham (1989) a partir del estudio de las láminas foliares en el suelo del bosque. Burnham estimó que para que una muestra de hojas del suelo contenga restos de las 25 especies de árboles y arbustos presentes en una hectárea de bosque templado, esta debería contener entre 350 a 400 hojas. Aunque el número total de hojas encontradas en los yacimientos citados duplican la cantidad calculada por Burnham, estas se mantienen dentro del mismo orden de magnitud.

\subsection{Aspectos complementarios sobre la reconstrucción de las paleofitocenosis}

La identificación y cuantificación de los taxones del registro fósil nos ha permitido reconstruir las paleofitocenosis de carácter azonal, extrazonal y zonal que poblaban los alrededores de cada depósito estudiado cuando fueron formados (Fig. 17). Sin embargo, como ha sido comentado anteriormente, el conjunto de fósiles encontrados constituye tan solo una pequeña muestra sesgada de las comunidades vegetales pasadas. En este apartado se analiza la corología, ecología y fitosociología de los taxones identificados con el objetivo de complementar la reconstrucción de las paleofitocenosis —ver apartado 4.6.—.

El área de estudio presenta una serie de características —litológicas, climáticas, geomorfológicas, etc.— que hacen que actualmente sea relativamente homogénea en cuanto a las comunidades vegetales que la habitan. Si asumimos que estos rasgos han determinado que este territorio fuese homogéneo desde el punto de vista florístico también en el pasado, 
podemos analizar los depósitos de un mismo estadío climático de forma conjunta, en tanto que reflejarían una vegetación similar. A continuación se proponen y discuten las comunidades vegetales que sugiere el registro de cada estadío climático considerado.

\subsubsection{Depósitos TUAG-PS, TUAG-T y Formación de Frías}

Las unidades litológicas TUAG-PS, TUAG-T de Tubilla del Agua, y la formación de Frías fueron formadas durante los MIS 7, 8 ó 9. Como ha sido discutido en el apartado 4.1 del capítulo de Resultados, el amplio intervalo de confianza de las dataciones y la incertidumbre sobre su fiabilidad no permiten adscribirlas a un estadío climático concreto.

La vegetación azonal que se desarrollaba en las cercanías de los depósitos estudiados estaba formada por Fontinalis antypiretica, Juncus sp. y Asplenium scolopendrium (Fig. 17). Junto a ellas debían aparecer un nutrido grupo de musgos y hepáticas, además otras especies que habitualmente habitan las formaciones de toba o paredes rezumantes, como por ejemplo Adiantum capillus-veneris o Carex, sp. (García Mijangos, 1997), las cuales podrían corresponderse con los restos de Poales incertae sedis 1. Los demás taxones azonales identificados en estos depósitos, son árboles o arbustos edafohigrófilos, los cuales crecerían en los suelos húmedos alrededor de la masa de agua embalsada por la represa que formaban TUAG-PS y TUAG-T en Tubilla del Agua, o sobre la formación de Frías. Estos debían constituir saucedas, similares a las asociaciones «comunidad de Salix atrocinerea y Sambucus nigra L.» y Salicetum fragilis, a las que se hace mención en el apartado 2.1.3., que García Mijangos (1997) describió en los Montes Obarenes.

Con respecto a la vegetación zonal, los taxones más abundantes fueron Quercus faginea y Pinus nigra (Fig. 17). De las tres grandes áreas de distribución del pino laricio en la Península Ibérica —el Pirineo Central y Oriental, el Sistema Ibérico y la Coordillera Bética Oriental (Regato, et al., 1991; Catalán, et al., 1991)—, son los pinares submediterráneos del Sistema Ibérico en donde $Q$. faginea cobra mayor protagonismo como especie acompañante 
(Regato \& Del Río, 2009). En este contexto geográfico, aparecen junto al pino laricio y el quejigo un cortejo florístico de árboles de pequeño porte, como Acer monspessulanum, Sorbus torminalis (L.) Crantz, Crataegus monogyna o Prunus mahaleb L. y arbustos de las especies Amelanchier ovalis, Ligustrum vulgare, Euonymus europaeus L., Lonicera etrusca y Viburnum lantana entre otros (Regato \& Del Río, 2009). Algunas de estas de estas especies acompañantes -Acer campestre, Sorbus aria, Hedera sp. Cornus sanguínea, Acer campestre, Corylus avellana y Buxus sempervirens - han sido encontradas en el registro de TUAG-T, TUAG-PS y FF (Fig. 17). La similitud de estos pinares del Sistema Ibérico con el registro fósil estudiado y con la vegetación actual del sector Castellano Cantábrico —excepto por la ausencia de P. nigra-, nos lleva a plantear la hipótesis de que la vegetación lonense del área de estudio podría ser similar a estas comunidades vegetales descritas.

Otro grupo de taxones de la flora Pleistocena de Tubilla y Frías más exigentes en humedad, pero no estrictamente edafohigrófilos, indican que también debía existir una comunidad vegetal extrazonal (Fig. 17), la cual se desarrollaría favorecida por la compensación edáfica que ofrecían los suelos del fondo de los valles y cañones. La presencia de cf. Tilia sp. sugiere una comunidad similar a las que forma hoy en día Tilia platyphyllos en los Montes Obarenes en el fondo de barrancos profundos, umbrosos y abruptos sobre suelos ricos en carbonatos, en las que otras especies del registro, como Buxus sempervirens, Sorbus aria y Acer campestre son acompañantes comunes (García Mijangos, 1997).

Acer cf. platanoides es el único taxón de todo el registro estudiado en esta Tesis, ausente de la vegetación actual del sector Castellano Cantábrico. En la actualidad, este arce se encuentra restringido en la Península a los Pirineos, donde, sin ser abundante, suele formar parte de bosques caducifolios mixtos junto con Fagus sylvatica, Fraxinus excelsior, Populus tremula, Tilia platyphyllos, Betula pendula, Acer opalus, Ulmus glabra, Corylus avellana, Sorbus aria, S. aucuparia y otros (Goñi, 2009). Esta flora es similar a la comunidad de Tilia descrita anteriormente, pero aparece en un entorno mucho más montano (Goñi, 
2009). Este hecho, unido a la incertidumbre sobre la identificación de este taxón, hace que su presencia en el registro deba ser tomada con reservas.

También formaría parte de esta comunidad extrazonal el género Betula. En la actualidad existen dos especies de abedul en la Península Ibérica: $B$. alba y $B$. pendula. Ambas tienen preferencia por enclaves con suelos ácidos y con cierta humedad (López, 2007). Consecuentemente, el sector Castellano Cantábrico, de litología predominantemente caliza y carácter submediterráneo, no constituye un territorio adecuado para estas especies. Aun así, el abedul no es un árbol tan discordante como Acer cf. platanoides, ya que, aunque es muy escaso, existen algunas pequeñas poblaciones en este territorio (Loidi Arregui \& Fernández Prieto, 1986; Alejandre, et al., 2006).

La presencia de Acer cf. platanoides y Betula sp. podrían indicar un clima más fresco que el actual. Esta hipótesis se vería respaldada por el hecho de que en la actualidad Buxus sempervirens no está presente en Tubilla del Agua ni en la comarca de La Lora, sino solo en la parte oriental del área de estudio (Alejandre, et al., 2006). Esta zona oriental posee un clima algo más húmedo, debido a que la influencia marina penetra con más facilidad que en la mitad occidental del sector Castellano Cantábrico dado que las elevaciones que se interponen entre la zona de estudio y el mar Cantábrico son menores (Ortega Villazán \& Morales Rodríguez, 2015). Como consecuencia de ello, las sierras adyacentes — Sierra de Cantabria y Montes de Vitoria - pertenecen al ámbito biogeográfico eurosiberiano (Loidi Arregui \& Fernández Prieto, 1986). En cualquier caso, la abundancia de restos de especies típicamente submediterráneas, como el pino laricio, el quejigo o el boj (Blanco, et al., 1997), apunta a un cierto grado de continentalidad. En definitiva, el clima reinante por aquel entonces podría ser del tipo Templado Oceánico o Mediterráneo Pluviestacional, similar al actual, pero con un ombrotipo más húmedo - quizás húmedo superior o hiperhúmedo- y una continentalidad algo menor —euoceánica acusada o semihiperoceánica—. 


\subsubsection{Revisión del estudio paleobotánico de la formación de Frías (Álvarez Ramis \& Fernández Marrón, 1975)}

La formación de Frías fue estudiada desde el punto de vista paleobotánico por Álvarez Ramis \& Fernández Marrón (1975) quienes, a partir del análisis de las impresiones foliares recogidas en este depósito, identificaron 10 taxones -Carpinus grandis, Myrica hakedefolia, Salix sp., Populus sp., Zelkova ungeri aff. Z. crenata, cf. Liquidambar europea, Prunus sp., Cercis aff. siliquastrum, Byttneriophyllum tiliaefolium y Berchemia multinervis-, algunos de los cuales son considerados por los autores citados como «limitantes del Mioceno Superior». Sin embargo, como ha sido discutido en el apartado 5.1. de este capítulo, las dataciones disponibles para este depósito tobáceo, entre las que se incluye la obtenida en esta Tesis $277 \pm 61$ ka (Tabla 11)—, sugieren una antigüedad Pleistocena.

Adicionalmente, algunas de las impresiones recogidas en las láminas que ilustran la publicación de Álvarez Ramis \& Fernández Marrón (1975) presentan un gran parecido con las encontradas por nosotros en los yacimientos estudiados, lo que nos hace dudar de su correcta identificación y, por lo tanto, de la edad miocena atribuida por los citados autores a este depósito. En la Tabla 13 se recoge una nueva propuesta de recatalogación de algunos de los fósiles figurados en la citada publicación. Estos taxones son coherentes con la flora ionense de Tubilla y Frías descrita en esta Tesis Doctoral, en tanto que, o bien han sido encontrado en estos depósitos o, como el caso de Amelanchier ovalis, o son especies que comúnmente les acompañan en la vegetación submediterránea actual de la zona de estudio.

\begin{tabular}{ccll}
\hline Lámina & Figura & Taxón descrito & Propuesta \\
\hline 1 & 2 & Berchemia multinervis & Amelanchier ovalis \\
\hline 1 & 3 & Cercis aff. siliquastrum & cf. Tilia sp. \\
\hline 1 & 4 & Cercis aff. siliquastrum & Salix sp. 3 \\
\hline 1 & 7 & Carpinus grandis & Rhamnus frangula \\
\hline 2 & 1 & cf. Liquidambar europaea & Acer sp. \\
\hline 2 & 4 & Prunus sp. & Buxus sempervirens \\
\hline 2 & 5 & Prunus sp. & Buxus sempervirens \\
\hline
\end{tabular}

Tabla 13. Propuesta de revisión taxonómica de algunas de las impresiones foliares del yacimiento de Frías figuradas por Álvarez Ramis \& Fernández Marrón, (1975) en la Lám. 1, Figs. 2, 3, 4 y 7, y Lám. 2, Figs. 1, 4 y 5 . 


\subsubsection{Unidad litológica TUAG-TP}

Este depósito se formó hace $95.970+6.673 /-6.318$ años, durante el MIS 5, periodo del cual es el único representante. Los taxones que formaban parte de la vegetación azonal representada en este yacimiento —Juncus sp., Salix sp. 1 y Salix sp. 3- sugieren que debía consistir en una sauceda compuesta por diferentes especies, tales como Salix cantabrica Rech. F. y S. salviifolia, cuyas hojas se asemejan a Salix sp. 1, y $S$. alba o S. fragilis, más próximas a Salix sp. 3. El resto de taxones identificados en esta formación —Pinus nigra, Quercus faginea, Sorbus aria y Hedera sp._- formarían parte de la vegetación zonal.

El pino laricio y el quejigo se postulan como las principales especies forestales de la cubierta forestal de este periodo, las cuales estarían acompañadas por un elenco de especies que no aparecen en el registro pero que, dado el clima submediterráneo que sugieren las dos especies anteriores, bien podrían ser algunos de los taxones encontrados en TUAG-PS/T — Acer campestre, Buxus sempervirens y Cornus sanguínea- o de requerimientos ecológicos similares -Crataegus monogyna, Prunus mahaleb L., Amelanchier ovalis, Euonymus europaeus L., Viburnum lantana, etc.-. Estas especies, como ha sido apuntado en el apartado anterior, acompañan hoy en día al pino laricio y al quejigo en los bosques mixtos que estas especies forman en el Sistema Ibérico (Regato \& Del Río, 2009). La mayor o menor participación de estos elementos en la vegetación zonal dependería del clima que, en cualquier caso, debía ser de tipo submediterráneo. En función del ombrotipo, termotipo y continentalidad específicos, y del efecto de la altitud y la topografía local, estas especies acompañantes podrían formar parte de la orla de la vegetación zonal, o buscar acomodo en terrenos más frescos o resguardados, de acuerdo a su tolerancia al frío y la sequía estival. 


\subsubsection{Comparación con la flora del yacimiento de EI Prat - Beceite, Teruel-}

Entre los escasos ejemplos de investigaciones paleobotánicas llevadas a cabo en depósitos tobáceos de la Península Ibérica se encuentra la que Martínez-Tudela, et al. (1986) y Badía-Gimeno \& Muñoz-Bertomeu (1999) realizaron en los materiales del río Matarraña, en Beceite -Teruel- El sistema de Beceite se compone de tres generaciones de toba formadas en el Pleistoceno Medio $-267 \mathrm{ka}$ - Pleistoceno Superior $-111 \pm 3,5 \mathrm{ka}-\mathrm{y}$ Holoceno, las cuales fueron datadas mediante la técnica del uranio-torio. Las investigaciones de los autores citados fueron llevadas a cabo sobre los depósitos del Pleistoceno Superior. El análisis de la flora de Beceite y su comparación con la encontrada en la estructura TUAGTP de Tubilla del Agua resulta de especial interés, dada la edad similar de ambos yacimientos y la semejanza de sus registros (Tabla 14).

Martínez-Tudela, et al. (1986) abordaron el estudio paleoflorístico del yacimiento, tanto desde un punto de vista palinológico como desde uno macroflorístico. A partir de las impresiones foliares, los autores citaron 22 taxones (Tabla 14). Posteriormente, BadíaGimeno \& Muñoz-Bertomeu (1999) identificaron 8 taxones a partir del estudio de 60 nuevos ejemplares. En una revisión posterior de las colecciones de fósiles recogidos por los autores anteriores, Peñalver et al. (2002) constataron su interés científico y patrimonial.

La flora de Beceite, al igual que la de TUAG-TP, contiene varios taxones propios de zonas húmedas o de la vegetación de ribera (Tabla 14), entre los que se distinguen tres grupos: (i) el primero, estaría formado por especies edafohigrófilas o hidrófitas que colonizarían el fitohermo y/o las zonas húmedas adyacentes como Cratoneurum commutatum (Hedw.), Eucladium verticillatum (Brid.) Bruch \& Schimp, Adiantum capillus-veneris L., cf. Juncus sp., Sparganium sp. y Molinia caerulea (L.) Moench; (ii) el segundo incluiría los sauces: Salix purpurea y S. eleagnos var. angustifolia; (iii) el tercer grupo lo compondrían dos especies riparias de porte arbóreo: Populus alba y Alnus glutinosa. 


\begin{tabular}{|c|c|c|c|c|}
\hline $\begin{array}{c}\text { Tipo de } \\
\text { vegetación }\end{array}$ & $\begin{array}{c}\text { Taxones encontrados en } \\
\text { Beceite }\end{array}$ & $\begin{array}{c}\text { TUAG-TP } \\
\text { Tubilla }\end{array}$ & $\begin{array}{l}\text { Yacimientos } \\
\text { estudiados }\end{array}$ & $\begin{array}{l}\text { Vegetación } \\
\text { actual }\end{array}$ \\
\hline \multirow{2}{*}{$\begin{array}{l}\text { Vegetación } \\
\text { zonal }\end{array}$} & Pinus nigra & & & \\
\hline & Quercus faginea & & & \\
\hline \multirow{10}{*}{$\begin{array}{l}\text { Vegetación } \\
\text { extrazonal }\end{array}$} & Sorbus aria & & & \\
\hline & Hedera sp. & & & \\
\hline & Corylus avellana & & & \\
\hline & Buxus sempervirens & & & \\
\hline & Fraxinus excelsior & & 1 & \\
\hline & Fraxinus angustifolia & & 1 & \\
\hline & Acer pseudoplatanus & & & \\
\hline & Angelica sylvestris & & & Escasa \\
\hline & cf. Vitis vinifera var. sylvestris & & & Escasa \\
\hline & Pistacia terebinthus. & & & \\
\hline \multirow{10}{*}{$\begin{array}{l}\text { Vegetación } \\
\text { azonal }\end{array}$} & Cratoneurum commutatum & & & \\
\hline & Eucladium verticillatum & & & \\
\hline & Adiantum capillus-veneris & & & \\
\hline & cf. Juncus sp, & & & \\
\hline & Sparganium sp. & & 2 & Escasa \\
\hline & Molinia caerulea & & & Escasa \\
\hline & Salix purpurea & & 3 & \\
\hline & Salix eleagnos var. angustifolia & & & \\
\hline & Populus alba & & & \\
\hline & Alnus glutinosa. & & & \\
\hline
\end{tabular}

Tabla 14. Taxones identificados en el yacimiento de Beceite -Teruel-, por Martínez-Tudela, et al. (1986) y Gimeno \& Muñoz-Bertomeu (1999) agrupados por tipo de vegetación. En sombreado verde se indica la presencia de estos taxones en el registro de TUAG-TP, en el de otros yacimientos estudiados en esta Tesis o en la vegetación actual del sector Castellano Cantábrico. ( $\left.{ }^{1}\right)$ El taxón encontrado es Fraxinus sp. (2) Podría corresponderse con Poales incertae sedis 1. $\beta$ ) Las hojas de esta especie son similares a las Salix sp. 2. La presencia de los taxones en la vegetación actual se ha determinado a partir del Atlas de la flora vascular silvestre de Burgos (Alejandre, et al., 2006)

Del primero de estos grupos, solo Juncus sp. ha sido encontrado en TUAG-TP, aunque este taxón debía estar acompañado por las especies propias de este tipo de ambientes húmedos citadas en Beceite. Tampoco faltaron en el entorno de TUAG-TP los sauces, como muestra el registro (Fig. 17). Sin embargo, sí están ausentes, no solo de este depósito sino de los registros de todos los afloramientos estudiados en esta Tesis Doctoral, los árboles propios de los bosques de ribera. Esta ausencia se atribuye a su preferencia por suelos ricos y profundos (López González, 2006), poco habituales en los valles y desfiladeros en donde se localizan la mayoría de los depósitos estudiados. Sin embargo, dados los requerimientos ecológicos similares a los de algunas especies encontradas, es muy probable que fuesen frecuentes en los tramos más bajos de los ríos. 
Con respecto a la vegetación zonal, la flora de Beceite también contiene, al igual que TUAG-TP, restos de $P$. nigra y $Q$. faginea. Además de estos, se citan un conjunto de taxones que formarían parte de las comunidades vegetales extrazonales, de los cuales tan solo Sorbus aria y Hedera sp. han sido encontrados en TUAG-TP. De los no presentes, algunos han sido hallados en otros depósitos del sector Castellano Cantábrico formados en estadíos climáticos diferentes _Fraxinus sp., Corylus avellana y Buxus sempervirens-. De otros taxones no se ha encontrado ningún resto —Acer pseudoplatanus L., Angelica sylvestris L., cf Vitis vinifera var. sylvestris y Pistacia terebinthus-, aunque habitan en la actualidad de forma natural en el área de estudio (Alejandre, et al., 2006) (Tabla 14). Las dos últimas especies citadas son propias de la vegetación mediterránea, de la cual no se ha encontrado ninguna especie en los depósitos estudiados en esta Tesis. A pesar de ello, las similitudes de la flora de Beceite con los registros del sector Castellano Cantábrico y la vegetación actual de este territorio (Tabla 14) sugieren que podrían haber poblado este territorio. Su ausencia se atribuye a la preferencia de estos elementos por estaciones alejadas de los entornos riparios donde se forman los edificios tobáceos, por ejemplo, las laderas en solana.

\subsubsection{Unidad litológica TUAG-TBH}

El taxón más abundante del registro de TUAG-TBH es Fagus sylvatica. El $60 \%$ de los fósiles encontrados en este depósito pertenecen a esta especie (Fig. 17). Las impresiones de hojas de haya se han encontrado por todo el frente de pared de esta formación, de $220 \mathrm{~m}$ de anchura y $12 \mathrm{~m}$ de altura. La abundancia y dispersión de los restos de haya sugiere que en las inmediaciones debía existir un hayedo casi monoespecífico, como los que se encuentran actualmente en la zona de estudio.

Fagus sylvatica es una especie de amplia valencia ecológica (Gandullo, et al., 2004) que en el contexto del sector Castellano Cantábrico forma comunidades vegetales extrazonales en las umbrías de las sierras, en donde se conserva cierta humedad ambiental 
(Loidi Arregui \& Fernández Prieto, 1986; García Mijangos, 1997; Loidi Arregui \& Fernández Prieto, 1986). Esto es debido a que este territorio constituye el extremo meridional de su área de distribución, y se encuentra, en términos climáticos, alejado de su óptimo eurosiberiano (Blanco, et al., 1997; López, 2007). El haya no es una especie que requiera de un gran volumen de precipitaciones, pero es muy sensible a la sequía estival y, debido a su intenso metabolismo durante el ciclo vegetativo, precisa de un ambiente húmedo en los meses de actividad (Blanco, et al., 1997). Es por ello que en el ámbito submediterráneo esta especie busca estaciones donde la sequedad del verano sea compensada por la abundancia de nieblas o la humedad ambiental (Loidi Arregui \& Fernández Prieto, 1986). Por otro lado, aunque soporta bien el frío en el periodo de reposo vegetativo, es muy sensible a las heladas tardías (Gandullo, et al., 2004; Blanco, et al., 1997).

La presencia de impresiones de estróbilos de Pinus nigra junto a los numerosos restos de haya es más difícil de interpretar. Por un lado, todos los moldes de piña de pino laricio fueron encontrados en un lateral de la formación, cerca de un salto de agua estacional en donde tiene lugar actualmente precipitación activa de toba. No existe ningún indicio de que la sección donde se encontraron las impresiones de estróbilos sea más moderna que el resto de la estructura TUAG-TBH, pero debido a la habitual complejidad estructural de las acumulaciones de toba, a veces no es posible distinguir las diferentes partes que las componen. Por estas dos razones, no se puede descartar completamente que las impresiones de estróbilos sean más modernas que el resto de la formación. Por otro lado, $F$. sylvatica podría haber formado parte de la vegetación zonal, ya que ambas especies, haya y pino laricio, pueden convivir bajo las condiciones climáticas adecuadas. Por ejemplo, ambas especies se pueden encontrar conviviendo en los pinares de Pinus nigra del piso oromediterráneo de los Pirineos, o en los Puertos de Beceite, en el Sistema Ibérico, donde existe una pequeña población relicta de hayas, pino laricio y pino silvestre (Regato \& Del Río, 2009). Aunque la posibilidad de que ambas especies formasen masas mixtas no se puede descartar, se considera poco probable, dado que el MIS 4 se enmarca en un contexto 
climático de regresión forestal (Sánchez-Goñi, et al., 1999) y acentuación de las condiciones glaciares (EPICA, 2004). Es por ello que consideramos más probable que el hayedo registrado en TUAG-TBH fuera de naturaleza extrazonal, como los que hoy en día existen en las umbrías del valle del Rudrón.

Además del haya y otros taxones asociados a zonas húmedas -Fontinalis antypiretica, Poales incertae sedis 1 y Salix sp. 1-, también se encuentra en el registro fósil de TUAG-TBH Corylus avellana, Sorbus aria y Hedera sp. Estos últimos tres taxones, junto con otros como Tilia platyphyllos, Acer campestre, Cornus sanguinea, Quercus faginea, Crataegus monogyna o Fraxinus excelsior, son especies que habitualmente forman parte de los hayedos del sector Castellano Cantábrico (Loidi Arregui \& Fernández Prieto, 1986; García Mijangos, 1997; Loidi, et al., 2011).

\subsubsection{Unidad litológica TUAG-TMM}

En esta formación, datada en el Último Máximo Glacial (Tabla 10), tan solo se han encontrado 5 taxones (Tabla 12), lo que dificulta la reconstrucción de la vegetación de este periodo. La presencia de Juncus sp. y Salix sp. 1 indican que, aún durante las fases más frías del Último Periodo Glacial, existía en este territorio una vegetación de ribera y zonas húmedas. Por su parte, la presencia de Sorbus aria, de óptimo eurosiberiano (Alejandre, et al., 2006; López, 2007) sugiere que podrían estar presentes otros taxones de requerimientos ecológicos similares que han sido citados en otros depósitos junto a esta especie, como por ejemplo Corylus avellana, Acer sp., Tilia sp., Rhamnus alpina, Cornus sanguinea, etc. Sin embargo, cabe esperar que en el contexto de aridez y frío del Último Máximo Glacial (Morla, 2003), estas especies estarían restringidas a los entornos protegidos y con humedad edáfica del fondo de los valles. Por su parte, la vegetación zonal estuvo formada por Pinus nigra, pero también podrían haberle acompañado el quejigo o la encina que, aunque no están presentes 
en el registro de TUAG-TMM, son más resistentes a la aridez que los taxones de óptimo eurosiberiano anteriormente citados.

\subsubsection{Depósitos TUAG-BH, TUAG-VBH, SD-BS, SD-BI, DRP, DRM y BO}

Las unidades litológicas TUAG-BH y TUAG-VBH de Tubilla del Agua, así como las barreras de Sedano — SD-BI y SD-BS—, los complejos tobáceos de los ríos Purón —DRP_ y Molinar —DRM— y la barrera de Ocio — BO— se formaron durante el Holoceno (Fig. 16). El conjunto de la flora de estas estructuras sugiere como vegetación zonal un bosque de tipo submediterráneo con un clima bastante similar al actual, en el que el pino laricio y el quejigo eran las especies forestales dominantes. El resto de los taxones submediterráneos que aparecen en estos depósitos —-Amelanchier ovalis, Berberis vulgaris y Buxus sempervirens— son comunes hoy en día en los quejigares del sector Castellano Cantábrico.

La única especie de la flora de estas estructuras ausente en la actualidad de la vegetación del sector Castellano Cantábrico es el pino laricio. Sus poblaciones naturales más cercanas se encuentran en el cañón del río Lobos, entre las provincias de Burgos y Soria (Buades, 1989), y en la cuenca del río Cega —Lastras de Cuellar, Segovia- (Fig. 25) (Catalán, et al., 1991; Rubio Sancho, et al., 2009). La del cañón del río Lobos se asienta sobre los páramos calizos de la parte meridional de este espacio natural (Buades, 1989), mientras que la del río Cega, de menor extensión, se localiza en unos afloramientos calcáreos que aparecen en un tramo ligeramente encañonado de este río, en una llanura arenosa donde predomina Pinus pinaster (Cuesta, et al., 2007). Las masas de pino laricio del Cañón del Río Lobos comparten territorio con Sabinares albares de la asociación Juniperetum hernisphaerico-thuriferae y quejigares pertenecientes al sintaxón Cephalanthero latifoliaequercetum fagineae (Buades, 1989). En este contexto, el pino laricio y la sabina albar ocupan los suelos más pobres, mientras que el quejigo aparece en las zonas con suelos algo más profundos y cierta compensación edáfica, como vaguadas o piedemontes (Buades, 1989). En 
ambos casos, les acompañan una cohorte de árboles de pequeño porte y arbustos, tales como Prunus spinosa, Crataegus monogyna, Arctostaphylos uva-ursi (L.) Spreng., Cistus laurifolius L., Juniperus communis L., Lonicera etrusca, Rhamnus saxatilis Jacq., Genista scorpius, Spiraea hipericifolia L., etc. (Buades, 1989). Este pinar presenta similitudes con la asociación que Regato (1992) describe en las montañas más continentales del Sistema Ibérico sur-occidental sobre sustratos dolomítico-calcáreos —Thalictro tuberosi-Pinetum salzmannii-, e incluso con la vegetación descrita en el apartado 5.4.2.1 para el yacimiento Eemiense de Beceite.

La presencia de elementos submediterráneos como Amelanchier ovalis y Berberis vulgaris, permite descartar a Fagus sylvatica como un elemento de la flora zonal. El haya, más exigente en las condiciones de humedad ambiental (Gandullo, et al., 2004; Blanco, et al., 1997), solo aparece junto a Pinus nigra en el piso oromediterráneo (Regato \& Del Río, 2009). Por lo tanto, el único resto de esta especie, encontrado la formación TUAG-BH de Tubilla, provendría de alguna población acantonada en las laderas orientadas al norte del valle del río Hornillo. Aunque en la actualidad no se encuentran hayas en este lugar, existen rodales de esta especie en parecidas condiciones a tan solo $2 \mathrm{~km}$, en el valle del Rudrón.

Con respecto a las barreras SD-BI y SD-BS de Sedano, como ha sido discutido en el apartado 5.1.2., estas conformaban en el pasado un sistema de dos lagunas tobáceas escalonadas. En este ecosistema fluviolacustre debía existir una vegetación palustre, dado que en el talud interior de la barrera superior aparecen numerosas incrustaciones de tallos huecos de unos 2-4 cm de diámetro que se han identificado como restos de un carrizal. En el Castellano Cantábrico, este tipo de vegetación que se desarrolla sobre suelos hidromorfos permanentemente inundados, son comunidades monoespecíficas o pauciespecíficas dominadas por especies como Phragmites australis, Typha domingensis o Scirpus lacustris L. (García Mijangos, 1997). 
La orilla no inundada estaría colonizada por vegetación riparia, compuesta principalmente por sauces del morfotipo Salix sp. 1, relacionado con las especies Salix salviifolia y $S$. cantabrica, y Salix sp. 2, cuyos restos presentan similitudes con los sauces de hoja ancha, como S. atrocinerea y S. caprea. Además de estos fanerófitos, debieron poblar las orillas de estas lagunas geófitos edafohigrófilos, de los que solo se han encontrado restos de Juncus sp. La fitocenosis zonal se correspondería con un bosque submediterráneo de Pinus nigra y Quercus faginea, como especies arbóreas principales. Este hipotético transecto de vegetación descrito para el sistema lacustre de Sedano se asemeja al existente en algunas de las pocas lagunas tobáceas bien conservadas que han sobrevivido hasta nuestros días. Este es el caso, por ejemplo, de la laguna Taravilla, en el Alto Tajo —Guadalajara—(Fig. 21), cuya vegetación perilagunar está integrada por franjas concéntricas de diferentes comunidades vegetales azonales (Valero Garcés, et al., 2004). Así, en las aguas poco profundas se desarrolla una vegetación de plantas acuáticas sumergidas. A continuación, sobre los suelos permanentemente inundados, se dispone un carrizal de Phragmites australis. En la siguiente banda de vegetación predominan hemicriptófitos como Juncus sp. y Carex sp., y en el entorno de las praderas juncales aparece un bosque ripario de la asociación Salicetum neotrichae (Molina \& Maldonado, 2002). En las laderas circundantes, donde no llega la influencia de la humedad de la laguna, se desarrolla la vegetación zonal, dominada por el pino laricio.

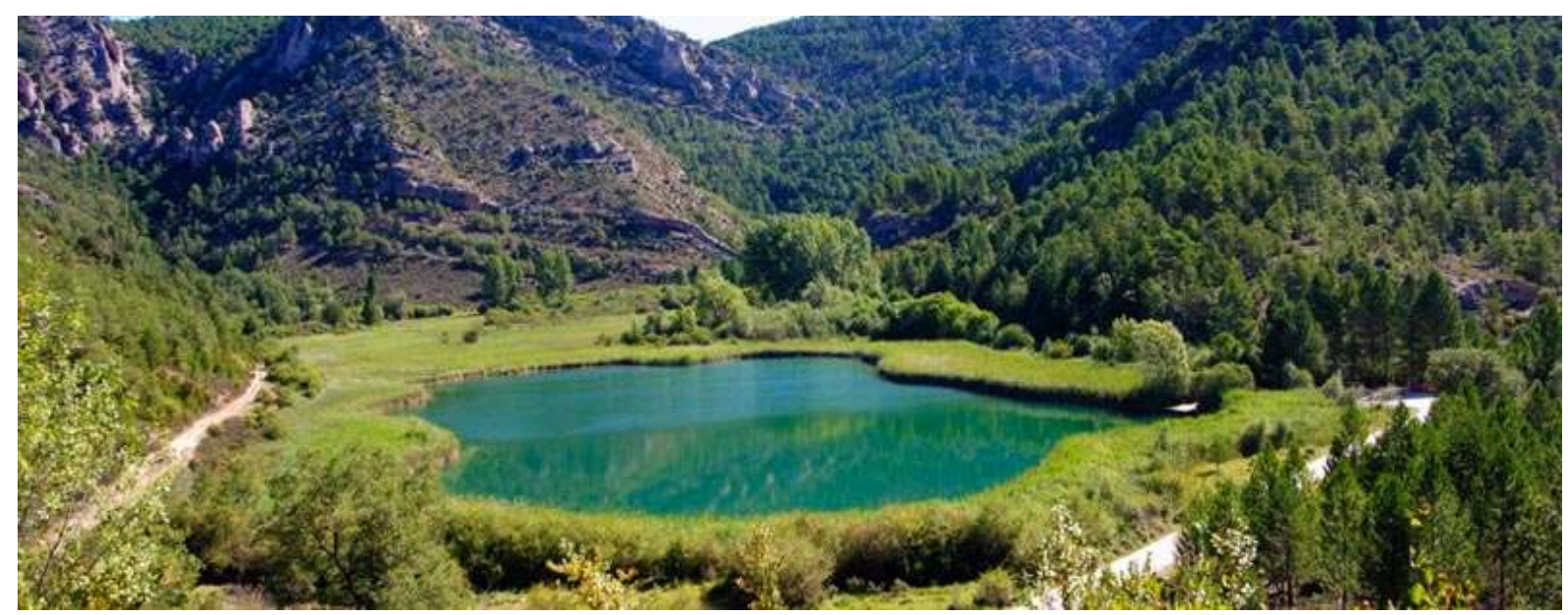

Figura 21. Laguna de Taravilla -Guadalajara-. Modelo excepcional de la vegetación de una laguna asociada a una formación tobácea de tipo barrera en un paraje de media montaña caliza de clima submediterráneo. 


\subsection{Evolución de la vegetación del sector Castellano Cantábrico en el Cuaternario Final}

Como resultado del proceso de reconstrucción de las paleofitocenosis realizada a partir del registro fósil —apartado 4.5- y su discusión en el apartado anterior, disponemos de una serie de hipótesis sobre la vegetación del sector Castellano Cantábrico en diferentes momentos del Cuaternario Final. En este apartado se integran estos resultados con información de carácter climático, paleobotánico y arqueológico para trazar la evolución de la vegetación en este territorio a lo largo del periodo considerado. En la Fig. 22 se presentan de forma sintética las hipótesis sobre la evolución de la vegetación en el contexto de los eventos relevantes para su evolución, como el clima, la dinámica de la formación de depósitos de toba y la acción antrópica.

\subsubsection{Pleistoceno Medio - Ioniense-}

El evento que marca el comienzo del loniense es la inversión magnética de BrunhesMatuyama, la última conocida, que tuvo lugar hace $781 \pm 5 \mathrm{Ka}$. Esta coincidió con el periodo en el que tuvo lugar la Revolución del Pleistoceno Medio, por la cual los ciclos de oblicuidad orbital de 41 Ka pasaron paulatinamente a ser de 100 ka (Head \& Gibbard, 2005). Después de este evento los interglaciares pasaron a ser más cortos y cálidos que anteriormente.

El efecto de este cambio en los ciclos climáticos sobre la cubierta vegetal de la Cuenca Mediterránea ha podido ser estudiado en algunos yacimientos paleobotánicos excepcionales, como por ejemplo, el de Tenaghi Philippon —Grecia—, el cual abarca los últimos 1,35 Ma (Tzedakis, et al., 2006). Las secuencias de este yacimiento registran la variación en el porcentaje de polen del componente arbóreo al ritmo de las oscilaciones climáticas, aunque este registro también apunta a la existencia de otros mecanismos climáticos independientes. Aunque los niveles de $\mathrm{CO}_{2}$ durante los periodos interglaciares eran del orden de 30-40 ppmv mayores después del Evento Mid-Brunhes (Siegenthaler, et al., 2005), no se constata en las 
series de Tenaghi Philippon que estos incrementos tuviesen un efecto significativo en el porcentaje de polen arbóreo. A partir del MIS 16, hace aproximadamente 650 ka, se observa una menor diversidad en la composición de la vegetación interglacial (Tzedakis, et al., 2006). Esta menor diversidad florística se relaciona con mecanismos orbitales, los cuales podrían estar también relacionados con la desaparición de algunos taxones de los registros de Atapuerca en el nivel TD8 de Gran Dolina (Rodríguez, et al., 2011), a la que se hace mención en la introducción de esta Tesis, y que tuvo lugar hace unos 500 ka (Falguères, et al., 1999).

Las secuencias polínicas de Atapuerca constituyen uno de los mejores registros paleobotánicos disponibles en el que enmarcar el registro paleobotánico del Pleistoceno Medio de Tubilla y Frías. El nivel TD 10-1 de Gran Dolina, fechado aproximadamente entre 379 ka y 337 ka (Falguères, et al., 1999), representa el estadío climático inmediatamente anterior a la formación de estos depósitos tobáceos. En su secuencia polínica se observa el aumento paulatino de los elementos mediterráneos, al mismo tiempo que un descenso del polen de plantas de medios secos y esteparios (Anexo I, Diagrama polínico 1) (Rodríguez, et al., 2011), lo que podría estar relacionado con el interglaciar MIS 9. La cubierta vegetal estaba formada por Pinus y Quercus y elementos termófilos, como Olea (García Antón, 1995). Posteriormente, en la zona polínica IIIb del nivel TG-12 de La Galería, en torno a unos 250 ka, se registra un aumento de los Quercus caducifolios y del conjunto de los taxones de tipo atlántico, a la vez que un descenso del componente mediterráneo (García-Antón \& SainzOllero, 1991). Este cambio encaja con el ligero enfriamiento registrado en la segunda mitad del estadío interglacial MIS 7 (EPICA, 2004). 


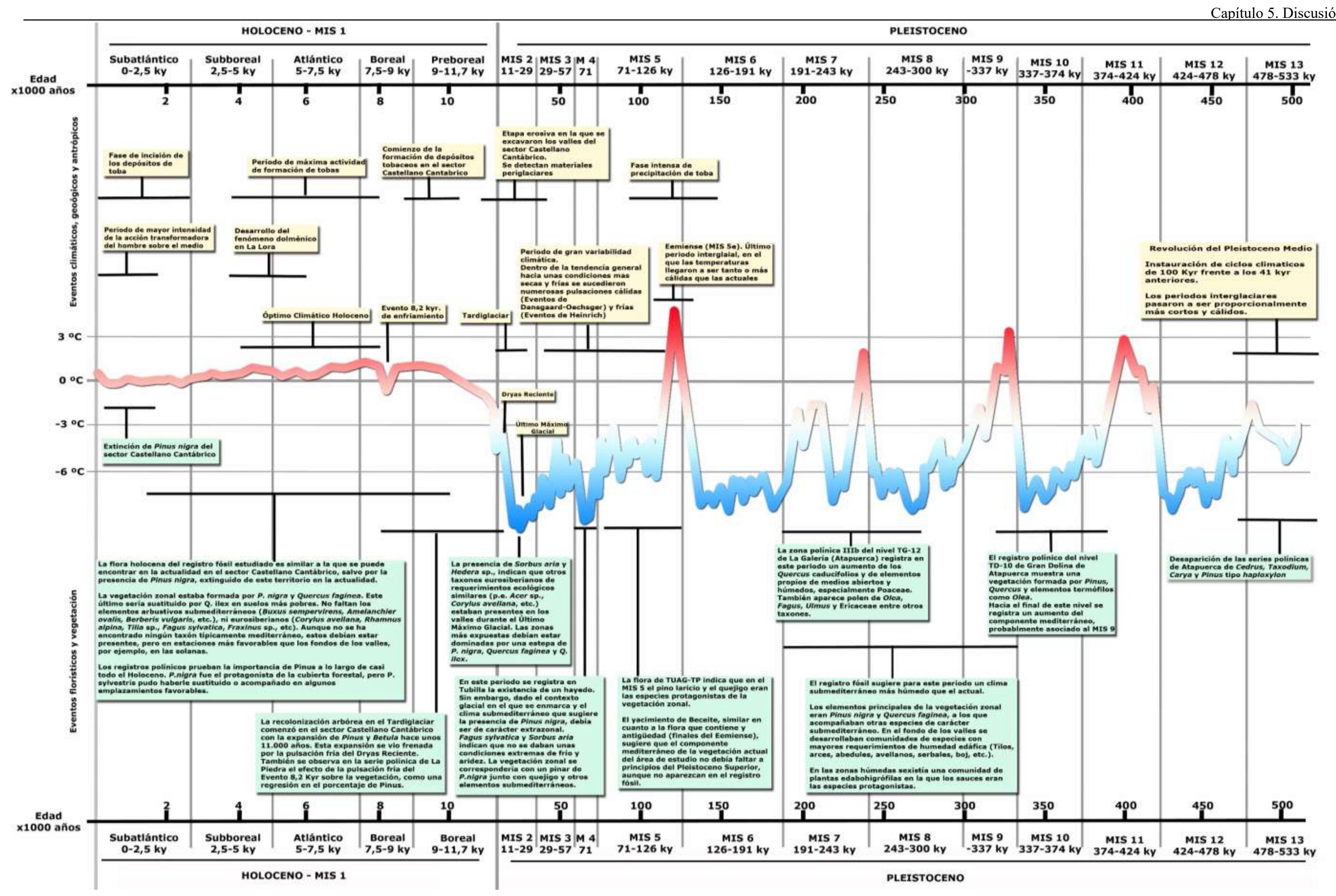

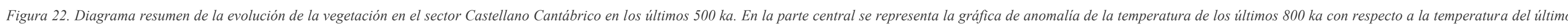

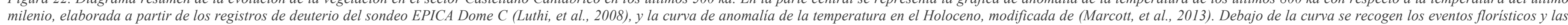
paleofitocenosis. Encima de la curva se indican algunos eventos climáticos, antrópicos y relacionados con la construcción de formaciones de toba. 
La cronología de esta última pulsación húmeda se ajusta en cierto modo al clima inferido para las unidades TUAG-PS y TUAG-T de Tubilla del Agua, probablemente formadas durante los MIS 7, 8 ó 9. Como ha sido comentado en el apartado 5.4.1., la presencia de Buxus sempervirens en esta parte del sector se interpreta como la evidencia de que, en el momento de la formación de estos depósitos, existía un clima interglacial de menor continentalidad que el actual. Es también probable que la flora del sector Castellano Cantábrico contase por aquel entonces con algunos elementos florísticos más eurosiberianos, como sugiere la presencia de Acer cf. platanoides en el registro. Esto podría verse refrendado por la detección en la Sierra de Atapuerca de polen de Juglans en la zona polínica III del nivel TG-12 de La Galería, así como de Carpinus betulus L. en la zona II del nivel TG-11 y V del nivel TG-12 del mismo yacimiento (García-Antón \& Sainz-Ollero, 1991). La edad de los niveles TG-11 y TG-12 se sitúa aproximadamente entre los 270 y 180 ka, respectivamente (Berger, et al., 2008; Falguères, et al., 2013). Ambos taxones — Juglans y Carpinus-, al igual que Acer platanoides, habitan en la actualidad de forma natural en ambientes muy diferentes a los del área de estudio, tanto climática como geográficamente. En este hipotético clima templado submediterráneo húmedo, la vegetación azonal, formada principalmente por sauces, continuaría estando restringida a los entornos con humedad edáfica; y los taxones eurosiberianos Corylus avellana, Betula sp., cf. Tilia sp. y Sorbus aria podrían haber tenido un mayor protagonismo, dadas las condiciones climáticas favorables para ellos.

Las principales especies forestales de la vegetación zonal del sector Castellano Cantábrico durante el Pleistoceno Medio podrían haber sido Pinus nigra y Quercus faginea. Esta hipótesis se ve respaldada por la presencia de ambas especies en los depósitos pleistocenos de Tubilla y Frías, pero también encuentra apoyo en los registros de las secuencias polínicas de los yacimientos de Atapuerca, en las cuales los taxones arbóreos más representados son Pinus y los Quercus caducifolios —además de los Quercus perennifolios- (García-Antón \& Sainz-Ollero, 1991). También apunta en la misma dirección 
el hallazgo de carbones de Pinus del grupo sylvestris/nigra en el nivel TE19 de la Sima del Elefante —Sierra de Atapuerca-, de entre 250 y 350 ka de antigüedad (Rosas, et al., 2006; Rodríguez, et al., 2011) o el hecho de que el polen de Quercus faginea se agrupe dentro del grupo de los robles caducifolios (Smit, 1973; Liu, et al., 2007).

El tercer elemento arbóreo que sobresale en los registros de este periodo en Atapuerca son los Quercus perennifolios (García-Antón \& Sainz-Ollero, 1991; García Antón, et al., 1995; Rodríguez, et al., 2011). La presencia de Pinus nigra y Quercus faginea en los yacimientos tobáceos pleistocenos estudiados indica un clima mediterráneo continental, en el que la encina no desentonaría. Como hemos visto en el apartado 2.3. del capítulo 2, los carrascales de la asociación Spiraeo-Quercetum rotundifoliae son en la actualidad comunes en el sector Castellano Cantábrico, donde ocupan las localidades más xéricas y de suelos más pobres que lo quejigares (Loidi Arregui \& Fernández Prieto, 1986). Sin embargo, no se puede descartar que, aun no faltando el pino laricio y el quejigo de la vegetación zonal, otros pinos y quercíneas también formasen parte de ella, y no hayan aparecido en el registro fósil. En efecto, si el clima fuese algo más húmedo que el actual, como hemos sugerido, esta señal polínica podrían provenir de especies de pinos y Quercus diferentes. Pinus sylvestris sería un buen candidato, el cual pudo formar masas mixtas junto con Pinus nigra, similares a las que hoy en día existen en el piso bioclimático oromediterráneo de las montañas Béticas orientales (Regato \& Del Río, 2009). Un clima algo más húmedo podría suponer también que junto al quejigo, coexistieron robles de óptimo eurosiberiano, como Quercus robur y $Q$. petraea (Matt.) Liebl (Blanco, et al., 1997). Por último, el polen de las quercíneas perennes podría corresponderse con el de Q. suber, especie de mayores exigencias de humedad que sus congéneres de hojas esclerófilas (López, 2007) y que, como ha sido comentado en el apartado 2.3., presenta algunas poblaciones relictas en el sector Castellano Cantabrico (García Mijangos, 1995). 
En resumen, la combinación de los hallazgos paleobotánicos ionenses de esta Tesis con las series polínicas de los yacimientos de Atapuerca, sugiere que las fracciones de polen de Pinus, Quercus caducifolios y Quercus perennifolios de estas secuencias podrían corresponderse con el pino laricio, el quejigo y la encina. Otras combinaciones - p.e. $P$. sylvestris, $Q$. robur, $Q$. suber- se consideran menos probables dada la ausencia de evidencias fósiles de estas últimas tres especies. En cuanto a la evolución de la vegetación en este periodo, de acuerdo a los estudios palinológicos de los yacimientos de Atapuerca (García-Antón \& Sainz-Ollero, 1991; García Antón, et al., 1995; Rodríguez, et al., 2011), las oscilaciones climáticas que tuvieron lugar entre 500 y 180 ka se manifestaron en la vegetación como la oscilación en el grado de protagonismo de los componentes principales de la vegetación, los pinos, y las quercíneas caducifolias y perennifolias.

\subsubsection{Pleistoceno Superior -Tarantiense-}

El límite inferior del loniense se suele establecer en $126 \mathrm{ka}$, coincidiendo con el comienzo del MIS 5 que, a su vez, marca el inicio del Tarantiense o Pleistoceno Superior. Durante los primeros milenios de este periodo —entre 126 y 110 ka— tuvo lugar el Óptimo Interglacial Eemiense o MIS 5e (Martinson, et al., 1987), el cual fue el último periodo en el que la temperatura media global fue tanto o más cálida que la actual (Kukla, et al., 2002).

El registro más antiguo del Pleistoceno Superior en la zona de estudio es el de la formación TUAG-TP de Tubilla del Agua, de 95.970 +6.673/-6.318 años de antigüedad. La flora de esta formación no aporta ningún elemento adicional con respecto a la de los depósitos del Pleistoceno Medio TUAG-PS/T de Tubilla del Agua y la formación de Frías (Fig. 16). El pino larico y el quejigo continúan estando presentes en esta formación, así como los elementos edafohigrófilos. Por lo tanto, cabe esperar que las comunidades vegetales de la vegetación zonal inferidas en el apartado anterior para el loniense, que estarían protagonizadas por el pino laricio, junto al que aparecerían el quejigo, la encina y otros 
taxones submediterráneos, eurosiberianos y algunos mediterráneos, continuarían formando la vegetación zonal del sector Castellano Cantábrico de comienzos del Tarantiense. No existen registros paleobotánicos cercanos a la zona de estudio de este periodo con los cuales contrastar nuestros datos, aunque el contenido paleobotánico del yacimiento de Beceite Teruel— supone una referencia valiosa, por su naturaleza tobácea y edad similar. En la flora de Beceite, como ya ha sido discutido en el apartado 5.4.2., además del pino laricio y el quejigo, están presentes otros taxones citados en Tubilla y Frías en el Pleistoceno Medio, así como en la vegetación actual del sector Castellano Cantábrico.

El sondeo marino MD99-2331 realizado en la costa atlántica gallega (Sánchez-Goñi, et al., 1999) aporta una perspectiva de la evolución climática, desde comienzos del Eemiense hasta finales del Tarantiense, en el occidente del continente europeo. Las secuencias polínicas de este testigo reflejan una tendencia general hacia la regresión de los bosques de Quercus y la expansión de brezales y la vegetación herbácea desde finales del MIS 5e y a lo largo de los MIS 4, 3 y 2 (Anexo I, Diagrama polínico 5). Esta tendencia es consecuente con la progresiva reducción de las temperaturas que se produjo durante estos estadíos (EPICA, 2004).

También son de interés para analizar la evolución de la vegetación en este periodo, las secuencias polínicas de la cueva de la Carihuela (Fernández, et al., 2007) y la cercana turbera de Padul (Pons \& Reille, 1988), ambas en la provincia de Granada. A pesar de encontrarse en el sureste de la Península y en un contexto climático y biogeográfico mediterráneo, constituyen uno de los mejores registros polínicos continentales del Tarantiense Ibérico. La base de la secuencia de la cueva de la Carihuela ha sido fechada en 117 ka y el limite superior en 1.292-1.012 cal BP (Fernández, et al., 2007). Por su parte, en la turbera de Padul han sido realizados varios sondeos, siendo la datación más antigua disponible la obtenida en el sondeo Padul 2, de 63.500 años de antigüedad (Pons \& Reille, 1988). Esta datación no se corresponde con la base de la secuencia, por lo que se ha 
propuesto que su inicio tendría una edad similar a la de la Carihuela. El sondeo Padul 3 recoge los registros más recientes, desde hace $34.478-31.787$ cal BP hasta 5.291-4.879 cal BP (Pons \& Reille, 1988).

En su conjunto, estas series polínicas también reflejan la instauración gradual de unas condiciones glaciales a lo largo de los MIS 5, 4, 3 y 2. Durante este periodo se observa la regresión de los Quercus, tanto caducifolios como perennifolios, así como de otros taxones más termófilos, como por ejemplo Olea y Pistacia, a la par que un aumento del polen de Pinus. Sin embargo, esta evolución no fue lineal, sino que, dentro de la tendencia general, tuvieron lugar oscilaciones climáticas que se dejaron notar en la vegetación. Por ejemplo, la secuencia de la Carihuela muestra una brusca reducción del porcentaje de polen de Pinus en torno a hace 28.000 años, al mismo tiempo que la expansión de la vegetación xero-heliofítica -Artemisia, Chenopodiaceae, Ephedra, etc.-, lo cual estaría relacionado con las condiciones más frías y secas del Último Máximo Glacial (Fernández, et al., 2007). La mejoría climática de finales del Pleistoceno Superior se registra en estos yacimientos hace unos 13 ka, y aparece como una rápida recuperación de los Quercus y el descenso en el porcentaje del polen de Pinus (Pons \& Reille, 1988; Fernández, et al., 2007).

En este contexto de paulatino enfriamiento y aridificación del clima tras el interglacial Eemiense (Abrantes, et al., 2012), cabe esperar que los taxones mesotérmicos citados en el Pleistoceno Medio en los yacimientos de Tubilla del Agua y Frías —cf. Tilia sp., Acer campestre, Corylus avellana y Buxus sempervirens-, así como aquellos que requieren suelos frescos - Betula sp. y Sorbus aria-, podrían haber visto reducida su área de distribución o haberse extinguido localmente. Simultáneamente, otras especies mejor adaptadas al frío y la aridez, como enebros y sabinas, podrían haber ido ganando protagonismo. Sin embargo, las poblaciones de los elementos principales de la vegetación zonal —pino laricio, quejigo y encina—, así como los de la azonal — principalmente sauces— , dada su adaptación al clima continental de los primeros y la vinculación con las zonas 
húmedas de los segundos, podrían haber persistido en mejores condiciones que las de los elementos mesotérmicos y eurosiberianos anteriormente citados.

La mencionada tendencia hacia la aridificación que tuvo lugar a partir del Eemiense contrasta con la abundancia de Fagus sylvatica registrada en la formación TUAG-TBH de Tubilla del Agua (Fig. 17), datada en 59.270+3.863/-3.738 años de antigüedad. Este hayedo podría constituir la vegetación zonal de esta zona pero, como fue discutido en el apartado 5.4.3, parece más probablemente que fuese una formación de carácter extrazonal, por lo que su existencia respondería a las condiciones de umbría y humedad ambiental de la cabecera del valle donde se emplaza la formación.

Como ha sido expuesto en el apartado 1.2. del capítulo de Introducción, el enfriamiento del clima entre el Eemiense y el Último Máximo Glacial no fue continuo. Dentro de la tendencia general hacia unas condiciones más frías y secas existieron pulsaciones cálidas y húmedas —interestadiales Dansgaard-Oeschger-, y enfriamientos bruscos del clima —eventos de Heinrich- (Adams, et al., 1999) (Fig. 23). Estas oscilaciones han quedado registradas en la secuencia polínica del anteriormente aludido sondeo marino MD99-2331 (Sánchez-Goñi, et al., 1999) como una disminución de la proporción de polen de taxones termófilos y un aumento de los de medios abiertos, como Ericaceae y Poaceae (Anexo I, Diagrama polínico 5). Igualmente, las pulsaciones frías del Tardiglaciar han sido detectadas a nivel local en las secuencias de algunas turberas de las montañas que bordean la Meseta Norte. Este es el caso de la secuencia polínica obtenida por Ruiz-Zapata, et al. (2002) en las proximidades de Quintanar de la Sierra -Burgos_, situada en la Sierra de Neila, en las estribaciones noroccidentales del Sistema Ibérico (Fig. 2). La base de este sondeo, datado en más de 20.965-19.875 cal BP, muestra la presencia de Quercus perennifolios, Fagus, Corylus e Ilex, lo que se asocia con la mejoría climática después del evento de Heinrich $\mathrm{H} 2$. A partir de entonces y hasta 15.115-14.790 cal BP, se suceden las oscilaciones climáticas dentro de un contexto glacial general (Anexo I, Diagrama polínico 2). Durante las fases algo más cálidas 
se observa la recuperación de Pinus, mientas que en las etapas frías aumenta la cantidad de polen de taxones propios de medios abiertos como Artemisia, Poaceae, Chenopodiaceae y Ephedra. La siguiente fase, que dura hasta hace 13.795-13.665 cal BP se relaciona con el Dryas Antiguo o Dryas I (Ruiz-Zapata, et al., 2002), periodo que algunos autores identifican con el evento de Heinrich H1 (Adams, et al., 1999). En esta zona polínica se registra un importante retroceso de la vegetación arbórea y un incremento notable de elementos estépicos. Después del Dryas antiguo se vuelve a recuperar la presencia de Pinus, hasta la llegada del Dryas reciente. En esta última etapa de enfriamiento, registrada entre 12.94512.610 cal BP y los $11.200-11.080$ cal BP, el paisaje estaba dominado por elementos estépicos -Artemisia, Ephedra y Poaceae- y durante ella tuvo lugar un descenso importante de la vegetación arbórea, especialmente de Pinus. A partir de este momento, se constata la mejoría climática de principios del Holoceno con la expansión paulatina de la cubierta arbolada, la cual estaba formada principalmente por Pinus, pero al que también acompañaban Salix, Betula, Quercus, Corylus, Fagus y Juniperus, entre otros.

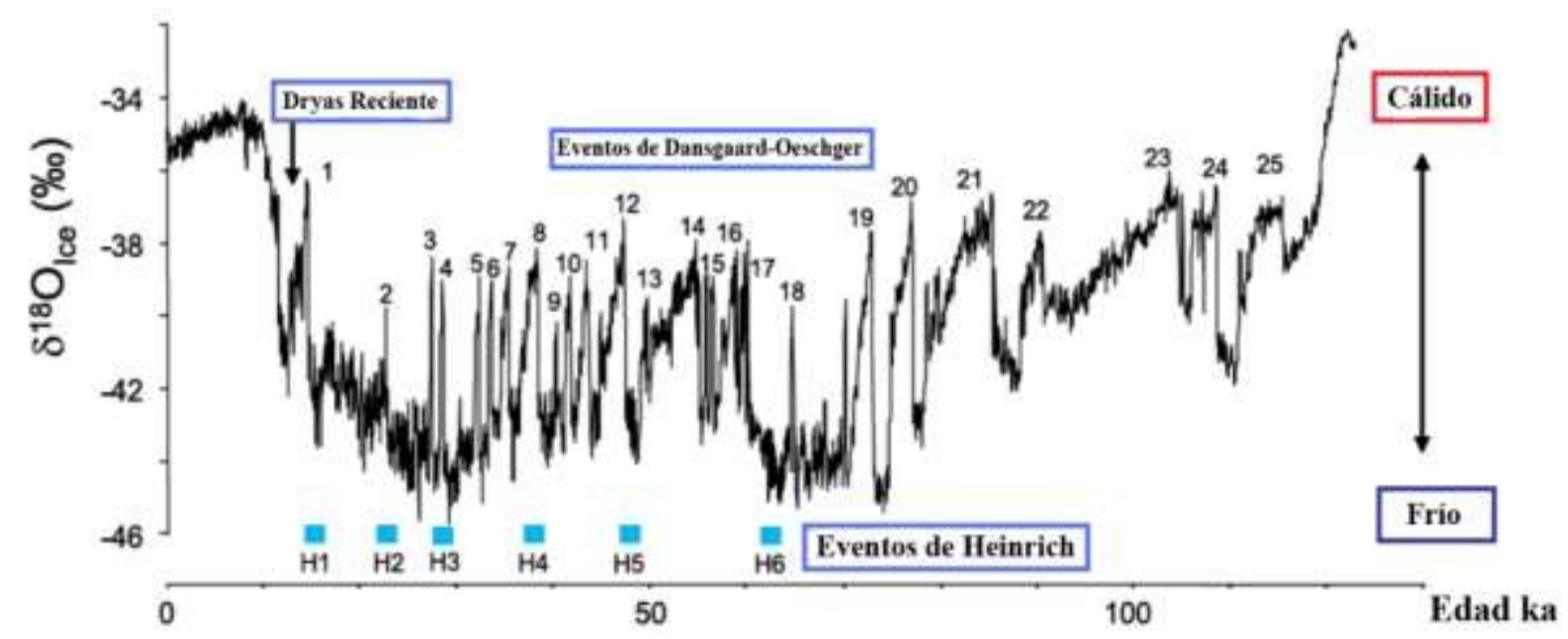

Figura 23. Registros de $\delta^{18} \mathrm{O}$ de del testigo de hielo North Greenland Ice Core Project - NGRIP_ de Groenlandia para los últimos $123 \mathrm{ka}$. Se representan los eventos de Heinrich y Dansgaard-Oeschger. (Kindler, et al., 2014)

Es en este contexto de máximo glacial en el que se enmarca el registro fósil de la formación TUAG-TMM de Tubilla del Agua, datada en $20.891+1.607 /-1.586$ años. Aunque 
solo se han identificado cinco taxones en este depósito, a partir de ellos se puede deducir que, a pesar de las condiciones glaciales, los principales tipos de vegetación descritos para periodos anteriores continuaban estando presentes. Tal es el caso de las saucedas que constituían la vegetación azonal, y de Pinus nigra, el cual podría ser el único representante de la vegetación zonal. Dadas las condiciones extremas del Último Máximo Glacial cabe la posibilidad de que el pino laricio formase masas puras, y que el quejigo, si estaba presente, solo le acompañase en las estaciones más adecuadas, como valles y barrancos. En este caso, las masas de $P$. nigra de los páramos de La Lora podrían parecerse a los bosques oromediterráneos que el pino laricio forma en el límite forestal superior del Sistema lbérico. Estos presentan una estructura aclarada en la que no hay estrato arbustivo y el suelo está cubierto por fanerófitos rastreros como Juniperus sabina, J. communis y brezos, entre otros (Regato \& Del Río, 2009). Esta vegetación es similar a la silvoestepa que ha sido sugerida para las mesetas del interior peninsular durante las épocas glaciares (Carrión, et al., 2010).

Con respecto a $Q$. faginea, aunque esta especie no ha sido encontrada en la formación TUAG-TMM, la presencia de Sorbus aria, una especie que requiere cierta humedad edáfica y ambiental (López, 2007), sugiere que el quejigo podría haber estado también presente durante el Último Máximo Glacial, por lo menos en el ambiente atemperado del fondo de valles y barrancos. En cuanto a la presencia de esta especie en las estaciones más expuestas del sector Castellano Cantábrico durante el periodo más frío de la última glaciación, como por ejemplo en los páramos de La Lora, tampoco se puede descartar. Como ha sido apuntado anteriormente, la capacidad del quejigo para reproducirse vegetativamente pudo suponer una ventaja adaptativa de esta especie para sobrevivir a las crisis climáticas (Morla, 2003). Por lo tanto, el paisaje vegetal de los páramos de la Plataforma Norcastellana durante Último Máximo Glacial pudo consistir en una estepa en la que Pinus nigra conformaba el estrato arbóreo, y quejigos de bajo porte, debido al envejecimiento de las cepas a causa de la reproducción vegetativa a la que estaba limitado, ocupasen el estrato arbustivo. Un tercer elemento integrante de esta vegetación sería Juniperus, cuya señal polínica aparece en las 
secuencias de La Piedra (Anexo I, Diagrama polínico 4) (Muñoz Sobrino, et al., 1996) y Quintanar de la Sierra (Anexo I, Diagrama polínico 2) (Ruiz-Zapata, et al., 2002) durante el Dryas Reciente. En este sentido, algunos autores - Morla, 2003- ya han sugerido que la Meseta Norte peninsular pudo estar cubierta durante el Último Máximo Glacial por una estepa crio-xérica (Ramil-Rego, et al., 1998) en la que especies de los géneros Juniperus L., Pinus y Quercus adaptadas al frío y la continentalidad, habrían sido las protagonistas del estrato arbóreo.

Por último, la evolución Tardiglaciar de la vegetación en el sector biogeográfico Castellano Cantábrico ha podido ser estudiada en las secuencias polínicas de la turbera de La Piedra (Anexo I, Diagrama polínico 4) y San Mamés de Abar, situadas en el sector suroccidental del área de estudio (Fig. 2). Las secuencias polínicas de estas turberas muestran un patrón de evolución de la vegetación similar al descrito en Quintanar de la Sierra (Anexo I, Diagrama polínico 2) (Muñoz Sobrino, et al., 1996). Los registros tardiglaciares de la turbera de La Piedra han sido datados a partir de una muestra obtenida de la base de la secuencia de una antigüedad de 14.592-13.949 cal BP (Muñoz Sobrino, et al., 1996). En la zona polínica correspondiente a este periodo —ZPL-1— el polen arbóreo predomina frente al herbáceo y arbustivo. Los taxones forestales dominantes son Pinus, Betula y Juniperus, a los que acompañan otros mesotérmicos como Fagus y Castanea, además de Quercus caducifolios y perennifolios. En la siguiente zona polínica -ZPL-2- se registra un empeoramiento climático que se manifiesta como una reducción del polen arbóreo y un incremento de las herbáceas; este estadío se correspondería con el Dryas reciente (Muñoz Sobrino, et al., 1996).

\subsubsection{Holoceno}

El periodo Holoceno comenzó hace 11.700 años (Walter, 1979), coincidiendo con el brusco aumento de la temperatura que tuvo lugar al final del Dryas reciente. Esta mejoría 
climática supuso la rápida recuperación de la vegetación arbórea, de Pinus y Betula primero —entre 10.000 y 9.500 años—y después, coincidiendo con el Óptimo Climático Holoceno, de los Quercus caducifolios después —entre 9.500 y 8.600 años— (Carrión, et al., 2000a). En la expansión de la cubierta forestal tras el Último Periodo Glacial, las quercíneas se extendieron por las montañas del ámbito eurosiberiano, mientras que los bosques de pinos sustituyeron a la estepa que poblaba la meseta del interior peninsular (Carrión, et al., 2010). En la región biogeográfica mediterránea, los pinos mantuvieron su dominancia en muchas zonas, aunque a lo largo del Holoceno tuvieron que hacer frente a una creciente competencia de las quercíneas y a la presión antrópica (Rubiales, et al., 2008; Rubiales, et al., 2010; García-Amorena, et al., 2011).

En el sector Castellano Cantábrico, el registro antracológico de la turbera de San Mamés de Abar —Burgos- (Fig. 2) muestra la recuperación holocena de la vegetación en diferentes etapas. Esta serie polínica, estudiada por Iriarte Chiapuso, et al. (2002), comienza con una fase arbolada atribuida al interestadial anterior al Dryas Reciente. En este periodo, en las inmediaciones de la turbera debía existir un bosque mixto de Pinus y Betula, a los que acompañaban de forma dispersa elementos eurosiberianos, como Ulmus, Quercus caducifolios y Corylus, y mesotérmicos, como Fraxinus, Fagus, y Castanea. En menor medida también aparecen algunos taxones de carácter mediterráneo, como Olea y Quercus perennifolios. Tras esta fase arbolada tuvo lugar un empeoramiento climático que se manifiesta en la secuencia como la reducción del polen arbóreo y la desaparición de los elementos mesotérmicos anteriormente citados. Esta etapa se relaciona con la fase de enfriamiento del Dryas Reciente que tuvo lugar entre hace 12.900 y 11.500 años (Adams, et al., 1999). La recolonización arbórea del entorno de San Mamés tras el Dryas Reciente comenzó en torno a hace 10.700 años con la expansión de Pinus y Betula. Por su parte, la turbera de La Piedra refleja una corta pero intensa fase de deforestación, datada en torno a hace 8.370-8.182 años cal BP (Muñoz Sobrino, et al., 1996), que podría estar relacionada con el Evento 8,2 Ka (Daley, et al., 2011). 
En cualquier caso, se debe tener en consideración que las turberas de San Mamés de Abar y La Piedra se encuentran en los páramos de la Lora, a una altitud de 920 msnm y 950 msnm respectivamente, por lo que sus secuencias reflejarían principalmente la evolución de la cubierta vegetal de esta zona del área de estudio. En el resto del territorio del sector Castellano Cantábrico, debido a la menor altitud de las depresiones principales —valles de Manzanedo, Valdivielso, Tobalina y Miranda-, el retroceso de la cubierta vegetal durante las fases frías pudo no haber sido ser tan acentuado. Particularmente, los taxones mesotérmicos podrían haberse visto afectados en menor medida que en las zonas más altas de La Lora. Algunas de las especies menos tolerantes al frío podrían haber sufrido una evolución parecida a la constatada para Buxus sempervirens, el cual ha sido citado en el Pleistoceno de Tubilla del Agua, pero en la actualidad solo se encuentra en la zona oriental de este territorio, a una menor altitud (Alejandre, et al., 2006).

La expansión del haya tras el Último Periodo Glacial tuvo lugar más tardíamente que la de Quercus, Betula o Pinus. En la serie polínica de Quintanar de la Sierra, aunque su polen aparece de forma esporádica a lo largo de buena parte del Holoceno, no empieza a ser abundante hasta hace aproximadamente 3.000 años (Anexo I, Diagrama 2) (Ruiz-Zapata, et al., 2002). También en la secuencia de San Mamés de Abar se observa una expansión tardía de esta especie, aunque en este último caso no se puede precisar el momento en que ocurrió por falta de dataciones en esa parte de la serie polínica.

La única impresión foliar de esta especie, encontrada en la estructura TUAG-BH de Tubilla del Agua, no contribuye mucho a clarificar la historia holocena de los hayedos en el sector Castellano Cantábrico. Los resultados geocronológicos solo nos permiten ubicar de forma genérica la formación este depósito en los periodos Subboreal y Boreal, entre 9 y 2,5 ka. Sin embargo, la presencia de esta especie en TUAG-BH nos permite deducir que, al menos en Tubilla del Agua, existieron en el Holoceno hayas en lugares en los que actualmente no existen. El ejemplar TUAG-BH-38 debió provenir de un árbol o grupo de ellos 
situados aguas arriba de la formación TUAG-BH, o en sus inmediaciones. Sin embargo, hoy en día los ejemplares de Fagus sylvatica más cercanos a este depósito se encuentran a más de un kilómetro de distancia, aguas abajo de la formación, por lo que difícilmente pudo ser transportada hasta este punto. Por lo tanto, debían existir en el pasado poblaciones más cercanas a TUAG-BH que han desaparecido.

Igualmente, entre el conjunto de restos de ejes y brácteas de piñas de Pinus nigra — ver apartado 4.4.3- encontrados en una oquedad de TUAG-PS, aparecieron restos de semillas de Fagus sylvatica, probablemente acumulados por algún roedor. En este caso, las hayas más cercanas se encuentran a más de $500 \mathrm{~m}$, por lo que no se considera probable que estas provengan de esta población, ya que los estudios realizados sobre la dispersión de bellotas por roedores demuestran que esta rara vez supera los $100 \mathrm{~m}$ de distancia (Perea, 2012). Este conjunto de restos indica que el haya habitaba en el pasado el fondo del valle del Hornillo, cerca del río, y que además existían en los alrededores pies de pino laricio y quejigo. El estróbilo femenino de Pinus nigra encontrado entre estos restos -TUAG-MR-P_ resultó tener una antigüedad de 2.311-2.065 cal BP por lo que la desaparición tanto del pino laricio como del haya de las inmediaciones de TUAG-PS, debe haberse producido en los dos últimos milenios. La presencia del haya en el fondo del valle, junto al río, es interesante, en tanto que hoy en día esta especie tan solo habita en las laderas umbrías.

En cuanto al contexto general de la evolución de la vegetación en el norte de la Península, se ha observado una tendencia hacia la reducción en el polen arbóreo a lo largo del Holoceno, al mismo tiempo que aumenta el de herbáceas tanto en el norte de España (Oliveira, 2012) (Fig. 24) como en el oeste de Francia (Naughton, et al., 2007). Esta tendencia podría enmarcarse dentro de un proceso de enfriamiento a gran escala que comenzó hace 9.000 años (Magri, 1995; Naughton, et al., 2007). Este enfriamiento puede haber sido producido por cambios en la mecánica orbital, ya que correlaciona con la reducción de la insolación en las latitudes medias y la disminución del isótopo $\delta^{18} \mathrm{O}$ registrado en los testigos 
de hielo obtenidos de los glaciares de Groenlandia (Johnsen, et al., 2001; Kindler, et al., 2014).

La vegetación del sector Castellano Cantábrico no habría sido ajena a esta evolución general, sin embargo, el impacto del cambio climático habría sido enmascarado completamente por la acción antrópica, a la cual se atribuye la intensa transformación del paisaje de este territorio desde el Neolítico (González Amuchastegui \& Serrano, 2015). Los autores citados establecen el comienzo de la intensificación de la ocupación humana de la cuenca alta del Ebro hacia mediados del periodo Atlántico, en torno a hace unos 6.000 años. Las primeras manifestaciones del fenómeno dolménico neolítico que tuvo lugar en el territorio geográfico de las parameras calcáreas de La Lora datan aproximadamente de ese periodo (Delibes, et al., 1993; Delibes \& Rojo, 1997). Este fenómeno cultural se caracteriza por la profusión de construcciones sepulcrales megalíticas edificadas con grandes losas de piedra 

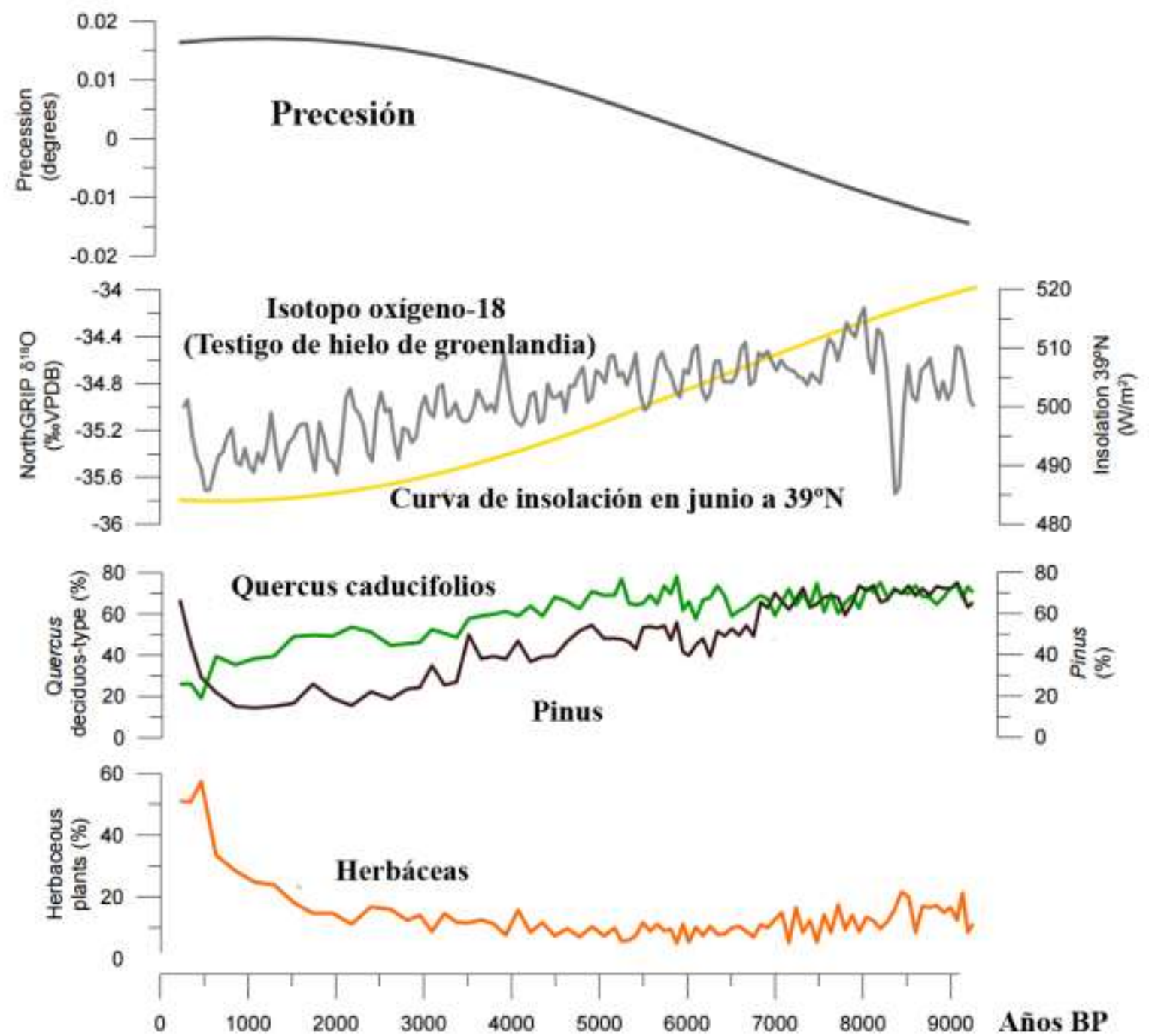

Figura 24. Correlación entre las curvas de polen de Quercus caducifolios, pinos y herbáceas medidas en el testigo KS05 10 (Oliveira, 2012), en el Golfo de Vizcaya, la señal de precesión, la curva de insolación en junio a $39^{\circ} \mathrm{N}$ (Berger, 1978) y la curva de concentración de $\delta^{18} \mathrm{O}$ en el testigo de hielo de Groenlandia NorthGRIP (Johnsen, et al., 2001; Kindler, et al., 2014). Modificado de Oliveira (2012).

en las zonas altas de los páramos. La construcción de estos túmulos se asocia al asentamiento de poblaciones tardoneolíticas o neolíticas de gran movilidad dedicadas principalmente a actividades económicas de carácter pastoril y ganadero (Campillo, 1984). La presencia de estas edificaciones en la comarca de La Lora no implica que las poblaciones calcolíticas se distribuyesen exclusivamente por este territorio, pero es aquí donde su legado permite datar estos primeros asentamientos. 
En resumen, la cubierta vegetal actual del área de estudio es el resultado de un largo proceso evolutivo, aunque las oscilaciones climáticas finicuaternarias no parecen haber afectado significativamente a la composición de esta cubierta vegetal. Sin embargo, desde el Neolítico, la cubierta vegetal ha experimentado un profundo cambio que se asocia a la acción antrópica. El impacto antrópico se ha materializado en la reducción de la cubierta forestal y la extinción del que probablemente haya sido el elemento más importante en la cubierta vegetal del sector biogeográfico Castellano Cantabrico desde el Pleistoceno Medio, el pino laricio. A continuación se analiza con más detalle el papel de esta especie en la cubierta vegetal holocena del área de estudio y las causas de su extinción.

\subsubsection{Presencia y extinción de Pinus en el sector Castellano Cantábrico durante Holoceno}

Numerosas series polínicas de turberas del Sistema Ibérico Norte — Hoyos de Iregua (Gil-García, et al., 2002) y Laguna del Hornillo (Gómez Lobo, 1993)—, la Meseta Norte — Espinosa de Cerrato (Franco-Múgica, et al., 2001), Laguna de la Roya (Allen, et al., 1996) y Laguna de Sanabria (Muñoz-Sobrino, et al., 2004)—y la Cordillera Cantábrica —Laguilín (García-Rovés, 2007), Puerto de Leitariegos (García-Rovés, 2007)— muestran el importante papel que los pinos han jugado en la cubierta vegetal de la meseta septentrional y montañas adyacentes durante casi todo el Holoceno. El sector Castellano Cantábrico, a caballo entre los tres dominios geográficos anteriores, no fue una excepción, como lo demuestran las secuencias de La Piedra y San Mamés de Abar, anteriormente descritas, además de otras dentro del área de estudio o su entorno inmediato —Huidobro (Iriarte Chiapusso, et al., 2003), Santa Gadea del Alfoz _Burgos_- (Iriarte Chiapusso, et al., 2003) y Valle de la Nava (Menéndez Amor, 1968)— (Fig. 2).

Sin embargo, a pesar del reconocido papel que los pinos tuvieron en el territorio mencionado (Rubiales, et al., 2010), las especies concretas registradas en los diferentes yacimientos se desconocen en muchos casos. Esto es debido a la similitud de los restos 
xilológicos y polínicos de algunas especies de pinos. Aunque algunos autores llegan a reconocer grupos de Pinus a partir del polen -i.e. gr. pinaster vs. gr. sylvestris (Ramil-Rego, et al., 1998; Carrión, et al., 2000b)—, o incluso a la identificación de especies a través de la madera — p.e. P. nigra y P. sylvestris (Figueiral \& Carcaillet, 2005; Rubiales, et al., 2007)—, la similitud de los caracteres morfológicos en el grupo $P$. sylvestris/nigra/uncinata, dificulta la identificación a nivel específico.

Debido a la similitud de este tipo de restos — polen y madera — el hallazgo de estróbilos es de gran ayuda para determinar las especies de pinos que poblaban un territorio. En este sentido, las citas de Pinus nigra en los depósitos tobáceos del sector Castellano Cantábrico, junto a las impresiones de piñas en toba encontradas en la localidad soriana de Fuentetoba -9.400-9.020 cal BP- (García-Amorena, et al., 2011) y los restos de estróbilos de las turberas de Cevico Navero —Palencia; 5.583-5.085 cal BP_ (Roig, et al., 1997), La Lomilla —Palencia; 9.890-9.501 cal BP_ (Alcalde-Olivares, et al., 2001) y Tubilla del Lago —Burgos; 4.233-3.836 cal BP y 3.556-3.209 cal BP cal BP- (Moreno Amat, et al., 2009) apuntan al importante papel que esta especie tuvo en la Meseta Norte y montañas adyacentes de litología caliza y clima submediterráneo.

Además del pino laricio, el hallazgo en algunos yacimientos de restos subfósiles de estróbilos femeninos ha permitido determinar también la presencia de Pinus sylvestris en algunas localidades de la Coordillera Cantábrica y Sistema Ibérico Norte. Entre estos hallazgos se encuentran los realizados en las localidades de Vega Cintoria —Soria; 29.345 +281/-271 cal BP- (Alcalde Olivares, et al., 2003), La Lomilla —Palencia; 8749-8.387 cal BP- (Alcalde-Olivares, et al., 2001), cabeceras de los ríos Porma, Curuelo y Esla —León; 5.272-4.847 cal BP—(Sanchez Hernando, et al., 1999) y Vega de Viejos —León; 2.330-2.010 cal BP- (Rubiales, et al., 2008). Adicionalmente, el pino silvestre ha sido citado a partir de maderas subfósiles en las turberas de La Piedra —Burgos- (Muñoz Sobrino, et al., 1996) y Quintana Redonda —Soria- (García Antón, et al., 1995), aunque estas deben ser tomadas 
con precaución debido a la ya aludida similitud entre la madera de ambas especies (Schweingruber, 1990). Todas estas citas, junto con la existencia de masas naturales relictas de P. sylvestris en la Cordillera Cantábrica en las localidades de Puebla de Lillo, —León-y Velilla de río Carrión —Palencia- (Fig. 25) han llevado a proponer una mayor representación de este taxón en las montañas que bordean la Meseta Norte, en general, y la Cordillera Cantábrica en particular, durante el Último Máximo Glacial y principios del Holoceno (RamilRego, et al., 1998; Rubiales, et al., 2010).

La aparición conjunta del pino laricio y silvestre en el yacimiento de La Lomilla (AlcaldeOlivares, et al., 2001) y, con más dudas, en La Piedra (Muñoz Sobrino, et al., 1996), sugiere que ambas especies pudieron coexistir dentro del sector Castellano Cantábrico en algún momento del Holoceno. Sin embargo, las masas autóctonas de Pinus sylvestris actualmente existentes en la Sierra de Árcena (Alejandre, et al., 2006) y otros territorios anexos del suroccidente de la provincia de Álava —Cuenca del Omecillo, Valderejo y Sobrón (Barredo \& Barredo, 2002)—, indica que la coexistencia pudo no haberse limitado a las parameras calizas del extremo occidental de este territorio, sino que también pudieron haber convivido en las sierras y valles orientales de este sector. Puede que la forma en que ambas especies se distribuían estuviese determinada por factores locales como, por ejemplo, la orientación y la insolación, y solo conviviesen en situaciones ecotonales, al igual que hoy en día ocurre en los pinares que ambas especies forman sobre sustratos calcáreos del piso submediterráneno de la vertiente suroriental del Sistema Ibérico — Sierra de Albarracín, Gúdar, Javalambre, Maestrazgo y Puertos de Beceite- (Pitarch, 2002; Mateo Sanz, 2008; Mateo Sanz, et al., 2013). Sin embargo, los rodales relictos de $P$. sylvestris del extremo suroccidental de la provinca de Álava se encuentran entre los 600-800 m, mientras que estas dos especies conviven en el Sistema Ibérico entre unos 1.400 y 1.500 msnm (Mateo Sanz, 2008). Esta diferencia se podría explicar por una mayor influencia mediterránea en el Sistema Ibérico, lo que obligaría a $P$. sylvestris a buscar estaciones más montanas y frescas. 


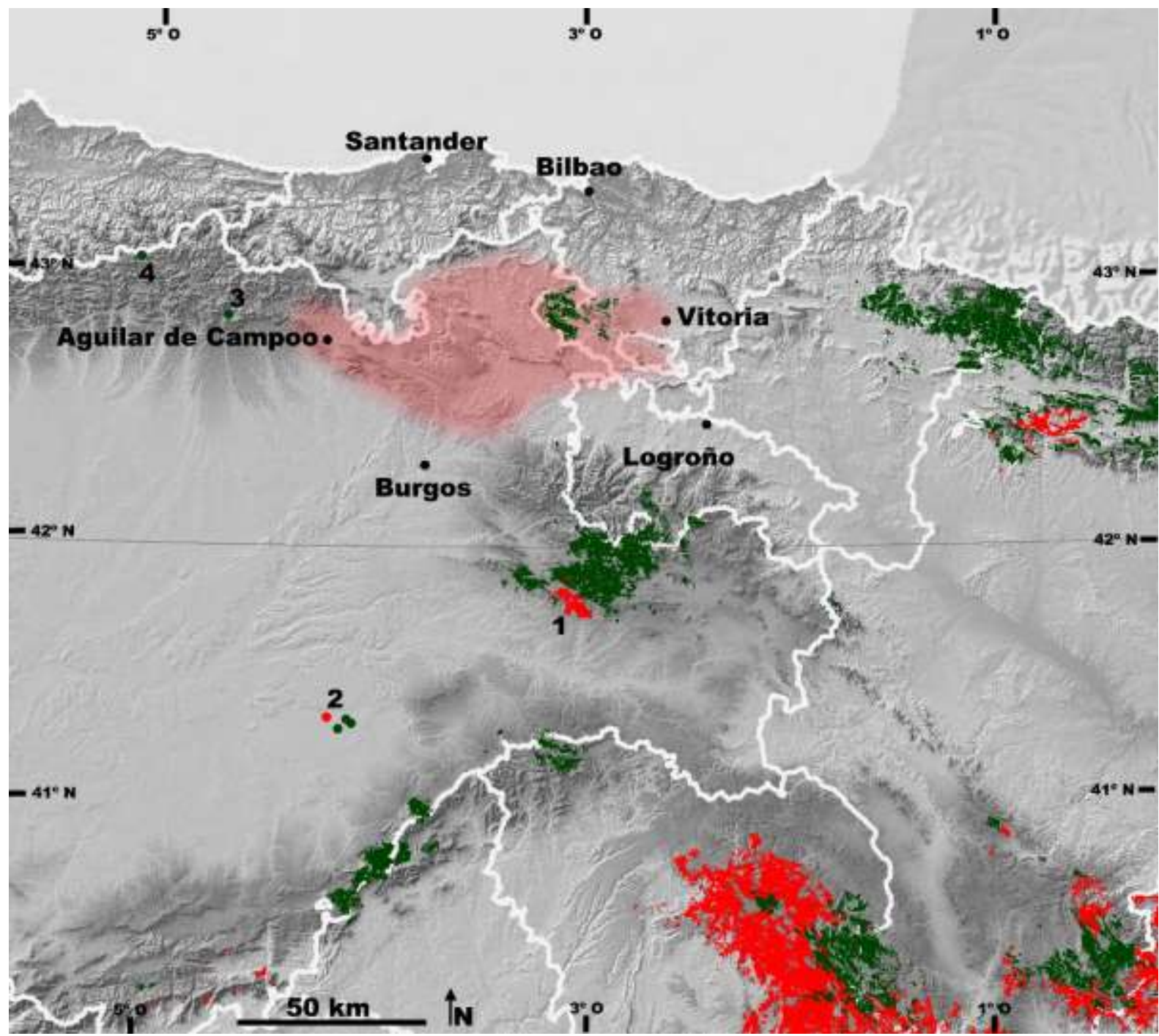

Figura 25. Masas naturales de Pinus nigra Arnold —en rojo-y Pinus sylvestris L. —en verde-. En el mapa se han señalado las poblaciones relictas de pino laricio del (1) Cañon del río Lobos -Soria-y (2) cuenca del río Cega - Segovia-, y las de pino silvestre de (3) Velilla del río Carrión - Palencia-y (4) Puebla de Lillo León-. El sector Castellano Cantábrico aparece sombreado en rosa. Modificado a partir del Mapa forestal de España a escala 1:400.000 (Ceballos, 1966). Del área de distribución del Pinus sylvestris L. dentro del sector Castellano Cantábrico se han eliminado algunas poblaciones de la provincia de Burgos que, como ha sido comentado en el apartado 2.3 del capítulo 2, no se consideran naturales (Barredo \& Barredo, 2002; Alejandre, et al., 2006).

La desaparición de los pinos de muchas regiones de la Meseta Norte y algunas de las montañas que la rodean, ha sido atribuida a la competencia con otras especies como $Q$. faginea y Q. ilex, las cuales se habrian visto favorecidas por la acción antrópica (GarcíaAmorena, et al., 2011; Roiron, et al., 2013). Habitualmente se señala al uso del fuego para la obtención de pastos como causa principal de la desaparición en los últimos milenios de los pinares en este territorio (Rubiales, et al., 2008; Rubiales, et al., 2010). En este sentido, ha 
sido demostrado que en masas mixtas de Pinus y Quercus afectadas por incendios forestales, los segundos tienden a sustituir a los primeros debido a su capacidad de rebrote de cepa, especialmente cuando se trata de $P$. nigra y $P$. sylvestris, las especies de pinos ibéricas más sensibles al fuego (Rodrigo, et al., 2004).

El fuego ha podido ser también el agente principal de la extinción del pino laricio del sector Castellano Cantábrico. En cualquier caso, su desaparición ha debido ser un proceso paulatino y tardío, a la luz de la antigüedad de algunos restos de esta especie. Tal es el caso de la piña, ejes de estróbilo y brácteas encontrados en una oquedad de la formación de TUAG-PS y datados en 1.370-1.540 cal BP —TUAG-BU-01- y 2.311-2.065 cal BP -TUAGMR-P- Los últimos rodales de esta especie en el sector Castellano Cantábrico podrían haber desaparecido en tiempos históricos, como sugiere el fitotopónimo Valdepinedo, que aparece en los fondos documentales de Tubilla del Agua hasta el siglo XVIII (ADPBU.CE), o en el nombre del Quintana del Pino, cerca de la localidad de La Piedra.

\subsection{El sector biogeográfico Castellano Cantábrico como refugio glacial}

Varios de los taxones identificados en esta Tesis han sido encontrados en depósitos formados en diferentes estadíos climáticos del Cuaternario Final (Fig. 16). Dada la variabilidad climática de este periodo (Fig. 1) (EPICA, 2004), cabe plantearse la cuestión de cuál fue su respuesta ante estas oscilaciones, y si se extinguieron de este territorio durante las etapas más frías o tan solo se replegaron a estaciones más favorables dentro del mismo. Parece probable que Pinus nigra, el cual ha sido encontrado en los yacimientos estudiados tanto en periodos interglaciares como durante el Último Máximo Glacial, ha estado presente de forma continua en el sector Castellano Cantábrico desde el Pleistoceno Medio.

El quejigo es también una especie submediterránea muy bien adaptada al clima continental, aunque algo menos resistente al frío y la sequía estival que el pino laricio (Blanco, 
et al., 1997; López, 2007). Ya se ha aludido a la importancia que pudo tener la capacidad de regeneración vegetativa de esta especie en su pervivencia cuando las condiciones glaciales eran tan severas que no permitían su reproducción mediante semillas. También pudo haber contribuido a la pervivencia del quejigo el carácter intermitente de las pulsaciones frías durante la última glaciación. En este sentido, ya ha sido comentado que el enfriamiento no fue gradual, si no que se sucedieron fases frías tras a las que siguieron otras cálidas, conocidas como eventos Dansgaard-Oeschger, que casi alcanzaron las condiciones de los interglaciares. Esta alternancia tuvo lugar en la forma de oscilaciones de alta frecuencia, con ciclos de tan solo unos 1.470 años (Fig. 23) (Rahmstorf, 2003). La transitoriedad de estas pulsaciones frías, unido la capacidad de reproducción vegetativa del quejigo, pudo haber contribuido a que no desapareciese de las estaciones más expuestas, como las parameras de La Lora. En este contexto climático extremo, tanto el quejigo como la encina pudieron haber adoptado un porte arbustivo, similar al que presentan en las masas de monte bajo de estas especies, donde los árboles se perpetúan mediante brotes de cepa (Gil Sánchez \& Torre Antón, 2007). En el caso del pino laricio, su supervivencia a las pulsaciones frías podría haberse visto favorecida por su gran longevidad (Regato, et al., 1991; Morla, 2003).

La presencia de Salix sp., Sorbus aria y Hedera sp. en el depósito TUAG-TMM, datado en el Último Máximo Glacial, sugiere que, por lo menos las especies de filiación eurosiberiana, si bien pudieron haber desaparecido de las zonas más expuestas a las condiciones glaciales, por lo menos estuvieron presentes en los valles y cañones del sector Castellano Cantábrico. Como ha sido comentado en el apartado 5.4.4., el reducido número de ejemplares encontrados tan solo ha permitido identificar cinco taxones, aunque es probable que también estuviesen presentes otros con requerimientos ecológicos similares a los citados, como por ejemplo Corylus avellana, Acer sp., Tilia sp., Rhamnus alpina, Cornus sanguinea, etc.

Con anterioridad al Último Máximo Glacial, pero también en un contexto climático general frío -MIS 4- (Fig. 16) (EPICA, 2004), habitaban la zona de estudio Fagus sylvatica 
y Corylus avellana. El haya, debido a su baja resistencia a la aridez, especialmente a la sequía estival (Blanco, et al., 1997), es una especie cuya distribución en sector Castellano Cantábrico pudo haberse visto afectada por las condiciones glaciales de frío y aridez. En efecto, existe constancia de que el descenso de la temperatura y precipitaciones del Último Periodo Glacial provocaron la disminución y fragmentación del área de ocupación interglacial de los taxones más termófilos, entre ellos el haya, los cuales quedaron relegados a refugios donde se daban las condiciones climáticas adecuadas (González-Sampériz, et al., 2010). Estos lugares sirvieron de reservorio genético y fueron los puntos a partir de los cuales se volvieron a expandir durante los periodos interglaciares (Rodríguez-Sánchez, et al., 2010). En el caso de Fagus sylvatica, ha sido probado que existieron refugios de esta especie en la Costa Cantábrica (Ramil-Rego, et al., 2000; López-Merino, et al., 2008; Magri, 2008; MuñozSobrino, et al., 2009). Sin embargo, el hallazgo de numerosas impresiones de hojas de haya en TUAG-TBH sugiere que también pudo haber sobrevivido en algunos emplazamientos más interiores. Quizás, en este contexto, se estableció en entornos de cierta higrometría edáfica, y no se expandió fuera de ellos hasta que se dieron las condiciones necesarias de humedad ambiental. Esto es lo que parece sugerir el registro de la turberas de La Piedra, en la cual el polen de esta especie aparece en pequeñas cantidades y de forma esporádica a lo largo de toda la secuencia (Muñoz Sobrino, et al., 1996). Esto se podría interpretar como que, si bien esta especie no estuvo presente de forma local en las altiplanicies donde se sitúa la turbera, existían algunas poblaciones cercanas. Esta hipótesis parece razonable, si tenemos en cuenta que el haya soporta bien el frío en el periodo de reposo vegetativo (Blanco, et al., 1997) y que la humedad edáfica y las condiciones microclimáticas de los barrancos podrían compensar la sequía estival. Aunque en La Piedra no se observa un aumento del polen de $F$. sylvatica, las secuencias de Quintanar de la Sierra (Ruiz-Zapata, et al., 2002) y San Mamés de Abar (Iriarte Chiapuso, et al., 2002) sí recogen una expansión tardía de esta especie.

En efecto, los factores fisiográficos —p.e. la elevación, la pendiente, la topografía, etc.- influyen sobre las variables meteorológicas, como por ejemplo la temperatura del aire, 
la precipitación, el viento, la insolación, la evapotranspiración, etc., lo que en última instancia determina la distribución de las especies vegetales (Coughlan \& Running, 1997). El efecto de la fisiografía sobre el clima puede llegar a ser notable, como ha sido comprobado en contextos montañosos, donde se han medido diferencias de hasta $5^{\circ} \mathrm{C}$ en la temperatura media de los meses más fríos y un $20 \%$ en la tasa de evapotranspiración con respecto a otras estaciones a la misma altitud (Dobrowski, et al., 2009). Como consecuencia de ello, las condiciones climáticas generales pueden ser moduladas en gran medida por la configuración geográfica local y regional, y determinar la composición y distribución de los ecosistemas terrestres (Ramil-Rego, et al., 2005; Daly, et al., 2009). En este sentido, ha sido probado que los microrrefugios, tales como gargantas, cañones, solanas, etc., tuvieron un papel clave en la supervivencia de pequeñas poblaciones fuera de sus refugios principales (Provan \& Bennett, 2008; Rull, 2009; Dobrowski, 2010). En el fondo de valles y cañones como los existentes en el sector Castellano Cantábrico, se reducen las oscilaciones térmicas y la evapotranspiración (Blanco, et al., 1997; Dobrowski, 2010). Adicionalmente, los valles y cañones también proporcionan protección frente al viento desecante, al mismo tiempo que en el fondo de estas depresiones se preserva mejor la humedad edáfica (Loehle, 2007). Por otro lado, en estos entornos pueden tener lugar fenómenos de inversión térmica, por lo que pueden llegar a ser no adecuados para especies sensibles a las bajas temperaturas (Dobrowski, 2010). En cualquier caso, la gran complejidad geomorfológica del sector Castellano Cantábrico ofrece numerosas combinaciones de elevaciones, orientaciones y relieves donde pudieron encontrar acomodo especies con diferentes requerimientos ecológicos.

Si bien la humedad edáfica y ambiental del fondo de los valles y cañones (Loehle, 2007) podría haber compensado la aridez glacial y haber garantizado la persistencia de taxones eurosiberianos y submediterráneos, más resistentes al frío, la respuesta de otras especies más térmicas que hoy pueblan este territorio - p.e. Quercus suber, Arbutus unedo L., Viburnum tinus L., Vitis vinífera L., Phillyrea angustifolia L., P. latifolia L., o Pistacia terebinthus L.(Alejandre, et al., 2006)—, es más incierta. Algunos de ellos pudieron haber 
experimentado extinciones locales durante las fases frías, del mismo modo que, como ya ha sido comentado, Buxus sempervirens ha desaparecido de la comarca de La Lora, donde habitaba en el Pleistoceno Medio. Una hipótesis alternativa es que estos elementos mediterráneos no estaban presentes en el sector Castellano Cantábrico durante la glaciación, pero llegaron a este territorio con la mejoría climática holocena. Esta hipótesis ha sido planteada por Montserrat-Martí (1987), quien propuso que las especies típicamente mediterráneas presentes en la parte oriental de la costa cantábrica -Quercus coccifera $L$, Pistacia lentiscus, Clematis flammula L., Olea europaea var. sylvestris (Mill.) Lehr, etc.llegaron a ese territorio desde la costa mediterránea a través del valle del Ebro. Estas habrían accedido a la cornisa cantábrica desde el sector Castellano Cantábrico a través de los corredores que suponen los valles del Cadagua, Nervión, Mena, etc. (Aseginolaza, et al., 1988; Loidi, et al., 2011). Sin embargo, la presencia de Fraxinus ornus y Q. suber en el sector Castellano Cantábrico no se ajustan al modelo anterior, ya que forman poblaciones aisladas y disyuntas (García Mijangos, 1995; Beltrán, 2006), lo que sugiere que podrían constituir poblaciones relictas de las que habitaban en este territorio antes de la última glaciación.

En definitiva, debido al carácter transicional del sector Biogeográfico Castellano Cantábrico, parece poco probable que este territorio haya sido el refugio glacial principal de las especies vegetales que lo pueblan, las cuales podrían estar más cerca de las costa. Sin embargo, su relieve quebrado ha podido ofrecer múltiples microrrefugios con condiciones climáticas diferentes, que constituyeron refugios interiores que ayudaron a preservar su diversidad florística y la recuperación de las poblaciones locales de estas especies. 


\section{CAPÍTULO 6. CONCLUSIONES}




\section{CONCLUSIONES}

En la presente Tesis Doctoral se ha abordado la prospección y estudio de seis yacimientos paleobotánicos ubicados en el sector biogeográfico Castellano Cantábrico, en las localidades de Tubilla del Agua, Sedano, Herrán, Tobera, Frías y Ocio. El análisis geocronológico y geomorfológico de este conjunto de yacimientos tobáceos ha permitido la identificación de 13 depósitos diferentes que datan del Cuaternario Final. La exploración de estos yacimientos ha dado como resultado el hallazgo de 1.820 impresiones de restos vegetales en toba, así como 42 restos vegetales subfósiles, los cuales ha sido identificados mediante morfología comparada con plantas actuales, ejemplares de herbario y bibliografía de referencia. El análisis de los datos obtenidos nos ha permitido llegar a las siguientes conclusiones:

1. Los depósitos tobáceos estudiados constituyen registros paleobotánicos de interés, ya que contienen abundantes restos vegetales que permiten su identificación taxonómica, generalmente hasta el rango de especie. Estos fósiles consisten principalmente en impresiones foliares y encostramientos de toba. Adicionalmente, la naturaleza litológica de estos depósitos ha permitido datarlos con relativa precisión mediante diferentes técnicas, lo que ha hecho posible ubicar su contenido paleobotánico a lo largo del tiempo.

2. Los seis yacimientos estudiados en esta Tesis — complejo tobáceo de Tubilla del Agua, Barreras de Sedano, complejos tobáceos de los ríos Purón y Molinar, formación de Frías y barrera de Ocio- presentan una tipología variada, que comprende formaciones colgadas en ladera, de barrera y mixtas. A partir de la datación de 15 muestras tomadas de tres de estos yacimientos - Tubilla, Sedano y Frías - se ha determinado que la formación de las diez unidades litológicas diferentes que los componen, tuvo lugar en diferentes periodos del Cuaternario Final. Los del Pleistoceno Medio se formaron en los 
Estadíos Isotópicos Marinos 7-9, los del Pleistoceno Superior en los MIS 5, 4 y 2, y los del holoceno han sido datados en diferentes fases de este periodo.

3. El yacimiento de Tubilla del Agua es, desde el punto de vista geomorfológico, el más complejo de todos los estudiados. En él se han identificado siete unidades litológicas que pertenecen a cinco generaciones diferentes. Las dos estructuras más antiguas datan del Pleistoceno Medio -MIS 7-8_y formaban parte de una única barrera que posteriormente fue incidida por el río, por lo que hoy en día se presentan como dos espolones tobáceos situados a ambos lados del valle. Las unidades litológicas del Pleistoceno Superior se corresponden con tres terrazas situadas a diferente cota, las cuales fueron formadas en los MIS 5, 4 y 2. Las estructuras restantes se depositaron durante los periodos Atlántico y Subatlántico del Holoceno -entre $5.000-7.500$ y 0-2.500 años respectivamenteEstos se corresponden con una barrera tobácea que cierra el valle y una serie de rellenos de naturaleza autóctona y alóctona aguas debajo de la represa.

4. Las barreras de sedano consisten en dos represas escalonadas coetáneas, que empezaron a depositarse hace aproximadamente 6.000 y cuyo crecimiento finalizó hace unos 4.000 años. Por su parte, el depósito de Frías tiene tipología de formación en ladera, y data del Pleistoceno Medio, de los MIS 8 ó 9.

5. A partir de los restos paleobotánicos estudiados se infiere que la vegetación del Pleistoceno Medio del sector Castellano Cantábrico estuvo formada por al menos tres comunidades vegetales diferentes: (i) una fitocenosis zonal que en la que Pinus nigra y Quercus faginea eran las especies más representativas (ii) otra extrazonal formada por un conjunto taxones eurosiberianos y mesofíticos con unos requerimientos de humedad edáfica o ambiental mayor que los anteriores, como cf. Tilia sp., Acer campestre, Sorbus aria, Corylus avellana, etc. y; (iii) una tercera azonal, riparia, asociada a los cauces de 
agua y los sistemas tobáceos activos, de la que los sauces son el taxón más abundante. Esta última es la mejor representada en los registros tobáceos estudiados.

6. El Pleistoceno Superior está representado por tres depósitos, todos ellos en Tubilla del Agua, datados en los MIS 5, 4 y 2. El más antiguo muestra una vegetación similar a la descrita en los yacimientos del Pleistoceno Medio del área de estudio, en la que el pino laricio y el quejigo seguirían siendo las especies protagonistas de la vegetación zonal. El registro fósil del edificio formado durante el MIS 4 sugiere la existencia de un bosque dominado por Fagus sylvatica, probablemente de carácter extrazonal, en el que también aparecen algunos elementos eurosiberianos, como Sorbus aria y Corylus avellana, y Pinus nigra. El tercero de estos depósitos, formado durante el Último Máximo Glacial, reportó solo cinco taxones, pero en él siguen estando presentes el pino laricio y los sauces.

7. La flora encontrada en los yacimientos holocenos es muy similar a la que hoy en día existe en el sector biogeográfico Castellano Cantábrico, salvo por la presencia del pino laricio, actualmente extinto de este territorio. Las comunidades vegetales que sugiere el registro fósil son similares a las descritas en los estadíos climáticos anteriores: saucedas que poblarían las zonas húmedas y riberas de los ríos y arroyos, comunidades extrazonales formadas por taxones mesotérmicos y eurosiberianos que crecían sobre suelos frescos, y un bosque zonal de pino laricio y quejigo a los que acompañaban otras especies submediterráneas —Berberis vulgaris, Buxus sempervirens y Amelanchier ovalis-.

8. El conjunto de restos atribuidos a Pinus nigra sugiere la presencia continua de esta especie en el sector Castellano Cantabrico desde el Pleistoceno Medio hasta hace por lo menos 1.500 años. Estos vestigios, junto con otras evidencias publicadas a las que se hace referencia en esta Tesis, sugieren que Pinus nigra tuvo un papel protagonista en la cubierta vegetal de la Meseta Norte y montañas adyacentes de litología caliza y clima 
submediterráneo a lo largo del Cuaternario Final. Su desaparición de la zona de estudio parece estar relacionada con la acción antrópica, especialmente con el uso del fuego.

9. La presencia durante el Último Máximo Glacial en Tubilla del Agua de especies poco tolerantes a la aridez como Salix sp., Sorbus aria y Hedera sp., y anteriormente, durante el MIS 4, de Fagus sylvatica y Corylus avellana, sugiere que el sector Castellano Cantábrico pudo haber constituido un refugio glacial para taxones de filiación eurosiberiana y submediterránea. La gran complejidad geomorfológica de este territorio ofrece estaciones diversas —-solanas, cañones, umbrías, humedales, etc.- donde pudieron encontrar acomodo especies con diferentes requerimientos ecológicos en periodos climáticamente adversos. 


\section{REFERENCIAS}

Adams, J., Maslin, M., Thomas, E., 1999. Sudden climate transitions during the Quaternary. Progress in Physical Geography, 23: 1-36.

Abrantes, F., Voelker, A., Sierro, F.J., Naughton, F., Rodrigues, T., Cacho, I., Ariztegui, D., Brayshaw, D., Sicre, M.A., Batista, L., 2012, Paleoclimate Variability in the Mediterranean Region, En: Mediterranean Climate: from Past to the Future. Elsevier, pp. 1-57.

ADPBU.CE., Archivo de la Diputación Provincial de Burgos. Fondo del Catastro del Marqués de la Ensenada, Libro Mayores de lo Raíz de seglares y Personal de seglares, Sig. 02098.

AHPB.PN, Archivo Histórico Provincial de Burgos. Protocolos Notariales del Distrito de Sedano, Ref. 3815.

Alcalde Olivares, C., Gómez Manzaneque, F., Postigo Mijarra, J.Mª., Sanz, E., Menéndez-Pidal, I., 2003. Pinus Sylvestris L. en el Pleistoceno superior del Duero (Vega Cintora, Soria, España). Revista de la Sociedad Española de Geomorfología y Asociación Española para el Estudio del Cuaternario, 17 (12): 21-28.

Alcalde-Olivares, C., García-Amorena, I., Gómez-Manzaneque, F., Maldonado Ruiz, J., Morla, C., Postigo, J, M., 2001. Estudio de los macrorrestos vegetales del yacimiento de Lomilla (Aguilar de Campoo, Palencia, España). Anales del Jardín Botánico de Madrid, 59: 101-112.

Alejandre, J., García-López, J., Mateo, G., 2006. Atlas de la flora vascular silvestre de Burgos. Burgos, Junta de Castilla y León y Caja Rural de Burgos, 924 pp.

Ali, A.A., Carcaillet, C., Guendon, J.L., Quinif, Y., Roiron, P., Terral, J.F., 2003a. The early Holocene treeline in the southern inner French Alps: new evidence from plant imprints within travertine. Global Ecology and Biogeography, 12: 411-419.

Ali, A.A., Guendon, J., Terral, J.R.P., 2003b. Les systèmes travertineux holocènes et les paléopaysages méditerranéens et subalpins (France): une analyse géobotanique séquentielle à haute résolution spatiale. Géographie physique et Quaternaire, 57 (2-3): 219-235.

Ali, A.A., Roiron, P., Chabal, L., Ambert, P., Gasco, J., André, J., Terral, J.F., 2008. Holocene hydrological and vegetation changes in Southern France inferred by the study of an alluvial travertine system (Saint-Guilhem-le-Désert, Hérault). Comptes Rendus Geoscience, 340: 356-366.

Ali, A.A., Terral, J., Guendon, J.R.P., 2003c. Holocene palaeoenvironmental changes in southern France: a palaeobotanical study of travertine at StAntonin,Bouches-du-Rhone. The Holocene, 13 (1): 165-170.

Allen, J.R.M., Huntley, B., Watts, W. A., 1996. The vegetation and climate of northwest Iberia over the last 14,000 yr. Journal of Quaternary Science, 11: 125-147. 
Allué, E., Euba, I., 2008. Los datos antracológicos de la secuencia neolítica de ElMirador (Atapuerca, Burgos): un estudio sobre el medio vegetaly la explotación de las especies leñosas. En: Actas del IV Congreso del Neolítico Peninsular. Alicante, MuseoArqueológico de Alicante, Diputación de Alicante, tomo 1, pp. 345-352.

Allué, E., Nadal, J., Estrada, A., García-Argüelles, P., 2007. Los datos antracológicos de la Balma del Gai (Bages, Barcelona): una aportación al conocimiento de la vegetación y la explotación de los recursos forestales durante el Tardiglaciar en el NE peninsular. Trabajos de Prehistoria, 64: 87-98.

Álvarez Ramis, C., Fernández Marrón, M., 1975. Estudio paleobotánico y datación estratigráfica del yacimiento terciario de Frías (Burgos). En: Primer Centenario de la Real Sociedad Española de Historia Natural (Sección Geológica). 27-41.

Ambert, P., Guendon, J., Vaudour, J., Magnin, F., 1992. Paléoenvironnements au pléistocene moyen dans la Vallée du Tarn: La formation travertineuse de la Rouquette (Creissels-Aveyron). Geobios, 14: 133-139.

Ambert, P., Quinif, Y., Roiron, P., Arthuis, R., 1995. Les travertins de la vallée du Lez, datations $230 \mathrm{Th} / 234 \mathrm{U}$ et environnements pléistocènes. Comptes rendus de l'Académie des sciences, 321: 667-674.

Amsler, M., 1900. Flore interglaciaire de Piànico. Compte Rendu des travaux de la Societé Helvétique de Sciencies Naturelles Réunie à Thusis, pp. 44-46.

Anderson, J.M., Anderson, H.M., Cleal C.J., 2007. Brief history of the Gymnosperms: classification, biodiversity, phytogeography and ecology. Strelitzia, 20, 1-280.

ANE (Atlas Nacional de España), 1986-2008. Mapa Geológico. Instituto Geográfico Nacional. http://www.ign.es/ane/ane1986-2008.

Aseginolaza, C., Gómez, D., Lizaur, X., Montserrat-Martí, G., Morante, G., Salaverria, M.R., Uribe-Echebarria, P.M., 1988. Vegetación de la Comunidad Autónoma del País Vasco. Vitoria-Gasteiz, Servicio de Publicaciones del Gobierno Vasco, $361 \mathrm{pp}$.

Ash, A., 1999. Manual of leaf architecture. Washington, Smithsonian Institution, 65 pp.

Atherton, I., Bosanquet, S., Llawley, M., 2010. Mosses and Liverworts of Britain and Ireland: a field guide. London, British Bryological Society, 865 pp.

Badía-Gimeno, S., Muñoz-Bertomeu, J., 1999. Estudio paleobotánico del travertino de El Prat (Beceite, Teruel): implicaciones paleoecológicas. Cidaris, 15-16: 2936 .

Barredo, J., Barredo, U., 2002. Aproximación al catálogo florístico de la cuenca del Omecillo Valderejo y Sobrón. Munibe (Ciencias Naturales-Natur Zientziak), 53: 57-130. 
Barrón, E., 1996. Estudio tafonómico y análisis paleoecológico de la macro y microflora miocena de la Cuenca de la Cerdaña. Madrid, Universidad Complutense de Madrid. Facultad de Ciencias Biológicas, 714 pp.

Barrón, E., 2003. Evolución de las floras terciarias en la Península Ibérica. Monografías del Jardín Botánico de Córdoba, 11: 63-74.

Barrón, E, Diéguez, C., 2005. Cuticular study of leaf compressions from the Late Miocene (Vallesian) diatomites of Cerdaña Basin (Eastern Pyrenees, Spain). Neues Jahrbuch für Geologie und Paläontologie - Abhandlungen, 237: 61-86.

Barrón, E., Rivas Caballero, M.R., Valle, M.F., 1996. Síntesis bibliográfica de la vegetación y clima de la Península lbérica durante el Neógeno. Revista Española de Paleontología. N ${ }^{\circ}$ Extraordinario. X Jornadas de Paleontología., pp. 225-236.

Barrón, E., Rivas-Carballo, R., Postigo-Mijarra, J.M., Alcalde-Olivares, C., Vieira, M., Castro, L., Pais, J., Valle-Hernández, M., 2010. The Cenozoic vegetation of the Iberian Peninsula: a synthesis. Review of Palaeobotany and Palynolog, 162: 382-402.

Bazile-Robert, E., 1979. Flore et vegetation du sud de la France pendant la dernière glaciation. Montpellier, University of Montpellier II, $115 \mathrm{pp}$.

Behrensmeyer, A.K., Hook, R., 1992. Paleoenvironmental contexts and taphonomic modes in the terrestrial fossil record. En: Terrestrial Ecosystems Through Time. Evolutionary paleoecology of terrestrial plants and animals. Chicago, University of Chicago Press, pp. 15-38.

Behrensmeyer, A.K., Kidwell, S., Gastaldo, R., 2000. Taphonomy and Paleobiology. Paleobiology, 26 (4): 103-144.

Beltrán, R., 2006. Distribución y autoecología de Prunus lusitanica L. en la Península Ibérica. Investigación agraria. Sistemas y recursos forestales, Fuera de serie, pp. 187-198.

Berastegi, A., Darquistade, A., García-Mijangos, I., 1997. Biogeografía de la España centro-septentrional. Itinera Geobotánica, 10: 149-182.

Berger, A., 1978. Long-term variations of daily insolation and Quaternary climatic changes. Journal of the Atmospheric Sciences, 35: 2362-2367.

Berger, G., Pérez-González, A., Carbonell, E., Arsuaga, J.L., Bermúdez de Castro, J.M., Kue, T.L, 2008. Luminescence chronology of cave sediments at the Atapuerca paleoanthropological site, Spain. Journal of Human Evolution, 55 (2): $300-311$.

Blanco, E., Casado, M.A., Costa, M., Escribano, R., García, M., Génova, M., Gómez, A., Gómez, F., Moreno, J. C., Morla, C., Regato, P., Sainz, H., 1997. Los bosques ibéricos: Una interpretación geobotánica. Barcelona: Planeta. 
Bowman, S., 1990. Radiocarbon Dating. "Interpreting the Past" series. London, British Museum Publications, $64 \mathrm{pp}$.

Bremer, P., Jongejans, J., 2010. Frost and forest stand effects on the population dynamics of Asplenium scolopendrium. Popular Ecology, 52 (1); 211-222.

Brochier, J.E., 1988. Cinq millènaires de sedimentation dans le marais holocène de la Resclauze (Gabian, Hèrault). Ėtude gèoarcheologique. En: Les èdifices travertineux et l'histoire de l'environnement dans le Midi de la France (Provence, Languedoc, Roussilon), U.A. 903 CNRS et A.T.P. PIREN, Aix-enProvence, pp. 117-136.

Broecker, W., Denton, G., 1989. The role of ocean-atmosphere reorganizations in glacial cycles. Geochimica et Cosmochimica Acta, 53: 2465-2501.

Buades, A., 1989. Las formaciones vegetales del Parque Natural del Cañón del río Lobos. Anales de Geografía de la Universidad Complutense, 9: 107-122.

Buck, W. R., Goffinet, B., 2000. Morphology and classification of mosses. En: Bryophyte Biology. Cambridge, Cambridge University Press, pp. 71-123.

Burnham, R., 1989. Relationships between standing vegetation and leaf litter in a paratropical forest: implications for paleobotany. Review of Palaeobotany and Palynology, 58 (1): 27-51.

Campillo, J., 1984. Hacia una sistematización del fenómeno dolménico en el NW Burgalés. KOBIE (Serie Paleoantropología y Ciencias Naturales), 14: 143-170.

Carreras, F., del Olmo, P., Ramírez, J., 1978. Memoria y cartografía del Mapa Geológico de España 1/50.000. Hoja 19-07 (109), Villarcayo. Madrid, Instituto Geogrófico y Minero de España, 43 pp.

Carreras, F., Ramírez, J., Aguilar, M. J., 1979. Memoria y cartografía del Mapa Geológico de España 1/50.000. Hoja 19-8 (135), Sedano. Madrid, Instituto Geológico y Minero de España, 38 pp.

Carrión, J.S., Fernández, S., González-Sampériz, P., López-Merino, L., Peña, L., Burjachs, F., López-Sáez, J. A., García-Antón, M., Carrión Marco, Y., Uzquiano, P., Postigo, J. M., Barrón, E., Allué, E., Badal, E., Dupré, M., Fierro, E., Munuera, M., Rubiales, J. M., García-Amorena, I., Jiménez Moreno, G., Gil Romera, G., Leroy, S., García-Martínez, M. S., Montoya, E., Fletcher, W., YII, E., Vieira, M., Rodríguez-Ariza, M. O., Anderson, S., Peñalba, C., Gil García, M. J., Pérez Sanz, A., Albert, R. M., Díez, M. J., Morales-Molino, C., Gómez Manzaneque, F., Parra, I., Ruiz Zapata, B., Riera, S., Zapata, L., Ejarque, A., Vegas, T., Rull, V., Scott, ., Abel Schaad, D., Andrade, A., Manzano, S., Navarro, C., Pérez Díaz, S., Moreno, E., Hernández-Mateo, L., Sánchez Baena, J. J., Riquelme, J. A., Iglesias, R., Franco, F., Chaín, C., Figueiral, I., Grau, E., Matos, M., Jiménez Espejo, F., Valle-Hernández, M., Rivas-Carballo, R., Arribas, A., Garrido, G., Muñiz, F., Finlayson, G., Finlayson, C., Ruiz, M., Pérez Jordá, G., Miras, Y., 2012. Paleoflora y Paleovegetación de la Península 
Ibérica e islas Baleares: Plioceno-Cuaternario. Madrid, Ministerio Economía y competitividad, Universidad de Murcia, Fundación Séneca, 972 pp.

Carrión, J.S., Fernández, S., González-Sampériz, P., Gil-Romera, G., Badal, E., Carrión-Marco, Y., López-Merino, L., López-Sáez, J.A., Fierro, E., Burjachs, F., 2010. Expected trends and surprises in the Lateglacial and Holocene vegetation history of the Iberian Peninsula and Balearic Islands. Review of Palaeobotany and Palynology, 162 (3): 458-475.

Carrión, J.S., Munuera, M., Navarro, C., Sáez, F., 2000a. Paleoclimas e Historia de la vegetación cuaternaria en España a través del análisis polínico. Complutum, 11: 115- 142.

Carrión, J.S., Navarro, V., Navarro, J., Munuera, M., 2000b. The distribution of cluster pine (Pinus pinaster) in Spain as derived from palaeoecological data: relationships with phytosociological classification. The Holocene, 10 (2): 243252.

Casas, C., Brugués, M., Cros, R. M., Sérgio, C., 2006. Handbook of mosses of the Iberian Peninsula and the Balearic Islands. Barcelona, Institut d'Estudis Catalans, $349 \mathrm{pp}$.

Casas, C., Fuertes, E., Brugues, M., Cros, R.M., Reinoso, J., 1992. Aportaciones a la flora briologica espanola. Notula 8. Los paramos de la Lora (Burgos, Espana). Stvdia Botánica, 10: 109-122.

Castroviejo, S., Aedo, C., Cirujano, S., Laínz, M., Montserrat, P., Morales, R., Muñoz Garmendia, F., Navarro, C., Paiva, J., Soriano, C., 1990. Flora Ibérica 2. Madrid, Real Jardín Botánico, CSIC, 900 pp.

Castroviejo, S., Aedo, C., Cirujano, S., Laínz, M., Montserrat, P., Morales, R., Muñoz Garmendia, F., Navarro, C., Paiva, J., Soriano, C., 1993. Flora Ibérica 3. Madrid: Real Jardín Botánico, CSIC, 784 pp.

Castroviejo, S., Aedo, C., Cirujano, S., Laínz, M., Montserrat, P., Morales, R., Muñoz Garmendia, F., Navarro, C., Paiva, J., Soriano, C., 1998. Flora Ibérica 6. Madrid: Real Jardín Botánico, CSIC, 640 pp.

Catalán, G., Gil, P., Galera, R., Martín, S., Agúndez, D., Alía, R., 1991. Las regiones de procedencia de Pinus Sylvestris L. y Pinus nigra Arn. subsp. Salzmanii (Dunal) Franco en España. Madrid, ICONA, 31 pp.

Ceballos, L., 1966. Mapa forestal de España a escala 1:400.000. Madrid, Ministerio de Agricultura, $48 \mathrm{pp}$.

Chapman, J., Reiss, M., 1992. Ecology: principles and applications. Cambridge, Cambridge University Press, $336 \mathrm{pp}$.

Chase, M., Reveal, J., 2009. A phylogenetic classification of the land plants to accompany APG III. Botanical Journal of the Linnean Society, 161: 122-127. 
CHE, 2010. Subcuenca del río Molinar. En: Aplicación del Índice Hidrogeomorfológico IHG a la cuenca del Ebro. Zaragoza, Confederación Hidrográfica del Ebro.

Chen, J.A., Zhang, D.D., Wang, S.J., Xiao, T.F., Huang, R.G., 2004. Factors controlling tufa deposition in natural waters at waterfall sites. Sedimentary Geology, 166: 353-366.

Christenhusz, J.M.M., 2011a. A new classification and linear sequence of extant gymnosperms. Phytotaxa, 19: 55-70.

Christenhusz, M. J. M., Zhang, X., Schneider, H., 2011b. A linear sequence of extant families and genera of lycophytes and ferns. Phytotaxa, 19: 7-54.

Cidad, J., 1988. Tubilla del Agua: apuntes históricos sobre el municipio. Burgos, Diputación de Burgos, 128 pp.

Clerici, E., 1887. Il travertino di Fiano romano. Bollettino del Servizio geologico d'Italia, 18: 99-128.

Conolly, A., Godwin, H., Megaw, E., 1950. Studies in the post-glacial history of British vegetation XI: late-glacial deposits in Comwall. Philosophical Transactions of the Royal Society of London, 234: 397-469.

Coughlan, J., Running, S., 1997. Regional ecosystem simulation: a general model for simulating snow accumulation and melt in mountainous terrain. Landscape Ecology, 12: 119-136.

Cracraft, J., Donoghue, M., 2004. Assembling the Tree of Life: Where We Stand at the Beginning of the 21st Century. En: Assembling the Tree of Life. Oxford, Oxford University Press, pp. 553-561.

Cuesta, I., Muñoz, R., Madrigal, J., Muñoz, J., 2007. Estudio de la composición y la diversidad de las comunidades vegetales del Cañón del Río Cega. Segovia, Caja Segovia, Obra Social y Cultural, 183 pp.

D’Anna, A., Evin, J., Guendon, J.L., Jaubert, J., Magnin, E., Otto, T., Quinif, Y., Roiron, P., Thinon, M., Vernet, J., Vaudour, J., 1988. Les édifices travertineux d'Auriol (Pont-de-Joux) et de Roquevaire (Saint-Vincent). Révision stratigraphique: contribution à l'histoire de l'environnement dans la vallée de l'Huveaune (Bouches-du-Rhône) depuis 50.000 ans. En: Les èdifices travertineux et l'histoire de l'environnement dans le Midi de la France (Provence, Languedoc, Roussilon), U.A. 903 CNRS et A.T.P. PIREN, Aix-en-Provence, 17-36.

Daley, T., Thomas, E.R., Holmes, J.A., Street-Perrott, F.A., Chapman, M.R., Tindall, J.C., Valdes, P.J., 2011. The $8.200 \mathrm{yr}$ BP cold event in stable isotope records from the North Atlantic region. Global and Planetary Change, 79 (3-4): 288302.

Daly, C., Conklin, D., Unsworth, M., 2009. Local atmospheric decoupling in complex topography alters climate change impacts. International Journal of Climatology, doi:10.1002/joc.2007. 
Dansgaard, W., Johnsen, S.J., Clausen, H.B., Dahl-Jensen, D., Gundestrup, N.S., 1993. Evidence for general instability of past climate from a $250-k y r$ ice-core record. Nature, 364: 218-220.

Delannoy, J., Guendon, J., Quinif, Y., Roiron, P., 1993. Formaciones travertínicas del piedemonte mediterráneo de la Serranía de Ronda (Málaga). Cuadernos de Geografía, 54: 189-222.

Delibes, G., Rojo, M., 1997. C14 y secuencia megalítica en la Lora burgalesa: acotaciones a la problemática de las dotaciones absolutas referetes a yacimientos dolménicos. En: O neolítico atlántico e as orixes do megalitismo: actas do Coloquio Internacional (Santiago de Compostela, 1-6 de abril de 1996). Santiago de Compostela, Coloquio Internacional o Neolítico Atlántico e as Orixes do Megalitismo, pp. 391-414.

Delibes, G., Rojo, M., Represa, J., 1993. Los dólmenes de La Lora. Salamanca: Junta de Castilla y León, Consejería de Cultura y Turismo, 115 pp.

Demko, T., Dubiel, R., Parrish, J., 1998. Plant taphonomy in incised valleys: Implications for interpreting paleoclimate from fossil plants. Geology, 26 (12): 1119-1122.

Desprat, S., Sánchez-Goñi, M.F., Naughton, F., Turon, J.L., Duprat, J., Malaizé, B., Cortijo, E., Peypouquet, J.P., 2007. Climate variability of the last five isotopic interglacials: Direct land-sea-ice correlation from the multiproxy analysis of North-Western Iberian margin deep-sea cores. En: Developments in Quaternary Science, 7: 375-386.

Desprat, S., Sánchez-Goñi, M.F., Turon, J.L., McManus, J.F., Loutre, M.F., Duprat, J., Malaizé, B., Peyron, O., Peypouquet, J.P., 2005. Is vegetation responsible for glacial inception during periods of muted insolation changes?. Quaternary Science Reviews, 24 (12-13): 1361-1374.

Dickson, C., Dickson, J., Mitchell, G., 1970. The Late Weichselian flora of the Isle of Man. Philosophical Transactions of the Royal Society of London , 258: 31-79.

Diéguez, C., Peyrot, D., Barrón, E., 2010. Floristic and vegetational changes in the Iberian Peninsula during Jurassic and Cretaceous. Review of Palaeobotany and Palynology, 162: 325-340.

Dilcher, D.I., 1974. Approaches to the identification of angiosperm leaf remains. The Botanical Review, 40 (1): 2-153.

Dobrowski, S., 2010. A climatic basis for microrefugia: the influence of terrain on climate. Global Change Biology, doi: 10.1111/j.1365-2486.2010.02263.x.

Dobrowski, S., Abatzoglou, J., Greenberg, J., Schladow, G., 2009. How much influence does landscape-scale physiography have on air temperature in a mountain environment?. Agricultural and Forest Meteorology, 149: 1751-1758. 
Dunwiddie, P., 1987. Macrofossil and pollen representation of coniferous trees in modern sediments from Washington. Ecology, 68 (1): 1-11.

Dupré, M., 1984. Palinología de los niveles VII a II. En: El yacimiento prehistórico de la cueva de Ekain (Deba, Guipúzcoa). Colección Barandiarán, 1: 61-63 .

Durán Valsero, J. , López Martínez, J., 1989. El Karst en España. Madrid, Sociedad Española de Geomorfología, 414 pp.

Eldrett, J., Greenwood, D., Harding, I., Huber, M., 2009. Increased seasonality through the Eocene to Oligocene transition in northern high latitudes. Nature, 459: 969973.

Emmert-Straubinger, E., 1991. Die Interglazial flora von Piànico (Prov. Bergamo, Italien). En: Proceedings of the Pan-European Palaeobotanical Conference, Vienna 19-23 September 1991. Vienna: Museum of Natural History, pp. 15-18.

Engler, A., 1903. Syllabus der Pflanzenfamilien: eine Übersicht über das gesamte Pflanzensystem mit Berücksichtigung der Medicinal und Nutzpflanzen nebst einer Übersicht über die Florenreiche und Florengebiete der Erde zum Gebrauch bei Vorlesungen und Studien über specie. Berlin: Gebrüder Borntraeger Verlag.

EPICA, community members, 2004. Eight glacial cycles from an Antarctic ice core. Nature, 429: 623-628.

Falguères, C., Bahain, J.J., Bischoff, J.L., Pérez-González, A., Ortega, A.I., Ollé, A., Quiles, A., Ghaleb, B., Moreno, D., Dolo, J.M., Shao, Q., Vallverdú, J., Carbonell, E., Bermúdez de Castro, J.M., Arsuaga, J.L., 2013. Combined ESR/U-series chronology of Acheulian hominid-bearing layers at Trinchera Galería site, Atapuerca, Spain. Journal of Human Evolution, 65 (2): 168-84.

Falguères, C., Bahain, J.J., Yokoyama, Y., Arsuaga, J.L., Bermudez de Castro, J.M., Carbonell, E., Bischoff, J.L., Dolo, J.M., 1999. Earliest humans in Europe: the age of TD6 Gran Dolina, Atapuerca, Spain. Journal of Human Evolution, 3 (4): 343-352.

Farizier, M., 1980. Recherches Sur les Macroflores Des Tufs Quaternaries Du Sud de la France (Mémoires École Pratiques des hautes Études). Montpelier, Université de Montpellier II, 326 pp.

Ferguson, D., 1985. The origin of leaf-assemblages-new light on an old problem. Review of Palaeobotany and Palynology, 46 (1/2): 88-117.

Fernández, S., Fuentes, N., Carrión, J.S., González-Sampériz, P., Montoya, E., Gil, G., Vega Toscano, G., Riquelme, J.A., 2007. The Holocene and Late Pleistocene pollen sequence of Carihuela Cave, southern Spain. Geobios 40, 75-90.

Figueiral, I., Carcaillet, C., 2005. A review of Late Pleistocene and Holocene biogeography of highland Mediterranean pines (Pinus type sylvestris) in 
Portugal, based on wood charcoal. Quaternary Science Reviews, 24: 24662476.

Florsheim, J., Ustin, S.L., Tang, Y., Di, B.; Huang, C., Qiao, X., Peng, H., Zhang, M., Cai, Y., 2013. Basin-scale and travertine dam-scale controls on fluvial travertine, Jiuzhaigou, southwestern China. Geomorphology, 180-181: 267280.

FNAEC, (Flora of North America Editorial Commitee) 2014. Flora of North America North of Mexico: Bryophyta. 28.

Ford, T.D., Pedley, H., 1996. A review of tufa and travertine deposits of the world. Earth-Sicience Reviews, 41: 117-175.

Franco-Múgica, F., García-Antón, M., Maldonado Ruiz, J., Morla, C., Sainz-Ollero, H., 2001. The Holocene history of Pinus forests in the Spanish Northern Meseta. The Holocene, 11: 343-358.

Frey, W., Stech, M., 2008. New suprageneric taxa of liverworts (Marchantiophyta) and mosses (Bryophyta). Nova Hedwigia, 87: 261-267.

Galán, P., 1990. Contribucion al estudio floristico de las comarcas de La Lora y Paramo de Masa (Burgos). Fontqueira, 30: 1-167.

Gandullo, J.M.; Blanco, A.; Sánchez, O.; Rubio, A.; Gómez, V., Elena, R., 2004. . Las estaciones ecológicas de los hayedos españoles.299 pp. Editorial: Monografías INIA: Serie Forestal N 8. Ministerio de Educación y Ciencia. 299. pp.

García-Amorena, I., Rubiales, J.M., Moreno Amat, E., Iglesias González, R., Gómez Manzaneque, F., 2011. New macrofossil evidence of Pinus nigra Arnold on the Northern Iberian Meseta during the Holocene. Review of Palaeobotany and Palynology, 163: 281- 288.

García Antón, M., 1995. Pollen analysis of Middle Pleistocene palaeovegetation at Atapuerca. En: Human Evolution in Europe and the Atapuerca evidence. Publicaciones de la Junta de Castilla y León 1, Valladolid, pp. 147-165.

García Antón, M., Franco, F., Maldonado, J., Morla, C., Sainz, H., 1995. Una secuencia polinica en Quintana Redonda (Soria). Evolución holocena del tapiz vegetal en el Sistema Ibérico septentrional. Anales del Jardin Botanico de Madrid, 52: 187-195.

García Antón, M. , Sainz-Ollero, H., 1991. Pollen records on the Atapuerca Middle Pleistocene site (Burgos, Spain). Palaeogeography, Palaeoclimatology, Palaeoecology, 85: 199-206.

García del Cura, M., Ordóñez, S., 2014. Petrología, texturas y minerología. En: Las tobas en España. Badajoz: Sociedad Española de Geomorfología, pp. 61-68. 
García Mijangos, I., 1995. Los alcornocales del sector Castellano-Cantábrico. Lazaroa, 15: 241 - 244.

García Mijangos, I., 1997. Flora y vegetación de los Montes Obarenes (Burgos). Guineana, Volumen 3.

García-Rovés, E., 2007. Dinámica de la Paleovegetación y cambios climáticos durante el Tardiglaciar y Holoceno en secuencias sedimentarias de la provincia de León. Leon: Universidad de León, 235 pp.

Garnett, E., Gilmour, M.A., Rowe, P.J., Andrews, J.E., Preece, R.C., 2004. 230Th/234U dating of Holocene tufas: possibilities and problems. Quaternary Science Reviews, 23: 947-958.

Gibbard, P., Head, M., 2009. The definition of the Quaternary System/Period and the Pleistocene Series/Epoch. Quaternaire, 20: 125-133.

Gil Sánchez, L., Torre Antón, M., 2007. Atlas forestal de Castilla y León. Valladolid, Consejería de Medio Ambiente, Junta de Castilla y León, 887 pp.

Gil-García, M., Dorado-Valiño, M., Valdeolmillos Rodríguez, A., Ruiz-Zapata, M., 2002. Late-glacial and Holocene paleoclimatic record from Sierra de Cebollera (northern Iberian Range, Spain). Quaternary International, 93-94: 13-18.

Goffinet, B., Buck, W.R. , Shaw, A.J., 2008. Morphology and Classification of the Bryophyta. En: Bryophyte Biology. New York, Cambridge University Press, pp. $55-138$.

Gómez Lobo, A., 1993. Historia de la vegetación durante los últimos 15.000 años en los Picos de Urbión (Soria) en base al análisis polínico. Alcalá de Henares: Universidad de Alcalá de Henares, Facultad de Ciencias.

Goñi, D., 2009. 9180 Bosques caducifolios mixtos de laderas abruptas, desprendimientos o barrancos (principalmente Tilio-Acerion). En: Bases ecológicas preliminares para la conservación de los tipos de hábitat de interés comunitario en España. Madrid: Ministerio de Medio Ambiente, y Medio Rural y Marino, $90 \mathrm{pp}$.

González Amuchastegui, M.J., 2014. Las tobas del Alto Tajo. En: Las tobas en España. Badajoz: Socidedad Española de Geomorfología, pp. 185-198.

González Amuchastegui, M.J., Serrano, E., 2007. Evolución geomorfológica, cambios ambientales e intervención humana durante el Holoceno en la cuenca alta del Ebro: las tobas de los valles del Purón y Molinar. Estudios Geográficos, 263: 527-546.

González Amuchastegui, M.J., Serrano, E., 2010. Las tobas del Alto Ebro: caracterización y evolución morfo genética. En: Avances de la Geomorfología en España 2008-2010. XI Reunión Nacional de Geomorfología. Solsona, Sociedad Española de Geomorfología. 
González Amuchastegui, M.J., Serrano, E., 2015. Quaternary tufa buildup stages in Mediterranean-Cantabric transitional environment (High Ebro Basin, Northern Spain). En: Sixth International Conferences on Geomorphology. International Association of Geomorphologists.

González Amuchastegui, M.J., Serrano, E., 1996. Cartografía geomorfológica del Valle de Tobalina (Burgos). Cuadernos do Laboratorio Xeolóxico de Laxe, 21: 737-748.

González Amuchastegui, M.J., Serrano, E., 2013. Acumulaciones tobáceas y evolución del paisaje: cronología y fases morfogenéticas en el Alto Ebro (Burgos). Cuaternario y Geomorfología, 27 (1-2): 9-32.

González Amuchastegui, M.J., Serrano, E., 2014a. Las tobas de la cuenca alta del Ebro. En: Las tobas en España. Badajoz: Sociedad Española de Geomorfología, pp. 119-139.

González Martín, J., González Amuchastegui, M.J., 2014a. Las acumulaciones tobáceas. En: Las tobas en España. Badajoz: Sociedad Española de Geomorfologia, pp. 3-18.

González Martín, J., González Amuchastegui, M.J., 2014b. Depósitos tobácesos: principales morfotipos. En: Las tobas en España. Badajoz: Sociedad Española de Gomorfología, pp. 18-38.

González Martín, J., Fidalgo, C., 2014c. Las acumulaciones tobáceas: exigencias ambientales y distribución espacio-temporal. En: Las tobas en España. Badajoz: Sociedad Española de Geomorfología, pp. 39-58.

González Martín, J., Ordóñez, S. , García del Cura, M., 1987. Evolución geomorfológica de las Lagunas de Ruidera (Albacete-Ciudad Real). Estudios Geológicos, 43,: 227-239.

González Pellejero, R., 1986. Dinámica de un espacio natural: Los cañones calcáreos del Ebro (Burgos). ERIA, 10: 5-86.

González Pellejero, R., Martínez, A., Allende, F., Frochoso, M., 2012. Las precipitaciones carbonatadas de los Cañones del Ebro: avances en su reconocimiento y cronología. En: Avances de la Geomorfología en España. Santander: Sociedad Española de Geomorfología y Universidad de Cantabria, pp. 401-404.

González, J.A., Fidalgo, C., Arteaga, C., González, M.J., Rubio, V., 2014. La degradación antrópica de los paisajes tobáceos. En: Las tobas en España. Badajoz: Sociedad Española de Geomorfología, pp. 317-338.

González-Sampériz, P. y otros, 2010. Steppes, savannahs, forest and phytodiversity reservoirs during the Pleistocene in the Iberian Peninsula. Review of Palaeobotany and Palynology, 162: 427-457. 
Greenwood, R., 1991. The taphonomy of plant macrofossils. En: The process of fossilization. London, Belhaven Press, pp. 141-169.

Hajdas, I., 2008. The Radiocarbon dating method and its applications in Quaternary studies. Quaternary Scince Journal - Eiszeitalter und Gegenwart, 57: 2-24.

Harmon, R., Glazek, J., Nowak, K., 1980. 230Th/234U dating of travertine from the Bilzingsleben archaeological site. Nature, 284 (5752): 132-135.

Haston, E. Richardson, J.E., Stevens, P.F., Chase, M.W., Harris, D.J., 2009. The Linear Angiosperm Phylogeny Group (LAPG) III: a linear sequence of the families in APG III. Botanical Journal of the Linnean Society, 161: 128-131.

Head, M., Gibbard, P., 2005. Early-Middle Pleistocene transitions: an overview and recommendation for the defining boundary. Geological Society. Special Publications, 247: 1-18.

Hearty, P., O'Leary, M.J., Kaufman, D.S., Page, M.C., Bright, J., 2004. Amino acid geochronology of individual foraminifer (Pulleniatina obliquiloculata) tests, north Queenland margin, Australia: a new approach to correlating and dating Quaternary tropical marine sediment cores. Paleoceanography, 19 (4). DOI: 10.1029/2004PA001059

Heinrich, H., 1988. Origin and consequences of cyclic ice rafting in the Northeast Atlantic Ocean during the past 130.000 years. Quaternary Research, 29 (2): 142-152.

Henning, G., Grün, R., Brunnacker, K., 1983. Speleothems, Travertins and Paleoclimates. Quaternary Research, 20: 1-29.

Herrera, C., 1992. Historical effects and sorting processes as explanations for contemporary ecological patterns: character syndromes in Mediterranean woody plants. American Naturalist, 140: 421-446.

Herrmann, H., 1957. Die Entstehungsgeschichte der postglazialen Kalktuffe der Umgebung von Weilheim (Oberbayern). Neues Jahrbuch fuer Geologie und Palaeontologie Abhandlungen. Neues Jahrbuch für Geologie und Paläontologie, 105: 11-46.

Hickey, L.J., 1973. Classification of the architecture of dicotyledonous leaves. American Journal of Botany, 60 (1): 17-33.

Hortolà, P., 1998. Datación por racemizacion de aminoacidos: Principios, técnicas y aplicaciones. Barcelona, Universitat de Barcelona, 102 pp.

III, A. P. G., 2009. An update of the Angiosperm Phylogeny Group classification for the orders and families of flowering plants: APG III. Botanical Journal of the Linnean Society, 161: 105-121.

Iriarte Chiapuso, M., Muñoz Sobrino, C., Ramil Rego, P., Rodríguez Guitián, M.A., 2002. Análisis palinológico de la turbera de San Mamés de Abar (Burgos). En: 
Palinología: diversidad y aplicaciones. Trabajos del XII Simposio de Palinología (APLE). León, Universidad de León, pp. 87-93.

Iriarte-Chiapusso, M. J., Ramil-Rego, P., Muñoz-Sobrino, C., 2003. El registro postglaciar de dos turberas situadas en el norte de la Provincia de Burgos. Polen, 13: 55-68.

Ivanovich. M., Harmon, R.S., 1992. Uranium series disequilibrium: Applications to Earth, Marine and Environmental Sciences. New York, Oxford University Press, $910 \mathrm{pp}$.

Jiménez-Moreno, G., Fauquette, S., Suc, J. P., 2010. Miocene to Pliocene vegetation reconstruction and climate estimates in the Iberian Peninsula from pollen data. Review of Palaeobotany and Palynology, 3 (162): 403-415.

Johnsen, S.J., Dahl-Jensen, D., Gundestrup, N., Steffensen, J.P., Clausen, H.B., Miller, H., Masson-Delmotte, V., Sveinbjornsdottir, A.E., White, J. 2001. Oxygen isotope and palaeotemperature records from six Greenland ice-core stations: Camp Century, Dye- 3, GRIP, GISP2, Renland and NorthGRIP. Journal of Quaternary Science, 16: $299-307$.

Juliá, R., 2014. La datación de tobas por uranio-torio. En: Las tobas en España. Badajoz, Sociedad Española de Geomorfología, pp. 89-96.

Kaufman, D., Manley, W., 1998. A new procedure for determining DL amino acid ratios in fossils using reverse phase liquid chromatography. Quaternary Geochronology, 17: 987-1000.

Kindler, P., Guillevic, M., Baumgartner, M., Schwander, J., Landais, A., Leuenberger, M., 2014. NGRIP temperature reconstruction from 10 to $120 \mathrm{kyr}$ b2k. Climate of the Past, 10: 887-902.

Kirschner, J., Novara, L.J., Novikov, V.S., Snogerup, S., Kaplan, Z., 1999. Supraspecific division of the genus Juncus (Juncaceae). Folia Geobotanica, 34 (3): 377-390.

Kukla, G.J., Bender, M.D., Beaulieu, J.L., de Bond, G., Broecker, W.S., Cleveringa, P.W., Gavin, J.E., Herbert, T.D., Imbrie, J., Jouzel, J., Keigwin, L.D., Knudsen, K.L., McManus, J., Merkt, J., Muhs, D.R., Muller, H., Poore, R.Z., Porter, S.C., Seret, G, 2002. Last interglacial climates. Quaternary Research, 58: 2-13.

Lang, J., Lucas, G., 1970. Contribution á l'études biohermes continentaux: barrages des lacs de BandeAmir (Afghanistan central). Bulletin Societé Géologique Française, 7: 834-842.

Lecoeuvre, C., Oris, F., Wallon, S., 2008. Paléoenvironnement au Néolithique à Saint Guilhem-le-Désert à travers l'étude de la flore fossile du travertin du gué des Gours.. Outils et méthodes pour la Reconstruction des Paléoenvironnements, 1: 6-17. 
Libby, W. F., 1967. History of Radiocarbon Dating. Department of Chemistry and Institute of Geophysics, University of California-Los Angeles, International Atomic Energy Agency, 23 pp.

Liu, Y.S., Zetter, R., Fergusonb, D., Mohr, B., 2007. Discriminating fossil evergreen and deciduous Quercus pollen: A case study from the Miocene of eastern China. Review of Palaeobotany and Palynology, 145: 289-303 .

Livnat, A. , Kronfeld, J., 1985. Paleoclimatic implications of U-Series dates for lake sediments and travertines in the Arava Rift Valley, Israel. Quaternary Research, 24: 164-172.

Llanos, H., Quinif, Y., Abalos, B., 1998. Evolución geodinámica reciente de la Sierra de Cantabria (Álava) en base a la datación U/Th de carbonatos continentales de las cuencas de los ríos Inflares y Ebro. Boletín Geológico y Minero, 109: 312.

Loehle, C., 2007. Predicting Pleistocene climate from vegetation in North America. Climate of the Past, 3: 109-118.

Loidi Arregui, J., Fernández Prieto, J., 1986. Datos sobre la biogeografía y vegetación del sector castellano-cantábrico (España). Documents phytosociologiques, 10 (1): 323-362.

Loidi, J. Biurrun, I., Campos, J.A., García-Mijangos, I., Herrera, M. 2011. La vegetación de la Comunidad Autónoma del País Vasco. Leyenda del mapa de series de vegetación a escala 1:50.000. Lejona (Vizcaya), Universidad del País Vasco, $196 \mathrm{pp}$.

López González, G., 2006. Árboles y arbustos de la Península Ibérica y Baleares. 2 ed. Madrid, Mundi Prensa, 1731 pp.

López Leiva, C., Espinosa Rincón, J. Bengoa Martínez de Mandojana, J., 2009. Mapa de vegetacion de Castilla y Leon sintesis 1:400.000. Junta de Castilla y León, Consejería de Medio Ambiente, 159 pp.

López, J. M., Allué, C., 2004. Plantas silvestres de la provincia de Burgos. Burgos: Caja de Burgos, 667 pp.

López-Merino, L., López-Sáez, J., Ruiz Zapata, M., Gil García, M., 2008. Reconstructing the history of beech (Fagus sylvatica L.) in the north-western Iberian Range (Spain): From Late-Glacial refugia to the Holocene anthropicinduced forests. Review of Palaeobotany and Palynology, 152 (1-2): 58-65.

Luthi, D. Le Floch, M., Bereiter, B., Blunier, T., Barnola, J.M., Siegenthaler, U., Raynaud, D., Jouzel, J., Fischer, H., Kawamura, K., Stocker, T.F., 2008. Highresolution carbon dioxide concentration record $650.000-800.000$ years before present. Nature, 453: 379-382.

Maffei, L., 1924. Contributo allo studio della flora fossile del deposito lacustre di Piànico. Atti Istituto Botanico Università di Pavia, Serie III (3): 47-69. 
Magnin, F., Guendon, J.L., Quinif, Y., Roiron, P., Thinon, M., 1990. Datations isotopiques et étude del paléoenvironnements de la formation à travertins de la Papeterie Vasino (Meyrargues, Bouches-du-Rhône, France). Mise en évidence de deux périodes de réchauffement durant le Riss. Comptes Rendus de l'Académie des Sciences, 310 (2): 1285-1292.

Magri, D., 1995. Some questions on the late-Holocene vegetation of Europe. The Holocene, 5: $354-360$.

Magri, D., 2008. Patterns of post-glacial spread and the extent of glacial refugia of European beech (Fagus sylvatica). Journal of Biogeography, 35: 450-463.

Mai, D., 1989. Development and regional differentation of the european vegetation during the Tertiary. Plant systematic and evolution, 162: 69-91.

Mai, D., 1991. Paleofloristic changes in Europe and the confirmation of the Arctotertiary-Palaeotropical geofloral concept. Review of Palaeobotany and Palynology, 68,: 29-36.

Manfra, L., Masi, U., Turi, B., 1976. La composizione isotopica dei travertini del Lazio. Geologica romana, 15: 127-174.

Mania, D., 2006. Stratigraphie, Klima- und Umweltentwicklung der letzten 400000 Jahre im Saalegebiet und Harzvorland (Forschungsstand 2006). Hercynia N. F., 39: $155-194$.

Manzo, E., Perri, E., Tucker, M., 2012. Carbonate deposition in a fluvial tufa system: processes and products (Corvino Valley - Southern Italy). Sedimentology, 59: 553-577.

Marchal, O., Cacho, I., Stocker, T.F., Grimalt, J.O., Calvo, E., Martrat, B., 2002. Apparent long-term cooling of the sea surface in the northeast Atlantic and Mediterranean during the Holocene. Quaternary Science Review, 21: 455-483.

Marcott, S., Shakun, J., Clark, P., Mix, A.C., 2013. A Reconstruction of Regional and Global Temperature for the Past 11,300 Years. Science, 339: 1198-1201.

Mariscal, B., 1993. Variación de la vegetación holocena (4300-280 BP) de Cantabria a través del análisis polínico de la turbera de Alsa. Estudios Geológicos, 49: 63-68.

Mariscal, B., 1995. Análisis polínico de los yacimientos de la Edad del Hierro de El Soto de Medinilla (campaña de 1989-1990) y El Cerro de La Mota en Medina del Campo, Valladolid. En: Arqueología y Medio Ambiente. El Primer Milenio AC. en el Duero Medio. Valladolid, Junta de Castilla y León, pp. 337-350.

Marquer, L., Otto, T., Nespoulet, R. , Chiotti, L., 2010. A new approach to study the fuel used in hearths by hunter-gatherers at the Upper Palaeolithic site of Abri Pataud (Dordogne, France). Journal of Archaeological Science, 37 (11): 27352746 . 
Martínez-Tudela, A., Robles, F., Santisteban, C., Grün, R., Hentzsch, B., 1986. Los travertinos del Río Matarraña, Beceite (Teruel) como indicadores paleoclimáticos del Cuaternario. En: Quaternary Climate in Western Mediterranean. Madrid, Universidad Autónoma de Madrid, pp. 307-324.

Martinson, D.G., Pisias, N.G., Hays, J.D., Imbrie, J., Moore, T.C. Jr., Shackleton, N.J., 1987. Age dating and the orbital theory of ice ages: development of a highresolution 0 to 300.000 years chronostratigraphy. Quaternary Research, 27: 129.

Mateo Sanz, G., 2008. Introducción a la flora de la Sierra de Albarracín (Teruel). Teruel, Centro de estudios de la Comunidad de Albarracín, 251 pp.

Mateo Sanz, G., Lozano Terrazas, J., Aguilella Palasí, A., 2013. Catálogo florístico de las sierras de Gúdar y Javalambre (Teruel). Teruel, Comarca de GúdarJavalambre y Jolube Consultor-Editor Botánico, 210 pp.

Meléndez, B., 1998. Tratado de Paleontología. Tomo I. Cuestiones generales de paleontología. Madrid: Consejo Superior de Investigaciones Científicas, 457 pp.

Melville, R., 1976. The terminology of leaf architecture. Taxon , 25 (5-6): 549-561.

Menéndez Amor, J., 1968. Estudio esporo-polínico de la turbera del valle de la Nava (provincia de Burgos). Boletín de la Real Sociedad Española de Historia Natural (Geología), 66: 35-39.

Merz-Preiß, M., Riding, R., 1999. Cyanobacterial tufa calcification in two freshwater streams: ambient environment, chemical thresholds and biological processes. Sedimentary Geology, 126: 103-124.

Meyer, H., Manchester, S., 1997. The Oligocene Bridge Creek Flora of the John Day Formation, Oregon. University of California Publisher, 141: 1-195.

Mitchel, G. F., 1940. Studies in Irish Quaternary deposits near Dunshaughlin. County Meath. Proceedings of the Royal Irish Academy 46(2).

Molina, J., Maldonado, J., 2002. Distribución de la vegetación palustre en cuatro lagunas celtibérico-alcarreñas. Ecología, 16: 73-82.

Montserrat-Martí, G., 1987. Historical interpretation of the distribution of several floristic elements of Vizcaya (Basque Country, N.Spain). Pirineos, 130: 65-74.

Moreno Amat, E., Iglesias, R., Hernández, L., Rubiales, J.M., Morales, C., Gómez, F., García-Amorena, I., 2009. Huellas de la presencia pasada de pinares montanos en la submeseta norte de la Península lbérica: Tubilla del Lago y Tubilla del Agua. $5^{\circ}$ Congreso Forestal Español, 5CFE01-100.

Morla, C., 2003. El paisaje vegetal Ibérico durante el cuaternario. Monografías de jardín botánico de Córdoba, 11: 75-93. 
Moscariello, A., Ravazzi, C., Brauer, A., Mangili, C., Chiesa, S., Rossi, S., Beaulieu, J.L., M., Reille., 2000. A long lacustrine record from the Piànico-Sèllere Basin (Middle-Late Pleistocene, Northern Italy). Quaternary International, 73-74: 4768.

Muñoz Sobrino, C., Ramil Rego, P., Delibes de Castro, G., Rojo, M., 1996. Datos paleobotánicos sobre la turbera de La Piedra (Páramo de Tozo, Burgos). En: Biogeografía Pleistocena-Holocena de la Península Ibérica. Santiago de Compostela: Xunta de Galicia, pp. 149-162.

Muñoz-Sobrino, C., Ramil-Rego, P. , Gómez-Orellana, L., 2004. Vegetation of the Pleistocene: a palaeoeocological reconstruction on the basis of two new pollen sequences. Vegetation History and Archaeobotany, 13: 1-22.

Muñoz-Sobrino, C., Ramil-Rego, P., Gómez-Orellana, L., Díaz Varela, R., 2005. Palynological data on major Holocene climatic events in NW Iberia. Boreas, 34 (3): 381-400.

Muñoz-Sobrino, C., Ramil-Rego, P., Gómez-Orellana, L., Ferreiro da Costa, J., Díaz Varela, R.A., 2009. Climatic and human effects on the post-glacial dynamics of Fagus sylvatica in NW Iberia. Plant Ecology, 203: 317.

Murr, J., 1926. Neue Übersicht über die fossile Flora der Höttinger Breccie. Jahrbuch der Geologischen Bundesanstalt, 76: 153-170.

Naughton, F., Bourillet, J.F., Sánchez Goñi, M.F., Turon, J.L., Jouanneau, J.M., 2007. Long term and millennial-scale climate variability in northwestern France during the last 8.850 years. The Holocene, 17: 939-953.

Ochev, V., 1993. Types of thanatocoenoses and burial patterns of terrestrial organisms. Paleontological Journal, 27 (1): 127-137.

Olivé Davó, A., Ramírez del Pozo, J., Riba Arderiu, O., 1979. Memoria del mapa geológico de España a escala 1:50.000, hoja de Miranda de Ebro. Madrid: Servicio de Publicaciones, Ministerio de Industria C.S.G.

Oliveira, D., 2012. Vegetation response to Holocene climate variability in southwestern Europe. Lisboa: ThMs, Universidade de Lisboa. Faculdade de Ciências. Departamento de Geologia, 159 pp.

Ollivier, V., Roiron, P., Balasescu, A., Nahapetyan, S., Gabrielyan, Y., Guendon, J.L., 2009. Milieux, processus, faci'es et dynamiques morphos'edimentaires des formations travertineuses quaternaires en relation avec les changements climatiques et les occupations humaines entre M'editerran'ee et Caucase. Studii de Preistorie, pp. 15-35.

Ordóñez, S., García del Cura, M., 2014. Hidroquímica elemental e isotópica y génesis de tobas. En: Las tobas de España. Badajoz, Sociedad Española de Geomorfología, pp. 75-88. 
Ordóñez, S., González Martín, J., García del Cura, M., 1990. Datación radiogénica (U 234 /U 238 y Th230/U234) de sistemas travertınicos del Alto Tajo (Guadalajara). Geogaceta, 8: 53-56.

Ortega Villazán, M., Morales Rodríguez, C., 2015. El clima de la Cordillera Cantábrica castellano-leonesa: diversidad, contrastes y cambios. Investigaciones Geográficas, 63: 45-67.

Ortiz, J.E., Torres, T., Julià, R., Delgado, A., Llamas, F.J., Soler, V., Delgado, J., 2004. Numerical dating algorithms of amino acid racemization ratios from continental ostracodes. Application to Guadix-Baza basin (southern Spain). Quaternary Science Reviews , 23 (5-6): 717-730.

Palamarev, E., 1987. Paleobotanical evidences of the Tertiary history and origin of the Mediterranean sclerophyll dendroflora. Plant Systematics and Evolution, 162: 93-107.

Pavlović, G., Zupanič, J., Prohić, E. , Tibljaš, D., 2002. Impressions of the Biota Associated With Waterfalls and Cascades from a Holocene Tufa in the Zrmanja River Canyon, Croatia. Geologia Croatica, 55 (1): 25-37.

Pedley, H., 1990. Classification and environmental models of cool freshwater tufas. Sedimentaryology Geology, 68: 143-154.

Pedley, M., Andrews, J., Ordoñez, S., García del Cura, M.A., González Martín, J.A., Taylor, D., 1996. Does climate control the morphological fabric of freshwater carbonates? A comparative study of Holocene barrage tufas from Spain and Britain. Palaeogeography, Palaeoclimatology and Palaeoecology, 121: 239257.

Peña, J., Sancho, C., Arenas, C., Auqué, L., Longares, L.A., Lozano, L.V., Meléndez, A,, Osácar, C., Pardo, G., Vázquez Urbez, M., 2014. Las tobas cuaternarias en el sector aragonés de la Cordillera Ibérica. En: Las tobas en España. Badajoz: Sociedad Española de Geomorfología, pp. 159-172.

Peñalver, E., Badía Gimeno, S., Muñoz Bertomeu, J., Ruiz González, M.X., 2002. Interés patrimonial de los travertinos del río Matarraña, Beceite; un yacimiento paleobotánico a proteger. En: El Patrimonio Paleontológico de Teruel. Teruel, Insituto de Estudios Turolenses, Diputaciónde Teruel, pp. 305-324.

Pentecost, A., 2005. Travertine. Berlin, Springer-Verlag, 445 pp.

Pentecost, A., Riding, R., 1986. Calcification in Cyanobacteria. En: Biomineralization of lower plants and animals. Systematic Association Special Volumen . Oxford: Clarenton Press, pp. 73-90.

Pentecost, A., Viles, H. A., 1994. A review and reassesment of travertine classification. Geographie Fhysique et Quaternaire, 48: 305-314.

Peñuelas, J., Comelles, M., 1984. Contribucion al estudio de los briofitos acuaticos de lagunas y charcas de España. Anales del Jardín Botánico, 2 (40): 325-334. 
Perea, R., 2012. Dispersión y predación de semillas por la fauna: Implicaciones en la regeneración forestal de bosques templados. Ecosistemas, 21 (1-2): 224-229.

Pérez Díaz, S., López-Merino, L., López-Sáez, J. A., 2007. Paleovegetación durante la Edad del Bronce en La Rioja Alavesa: análisis palinológico del yacimiento de Peña Parda (Laguardia, Álava). Cuadernos de Arqueología de la Universidad de Navarra, 15: 177-192.

Pineda Velasco, A., Arce Duarte, J., Martín Serrano, A., 1997. Mapa Geológico de España 1:50.000, Hoja 200 (Burgos). Madrid: Instituto Tecnológico y Geominero de España.

Pitarch, R., 2002. Estudio de la flora y vegetación de las sierras orientales del Sistema Ibérico: La Palomita, Las Dehesas, El Rayo y Mayabona (Teruel). Zaragoza, Consejo de Protección de la Naturaleza de Aragón. 520 pp.

Pons, A., Reille, M., 1988. The Holocene and Late Pleistocene pollen record from Padul (Granada, Spain): a new study. Palaeogeography, Palaeoclimatology, Palaeoecology, 66: 243-263.

Postigo, J., 2003. Contribución al conocimiento de la vegetación pleistocena de la Península Ibérica. Estudio paleobotánico de macrorrestos vegetales fósiles. Tesis Doctoral. Thesis, Madrid: Facultad de Ciencias, Universidad Autónoma de Madrid.

Postigo-Mijarra, J. M., Barrón, E., Gómez Manzaneque, F., Morla, C., 2009. Floristic Changes In The Iberian Peninsula And Balearic Islands (South-West Europe ) During The Cenozoic. Journal Of Biogeography, 11 (36): 2025-2043.

Postigo-Mijarra, J.M., Morla, C., Barrón, E., Morales-Molino, C., García, S. 2010. Patterns of extinction and persistence of Arctotertiary flora in Iberia during the Quaternary. Review of palaeobotany and Palynology, 162: 416-426.

Provan, J., Bennett, K., 2008. Phylogeographic insights into cryptic glacial refugia. Trends in Ecology and Evolution, 23: 564-571.

Pujalte, V., 1982. La evolución paleogeográfica de la cuenca Wealdense de Cantabria. Cuadernos de Geología Ibérica, 8: 65-83.

Rahmstorf, S., 2003. Timing of abrupt climate change: a precise clock. Geophysical Research Letters, 30 (10): 1-4.

Ramil-Rego, P., Iriarte, M., Muñoz Sobrino, C., Gómez-Orellana, L., 2005. Cambio climático y dinámica temporal del paisaje y de los hábitats en las ecorregiones del NW de la Península Ibérica durante el Pleistoceno superior. Numibe, 57: 537-551.

Ramil-Rego, P., Muñoz-Sobrino, C., Rodríguez-Guitián, M., Gómez-Orellana, L., 1998. Differences in the vegetation of the North Iberian Peninsula during the last 16,000 years. Plant Ecology, 138: 41-62. 
Ramil-Rego, P., Rodríguez Guitian, M., Muñoz Sobrino, C., 2000. Some considerations about the postglacial distribution of Fagus sylvatica in the Iberian peninsula. Folia Geobotanica, 35: 241-271.

Ramírez, J., Aguilar, M. , Leal, M. C., 1979. Memoria y cartografía del Mapa Geológico de España 1/50.000. Hoja 20-8 (110), Medina de Pomar. Madrid, Instituto Geográfico y Minero de España, 42 pp.

Ramírez, J., Olivé, A., Martín, J.M., Aguilar, M., Leal, M.C., 1980. Memoria y cartografía del Mapa Geológico de España 1/50.000. Hoja 20-8 (136), Oña. Madrid, Instituto Geológico y Minero de España, 42 pp.

Raunkiær, C., 1934. The Life Forms of Plants and Statistical Plant Geography. Oxford University Press.

Regato, P., 1992. Las representaciones relictas de Pinus nigra Arnold en cl Sistema Central espafiol. Boletín de la Real Sociedad Española de Historia Natural (Sección de Biología), 88: 63-71.

Regato, P., Del Río, M., 2009. 9530 Pinares (sud-) mediterráneos de Pinus nigra endémicos. En: VV.AA., Bases ecológicas preliminares para la conservación de los tipos de hábitat de interés comunitario en España. Madrid, Ministerio de Medio Ambiente, y Medio Rural y Marino, 95 pp.

Regato, P., Elena, R. , Sánchez Palomares, O., 1991. Estudio autoecológico comparativo de Pinus nigra Arn. subsp. salzmannii de la Península lbérica y otras subespecies de la región circunmediterránea. Investigación Agraria. Sistemas y Recursos Forestales, 0 (1): 49-59.

Richards, P. W., 1946. The introduction of Fontinalis antipyretica Hedw. into South Africa and its biological effects. Transactions of the British Bryological Society, $16 \mathrm{pp}$.

Rivas-Martínez, S., 1987. Memoria del mapa de series de vegetación de España 1:400.000. Madrid, Icona, Serie Técnica. Servicio de Publicaciones del Ministerio de Agricultura, Pesca y Alimentación, 268 pp.

Rivas-Martínez, S., 2007. Mapa de series, geoseries y geopermaseries de vegetación de España: Memoria del mapa de vegetación potencial de España. Itinera Geobotánica, I (17).

Rivas-Martínez, S., 20011a. Mapa de series, geoseries y geopermaseries de vegetación de España: Memoria del mapa de vegetación potencial de España. Itinera Geobotánica, II (1) (18).

Rivas-Martinez, S., 2011b. Mapa de series, geoseries y geopermaseries de vegetación de España: Memoria del mapa de vegetación potencial de España. Itinera Geobotánica, II (2) (18).

Rodá, I., 1982. Ciencias, metodologías y técnicas aplicadas a la Arqueología. Barcelona, Fundación La Caixa, 292 pp. 
Rodrigo, A., Retana, J., Picò, F., 2004. Direct regeneration is not the only response of Mediterranean forest to large fires. Ecology, 85: 716-729.

Rodrigues, T., Grimalt, J.O., Abrantes, F.G., Flores, J.A., Lebreiro, S.M., 2009. Holocene interdependences of changes in sea surface temperature, productivity, and fluvial inputs in the Iberian continental shelf (Tagus mud patch). Geochemistry, Geophysics, Geosystems, 10 (7).

Rodriguez Estrella, T. y otros, 2002. Contribución de las medidas de conductividad y $\mathrm{pH}$, en las aguas de la Cueva de Los Chorros del río Mundo (Albacete), a la génesis del enigmático "reventón". Karst and Environment, pp. 199-209.

Rodríguez, J., Burjachs, F., Cuenca-Bescós, G., García, N., Van der Made, J., Pérez González, A., Blain, H.A., Expósito, I., López-García, J.M., García Antón, M., Allué, E., Cáceres, I., Huguet, R., Mosquera, M., Ollé, A., Rosell, J., Parés, J.M., Rodríguez, X.P., Díez, C., Rofes, J., Sala, R., Saladié, P.; Vallverdú, J., Bennasar, M.L., Blasco, R., Bermúdez de Castro, J.M., Carbonell, E. 2011. One million years of environmental changes and cultural evolution at Atapuerca (Burgos, Spain). Quaternary Science Reviews, 30: 1396-1412.

Rodríguez-Sánchez, F., Hampe, A., Jordano, P., Arroyo, J., 2010. Past tree range dynamics in the Iberian Peninsula inferred through phylogeography and palaeodistribution modelling: a review. Review of Palaeobotany and Palynology, 162: 507-521.

Rogerson, M., Pedley, H., Wadhawan, J., Mlddleton, R., 2008. New insights into biological in-fluence on the geochemistry of freshwater carbonate deposits. Geochim. Geochimica et Cosmochimica Acta, 72: 4976-4987.

Roglic, J., 1977. Les lacs de Plitvice (Yougoslavie). Norois, 95 Bis: 305-318.

Roig, S., Gómez Manzaneque, F., Masedo, F., Morla, C., Sánchez, L., 1997. Estudio paleobotánico de estróbilos y maderas subfósiles Holocenas en el yacimiento de Cevico Navero (Palencia, España). Anales del Jardín Botánico de Madrid, 55 (1): 111-123.

Roiron, P., 1983. Nouvelle étude de la macroflore Plio-Pléistocéne de Crespia (Catalogne, Espagne). Geobios, 16 (6): 687-715.

Roiron, P., Ali, A.A., Guendon, J.L., Migueres, M.E., Muller, S., Ollivier, V., 2006. La flore fossile du système travertineux du Serre de Montdenier (Alpes de Haute Provence, France) : un nouveau jalon dans l'histoire de la végétation holocène des Alpes du Sud. Quaternaire, 17(2), pp. 69-77.

Roiron, P., Chabal, L., Figueiral, I., Terral, J.F., Ali, A.A., 2013. Macroremains, Palaeobiogeography of Pinus nigra Arn. subsp. salzmannii (Dunal) Franco in the northwestern western Mediterranean Basin: A review based on. Review of Palaeobotany and Palynology, 194: 1-11. 
Roman-Amat, B., 1984. Contribution à l'exploration et à la valorisation de la variabilité intraspécifique et individuelle du pin laricio de Corse, Pinus nigra Arn, ssp. laricio var corsicana Loud. Tesis Doctoral, University of Paris Sud Orsay.

Rosas, A. Huguet, R., Pérez-González, A., Carbonell, E., Bermúdez de Castro, J.M., Vallverdú, J., van der Made, J., Allué, E., García, N., Martínez-Pérez, R., Rodríguez, J. Sala, R., Saladie, P., Benito, A., Martínez-Maza, C., Bastir, M., Sánchez, A, Parés, J.M., 2006. The "Sima del Elefante" cave site at Atapuerca (Spain). Estudios Geológicos, 62 (1): 327-348.

Rubiales, J., García-Amorena, I., García Álvarez, S., Gómez Manzaneque, F., 2008. The Late Holocene extinction of Pinus sylvestris in the western Cantabrian Range (Spain). Journal of Biogeography, 35 (10): 1840-1850.

Rubiales, J.M., García-Amorena, I., Genova, M., Gómez-Manzaneque, F., Morla, C., 2007. The Holocene history of highland pine forests in a submediterranean mountain: the case of Gredos mountain range (Iberian Central range, Spain). Quaternary Science Review, Volumen 26 (13-14): 1759-1770.

Rubiales, J., García-Amorena, I., Hernández, L., Génova, M., Martínez, F., González Manzaneque, F., Morla, C., 2010. Late Quaternary dinamics of pine woods in the Iberian Mountains. Review of Palaeobotany and Palynology, 162: 476-491.

Rubio Sancho, J., Cabaña Nigro, A., Oria de Rueda, J., 2009. Estudio de las masas relictas de Pinus nigra salzmannii (Dunal) Franco en el entorno del río Cega (Segovia). En: $5^{\circ}$ Congreso Forestal Español. Sociedad Española de Ciencias Forestales.

Rubio, C., 2000. Estudio paleobotánico en tobas carbonatadas del Cuaternario de la localidad de cañizar del Olivar (Teruel). Revista Teruel, 88-89 (1): 155-177.

Ruiz Alonso, M., Zapata, L., 2003. Análisis antracológico del yacimiento arqueológico de Peña Parda. Cuadernos de Arqueología de la Universidad de Navarra, 11: 217-252.

Ruiz de la Torre, J., 2006. Flora Mayor. Madrid, Organismo Autónomo Parques Nacionales. Dirección General para la Biodiversidad, 1756 pp.

Ruiz-Zapata, M.B., Gil-García, M.J., Dorado-Valiño, M., Valdeolmillos, A., Vegas, J, Pérez González, A., 2002. Clima y vegetación durante el Tardiglaciar y el Holoceno en la Sierra de Neila (Sistema Ibérico Noroccidental). Cuaternario y Geomorfología, 16 (1-4): 9-20.

Ruiz-Zapata, M., Gil-García, M., Dorado-Valiño, M., Valdeolmillos Rodríguez, A., 2005. El paisaje vegetal durante el Pleistoceno medio en el interior de la península. Zona arqueológica: yacimientos paleolíticos de Ambrona y Torralba (Soria). Un siglo de investigaciones arqueológicas 5: 214-221.

Rull, V., 2009. Microrefugia. Journal of Biogeography. Journal of Biogeography, 36: 481-484. 
Rytz, W., 1953. Uber Interglaziarl floren und Interglazialclimate mit besonderer Berükcksichtigung der Pflanzenreste von Gondswill-Zell und Piànico. Berichte Der Deutschen Botanischen Gesellschaft 6, 65(9): 315-318.

Salas, V., 1992. Propuesta de modelo climático para el Holoceno en la vertiente cantábrica en base a los datos polínicos. Cuaternario y geomorfología, 6 (1-4): 63-69.

Sanchez Hernando, L., Gomez Manzaneque, F., Masedo, F., Morla, C., del Nido, J., 1999. Identification de macrorrestos vegetales holocenos en las cuencas altas de los rios Porma, Curueno y Esla (Leon, Espana).. Boletin de la Real Sociedad Espanola de Historia Natural (Secc. Biol), 95: 31-42.

Sánchez Palomares, O., Elena Rossello, R., Carretero Carrero, M., 1990. Caracterizacion edafica de los pinares autoctonos Espanoles de Pinus Nigra Ard. Comunicaciones I.N.I.A. Serie Recursos naturales, 55.

Sánchez-Goñi, M., Eynaud, F., Turon, J., Shackleton, N.J., 1999. High resolution palynological record off the Iberian margin: direct land-sea correlation for the Last Interglacial complex. Earth and Planetary Science Letters, 171: 123-137.

Sanders, D., Ostermann, M., 2006. Sedimentology and depositional setting of the "warm-interglacial" fossil flora of the Höttinger Brekzie (Pleistocene, Northern Calcarcous Alps, Austria): a reconstruction. Veröffentlichungen Tiroler Landesmuseum Ferdinandeum, 86: 91-118.

Schweingruber, F., 1990. Anatomy of European woods. Stuttgart, Stuttgart Publishers, $800 \mathrm{pp}$.

Sernander, R., 1908. On the evidence of post-glacial changes of climate furnished by the peat mosses of northern Europe. Geologiska Föreningens i Stockholm Förhaldlinger, 30: 365-478.

Shackleton, N., Opdyke, N., 1973. Oxygen isotope and paleomagnetic stratigraphy of equatorial Pacific Core V28-238: oxygen isotope temperatures and ice volume on a 105 year and 106 year scale. Quaternary Research, 3: 39-55.

Siegenthaler, U., Stocker, T.F., Monnin, E., Luüthi, D., Schwander, J., Stauffer, B., Raynaud, D., Barnola, J.M., Fischer, H., Masson-Delmotte, V., Jouzel, J., 2005. Stable carbon cycle-climate relationship during the late Pleistocene. Science, 310: 1313-1317.

Smit, A., 1973. A scanning electron microscopical study of the pollen morphology in the genus Quercus. Acta Botanica Neerlandica, 22 (6): 55-665.

Sordelli, F., 1873. Descrizione di alcuni avanzi vegetali delle argille plioceniche lombarde, collàggiunta di un Elenco delle piante fossili flnora conosciute in Lombardia. Atti della Società Italiana di Scienze Naturali, 16 (II). 
Spicer, R., 1981. The sorting and deposition of allochthonous plant material in a modern environment at Silwood Lake, Silwood Park, Berkshire, England. Geological Survey Professional Paper, 1143: 1-77.

Spicer, R., 1989. The formation and interpretation of plant fossil assemblage. Advances in Botanical Research, 16: 96-191.

Spicer, R., 1991. Plant taphonomic processes. En: Taphonomy: releasing the data locked in the fossil record. New York, Plenum press, pp. 71-113.

Spicer, R., Greer, A., 1986. Plant taphonomy in fluvial and lacustrine systems. En: Land Plants. Tennessee, University of Tennessee Studies in Geology, pp. 1026.

Srdoc, D., Krajkar-Bronic, I., Horvatincic, N., Obelic, B., 1986a. Increase in 14C activity on dissolved inor-ganic carbon along a river course. Radiocarbon, 28: 515-521.

Srdoc, D., Horvatincic, N., Obelic, B., Krakcar-Bronic, I., O'Malley, P., 1986b. The effects of contamination of calcareous sediments on their radiocarbon ages. Radiocarbon, 28: 510-514.

Stearns, S., Hoekstra, R., 2000. Evolution. An introduction. Oxford, Oxford University Press, $381 \mathrm{pp}$.

Stearn, W., 1983. Botanical Latin. History, Grammar, Syntax, Terminology and Vocabulary. Newton Abbot, Devon: David, Charles, 546 pp.

Sternberg, R., 1992. Radiocarbon fluctuations and the geomagnetic field. En: Radiocarbon After Four Decades. New York, Springer Verlag, pp. 93-116.

Summerhayes, C., 2015. Earth's Climate Evolution. Oxford, Wiley-Blackwell, 416 pp.

Taylor, R., 1987. Radiocarbon Dating. An archaeological perspective. Orlando, Academic Press, 212.

Tzedakis, P. C., Hooghiemstra, H. , Pälike, H., 2006. The last 1.35 million years at Tenaghi Philippon: revised chronostratigraphy and long-term vegetation trends. Quaternary Science Reviews, 25: 3416-3430.

Uribe-Echebarría, P., 2012. Estudio de la Flora Vascular de Montes de Vitoria (Álava). Vitoria-Gasteiz, Centro de Estudios Ambientales, Ingurugiro Gaietarako Ikastegia, 377 pp.

Usdowski, E., Hoefs, J., Menschel, G., 1979. Relationship between ${ }^{13} \mathrm{C}$ and ${ }^{18} \mathrm{O}$ fractionation and changesin major element composition in a recent calcitedepositing spring - a model of chemical variations withinorganic $\mathrm{CaCO} 3$ precipitation. Earth and Planetary Science Letters, 42: 267-276.

Uzquiano, P., Zapata, L., 2000. Vegetación y subsistencia durante la Edad del Bronce en el Cantábrico orienta: La cueva de Arenaza (S. Pedro de Galdames, Bizkaia). En: "Contributos das Ciências e das Tecnologias para a Arqueologia 
da Península Ibérica. Actas do $3^{\circ}$ Congresso de Arqueologia Peninsular IX, ADECAP. Porto: Actas do $3^{\circ}$ Congresso de Arqueologia Peninsular IX, ADECAP, pp. 51-68.

Valero Garcés, J., Delgado Huertas, A., González Sampériz, P., Schwalb, A., Moreno Caballud, A., Edwards, L., González-Barrios, A., 2004. El registro de la Laguna de Taravilla (AltoTajo, Sistema Ibérico) como sensor de cambios paleohidrológicos y paleoambientales. Geotemas, 6 (5): 157-160.

Vaudour, J., 1986. Travertines holocènes et pression anthropique. Mediterranèe, 57 (1-2): 168-173.

Vent, W., 1955. Uber dic Flora des Riss-Wúrm Interglazials in Mitteldeutschland mit besonderer Bertickschtigung der IImialtravertine von Weimar-Ebringsdorf. Wissenschaftliche Zeitschrift der Friedrich-Schiller-Universitat Jena, 4: 467485 .

Vent, W., 1978. Die Flora des Travertins von Burgtonna in Thüringen. Quartärpaläontologie, 3: 59-65.

Vera, J. A., 2004. Geología de España. Madrid: Instituto Geológico y Minero Español, $885 \mathrm{pp}$.

Vernet, J., Ambert, P., Andre, J., Brugal, J.Ph., Casanova, J., Michaux, J., Semah, F., 1984. Paleoenvironnements quaternaires dans la région de millau (Bordure Méditerranéenne du Massif Central, France) A partir des travertins, des macroflores et des faunes. Geobios, 17: 125-131.

Vernet, J. M. N., Bazile, F. , Brugal, J., 2008. Travertins et terrasses de la moyenne vallée du Tarn à Millau (sud du Massif central, Aveyron, France) : datations $\mathrm{OSL}$, contribution à la chronologie et aux paléoenvironnements. Quaternaire, 19 (1): 3-10.

Villalta, J., Vicente, J., 1972. Una flora del Cuaternario antiguo en las cercanías de Crespià.. Acta Geológica Hispánica , 7 (4): 120-128.

Von Heinrich, M., 1977. Geologie des Jungtertiärbeckens von Tarnsweg mit kristalliner Umrahmung. Jahrbuch der Geologischen Bundesanstalt, 120: 295-341.

Walker, M., Johnsen, S., Rasmussen, S.O., Popp, T., Steffensen, J.P., Gibbard, P., Hoek, W., Lowe, J., Andrews, J., Bjo; Cwynar, L.C., Hughen, K., Kershaw, P., Kromer, B., Litt, T.; Lowe, D. J., Nakagawa, T., Newnham, R., Schwander, J., 2009. The Global Stratotype type Section and Point (GSSP) for the base of the Holocene Series/Epoch (Quaternary System/Period) in the NGRIP ice core. Journal of Quaternary Science, 24 (1): 3-17.

Walter, H., 1979. Vegetation of the Earth and Ecological Systems of the Geobiosphere. New York, Springer-Verlag, 318 pp. 
Wehmiller, J. F., Miller, G., 2000. Aminostratigraphic dating methods in Quaternary geology. En: Quaternary Geochronology, Methods and Applications. Washington, DC, American Geophysical Union Reference Shelf, pp. 187-222.

Willis, K., McElwain, J. C., 2002. The evolution of plants. Nueva York, Oxford University Press, 389 pp.

Wilson, K., Morrison, D., 1998. Monocots: Systematics and Evolution. Sydney, CSIRO Publishing, 745.

Wolfe, J. A., 1985. Distribution of major vegetational types during the Tertiary. Geophysical Monography, 32: 357-375.

Zachos, J., Pagani, M., Sloan, L., Thomas, E., Billups, K., 2001. Trends, rhythms, and aberrations in global climate $65 \mathrm{Ma}$ to Present. Science, 262: 686-693.

Zapata, L., 2001. El uso de los recursos vegetales en Aizpea (Navarra, Pirineo occidental): la alimentación, el combustible y el bosque. En: Cazadoresrecolectores en el Pirineo navarro. El sitio de Aizpea entre 8000 y 6000 años antes de ahora. Veleia. Anejos Series Maior 10 . Vitoria-Gasteiz: UPV/EHU, pp. 325-359.

Zhang, D., Zhang, Y., Zhu, A., Chen, X., 2001. Physical mechanisms of river waterfall tufa (travertine) formation. Journal of Sedimentary Research, 71: 205 - 216. 


\section{Anexo I. Diagramas polínicos}

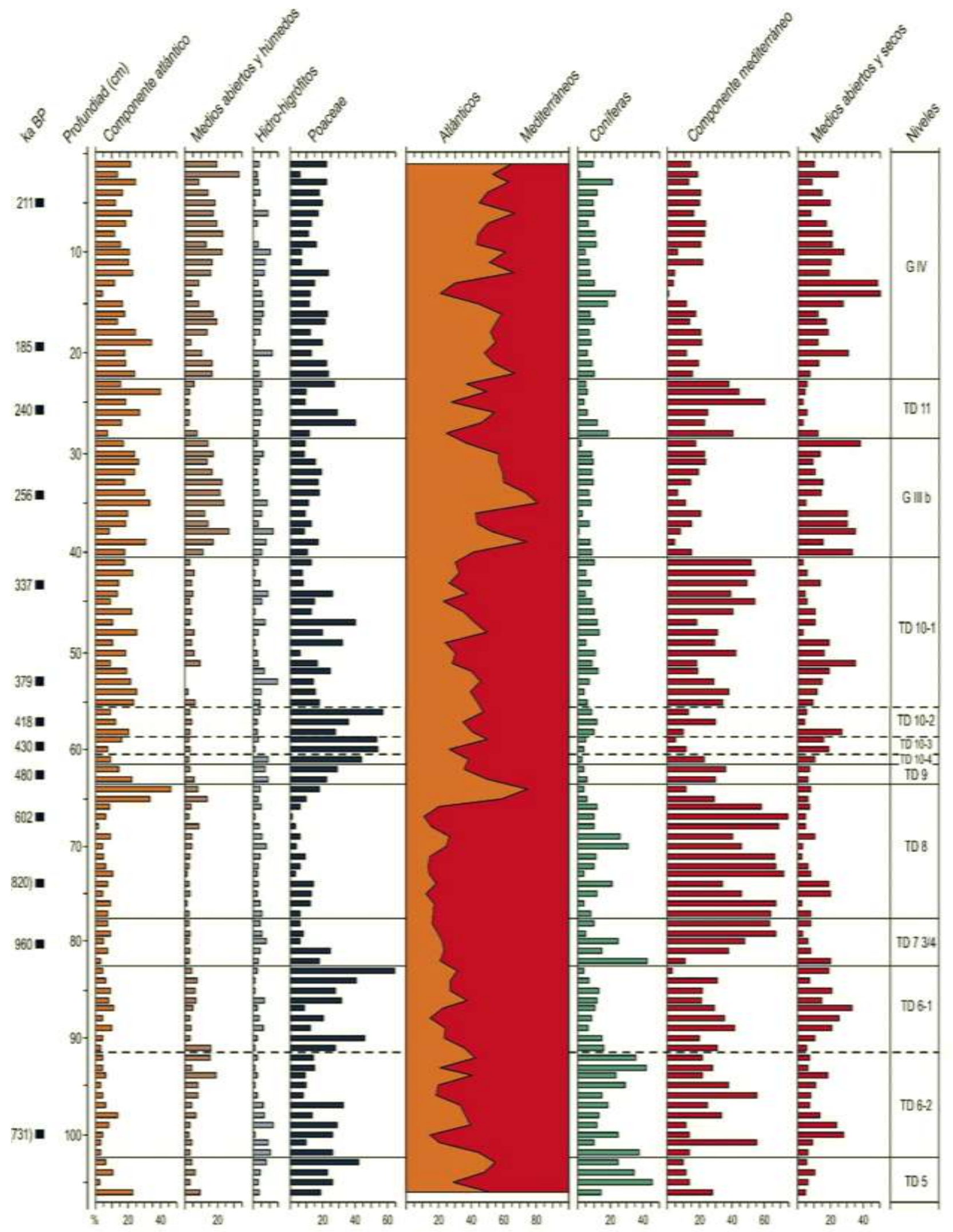

Diagrama polínico 1. Diagrama polínico combinado para las secuencias de Gran Dolina (TD) y Galería (G) Burgos-. Carrión (2012), redibujado de Rodríguez, et al. (2011). 


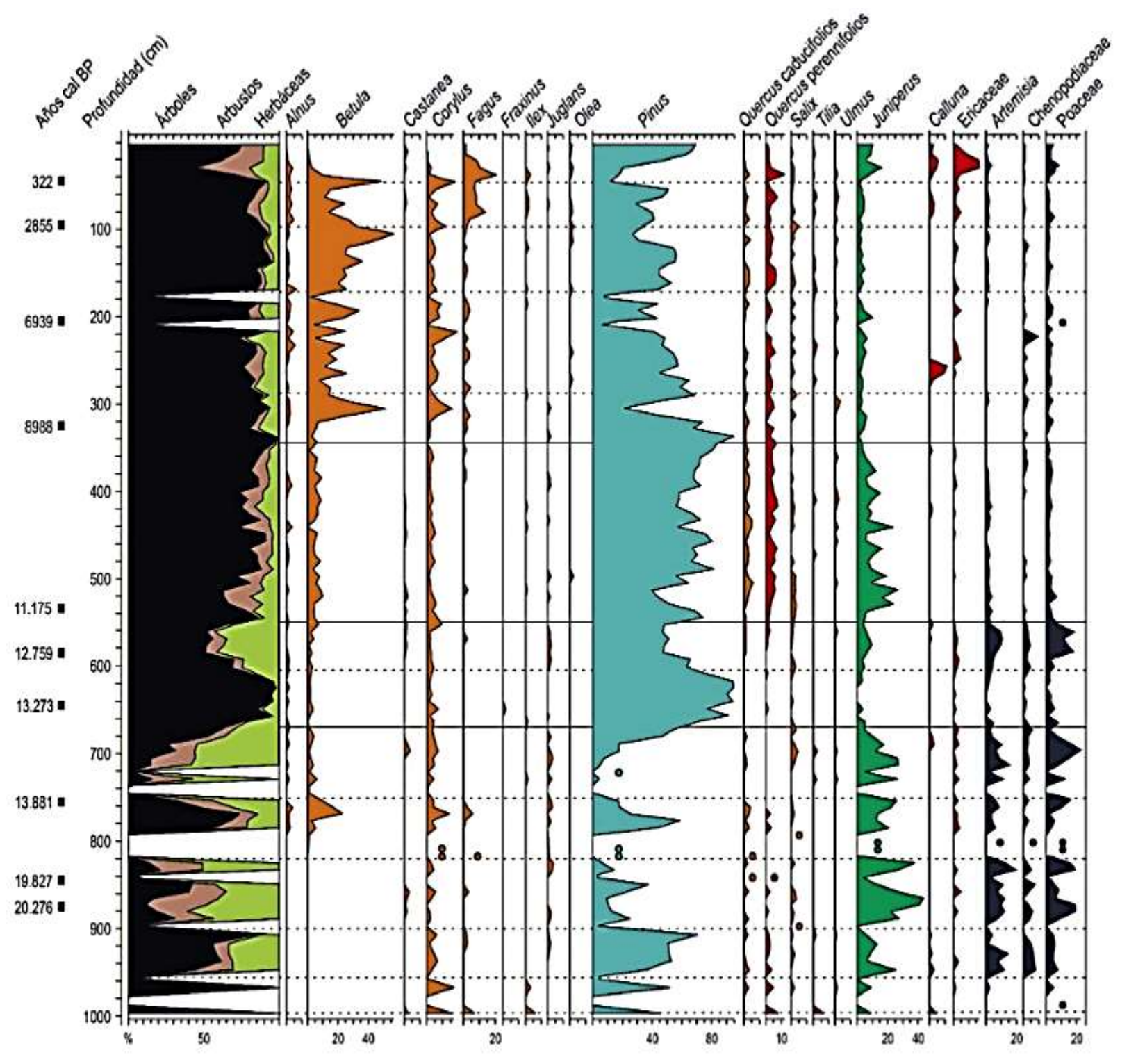

Diagrama polínico 2. Sondeo de Quintanar de la Sierra -Burgos-. Carrión (2012), redibujado de Ruiz-Zapata, et al. (2002). 


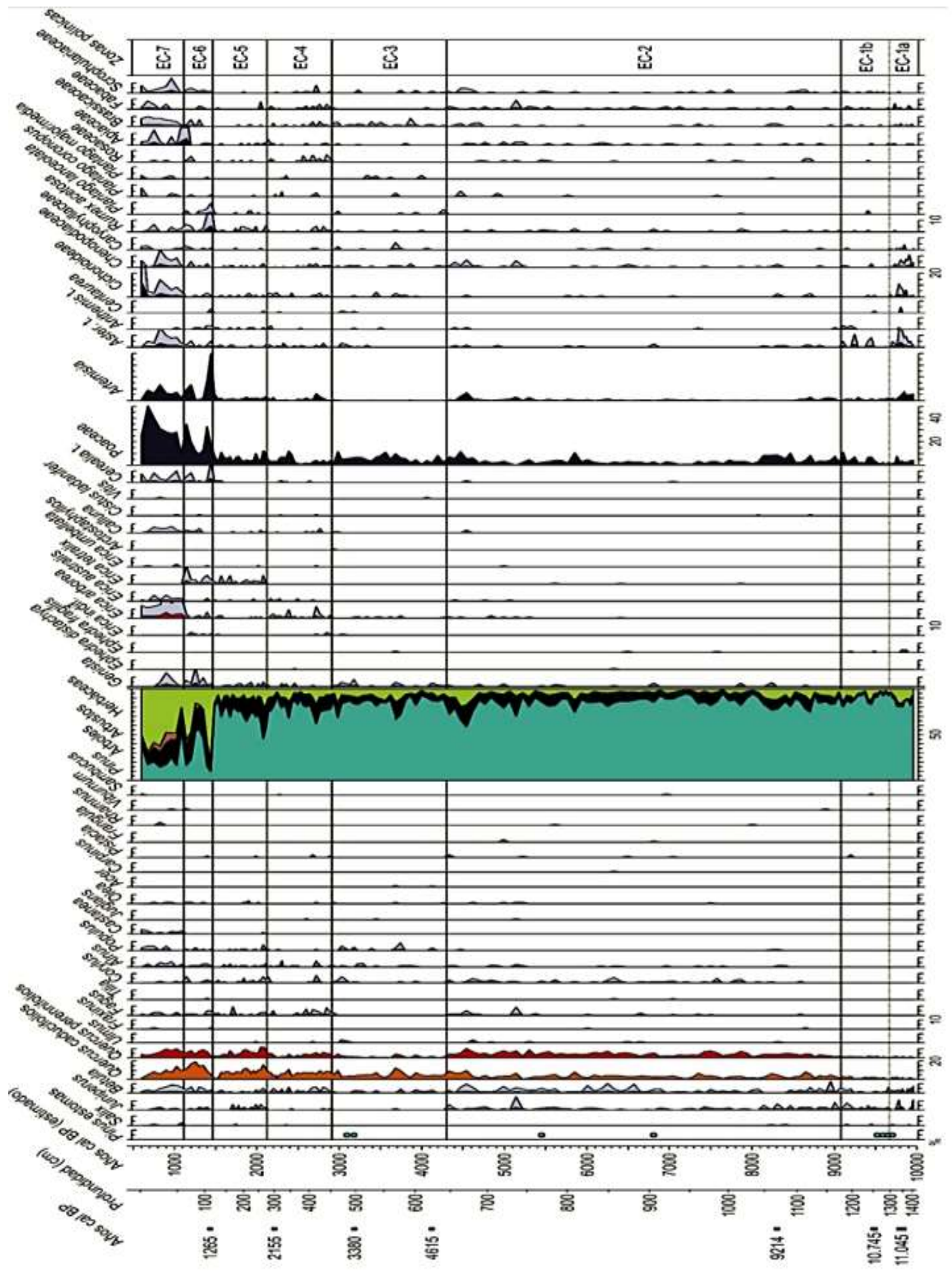

Diagrama polínico 3. Sondeo de Espinosa de Cerrato - Palencia-. Carrión (2012), redibujado de Franco-Múgica, et al. (2001). 


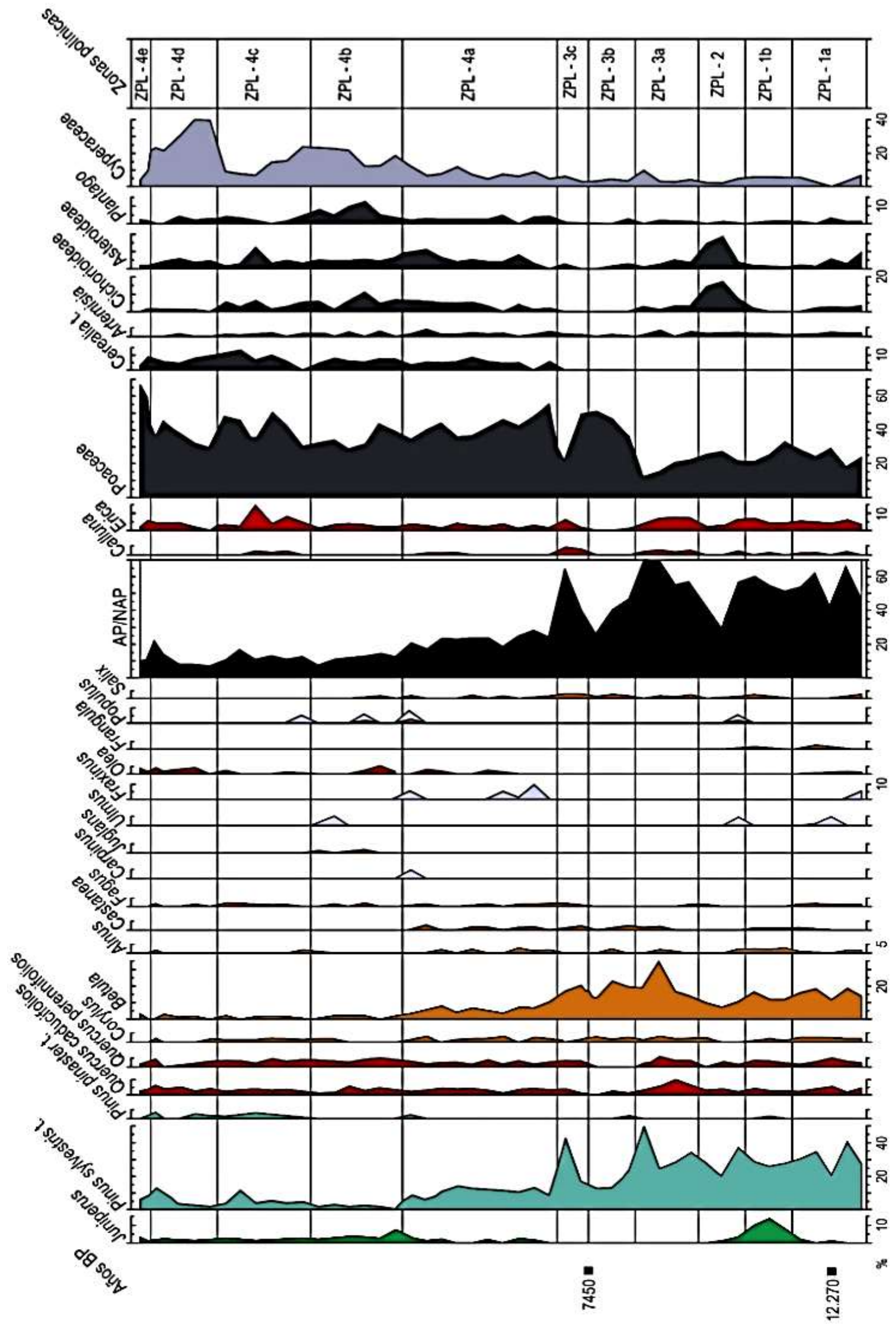

Diagrama polínico 4. Sondeo de La Piedra -Burgos-. Carrión (2012), redibujado de Muñoz Sobrino, et al. (1996). 


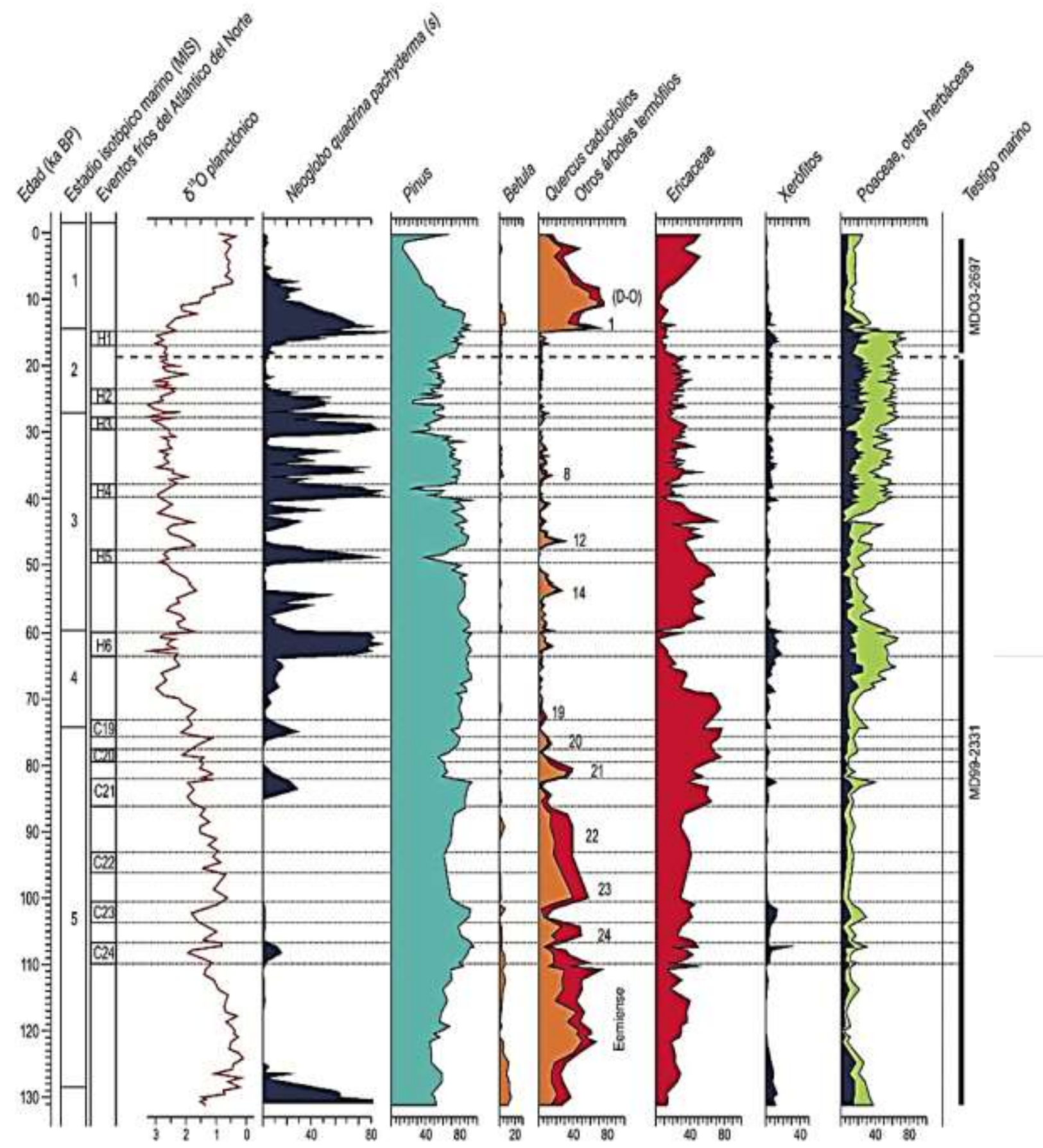

Diagrama polínico 5. Sondeo marino MD99-2331y MD03-2697 para el intervalo 0-15 Ka. Basado en Sánchez-Goñi, et al. (1999) y modificado de Carrión (2012). 


\section{Anexo II. Parámetros Fitoclimáticos}

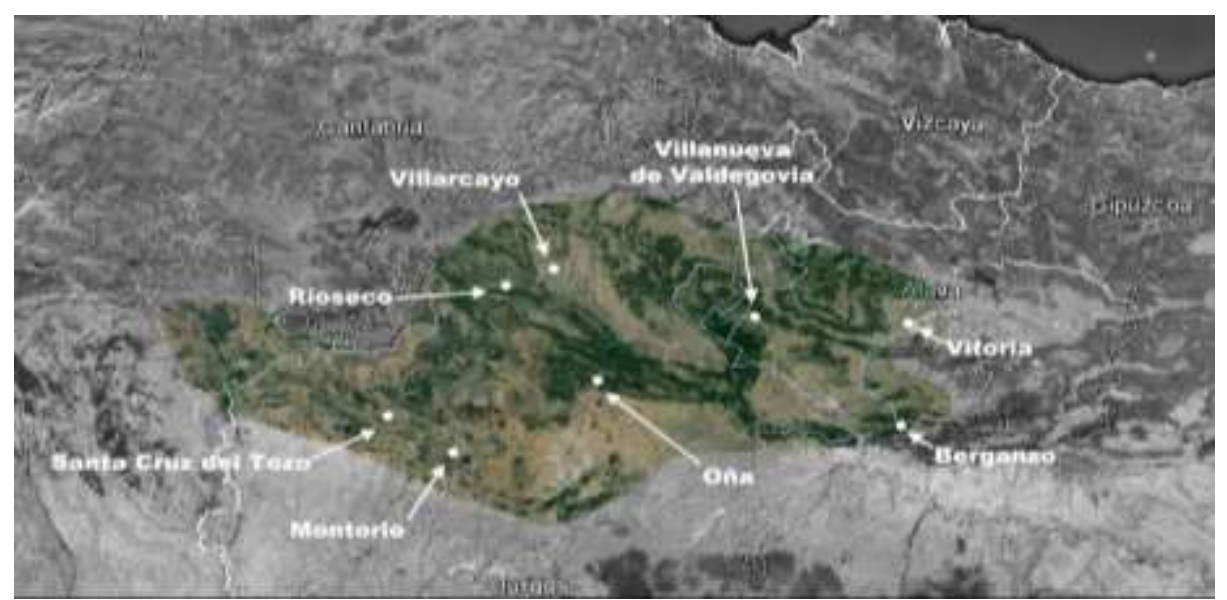

Mapa de ubicación de las estaciones meteorológicas dentro del sector biogeográfico Castellano Cantábrico

\begin{tabular}{ccccccc}
\hline Localidad & Provincia & $\begin{array}{c}\text { Periodo } \\
\text { Temperatur } \\
\text { as }\end{array}$ & $\begin{array}{c}\text { Periodo } \\
\text { pluviometr } \\
\text { ía }\end{array}$ & Altitud & Latitud & Longitud \\
\hline Berganzo & Álava & $1951-1992$ & $1961-1986$ & 578 & N4238 & W00247 \\
\hline $\begin{array}{c}\text { Villanueva de } \\
\text { Valdegovía }\end{array}$ & Álava & $1977-1991$ & $1977-1991$ & 590 & N4250 & W00306 \\
\hline Vitoria & Álava & $1919-1980$ & $1919-1980$ & 550 & N4250 & W00240 \\
\hline Montorio & Burgos & $1900-1989$ & $1951-1989$ & 944 & N4235 & W00346 \\
\hline Oña & Burgos & $1951-1967$ & $1900-1992$ & 598 & N4243 & W00324 \\
\hline Santa Cruz del Tozo & Burgos & $1966-1995$ & $1951-1989$ & 940 & N4238 & W00352 \\
\hline Rioseco & Burgos & $1960-1997$ & $1973-1988$ & 600 & N4253 & W00337 \\
\hline Villarcayo & Burgos & $1959-1997$ & $1930-1997$ & 595 & N4256 & W00334 \\
\hline
\end{tabular}

Datos de las estaciones meteorológicas del sector biogeográfico Castellano Cantábrico. Rivas-Martínez (2007)

\begin{tabular}{|c|c|}
\hline Índice & Descripción \\
\hline $\mathrm{T}$ & Temperatura media mensual ${ }^{\circ} \mathrm{C}$ \\
\hline$P$ & Precipitación mensual mm \\
\hline IT & $\begin{array}{l}\text { (Índice de Termicidad): suma en décimas de grado de la } \\
\text { temperatura media anual, la temperatura media de las } \\
\text { mínimas del mes más frío y la temperatura media de las } \\
\text { máximas del periodo mensual más frío. }\end{array}$ \\
\hline TP & $\begin{array}{l}\text { (Temperatura positiva anual): sumatorio de los meses de } \\
\text { Ti superior a } 0^{\circ} \mathrm{C} \text { en décimas de grados centígrados }\end{array}$ \\
\hline IC & $\begin{array}{l}\text { (Índice de continentalidad simple): Tmax-Tmin en grados } \\
\text { centígrados }\end{array}$ \\
\hline ITC & Índice de termicidad compensado \\
\hline TPS & $\begin{array}{l}\text { Temperatura positiva del trimestre estival en décimas de } \\
\text { grados centígrados TP: temperatura positiva anual: Suma } \\
\text { en décimas de grados centígrados de las temperaturas } \\
\text { medias mensuales. } \mathrm{Ti}>0 \mathrm{OC}\end{array}$ \\
\hline 10 & $\begin{array}{l}\text { (Índice Ombrotérmico Anual): sumatorio de la temperatura } \\
\text { mensual en grados centígrados de los meses de } \\
\text { temperatura media superior a cero grados centígrados. }\end{array}$ \\
\hline 101 & $\begin{array}{l}\text { (Índice ombrotérmico del mes más cálido del trimestre } \\
\text { estival }\end{array}$ \\
\hline 102 & $\begin{array}{l}\text { (Índice ombrotérmico del bimestre más cálido del trimestre } \\
\text { estival }\end{array}$ \\
\hline 103 & (Índice ombrotérmico del trimestre estival \\
\hline 104 & $\begin{array}{l}\text { (Índice ombrotérmico del cuatrimestre resultante de la } \\
\text { suma del trimestre estival y del mes inmediatamente } \\
\text { anterior }\end{array}$ \\
\hline
\end{tabular}

Leyenda de la tabla de parámetros bioclimáticos. Rivas-Martínez (2007) 


\begin{tabular}{|c|c|c|c|c|c|c|c|c|c|c|c|c|c|c|c|c|c|c|c|}
\hline & Ene. & Feb. & Mar. & Abr. & May. & Jun. & Jul. & Ago. & Sep. & Oct. & Nov. & Dic. & Año & IT & TP & IC & IO1 & IO3 & Bioclima \\
\hline${ }^{\circ} \mathbf{C} / \mathbf{m m}$ & $\mathbf{T} / \mathbf{P}$ & $\mathbf{T} / \mathbf{P}$ & $\mathbf{T} / \mathbf{P}$ & $\mathbf{T} / \mathbf{P}$ & $\mathbf{T} / \mathbf{P}$ & $\mathbf{T} / \mathbf{P}$ & $\mathbf{T} / \mathbf{P}$ & $\mathbf{T} / \mathbf{P}$ & $\mathbf{T} / \mathbf{P}$ & $\mathbf{T} / \mathbf{P}$ & $\mathbf{T} / \mathbf{P}$ & $\mathbf{T} / \mathbf{P}$ & $\mathbf{T} / \mathbf{P}$ & ITC & TPS & IO & $\mathrm{IO2}$ & IO4 & Continentalidad-Cintura latitudinal \\
\hline \multirow{2}{*}{ Berganzo } & 4,4 & 5,9 & 8,4 & 10,4 & 13,6 & 17,3 & 20,3 & 20,3 & 17,2 & 12,4 & 7,6 & 5,2 & 11,9 & 208 & 1,430 & 15,9 & 1,20 & 1,8 & \multirow{2}{*}{$\begin{array}{l}\text { Mediterráneo Pluviestacional-Oceánico } \\
\text { Supramediterráneo Inferior - Subhúmedo Inferior } \\
\text { Oceánico Euoceánico Atenuado-Eutemplado }\end{array}$} \\
\hline & 52 & 49 & 49 & 70 & 65 & 52 & 24 & 28 & 46 & 57 & 67 & 62 & 621 & 208 & 579 & 4,34 & 1,30 & 2,37 & \\
\hline \multirow{2}{*}{ Villanueva de Valdegovía } & 3,7 & 4,9 & 7,8 & 9,5 & 11,9 & 15,3 & 18,3 & 18,5 & 16,0 & 12,9 & 7,9 & 5,1 & 10,9 & 184 & 1309 & 14,8 & 1,59 & 2,60 & \multirow{2}{*}{$\begin{array}{l}\text { Templado Oceánico (Submediterráneo) } \\
\text { Mesotemplado Inferior - Húmedo Inferior } \\
\text { Oceánico Euoceánico Acusao-Eutemplado }\end{array}$} \\
\hline & 67 & 69 & 71 & 89 & 90 & 58 & 29 & 49 & 54 & 70 & 74 & 74 & 791 & 184 & 521 & 6,05 & 2,11 & 3,52 & \\
\hline \multirow{2}{*}{ Vitoria } & 4,7 & 5,7 & 8,1 & 9,8 & 13,0 & 16,2 & 18,7 & 19,1 & 16,9 & 12,9 & 8,0 & 5,4 & 11,5 & 210 & 1385 & 14,4 & 1,89 & 2,83 & \multirow{2}{*}{$\begin{array}{l}\text { Templado Oceánico (Submediterráneo) } \\
\text { Mesotemplado Superior - Húmedo Inferior } \\
\text { Oceánico Euoceánico Acusao-Eutemplado }\end{array}$} \\
\hline & 91 & 77 & 77 & 81 & 81 & 65 & 35 & 41 & 58 & 79 & 93 & 98 & 877 & 210 & 540 & 6,33 & 2,03 & 3,34 & \\
\hline \multirow{2}{*}{ Montorio } & 2,8 & 4,0 & 6,8 & 8,9 & 12,5 & 16,5 & 19,4 & 19,2 & 16,2 & 11,5 & 6,4 & 3,7 & 10,7 & 163 & 1279 & 16,6 & 1,38 & 2,05 & \multirow{2}{*}{$\begin{array}{l}\text { Mediterráneo Pluviestacional-Oceánico } \\
\text { Supramediterráneo Inferior - Húmedo Inferior } \\
\text { Oceánico Euoceánico Atenuado-Eutemplado }\end{array}$} \\
\hline & 85 & 81 & 63 & 75 & 73 & 55 & 31 & 27 & 51 & 69 & 89 & 92 & 791 & 163 & 551 & 6,19 & 1,50 & 2,75 & \\
\hline \multirow{2}{*}{ Oña } & 3,7 & 4,9 & 7,5 & 9,4 & 12,8 & 16,1 & 18,9 & 18,8 & 15,7 & 11,5 & 7,0 & 4,5 & 10,9 & 182 & 1308 & 15,2 & 1,67 & 2,17 & \multirow{2}{*}{$\begin{array}{l}\text { Mediterráneo Pluviestacional-Oceánico } \\
\text { Supramediterráneo Inferior - Subhúmedo Inferior } \\
\text { Oceánico Euoceánico Atenuado-Eutemplado }\end{array}$} \\
\hline & 63 & 55 & 53 & 61 & 66 & 54 & 32 & 32 & 46 & 59 & 69 & 68 & 658 & 182 & 5,38 & 5,03 & 1,68 & 2,74 & \\
\hline \multirow{2}{*}{ Santa Cruz del Tozo } & 2,0 & 3,2 & 5,8 & 7,4 & 10,6 & 14,2 & 17,0 & 17,1 & 14,6 & 10,5 & 5,9 & 3,0 & 9,3 & 134 & 1113 & 15,1 & 1,51 & 2,20 & \multirow{2}{*}{$\begin{array}{l}\text { Mediterráneo Pluviestacional-Oceánico } \\
\text { Supramediterráneo Superior - Húmedo Inferior } \\
\text { Oceánico Euoceánico Atenuado-Eutemplado }\end{array}$} \\
\hline & 71 & 64 & 57 & 83 & 73 & 52 & 29 & 26 & 46 & 72 & 81 & 93 & 745 & 134 & 483 & 6,70 & 1,60 & 3,05 & \\
\hline \multirow{2}{*}{ Rioseco } & 3,9 & 5,1 & 7,6 & 9,5 & 13,0 & 16,4 & 19,1 & 19,2 & 16,6 & 12,2 & 7,1 & 4,6 & 11,2 & 188 & 1343 & 15,3 & 1,82 & 2,20 & \multirow{2}{*}{$\begin{array}{l}\text { Templado Oceánico (Submediterráneo) } \\
\text { Supratemplado Inferior - Subhúmedo Superior } \\
\text { Oceánico Euoceánico Atenuado-Eutemplado }\end{array}$} \\
\hline & 84 & 64 & 61 & 83 & 68 & 48 & 35 & 38 & 47 & 65 & 82 & 81 & 755 & 188 & 547 & 5,62 & 1,90 & 2,78 & \\
\hline \multirow[b]{2}{*}{ Villarcayo } & 3,0 & 4,5 & 7,5 & 9,7 & 13,3 & 17,1 & 19,8 & 19,8 & 16,9 & 11,9 & 6,4 & 3,7 & 11,2 & 172 & 1339 & 16,8 & 1,80 & 2,31 & \multirow{2}{*}{$\begin{array}{l}\text { Templado Oceánico (Submediterráneo) } \\
\text { Supratemplado Inferior - Subhúmedo Superior } \\
\text { Oceánico Euoceánico Atenuado-Eutemplado }\end{array}$} \\
\hline & 74 & 68 & 55 & 67 & 64 & 58 & 36 & 37 & 41 & 59 & 80 & 83 & 722 & 172 & 567 & 5,39 & 1,84 & 2,77 & \\
\hline
\end{tabular}

Datos mensuales de temperatura y precipitación, parámetros bioclimáticos y diagnosis bioclimática de las estaciones meteorológicas situadas en el sector Castellano Cantábrico. Rivas-Martínez (2007) 

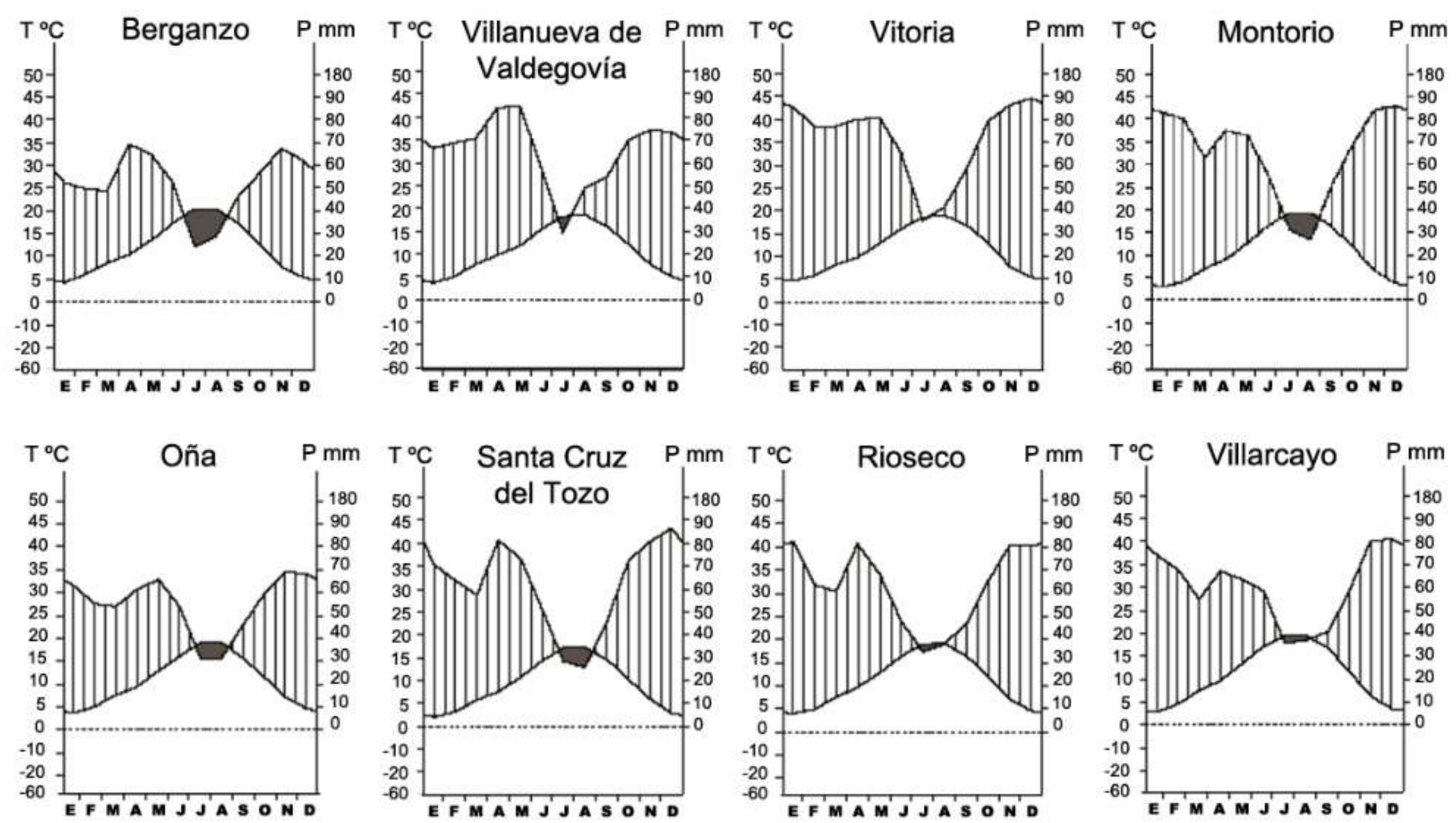

Bioclimogramas de las estaciones meteorológicas del sector biogeográfico Castellano Cantábrico. Rivas-Martínez (2007) 


\section{Anexo III. Leyenda del mapa de series de vegetación del sector Castellano Cantábrico}

2e) Serie subalpina orocantábrica silicícola del enebro rastrero o Juniperus nana (Junipero nanae-Vaccinieto uliginosi sigmetum).

2f) Serie subalpina orocantábrica basófila del enebro rastrero o Juniperus nana (Daphno cantabricae-Arctostaphyleto sigmetum).

5b) Serie montana orocantábrica y cantabroeuskalduna basófila del haya o Fagus sylvatica (Carici sylvaticae-Fageto sigmetum).

5f) Serie montana orocantábrica y cantabroeuskalduna basófila y xerófila del haya o Fagus sylvatica (Epipactidi helleborines-Fageto sigmetum).

5g) Serie montana cantabroeuskalduna y pirenaica occidental acidófila del haya o Fagus sylvatica (Saxifrago hirsutae-Fageto sigmetum).

5h) Serie montana orocantábrica acidófila del haya o Fagus sylvatica (Luzulo henriquesii-Fageto sigmetum).

6a) Serie colino-montana orocantábrica, cantabroeuskalduna y galaicoasturiana mesofítica del fresno o Fraxinus excelsior (Polysticho setijeri-Fraxineto excelsioris sigmetum).

6b) Serie montana cantabroeuskalduna mesofítica del roble o Quercus robur (Crataego laevigatae-Querceto roboris sigmetum).

6ba) Serie montana cantabroeuskalduna mesofítica del roble o Quercus robur (Crataego laevigatae-Querceto roboris sigmetum). Facción planícola con Ulmus campestris

7a) Serie montana orocantábrica acidófila del abedul o Retula celtiberica (Luzulo henriquesii-Betuleto celtibericae sigmetum).

8b) Serie colino-montana cantabroeuskalduna acidófila del roble o Quercus robur (Tamo communis-Querceto roboris sigmetum).

9a) Serie montana cantabroeuskalduna acidófila del roble melojo o Quercus pyrenaica (Melampyro pratensis-Querceto pyrenaicae sigmetum).

9b) Serie montana orocantábrica y galaico-astur acidófila del roble melojo o Quercus pyrenaica (Linario triornithophoraeQuerceto pyrenaicae sigmetum).

10) Serie montana pirenaica del roble peloso o Quercus pubescens (Buxo sempervirentis-Querceto pubescentis sigmetum).

11a) Serie colina cantabro-euskalduna relicta de la alsina y encina híbrida o Quercus ilex y Quercus x ambigua (Lauro nobilis-Querceto ilicis sigmetum). 
$11 \mathrm{ba})$ Serie colina cantabro-euskalduna relicta de la alsina y encina híbrida o Quercus ilex y Quercus x ambigua (Lauro nobilis-Querceto ilicis sigmetum). Facción silicícola de Arbutus unedo.

13d) Serie oromediterránea ibérico-soriana silicícola de Juniperus nana o enebro rastrero (Vaccinio myrtilli-Junipereto nanae sigmetum).

15a) Serie supra-mesomediterránea ayllonense silicícola de Fagus sylvatica o haya (Galio rotundifolii-Fageto sigmetum).

16b) Serie supramediterránea ibérico-soriana silicícola de Fagus sylvatica o haya (IliciFageto sigmetum).

18a) Serie supramediterránea carpetano-ibérico-alcarreña subhúmeda silicícola de Quercus pyrenaica o roble melojo (Luzulo jorsteri-Querceto pyrenaicae sigmetum).

18b) Serie supramediterránea ibéríco-ayllonense, húmeda silicíeola de Quercus pyrenaica. (Festuco heterophyllae-Querceto pyrenaicae sigmetum)

18bb) Serie supramediterránea ibéríco-ayllonense, húmeda silicíeola de Quercus pyrenaica. Festuco heterophyllae-Querceto pyrenaicae sigmetum). Facción supramesomediterránea con Erica aragonensis.

19b) Serie supra-mesomediterránea castellanoalcarreño-manchega basófila de Quercus faginea o quejigo (Cephalanthero longijoliae-Querceto fagineae sigmetum).

19d) Serie supramediterránea castellano-cantábrica y riojano-estellesa basófila de Quercus faginea. (Spiraeo obovatae-Querceto fagineae sigmetum). Facción supramediterránea.

19dd) Serie supramediterránea castellano-cantábrica y riojano-estellesa basófila de Quercus faginea. (Spiraeo obovatae-Querceto fagineae sigmetum). Facción mesomediterránea.

22a) Serie supramediterránea castellano-maestrazgo-manchega basófila de Quercus rotundifolia o encina (Junipero thuriferaeQuerceto rotundifoliae sigmetum).

22b) Serie mesomediterránea manchega y aragonesa basófila de Quercus rotundifolia o encina (Bupleuro rigidi-Querceto rotundifoliae sigmetum).

22c) Serie supramediterránea castellano-cantábrica y riojano-estellesa basófila de Quercus rotundifolia o encina (Spiraeo hispanicae-Querceto rotundifoliae sigmetum).

24a) Serie supra-mesomediterránea guadarrámica, ibérico-soriana, celtibéricoalcarreña y leonesa silicícola de Quercus rotundifolia o encina (Junipero oxycedriQuerceto rotundifoliaesigmetum). 


\section{Anexo IV. Siglado de los fósiles}

\section{Fontinalis antipyretica}

TUAG-TBH-75, TUAG-PS-260, SD-BS-49, SD-BS-50

\section{Asplenium scolopendrium}

FF-21

\section{Pinus nigra}

TUAG-TRESP-1, TUAG-P, TUAG-MR-P, TUAG-BU-01, TUAG-VBH-46, TUAG-VBH-47, TUAG-VBH-48, TUAG-BH-14, TUAG-BH-15, TUAG-TMM-1, TUAG-TMM-2, TUAG-TBH-76, TUAG-TBH-77, TUAG-TP-27, TUAG-TP-28, TUAG-TP-29, TUAG-PS-1, TUAG-PS-2, TUAG-PS-3, TUAG-PS-4, TUAG-PS-5, TUAG-PS-6, SD-BI-33, SD-BI-34, SD-BI-35, SD-BI-36, DRP-58, DRP-59, DRP-60, DRP-61, DRM-139, DRM-140, DRM141, DRM-142, FF-1, FF-2, BO-1, BO-2, BO-3, BO-4, BO-5.

\section{Pinus sp.}

TUAG-VBH-49, TUAG-VBH-50, TUAG-VBH-51, TUAG-VBH-52, TUAG-VBH-53, TUAG-VBH-54, TUAGVBH-55, TUAG-VBH-56, TUAG-VBH-57, TUAG-VBH-58, TUAG-VBH-59, TUAG-VBH-60, TUAG-VBH-61, TUAG-VBH-62, TUAG-VBH-63, TUAG-VBH-64, TUAG-VBH-65, TUAG-VBH-66, TUAG-VBH-67, TUAGVBH-68, TUAG-VBH-69, TUAG-VBH-70, TUAG-VBH-71, TUAG-VBH-72, TUAG-VBH-73, TUAG-VBH-74, TUAG-BH-16, TUAG-BH-17, TUAG-BH-18, TUAG-BH-19, TUAG-BH-20, TUAG-BH-21, TUAG-BH-22, TUAG-BH-23, TUAG-BH-24, TUAG-BH-25, TUAG-BH-26, TUAG-BH-27, TUAG-BH-28, TUAG-TBH-78, TUAG-TBH-79, TUAG-TBH-80, TUAG-TBH-81, TUAG-TBH-82, TUAG-TP-30, TUAG-TP-31, TUAG-TP-32, TUAG-TP-33, TUAG-TP-34, TUAG-TP-35, TUAG-TP-36, TUAG-TP-37, TUAG-T-6, TUAG-T-7, TUAG-PS-7, TUAG-PS-8, TUAG-PS-9, TUAG-PS-10, TUAG-PS-11, TUAG-PS-12, TUAG-PS-13, TUAG-PS-14, TUAG-PS15, TUAG-PS-16, TUAG-PS-17, TUAG-PS-18, TUAG-PS-19, TUAG-PS-20, TUAG-PS-21, TUAG-PS-22, TUAG-PS-23, TUAG-PS-24, TUAG-PS-25, SD-BI-37, SD-BI-38, SD-BI-39, SD-BI-40, SD-BI-41, SD-BI-42, DRP-62, DRP-63, DRP-64, DRP-65, DRP-66, DRP-67, DRP-68, DRP-69, DRP-70, DRP-71, DRP-72, DRP-73, DRP-74, DRP-75, DRP-76, DRP-77, DRP-78, DRP-79, DRP-80, DRP-81, DRP-82, DRP-83, DRP-84, DRP-85, DRP-86, DRP-87, DRP-88, DRP-89, DRP-90, DRP-91, DRP-92, DRP-93, DRP-94, DRP-95, DRP-96, DRP-97, DRP-98, DRP-99, DRP-100, DRP-101, DRP-102, DRP-103, DRP-104, DRP-105, DRP-106, DRP-107, DRP108, DRP-109, DRP-110, DRP-111, DRP-112, DRP-113, DRP-114, DRP-115, DRP-116, DRP-117, DRP-118, DRP-119, DRP-120, DRP-121, DRP-122, DRP-123, DRM-143, DRM-144, DRM-145, DRM-146, DRM-147, DRM-148, DRM-149, DRM-150, DRM-151, DRM-152, DRM-153, DRM-154, DRM-155, DRM-156, DRM157, DRM-158, DRM-159, DRM-160, DRM-161, DRM-162, FF-3, FF-4, FF-5, FF-6, FF-7, FF-8, FF-9, FF10, FF-11, FF-12, FF-13.

\section{Poales incertae sedis 1}

TUAG-VBH-87, TUAG-VBH-88, TUAG-VBH-89, TUAG-VBH-90, TUAG-VBH-91, TUAG-VBH-92, TUAGVBH-93, TUAG-VBH-94, TUAG-VBH-95, TUAG-VBH-96, TUAG-VBH-97, TUAG-VBH-98, TUAG-VBH-99, TUAG-VBH-100, TUAG-VBH-101, TUAG-VBH-102, TUAG-VBH-103, TUAG-BH-40, TUAG-TBH-1, TUAGTBH-2, TUAG-TP-2, TUAG-TP-3, TUAG-T-1, TUAG-T-2, TUAG-T-3, TUAG-T-4, TUAG-T-5, TUAG-PS-51, SD-BS-45, SD-BI-159, SD-BI-160, SD-BI-161, SD-BI-162, SD-BI-163, SD-BI-164, SD-BI-165, SD-BI-166, SDBI-167, SD-BI-168, SD-BI-169, SD-BI-170, SD-BI-171, SD-BI-172, SD-BI-173, SD-BI-174, SD-BI-175, SDBI-176, SD-BI-177, SD-BI-178, SD-BI-179, SD-BI-180, SD-BI-181, DRP-270, DRP-271, DRP-272, DRP-273, DRP-274, DRP-275, DRP-276, DRP-277, DRP-278, DRP-279, DRP-280, DRP-281, DRP-282, DRP-283, DRP-284, DRP-285, DRP-286, DRP-287, DRP-288, DRP-289, DRP-290, DRP-291, DRP-292, DRP-293, DRP-294, DRP-295, DRP-296, DRP-297, DRP-298, DRP-299, DRP-300, DRP-301, DRP-302, DRP-303, DRP-304, DRM-107, DRM-108, DRM-109, DRM-110, DRM-111, DRM-112, DRM-113, DRM-114, DRM115, DRM-116, DRM-117, DRM-118, FF-14. 


\section{Poales incertae sedis 2}

SD-BS-22.

\section{Juncus sp.}

TUAG-TMM-3, TUAG-TMM-4, TUAG-TP-1, TUAG-PS-52, TUAG-PS-53, SD-BS-46, SD-BS-47, SD-BI-43, SD-BI-44, DRM-124, FF-15.

\section{Berberis vulgaris}

TUAG-VBH-1, TUAG-VBH-2, TUAG-VBH-3, TUAG-BH-48, SD-BS-48, SD-BI-205, SD-BI-206, SD-BI-207, SD-BI-208, SD-BI-209, SD-BI-210, SD-BI-211, SD-BI-212, SD-BI-213, SD-BI-214, SD-BI-215, SD-BI-216, SD-BI-217, SD-BI-218, SD-BI-219, SD-BI-220, SD-BI-221, SD-BI-222, SD-BI-223.

\section{Buxus sempervirens}

TUAG-PS-145, TUAG-PS-146, TUAG-PS-147, TUAG-PS-148, TUAG-PS-149, TUAG-PS-150, TUAG-PS-151, TUAG-PS-152, TUAG-PS-153, TUAG-PS-154, TUAG-PS-155, TUAG-PS-156, TUAG-PS-157, TUAG-PS-158, TUAG-PS-159, TUAG-PS-160, TUAG-PS-161, TUAG-PS-162, TUAG-PS-163, TUAG-PS-164, TUAG-PS-165, TUAG-PS-166, TUAG-PS-167, TUAG-PS-168, TUAG-PS-169, TUAG-PS-170, TUAG-PS-171, TUAG-PS-172, TUAG-PS-173, TUAG-PS-174, TUAG-PS-175, TUAG-PS-176, TUAG-PS-177, TUAG-PS-178, TUAG-PS-179, TUAG-PS-180, TUAG-PS-181, TUAG-PS-182, TUAG-PS-183, TUAG-PS-184, TUAG-PS-185, TUAG-PS-186, TUAG-PS-187, TUAG-PS-188, TUAG-PS-189, TUAG-PS-190, TUAG-PS-191, TUAG-PS-192, TUAG-PS-193, TUAG-PS-194, TUAG-PS-195, TUAG-PS-196, TUAG-PS-197, TUAG-PS-198, TUAG-PS-199, TUAG-PS-200, TUAG-PS-201, TUAG-PS-202, TUAG-PS-203, TUAG-PS-204, TUAG-PS-205, TUAG-PS-206, TUAG-PS-207, TUAG-PS-208, TUAG-PS-209, TUAG-PS-210, TUAG-PS-211, TUAG-PS-212, TUAG-PS-213, TUAG-PS-214, TUAG-PS-215, TUAG-PS-216, TUAG-PS-217, TUAG-PS-218, TUAG-PS-219, TUAG-PS-220, DRP-236, DRP-237, DRP-238, DRP-239, DRP-240, DRP-241, DRP-242, DRP-243, DRP-244, DRP-245, DRP-246, DRP-247, DRP-248, DRP-249, DRP-250, DRP-251, DRP-252, DRP-253, DRP-254, DRP-255, DRP-256, DRP-257, DRP-258, DRP-259, DRP-260, DRP-261, DRP-262, DRP-263, DRP-264, DRP-265, DRP-266, DRP-267, DRP-268, DRP-269.

\section{Salix eleagnos}

TUAG-PS-36, TUAG-PS-37, TUAG-PS-38, TUAG-PS-39, TUAG-PS-40, TUAG-PS-41, TUAG-PS-42, TUAGPS-43, TUAG-PS-44, TUAG-PS-45, TUAG-PS-46, TUAG-PS-47, TUAG-PS-48, TUAG-PS-49, TUAG-PS-50, DRP-305, DRP-306, DRP-307, DRP-308, DRP-309, DRP-310, DRP-311, DRP-312, DRP-313, DRP-314, DRP-315, DRP-316, DRP-317, DRP-318, DRP-319, DRP-320, FF-16, FF-17, FF-18, FF-19, FF-20.

\section{Salix sp. 1}

TUAG-BH-41, TUAG-TBH-11, TUAG-TP-51, TUAG-PS-63, TUAG-PS-64, TUAG-PS-65, TUAG-PS-66, TUAG-PS-67, TUAG-PS-68, TUAG-PS-69, TUAG-PS-70, TUAG-PS-71, TUAG-PS-72, TUAG-PS-73, TUAGPS-74, TUAG-PS-75, TUAG-PS-76, TUAG-PS-77, TUAG-PS-78, TUAG-PS-79, TUAG-PS-80, TUAG-PS-81, TUAG-PS-82, TUAG-PS-83, TUAG-PS-84, TUAG-PS-85, TUAG-PS-86, TUAG-PS-87, TUAG-PS-88, TUAGPS-89, TUAG-PS-90, TUAG-PS-91, TUAG-PS-92, TUAG-PS-93, TUAG-PS-94, TUAG-PS-95, TUAG-PS-96, TUAG-PS-97, TUAG-PS-98, TUAG-PS-99, TUAG-PS-100, TUAG-PS-101, TUAG-PS-102, TUAG-PS-103, TUAG-PS-104, TUAG-PS-105, TUAG-PS-106, TUAG-PS-107, TUAG-PS-108, TUAG-PS-109, TUAG-PS-110, TUAG-PS-111, TUAG-PS-112, TUAG-PS-113, TUAG-PS-114, TUAG-PS-115, TUAG-PS-116, TUAG-PS-117, TUAG-PS-118, TUAG-PS-119, TUAG-PS-120, TUAG-PS-121, TUAG-PS-122, TUAG-PS-123, TUAG-PS-124, TUAG-PS-125, TUAG-PS-126, TUAG-PS-127, TUAG-PS-128, TUAG-PS-129, TUAG-PS-130, TUAG-PS-131, TUAG-PS-132, TUAG-PS-133, TUAG-PS-134, TUAG-PS-135, TUAG-PS-136, TUAG-PS-137, TUAG-PS-138, TUAG-PS-139, TUAG-PS-140, TUAG-PS-141, TUAG-PS-142, TUAG-PS-143, TUAG-PS-144, SD-BS-53, SDBS-54, SD-BS-55, SD-BS-56, SD-BS-57, SD-BS-58, SD-BS-59, SD-BS-60, SD-BS-61, SD-BS-62, SD-BS-63, 
SD-BS-64, SD-BS-65, SD-BS-66, SD-BS-67, SD-BS-68, SD-BS-69, SD-BS-70, SD-BS-71, SD-BS-72, SD-BS73, SD-BS-74, SD-BS-75, SD-BS-76, SD-BS-77, SD-BS-78, SD-BS-79, SD-BS-80, SD-BS-81, SD-BS-82, SDBS-83, SD-BS-84, SD-BS-85, SD-BS-86, SD-BS-87, SD-BS-88, SD-BS-89, SD-BS-90, SD-BS-91, SD-BS-92, SD-BS-93, SD-BS-94, SD-BS-95, SD-BS-96, SD-BS-97, SD-BS-98, SD-BS-99, SD-BS-100, SD-BS-101, SD-BI182, SD-BI-183, SD-BI-184, SD-BI-185, SD-BI-186, SD-BI-187, SD-BI-188, SD-BI-189, SD-BI-190, SD-BI191, SD-BI-192, SD-BI-193, DRM-125, DRM-126, DRM-127, DRM-128, DRM-129, DRM-130, DRM-131, DRM-132, DRM-133, DRM-134, DRM-135, DRM-136, DRM-137, DRM-138.

\section{Salix sp. 2}

TUAG-TMM-5, TUAG-TMM-6, TUAG-TMM-7, TUAG-TMM-8, TUAG-TMM-9, TUAG-TMM-10, TUAGTMM-11, TUAG-TMM-12, TUAG-TMM-13, TUAG-TMM-14, TUAG-TMM-15, TUAG-TMM-16, TUAGTMM-17, TUAG-TMM-18, TUAG-TMM-19, TUAG-TMM-20, TUAG-TMM-21, TUAG-TMM-22, TUAGTMM-23, TUAG-TMM-24, TUAG-T-10, TUAG-T-11, TUAG-PS-26, TUAG-PS-27, TUAG-PS-28, TUAG-PS29, TUAG-PS-30, TUAG-PS-31, TUAG-PS-32, TUAG-PS-33, TUAG-PS-34, TUAG-PS-35, SD-BS-51, SD-BS52, SD-BI-194, SD-BI-195, SD-BI-196, SD-BI-197, SD-BI-198, SD-BI-199, SD-BI-200, SD-BI-201, SD-BI202, SD-BI-203, SD-BI-204, DRP-321, DRP-322, DRP-323, DRP-324, DRP-325, DRP-326, DRP-327, DRP328, DRP-329, DRP-330, DRP-331, DRP-332, DRP-333, DRP-334, DRP-335, DRP-336, DRM-121, DRM122, DRM-123, FF-82, FF-83, FF-84, FF-85.

\section{Salix sp. 3}

TUAG-VBH-144, TUAG-VBH-145, TUAG-TP-4, TUAG-TP-5, TUAG-TP-6, TUAG-TP-7, TUAG-TP-8, TUAGTP-9, TUAG-TP-10, TUAG-TP-11, TUAG-TP-12, TUAG-TP-13, TUAG-TP-14, TUAG-TP-15, TUAG-TP-16, TUAG-TP-17, TUAG-TP-18, TUAG-TP-19, TUAG-TP-20, TUAG-TP-21, TUAG-TP-22, TUAG-TP-23, TUAGTP-24, TUAG-TP-25, TUAG-TP-26.

\section{Amelanchier ovalis}

TUAG-BH-1 TUAG-BH-2 TUAG-BH-3 TUAG-BH-4 TUAG-BH-5 TUAG-BH-6 TUAG-BH-7 TUAG-BH-8 TUAGBH-9 TUAG-BH-10 TUAG-VBH-134 TUAG-VBH-135 TUAG-VBH-136 TUAG-VBH-137 TUAG-VBH-138 TUAG-VBH-139 TUAG-VBH-140 TUAG-VBH-141 TUAG-VBH-142 TUAG-VBH-143, SD-BS-103 SD-BS-104 SD-BS-105 SD-BS-106 SD-BS-107 SD-BS-108 SD-BS-109 SD-BS-110 SD-BS-111 SD-BS-112 SD-BS-113 SDBS-114 SD-BS-115 SD-BS-116 SD-BS-117 SD-BS-118 SD-BS-119 SD-BS-120 SD-BS-121 SD-BS-122 SD-BS123 SD-BS-124 SD-BS-125 SD-BS-126 SD-BS-127, SD-BS-102, SD-BI-224, SD-BI-225, SD-BI-226, SD-BI227, SD-BI-228, SD-BI-229, SD-BI-230, SD-BI-231, SD-BI-232, SD-BI-233, SD-BI-234, SD-BI-235, SD-BI236, SD-BI-237, SD-BI-238, SD-BI-239, SD-BI-240, SD-BI-241, SD-BI-242, SD-BI-243, SD-BI-244, SD-BI245, SD-BI-246, SD-BI-247, SD-BI-248, SD-BI-249, SD-BI-250, SD-BI-251, SD-BI-252, SD-BI-253SD-BI-254 SD-BI-255 SD-BI-256 SD-BI-257 SD-BI-258 SD-BI-259 SD-BI-260 SD-BI-261 SD-BI-262 SD-BI-263 SD-BI264 SD-BI-265 SD-BI-266 SD-BI-267 SD-BI-268 SD-BI-269 SD-BI-270 SD-BI-271 SD-BI-272 SD-BI-273 SDBI-274 SD-BI-275 SD-BI-276 SD-BI-277 SD-BI-278 SD-BI-279 SD-BI-280 SD-BI-281 SD-BI-282 SD-BI-283 SD-BI-284 SD-BI-285 SD-BI-286 SD-BI-287 SD-BI-288 SD-BI-289 SD-BI-290 SD-BI-291 SD-BI-292 SD-BI293 SD-BI-294 SD-BI-295 SD-BI-296 SD-BI-297 SD-BI-298 SD-BI-299 SD-BI-300 SD-BI-301 SD-BI-302 SDBI-303 SD-BI-304 SD-BI-305 SD-BI-306 SD-BI-307 SD-BI-308 SD-BI-309 SD-BI-310 SD-BI-311 SD-BI-312 SD-BI-313 SD-BI-314 SD-BI-315 SD-BI-316 SD-BI-317 SD-BI-318 SD-BI-319 SD-BI-320 SD-BI-321 SD-BI322 SD-BI-323 SD-BI-324 SD-BI-325 SD-BI-326 SD-BI-327 SD-BI-328 SD-BI-329 SD-BI-330 SD-BI-331 SDBI-332 SD-BI-333 SD-BI-334 SD-BI-335 SD-BI-336 SD-BI-337 SD-BI-338 SD-BI-339 SD-BI-340 SD-BI-341 SD-BI-342 SD-BI-343 SD-BI-344 SD-BI-345 SD-BI-346 SD-BI-347 SD-BI-348 SD-BI-349 SD-BI-350 SD-BI351, DRP-187, DRP-188, DRP-189, DRP-190, DRP-191, DRP-192, DRP-193, DRP-194, DRP-195, DRP-196, DRP-197, DRP-198, DRP-199, DRP-200, DRP-201，DRP-202，DRP-203，DRP-204，DRP-205，DRP-206, DRP-207, DRP-208, DRP-209, DRP-210, DRP-211, DRP-212, DRP-213, DRP-214, DRP-215, DRP-216, DRP-217, DRP-218, DRP-219, DRM-119, DRM-120. 


\section{Sorbus aria}

TUAG-VBH-4, TUAG-VBH-5, TUAG-VBH-6, TUAG-VBH-7, TUAG-VBH-8, TUAG-VBH-9, TUAG-VBH-10, TUAG-VBH-11, TUAG-VBH-12, TUAG-VBH-13, TUAG-VBH-14, TUAG-VBH-15, TUAG-VBH-16, TUAGVBH-17, TUAG-VBH-18, TUAG-VBH-19, TUAG-VBH-20, TUAG-VBH-21, TUAG-VBH-22, TUAG-VBH-23, TUAG-VBH-24, TUAG-VBH-25, TUAG-VBH-26, TUAG-VBH-27, TUAG-VBH-28, TUAG-VBH-29, TUAGVBH-30, TUAG-VBH-31, TUAG-VBH-32, TUAG-VBH-33, TUAG-VBH-34, TUAG-VBH-35, TUAG-VBH-36, TUAG-VBH-37, TUAG-VBH-38, TUAG-VBH-39, TUAG-VBH-40, TUAG-VBH-41, TUAG-VBH-42, TUAGVBH-43, TUAG-VBH-44, TUAG-VBH-45, TUAG-BH-36, TUAG-BH-37, TUAG-BH-38, TUAG-BH-39, TUAGBH-40, TUAG-BH-41, TUAG-BH-42, TUAG-TMM-42, TUAG-TMM-43, TUAG-TMM-44, TUAG-TMM-45, TUAG-TMM-46, TUAG-TMM-47, TUAG-TMM-48, TUAG-TMM-49, TUAG-TMM-50, TUAG-TMM-51, TUAG-TBH-61, TUAG-TBH-62, TUAG-TBH-63, TUAG-TBH-64, TUAG-TBH-65, TUAG-TP-106, TUAG-PS249, TUAG-PS-250, TUAG-PS-251, TUAG-PS-252, TUAG-PS-253, TUAG-PS-254, TUAG-PS-255, SD-BS10, SD-BS-11, SD-BS-12, SD-BS-13, SD-BS-14, SD-BS-15, SD-BS-16, SD-BS-17, SD-BI-45, SD-BI-46, SD-BI47, SD-BI-48, SD-BI-49, SD-BI-50, SD-BI-51, SD-BI-52, SD-BI-53, SD-BI-54, SD-BI-55, SD-BI-56, SD-BI-57, SD-BI-58, SD-BI-59, SD-BI-60, SD-BI-61, SD-BI-62, SD-BI-63, SD-BI-64, SD-BI-65, SD-BI-66, SD-BI-67, SDBI-68, SD-BI-69, SD-BI-70, SD-BI-71, SD-BI-72, SD-BI-73, SD-BI-74, SD-BI-75, SD-BI-76, SD-BI-77, SD-BI78, SD-BI-79, SD-BI-80, SD-BI-81, SD-BI-82, SD-BI-83, SD-BI-84, SD-BI-85, SD-BI-86, SD-BI-87, SD-BI-88, SD-BI-89, SD-BI-90, SD-BI-91, SD-BI-92, SD-BI-93, SD-BI-94, SD-BI-95, SD-BI-96, SD-BI-97, SD-BI-98, SDBI-99, SD-BI-100, SD-BI-101, SD-BI-102, SD-BI-103, SD-BI-104, SD-BI-105, SD-BI-106, SD-BI-107, SD-BI108, SD-BI-109, SD-BI-110, SD-BI-111, SD-BI-112, SD-BI-113, SD-BI-114, SD-BI-115, SD-BI-116, SD-BI117, SD-BI-118, SD-BI-119, SD-BI-120, SD-BI-121, SD-BI-122, SD-BI-123, SD-BI-124, SD-BI-125, DRP220, DRP-221, DRP-222, DRP-223, DRP-224, DRP-225, DRP-226, DRP-227, DRP-228, DRP-229, DRP-230, DRP-231, DRP-232, DRP-233, DRP-234, DRP-235, DRM-1, DRM-2, DRM-3, DRM-4, DRM-5, DRM-6, DRM-7, DRM-8, DRM-9, DRM-10, DRM-11, DRM-12, DRM-13, DRM-14, DRM-15, DRM-16, DRM-17, DRM-18, DRM-19, DRM-20, DRM-21, DRM-22, DRM-23, DRM-24, DRM-25, DRM-26, DRM-27, DRM28, DRM-29, DRM-30, DRM-31, DRM-32, DRM-33, DRM-34, DRM-35, DRM-36, DRM-37, DRM-38, DRM-39, DRM-40, DRM-41, FF-114, FF-115, FF-116.

\section{Rhamnus alpina}

TUAG-BH-29, TUAG-BH-30, TUAG-BH-31, TUAG-BH-32, TUAG-BH-33, TUAG-BH-34, TUAG-BH-35, SDBS-18, SD-BS-19, SD-BS-20, SD-BS-21, SD-BI-1, SD-BI-2, SD-BI-3, SD-BI-4, SD-BI-5, SD-BI-6, SD-BI-7, SDBI-8, SD-BI-9, SD-BI-10.

\section{Rhamnus frangula}

TUAG-PS-256, TUAG-PS-257, TUAG-PS-258, TUAG-PS-259, DRP-51, DRP-52, DRP-53, DRP-54, DRP-55, DRP-56, DRP-57.

\section{Betula sp.}

TUAG-PS-54, TUAG-PS-55, TUAG-PS-56, TUAG-PS-57, TUAG-PS-58, TUAG-PS-59, TUAG-PS-60, TUAGPS-61, TUAG-PS-62.

\section{Corylus avellana}

TUAG-VBH-75, TUAG-VBH-76, TUAG-VBH-77, TUAG-VBH-78, TUAG-VBH-79, TUAG-VBH-80, TUAGVBH-81, TUAG-VBH-82, TUAG-VBH-83, TUAG-VBH-84, TUAG-VBH-85, TUAG-TBH-3, TUAG-TBH-4, TUAG-TBH-5, TUAG-TBH-6, TUAG-TBH-7, TUAG-TBH-8, TUAG-TBH-9, TUAG-TBH-10, TUAG-PS-230, TUAG-PS-231, TUAG-PS-232, DRP-173, DRP-174, DRP-175, DRP-176, DRP-177, DRP-178, DRP-179, DRP-180, DRP-181, DRP-182, DRP-183, DRP-184, DRP-185, DRM-42, DRM-43, DRM-44, DRM-45, DRM46, DRM-47, DRM-48, DRM-49, DRM-50, DRM-51, DRM-52, DRM-53, DRM-54, DRM-55, DRM-56, FF22, FF-23, FF-24, FF-25, FF-26, FF-27, FF-28, FF-29, FF-30, FF-31, FF-32, FF-33, FF-34, FF-35, FF-36, FF- 
37, FF-3,8 FF-39, FF-40, FF-4,1 FF-4,2 FF-43, FF-44, FF-45, FF-46, FF-47, FF-48, FF-49, FF-50, FF-51, FF52, FF-53, FF-54, FF-55, FF-56, FF-57, FF-58, FF-59, FF-60, FF-61, FF-62, FF-63, FF-64, FF-65, FF-66, FF67, FF-68, FF-69, FF-70, FF-71, FF-72, FF-73, FF-74, FF-75, FF-76, FF-77.

\section{Fagus sylvatica}

TUAG-BH-38, TUAG-TBH-12, TUAG-TBH-13, TUAG-TBH-14, TUAG-TBH-15, TUAG-TBH-16, TUAG-TBH17, TUAG-TBH-18, TUAG-TBH-19, TUAG-TBH-20, TUAG-TBH-21, TUAG-TBH-22, TUAG-TBH-23, TUAGTBH-24, TUAG-TBH-25, TUAG-TBH-26, TUAG-TBH-27, TUAG-TBH-28, TUAG-TBH-29, TUAG-TBH-30, TUAG-TBH-31, TUAG-TBH-32, TUAG-TBH-33, TUAG-TBH-34, TUAG-TBH-35, TUAG-TBH-36, TUAG-TBH37, TUAG-TBH-38, TUAG-TBH-39, TUAG-TBH-40, TUAG-TBH-41, TUAG-TBH-42, TUAG-TBH-43, TUAGTBH-44, TUAG-TBH-45, TUAG-TBH-46, TUAG-TBH-47, TUAG-TBH-48, TUAG-TBH-49, TUAG-TBH-50, TUAG-TBH-51, TUAG-TBH-52, TUAG-TBH-53, TUAG-TBH-54, TUAG-TBH-55, TUAG-TBH-56, TUAG-TBH57, TUAG-TBH-58, TUAG-TBH-59, TUAG-TBH-60.

\section{Quercus faginea}

TUAG-VBH-104, TUAG-VBH-105, TUAG-VBH-106, TUAG-VBH-107, TUAG-VBH-108, TUAG-VBH-109, TUAG-VBH-110, TUAG-VBH-111, TUAG-VBH-112, TUAG-VBH-113, TUAG-VBH-114, TUAG-VBH-115, TUAG-VBH-116, TUAG-VBH-117, TUAG-VBH-118, TUAG-VBH-119, TUAG-VBH-120, TUAG-VBH-121, TUAG-VBH-122, TUAG-VBH-123, TUAG-VBH-124, TUAG-VBH-125, TUAG-VBH-126, TUAG-VBH-127, TUAG-VBH-128, TUAG-VBH-129, TUAG-VBH-130, TUAG-VBH-131, TUAG-VBH-132, TUAG-VBH-133, TUAG-BH-39, TUAG-TP-52, TUAG-TP-53, TUAG-TP-54, TUAG-TP-55, TUAG-TP-56, TUAG-TP-57, TUAGTP-58, TUAG-TP-59, TUAG-TP-60, TUAG-TP-61, TUAG-TP-62, TUAG-TP-63, TUAG-TP-64, TUAG-TP-65, TUAG-TP-66, TUAG-TP-67, TUAG-TP-68, TUAG-TP-69, TUAG-TP-70, TUAG-TP-71, TUAG-TP-72, TUAGTP-73, TUAG-TP-74, TUAG-TP-75, TUAG-TP-76, TUAG-TP-77, TUAG-TP-78, TUAG-TP-79, TUAG-TP-80, TUAG-TP-81, TUAG-TP-82, TUAG-TP-83, TUAG-TP-84, TUAG-TP-85, TUAG-TP-86, TUAG-TP-87, TUAGTP-88, TUAG-TP-89, TUAG-TP-90, TUAG-TP-91, TUAG-TP-92, TUAG-TP-93, TUAG-TP-94, TUAG-TP-95, TUAG-TP-96, TUAG-TP-97, TUAG-TP-98, TUAG-TP-99, TUAG-TP-100, TUAG-TP-101, TUAG-TP-102, TUAG-TP-103, TUAG-TP-104, TUAG-TP-105, TUAG-T-8, TUAG-PS-170, TUAG-PS-263, TUAG-PS-264, TUAG-PS-265, TUAG-PS-266, TUAG-PS-267, TUAG-PS-268, TUAG-PS-269, TUAG-PS-270, TUAG-PS-271, TUAG-PS-272, TUAG-PS-273, TUAG-PS-274, SD-BS-1, SD-BS-2, SD-BS-3, SD-BS-4, SD-BS-5, SD-BS-6, SDBS-7, SD-BS-8, SD-BS-9, SD-BI-126, SD-BI-127, SD-BI-128, SD-BI-129, SD-BI-130, SD-BI-131, SD-BI-132, SD-BI-133, SD-BI-134, SD-BI-135, SD-BI-136, SD-BI-137, SD-BI-138, SD-BI-139, SD-BI-140, SD-BI-141, SD-BI-142, SD-BI-143, SD-BI-144, SD-BI-145, SD-BI-146, SD-BI-147, SD-BI-148, SD-BI-149, SD-BI-150, SD-BI-151, SD-BI-152, SD-BI-153, SD-BI-154, SD-BI-155, SD-BI-156, SD-BI-157, SD-BI-158, DRP-25, DRP26, DRP-27, DRP-28, DRP-29, DRP-30, DRP-31, DRP-32, DRP-33, DRP-34, DRP-35, DRP-36, DRP-37, DRP38, DRP-39, DRP-40, DRP-41, DRP-42, DRP-43, DRP-44, DRP-45, DRP-46, DRP-47, DRP-48, DRP-49, DRP50, DRP-186, DRM-57, DRM-58, DRM-59, DRM-60, DRM-61, DRM-62, DRM-63, DRM-64, DRM-65, DRM-66, DRM-67, DRM-68, DRM-69, DRM-70, DRM-71, DRM-72, DRM-73, DRM-74, DRM-75, DRM76, DRM-77, DRM-78, DRM-79, DRM-80, DRM-81, DRM-82, DRM-83, DRM-84, DRM-85, DRM-86, DRM-87, DRM-88, FF-78, FF-79, FF-80, FF-81.

\section{Acer campestre}

FF-86, FF-87, FF-88, FF-89, FF-90, FF-91, FF-92, FF-93, FF-94, FF-95, FF-96, FF-97, FF-98, FF-99, FF-100, FF-101, FF-102, FF-103, FF-104, FF-105, FF-106, FF-107, FF-108.

\section{Acer cf. platanoides}

TUAG-PS-261, TUAG-PS-262

\section{cf. Tilia sp.}


TUAG-PS-233, TUAG-PS-234, TUAG-PS-235, TUAG-PS-236, TUAG-PS-237, TUAG-PS-238, TUAG-PS-239, TUAG-PS-240, TUAG-PS-241, TUAG-PS-242, TUAG-PS-243, TUAG-PS-244, TUAG-PS-245, TUAG-PS-246, TUAG-PS-247, TUAG-PS-248, DRM-104, DRM-105, DRM-106.

\section{Cornus sanguínea}

TUAG-VBH-86, TUAG-PS-221, TUAG-PS-222, TUAG-PS-223, TUAG-PS-224, TUAG-PS-225, TUAG-PS226, TUAG-PS-227, TUAG-PS-228, TUAG-PS-229, FF-109.

\section{Fraxinus sp.}

DRP-124, DRP-125, DRP-126, DRP-127, DRP-128, DRP-129, DRP-130, DRP-131, DRP-132, DRP-133, DRP-134, DRP-135, DRP-136, DRP-137, DRP-138, DRP-139, DRP-140, DRP-141, DRP-142, DRP-143, DRP-144, DRP-145, DRP-146, DRP-147, DRP-148, DRP-149, DRP-150, DRP-151, DRP-152, DRP-153, DRP-154, DRP-155, DRP-156, DRP-157, DRP-158, DRP-159, DRP-160, DRP-161, DRP-162, DRP-163, DRP-164, DRP-165, DRP-166, DRP-167, DRP-168, DRP-169, DRP-170, DRP-171, DRP-172

\section{Hedera sp.}

TUAG-BH-42, TUAG-BH-43, TUAG-BH-44, TUAG-BH-45, TUAG-BH-46, TUAG-BH-47, TUAG-TMM-25, TUAG-TMM-26, TUAG-TMM-27, TUAG-TMM-28, TUAG-TMM-29, TUAG-TMM-30, TUAG-TMM-31, TUAG-TMM-32, TUAG-TMM-33, TUAG-TMM-34, TUAG-TMM-35, TUAG-TMM-36, TUAG-TMM-37, TUAG-TMM-38, TUAG-TMM-39, TUAG-TMM-40, TUAG-TMM-41, TUAG-TBH-66, TUAG-TBH-67, TUAG-TBH-68, TUAG-TBH-69, TUAG-TBH-70, TUAG-TBH-71, TUAG-TBH-72, TUAG-TBH-73, TUAG-TBH74, TUAG-TP-38, TUAG-TP-39, TUAG-TP-40, TUAG-TP-41, TUAG-TP-42, TUAG-TP-43, TUAG-TP-44, TUAG-TP-45, TUAG-TP-46, TUAG-TP-47, TUAG-TP-48, TUAG-TP-49, TUAG-TP-50, TUAG-T-9, SD-BS-23, SD-BS-24, SD-BS-25, SD-BS-26, SD-BS-27, SD-BS-28, SD-BS-29, SD-BS-30, SD-BS-31, SD-BS-32, SD-BS33, SD-BS-34, SD-BS-35, SD-BS-36, SD-BS-37, SD-BS-38, SD-BS-39, SD-BS-40, SD-BS-41, SD-BS-42, SDBS-43, SD-BS-44, SD-BI-11, SD-BI-12, SD-BI-13, SD-BI-14, SD-BI-15, SD-BI-16, SD-BI-17, SD-BI-18, SD-BI19, SD-BI-20, SD-BI-21, SD-BI-22, SD-BI-23, SD-BI-24, SD-BI-25, SD-BI-26, SD-BI-27, SD-BI-28, SD-BI-29, SD-BI-30, SD-BI-31, SD-BI-32, DRP-1, DRP-2, DRP-3, DRP-4 DRP-5, DRP-6, DRP-7, DRP-8, DRP-9, DRP10, DRP-11, DRP-12, DRP-13, DRP-14, DRP-15, DRP-16, DRP-17, DRP-18, DRP-19, DRP-20, DRP-21, DRP22, DRP-23, DRP-24, DRM-89, DRM-90, DRM-91, DRM-92, DRM-93, DRM-94, DRM-95, DRM-96, DRM97, DRM-98, DRM-99, DRM-100, DRM-101, DRM-102, DRM-103, FF-110, FF-111, FF-112, FF-113.

\section{Dicotylophyllum sp. 1}

TUAG-BH-11, TUAG-BH-12, TUAG-BH-13 